IURI BALDACONI DA SILVA BISPO

APRIMORAMENTO DE MÉTODO PARA INFERÊNCIA DE ESPECTRO DE ONDAS A PARTIR DE MOVIMENTOS DE SISTEMAS OCEÂNICOS

SÃO PAULO

2011 
IURI BALDACONI DA SILVA BISPO

\section{APRIMORAMENTO DE MÉTODO PARA INFERÊNCIA DE ESPECTRO DE ONDAS A PARTIR DE MOVIMENTOS DE SISTEMAS OCEÂNICOS}

Dissertação apresentada à Escola Politécnica da Universidade de São Paulo para obtenção do título de Mestre em Engenharia. 
IURI BALDACONI DA SILVA BISPO

\section{APRIMORAMENTO DE MÉTODO PARA INFERÊNCIA DE ESPECTRO DE ONDAS A PARTIR DE MOVIMENTOS DE SISTEMAS OCEÂNICOS}

Dissertação apresentada à Escola Politécnica da Universidade de São Paulo para obtenção do título de Mestre em Engenharia.

Área de Concentração:

Engenharia Naval e Oceânica

Orientador: Prof. Dr. Alexandre Nicolaos Simos

SÃO PAULO

2011 
Este exemplar foi revisado e alterado em relação à versão original, sob responsabilidade única do autor e com a anuência de seu orientador.

São Paulo, 18 de dezembro de 2011.

Assinatura do autor

Assinatura do orientador

\section{FICHA CATALOGRÁFICA}

Bispo, luri Baldaconi da Silva

Aprimoramento de método para inferência de espectro de ondas a partir de movimentos de sistemas oceânicos / I.B.S. Bispo. - ed.rev. - São Paulo, 2011.

$183 p$.

Dissertação (Mestrado) - Escola Politécnica da Universidade de São Paulo. Departamento de Engenharia Naval e Oceânica.

1. Inferência Bayesiana 2. Espectros (Estimativa; Modelos) 3. Critério ABIC I. Universidade de São Paulo. Escola Politéc nica. Departamento de Engenharia Naval e Oceânica II. t. 
Aos meus familiares 


\section{Agradecimentos}

Ao Prof. Alexandre Nicolaos Simos, o qual me orientou neste trabalho com dedicação e disposição exemplares, sempre disposto a sanar minhas dúvidas e me ajudar com temas com os quais eu não tinha a mínima familiaridade necessária para a compreensão.

Ao Prof. Eduardo Aoun Tannuri pelo constante apoio e bom humor nas cansativas reuniões do projeto de pesquisa.

Ao Prof. José Jaime da Cruz por sua constante humildade e disposição em ajudar.

A estes três professores em especial o meu agradecimento por partilharem seu conhecimento de forma clara e me passarem tantos ensinamentos ao longo destes 30 meses.

À Olga Yoshida pela revisão da parte de estatística Bayesiana e preocupação quanto ao meu desempenho.

Aos colegas do TPN que me apoiaram nesta difícil jornada e a todos meus amigos que acreditaram em mim e me apoiaram. A todos estes eu agradeço especialmente pelas piadas.

Aos músicos das minhas bandas prediletas, pois sem suas músicas eu não teria mantido a sanidade.

Aos meus pais, Magali e João, e ao meu avô, Dante, por terem plantado em mim, desde pequeno, a semente da curiosidade e da busca pelo conhecimento, me incentivando a questionar o porquê das coisas.

Às minhas irmãs, Nadja e Giulia, pela admiração injustificada e confiança em tantos momentos difíceis.

À minha namorada, amiga e companheira dos mais variados momentos, Daniela Leonel, por acreditar na minha capacidade quando até mesmo eu duvidei e por sempre confiar no meu bom senso. 


\section{Resumo}

Este trabalho envolve dois diferentes aspectos da estimação de espectros direcionais de onda a partir de movimentos de $1^{a}$ ordem da embarcação. Sendo a estimação do espectro de ondas feita por meio de um método Bayesiano, existe a necessidade da calibração dos hiperparâmetros derivados da modelagem Bayesiana. O primeiro assunto abordado é a determinação de uma metodologia de calibração dos hiperparâmetros necessários à estimação do espectro direcional de ondas. Desenvolve-se ao longo deste uma primeira análise de um método aplicável a qualquer embarcação do tipo FPSO para a determinação a priori de valores de dois hiperparâmetros de controle da suavização da estimativa. Obtém-se resultados indicativos de que é possível definir valores destes hiperparâmetros dependentes de quantidades observáveis como calado da embarcação e período das ondas, de modo que os erros de estimação ainda se mantém muito próximos aos encontrados por valores ótimos dos hiperparâmetros.

Isto leva à conclusão de que na abordagem atual, com valores fixos a cada calado, erros excessivos e desnecessários podem ocorrer no processo de estimação.

O segundo tema trata da estimação paramétrica de espectros, utilizando modelos paramétricos de descrição de espectros como forma de obtenção de estatísticas de mar. Abordam-se também os assuntos de mares cruzados, donde se faz necessária a identificação da bimodalidade dos espectros para a estimação correta das estatísticas de mar.

Palavras-chave: Inferência Bayesiana, Estimação de espectro direcional, Critério ABIC. 


\section{Abstract}

In this work, two differents aspects of directional wave spectra estimation from $1^{\text {st }}$ order ship motions are presented. As the estimation of wave spectrum is made by means of a Bayesian method, it is necessary to calibrate the hyperparameters derived from Bayesian modeling. The first addressed subject is the determination of a calibration methodology of the hyperparameters needed for the directional wave spectrum estimation. It is developed through this work a first analysis of an applicable method to any vessel of FPSO type for the prior determination of values for this two hyperparameters depending on observable quantities, such as draft of the vessel and wave period, in such a way that the estimation errors are still very close to those found by optimum values of the hyperparameters.

This leads to the conclusion that in the current approach excessive and unecessary errors can occurr on the estimation process.

The second subject addresses the parametric estimation of spectra, using parametric models of spectrum description to acquire the sea statistics. For this purpose, it became necessary the study of crossed-sea states, which was employed in the bimodal spectrum identification for the correct estimation of sea statistics.

Keywords: Bayesian inference, Directional spectrum estimation, ABIC criterion. 


\section{Lista de Figuras}

1 FPSO P-50 da PETROBRAS. . . . . . . . . . . . . . . . . . p. 16

2 Representação esquemática do processo de estimação completo - em vermelho está destacada a parte principal da qual trata este trabalho. . . . . . . . p. 18

3 Graus de liberdade da embarcação. . . . . . . . . . . . . . . . . . . . . . . . . . . . $\quad$ p. 29

4 Embarcações utilizadas como referência para ensaios em escala em (SPARANO, 2008). . . . . . . . . . . . . . . . . . . . . . p. 30

5 Comparação entre espectros de potência teórico e estimados. . . . . . . . . . p. 45

6 Mapas dos espectros direcionais teórico e estimados para os casos da tabela 1. p. 46

7 Espectros direcionais teórico e estimados para os casos da tabela 1. . . . . . . p. 47

8 Discretização das direç̃oes médias de incidência de ondas. . . . . . . . . . . . . . p. 49

9 Modelo do FPSO P-50 utilizado no Dynasim. . . . . . . . . . . . . . . p.50

10 Exemplo de séries temporais dos movimentos geradas pelo Dynasim para os 6 graus de liberdade do FPSO P-50 em calado leve. . . . . . . . . . . p. 51

11 Representação esquemática do processo exaustivo de cálculo do melhor espectro estimado. . . . . . . . . . . . . . . . . . . . . . . . . . . . . . . p. 54

12 Resultados da estimação exaustiva com uso do erro $_{a b s}$ para espectro com parâmetros $H_{s}=4 m, T_{p}=10 \mathrm{~s}$ e $\theta_{m}=120^{\circ}$ com embarcação em calado leve. . p. 56

13 Resultados da estimação exaustiva com uso do erro $_{a b s}$ para espectro com parâmetros $H_{s}=4 m, T_{p}=8,5 \mathrm{~s}$ e $\theta_{m}=45^{\circ}$ com embarcação em calado cheio. . p. 58

14 Superfícies de erro $_{a b s}$ para os 3 calados - $H_{s}=4 m, T_{p}=12 s$ e $\theta_{m}=0^{\circ} \ldots \quad$ p. 60

15 Superfícies de erro $_{a b s}$ para o mar $H_{s}=4 m, T_{p}=12 \mathrm{~s}$ com direções $\theta_{m}=0^{\circ}$, $\theta_{m}=90^{\circ}$ e $\theta_{m}=180^{\circ}$ - Calado intermediário.

16 Soma dos valores de erro $_{a b s}$ nas direções para o caso de mar 3 com embarcação em calado $9 \mathrm{~m}$.

17 Resultados da estimação utilizando valores dos hiperparâmetros referentes ao mínimo da soma - Espectro com parâmetros $H_{s}=4 \mathrm{~m}, T_{p}=10 \mathrm{~s}$ e $\theta_{m}=120^{\circ}$ com embarcação em calado leve.

18 Erros percentuais $\Delta H_{s}$ em relação ao teórico do mar 1, em cada calado Curvas: Exaustão; Soma dos erros e; Hiperparâmetros fixos globalmente.

19 Erros percentuais $\Delta H_{s}$ em relação ao teórico do mar 2, em cada calado Curvas: Exaustão; Soma dos erros e; Hiperparâmetros fixos globalmente. . . . .

20 Erros percentuais $\Delta H_{s}$ em relação ao teórico do mar 3, em cada calado Curvas: Exaustão; Soma dos erros e; Hiperparâmetros fixos globalmente. 
21 Erros percentuais $\Delta H_{s}$ em relação ao teórico do mar 4, em cada calado Curvas: Exaustão; Soma dos erros e; Hiperparâmetros fixos globalmente.

22 Erros percentuais $\Delta H_{s}$ em relação ao teórico do mar 5, em cada calado Curvas: Exaustão; Soma dos erros e; Hiperparâmetros fixos globalmente. . . . p. 68

23 Superfícies de $u_{1}$ e $u_{2}$ em função dos calados e dos períodos de pico $T_{p}$. . . . p.69

24 Representação esquemática do algoritmo de pós-processamento. . . . . . . . . p.73

25 Exemplo de espectros de potência utilizando os modelos de JONSWAP e Hogben \& Cobb com $H_{s}=4,5 m$ e $T_{p}=10,3 s-\lambda=1,5$ para Hogben \& Cobb e $\gamma=3,3$ para JONSWAP.

26 Espectro teóricos dos exemplos apresentados na tabela 6.

27 Mapas do espectro direcional de onda para os casos com $s$ fixo e $s$ variável dos exemplos 1 e 4.

28 Mapas do espectro direcional de onda para os casos com $s$ fixo e $s$ variável dos exemplos 2 e 5 .

29 Mapas do espectro direcional de onda para os casos com $s$ fixo e $s$ variável dos exemplos 3 e 6 .

30 Espectro de potência com $s$ fixo e $s$ variável para os exemplos 1 e 4 .

31 Mapas do espectro direcional de onda para os casos com $s$ fixo e $s$ variável dos exemplos 7 e 10 .

32 Mapas do espectro direcional de onda para os casos com $s$ fixo e $s$ variável dos exemplos 8 e $11 \ldots \ldots \ldots \ldots$. . . . . . . . . . . . . . . . . 88

33 Mapas do espectro direcional de onda para os casos com $s$ fixo e $s$ variável dos exemplos 9 e 12. . . . . . . . . . . . . . . . . . . p. 89

34 Esquema ilustrativo: Critério proposto por (KOBUNE; SASAKI; HASHIMOTO, 1985). p. 94

35 Esquema ilustrativo: Critério proposto por (KUIK; VLEDDER; HOLTHUUSEN, 1988). p. 95

36 Esquema ilustrativo: Critério proposto por (BESNARD; BENOIT, 1994) . . . . . p. 97

37 Critério proposto em (KOBUNE; SASAKI; HASHIMOTO, 1985) - Resultados para espectros direcionais dos ensaios. . . . . . . . . . . . . . . . . . . . . . . p. 101

38 Critério proposto em (KUIK; VLEDDER; HOLTHUUSEN, 1988) - Resultados para espectros direcionais dos ensaios. . . . . . . . . . . . . . . . . . . . . . p. 101

39 Critério proposto em (BESNARD; BENOIT, 1994) - Resultados para espectros direcionais dos ensaios. . . . . . . . . . . . . . . . . . . . . . . . p. 102

40 Critério proposto em (PISCOPIA; PANIZZO; GIROLAMO, 2004) - Resultados para espectros direcionais dos ensaios. . . . . . . . . . . . . . . . . . . . . . . . p. 102

41 Espectros teórico e estimados com diferentes valores de $u_{1}$ e $u_{2}$ com cálculo de erro pelo modelo erro $_{\text {quad }}$. . . . . . . . . . . . . . . . . . . . . . p. 128

42 Diferença absoluta entre espectros teórico e estimados nos casos ótimo e com baixa suavização. . . . . . . . . . . . . . . . . . . . . . . . . . . . . . . . . . . p. 129 
43 Espectro direcional ótimo estimado utilizando-se a formulação erro abs $_{\text {. }}$. . . . . p. 129

44 RAOs de amplitude do FPSO P-50 em calado leve $(9 \mathrm{~m}) \ldots \ldots$. . . . . . . . . p. 132

45 RAOs de amplitude do FPSO P-50 em calado intermediário $(14,5 \mathrm{~m})$. . . . . . p. 133

46 RAOs de amplitude do FPSO P-50 em calado cheio $(21 \mathrm{~m}) . \ldots$. . . . . . . . . . p. 134

47 Mapas dos espectros direcionais estimados para o mar 1 , com $H_{s}=2 m$, $T_{p}=10 s$ e $s=150$, FPSO P-50 em calado leve. . . . . . . . . . . . . . . p. 148

48 Mapas dos espectros direcionais estimados para o mar 1 , com $H_{s}=2 \mathrm{~m}$, $T_{p}=10 s$ e $s=150$, FPSO P-50 em calado intermediário. . . . . . . . . . p. 149

49 Mapas dos espectros direcionais estimados para o mar 1 , com $H_{s}=2 m$, $T_{p}=10 s$ e $s=150$, FPSO P-50 em calado cheio. . . . . . . . . . . . . . p. 150

50 Mapas dos espectros direcionais estimados para o mar 2, com $H_{s}=4 \mathrm{~m}$, $T_{p}=8,5 s$ e $s=150$, FPSO P-50 em calado leve. . . . . . . . . . . . . p. 151

51 Mapas dos espectros direcionais estimados para o mar 2, com $H_{s}=4 m$, $T_{p}=8,5 s$ e $s=150$, FPSO P-50 em calado intermediário. . . . . . . . . . p. 152

52 Mapas dos espectros direcionais estimados para o mar 2, com $H_{s}=4 m$, $T_{p}=8,5 s$ e $s=150$, FPSO P-50 em calado cheio. . . . . . . . . . . . . p. 153

53 Mapas dos espectros direcionais estimados para o mar 3, com $H_{s}=4 m$, $T_{p}=10 s$ e $s=150$, FPSO P-50 em calado leve.

54 Mapas dos espectros direcionais estimados para o mar 3, com $H_{s}=4 \mathrm{~m}$, $T_{p}=10 s$ e $s=150$, FPSO P-50 em calado intermediário.

55 Mapas dos espectros direcionais estimados para o mar 3, com $H_{s}=4 m$, $T_{p}=10 s$ e $s=150$, FPSO P-50 em calado cheio.

56 Mapas dos espectros direcionais estimados para o mar 4, com $H_{s}=4 \mathrm{~m}$, $T_{p}=12 s$ e $s=150$, FPSO P-50 em calado leve.

57 Mapas dos espectros direcionais estimados para o mar 4, com $H_{s}=4 \mathrm{~m}$, $T_{p}=12 s$ e $s=150$, FPSO P-50 em calado intermediário. . . . . . . . . . p. 158

58 Mapas dos espectros direcionais estimados para o mar 4, com $H_{s}=4 m$, $T_{p}=12 s$ e $s=150$, FPSO P-50 em calado cheio. . . . . . . . . . . . . . p. 159

59 Mapas dos espectros direcionais estimados para o mar 5, com $H_{s}=4 \mathrm{~m}$, $T_{p}=14 s$ e $s=150$, FPSO P-50 em calado leve. . . . . . . . . . . . . . . p. 160

60 Mapas dos espectros direcionais estimados para o mar 5, com $H_{s}=4 m$, $T_{p}=14 s$ e $s=150$, FPSO P-50 em calado intermediário. . . . . . . . . . . . p. 161

61 Mapas dos espectros direcionais estimados para o mar 5, com $H_{s}=4 m$, $T_{p}=14 s$ e $s=150$, FPSO P-50 em calado cheio. . . . . . . . . . . . . . p. 162

62 Espectros resultantes das estimações para o ensaio W06-10109. . . . . . . . . p. 164

63 Espectros resultantes das estimações para o ensaio W06-10200. . . . . . . . . p. 165

64 Espectros resultantes das estimações para o ensaio W06-10300. . . . . . . . . p. 166

65 Espectros resultantes das estimações para o ensaio W06-10400. . . . . . . . . p. 167 
66 Espectros resultantes das estimações para o ensaio W06-10500. . . . . . . . . p. 168

67 Espectros resultantes das estimações para o ensaio W06-20100. . . . . . . . . p. 169

68 Espectros resultantes das estimações para o ensaio W06-20200. . . . . . . . . p. 170

69 Espectros resultantes das estimações para o ensaio W06-20300. . . . . . . . . p. 171

70 Espectros resultantes das estimações para o ensaio W06-20400 . . . . . . . . p. p. 172

71 Espectros resultantes das estimações para o ensaio W06-20500. . . . . . . . . p. 173

72 Espectros resultantes das estimações para o ensaio W07-10102. . . . . . . . . p. 174

73 Espectros resultantes das estimações para o ensaio W07-10202. . . . . . . . . p. 175

74 Espectros resultantes das estimações para o ensaio W07-10301. . . . . . . . . p. 176

75 Espectros resultantes das estimações para o ensaio W07-10401. . . . . . . . . p. 177

76 Espectros resultantes das estimações para o ensaio W07-20104. . . . . . . . . p. 178

77 Espectros resultantes das estimações para o ensaio W07-20203. . . . . . . . . p. 179

78 Espectros resultantes das estimações para o ensaio W07-20301. . . . . . . . . p. 180

79 Espectros resultantes das estimações para o ensaio W07-20401. . . . . . . . p. 181 


\section{Lista de Tabelas}

$1 \quad$ Exemplo de valores de $u_{1}$ e $u_{2} \ldots \ldots \ldots \ldots$ p. 44

2 Valores de $H_{s}$ e $T_{p}$ utilizados para geração de espectros direcionais de onda. . p.49

3 Principais dados do FPSO P-50 . . . . . . . . . . . . . . . . . . p. 50

4 Valores de $u_{1}$ em função dos períodos de pico e dos calados. . . . . . . . . . . p. 69

5 Valores de $u_{2}$ em função dos períodos de pico e dos calados. . . . . . . . . . . p. 69

6 Valores adotados para os parâmetros nos exemplos do modelo de Hogben \& Cobb. $H_{s_{i}}$ em $[\mathrm{m}], \omega_{m_{i}}$ em $[\mathrm{rad} / \mathrm{s}]$ e $\theta_{m_{i}}$ em $[\mathrm{rad}] \ldots \ldots \ldots$. . . . . . . . . . . 78

7 Valores típicos de $s_{\max }$ para diferentes situações de mar. . . . . . . . . . . . p.79

8 Valores adotados para os parâmetros nos exemplos do modelo de Hogben \& Cobb utilizando a formulação com $s$ variável. $H_{s_{i}}$ em $[\mathrm{m}], \omega_{m_{i}}$ em $[\mathrm{rad} / \mathrm{s}] \mathrm{e}$ $\theta_{m_{i}}$ em $[\mathrm{rad}]$.

9 Valores adotados para os parâmetros nos exemplos do modelo JONSWAP. $H_{s_{i}}$ em $[m], \omega_{p_{i}}$ em $[\mathrm{rad} / \mathrm{s}]$ e $\theta_{m_{i}}$ em $[\mathrm{rad}] \ldots \ldots \ldots \ldots \ldots \ldots \ldots$

10 Valores adotados para os parâmetros nos exemplos do modelo JONSWAP utilizando a formulação com $s$ variável. $H_{s_{i}}$ em $[m], \omega_{p_{i}}$ em $[\mathrm{rad} / \mathrm{s}]$ e $\theta_{m_{i}}$ em

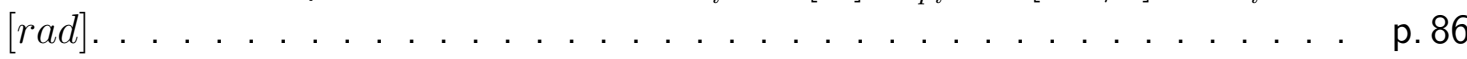

11 Valores teóricos dos espectros direcionais unimodais gerados no ensaio em escala. p. 99

12 Valores teóricos dos espectros direcionais bimodais gerados no ensaio em escala. p. 99

13 Classificação dos espectros direcionais gerados no ensaio em escala de acordo com cada critério. . . . . . . . . . . . . . . . . . . . . . . . p. 100

14 Valores de $\chi$ para os espectros dos ensaios em escala. . . . . . . . . . . . . p. 103

15 Parâmetros a serem estimados para cada modelo. . . . . . . . . . . . . . . . p. 105

16 Intervalos de otimização para cada parâmetro. . . . . . . . . . . . . p. 106

17 Resultados das estimações de $H_{s}$ em [m] na escala real para casos considerados unimodais. . . . . . . . . . . . . . . . . . . . . . . . . . . . . . . p. 107

18 Resultados das estimações de $T_{p}$ em [s] na escala real para casos considerados unimodais. . . . . . . . . . . . . . . . . . . . . p. 108

19 Resultados das estimações de $H_{s_{1}}$ e $H_{s_{2}}$ em [m] na escala real para casos considerados bimodais. . . . . . . . . . . . . . . . . . . . . . . . . . . . . . . p. 109

20 Resultados das estimações de $T_{p_{1}}$ e $T_{p_{2}}$ em [s] na escala real para casos considerados bimodais. . . . . . . . . . . . . . . . . . . . . p. 109

21 Resultados das estimações de $\theta_{m_{1}}$ e $\theta_{m_{2}}$ em [graus] na escala real. . . . . . . . p. 110 
22 Estatísticas globais em escala real - $H_{s}$ em [m], $T_{p}$ em [s] e $\theta_{m}$ em [graus]. . . p. 111

23 Resultados das estimações de $\gamma_{1}$ e $\gamma_{2}$ - apenas para JONSWAP. . . . . . . . . p. 112

24 Resultados das estimações de $\lambda_{1}$ e $\lambda_{2}$ - apenas para Hogben \& Cobb. . . . . . p. 113

25 Resultados das estimações de $s_{1}, s_{2}, s_{\max 1}$ e $s_{\max _{2}}$. . . . . . . . . . p. 114

26 Tempo de execução das estimações paramétricas em segundos. . . . . . . . . p. p. 115

27 Valores de $u_{1}$ e $u_{2}$ utilizados na comparação das formulações de erro. . . . . . p. 127

28 Formulações de erro e valores obtidos para a comparação das formulações de erro. . . . . . . . . . . . . . . . . . . . . . . . . . . . . . . . . . . . . . . . p. 129

29 Resultados do processo exaustivo para o Mar $1-H_{s}=2 m$ e $T_{p}=10 \mathrm{~s}$. . . . p. 136

30 Resultados do processo exaustivo para o Mar $2-H_{s}=4 m$ e $T_{p}=8,5 s$. . . p. 137

31 Resultados do processo exaustivo para o Mar $3-H_{s}=4 m$ e $T_{p}=10 \mathrm{~s}$. . . . p. 138

32 Resultados do processo exaustivo para o Mar $4-H_{s}=4 m$ e $T_{p}=12 \mathrm{~s}$. . . . p. 139

33 Resultados do processo exaustivo para o Mar $5-H_{s}=4 m$ e $T_{p}=14 s$. . . . p. 140

34 Resultados do mínimo da soma para o Mar $1-H_{s}=2 m$ e $T_{p}=10 s$. . . . . p. 142

35 Resultados do mínimo da soma para o Mar $2-H_{s}=4 m$ e $T_{p}=8,5 s$. . . . p. 143

36 Resultados do mínimo da soma para o $\operatorname{Mar} 3-H_{s}=4 m$ e $T_{p}=10 s$. . . . . p. 144

37 Resultados do mínimo da soma para o Mar $4-H_{s}=4 m$ e $T_{p}=12 s$. . . . p. 145

38 Resultados do mínimo da soma para o Mar $5-H_{s}=4 m$ e $T_{p}=14 s$. . . . . p. 146 


\section{Sumário}

1 Introdução $\quad$ p. 15

2 Revisão Bibliográfica $\quad$ p. 23

2.1 Modelos paramétricos . . . . . . . . . . . . . . . . . . . . p. 23

2.2 Critérios de bimodalidade . . . . . . . . . . . . . . . . . . p. 25

2.3 Inferência Bayesiana . . . . . . . . . . . . . . . . . . . . . . . . p. 27

2.4 Método Bayesiano de estimação de espectros direcionais . . . . . . . . . . . . . p. 28

3 Método Bayesiano $\quad$ p. 32

3.1 Estimação da função de espalhamento direcional . . . . . . . . . . . . . . . . p.32

3.2 Estimação do espectro direcional a partir de movimentos de $1^{\text {a }}$ ordem . . . . . p. 36

4 Análise de sensibilidade: calibração dos hiperparâmetros

4.1 Introdução . . . . . . . . . . . . . . . . . . . . . . . . . . p. 42

4.2 Motivação . . . . . . . . . . . . . . . . . . . . . . . . . . p. 43

4.3 Metodologia de calibração dos hiperparâmetros . . . . . . . . . . . . . p. 48

4.3.1 Processo exaustivo de cálculo de erros mínimos . . . . . . . . . . . . p. 53

4.3.2 Critério de escolha dos hiperparâmetros $u_{1}$ e $u_{2} \quad \ldots \ldots$. . . . . . . p. 60

4.4 Discussão dos resultados . . . . . . . . . . . . . . . . . . . . . . . . . . . . . . . . . . $\quad$ p.64

5 Pós-processamento $\quad$ p. 71

5.1 Introdução . . . . . . . . . . . . . . . . . . . . . p. . . . . . .

5.2 Espectro Direcional de Energia f . . . . . . . . . . . . . . . . . . . . . p.74

5.3 Modelo proposto por Hogben \& Cobb . . . . . . . . . . . . . . . . . . p. 77

5.4 Modelo JONSWAP $\ldots \ldots \ldots \ldots$

5.5 Critério de Bimodalidade . . . . . . . . . . . . . . . . p. 90

5.5.1 Espalhamento direcional . . . . . . . . . . . . . . . . . . . . . . . . p. 91

5.5.2 Critério proposto por (KOBUNE; SASAKI; HASHIMOTO, 1985) . . . . . . p. 93

5.5.3 Critério proposto por (KUIK; VLEDDER; HOLTHUUSEN, 1988) . . . . . . p. 94

5.5.4 Critério proposto por (BESNARD; BENOIT, 1994) . . . . . . . . . p. 96 
5.5.5 Critério proposto por (PISCOPIA; PANIZZO; GIROLAMO, 2004) . . . . . . p. 97

5.5.6 Comparação dos critérios . . . . . . . . . . . . . . . . . . p. 98

5.6 Estimação Paramétrica . . . . . . . . . . . . . . . . . . . . . . . p. 104

5.6.1 Algoritmo de estimação . . . . . . . . . . . . . . . . . . . . . p. 104

5.6.2 Parâmetros e limites . . . . . . . . . . . . . . . . . . . p. 105

5.6.3 Resultados das estimações . . . . . . . . . . . . . . . . . . . p. 106

5.6.4 Conclusões sobre a estimação . . . . . . . . . . . . . . . . . . . . . . p. 115

6 Conclusão e sugestões de trabalhos futuros $\quad$ p. 117

Apêndice A - Conceitos básicos de estatística Bayesiana $\quad$ p. 120

A.1 Introdução . . . . . . . . . . . . . . . . . . . . . . . . . . p. 120

A.2 Conceitos básicos de estatística Bayesiana . . . . . . . . . . . . . . . . p. 121

A.2.1 O teorema de Bayes . . . . . . . . . . . . . . . . . . . p. 121

A.3 Abordagem Bayesiana à solução de sistemas lineares de alta ordem . . . . . . p. 122

Apêndice B - Cálculo do erro do método de calibração e normalização dos $\begin{array}{ll}\text { espectros } & \text { p. } 126\end{array}$

Apêndice C - RAOs do FPSO P-50 p. 131

Apêndice D - Tabelas de resultados do caso exaustivo $\quad$ p. 135

Apêndice E - Tabelas de resultados das somas dos erros $\quad$ p. 141

Apêndice F - Mapas dos espectros estimados com hiperparâmetros definidos $\begin{array}{lr}\text { pela metodologia de calibração. } & \text { p. } 147\end{array}$

Apêndice G - Resultados da estimação paramétrica $\quad$ p. 163

$\begin{array}{ll}\text { Referências } & \text { p. } 182\end{array}$ 


\section{Introdução}

O conhecimento mais detalhado sobre o estado de mar ao qual uma embarcação está sujeita é um tema importante no que diz respeito ao desenvolvimento de novas tecnologias em engenharia naval e oceânica. Tais informações obtidas em escala real podem ser usadas na validação de modelos analíticos e numéricos de previsão do comportamento de embarcações, sendo este tipo de ferramenta muito utilizada nesta área do conhecimento, dadas as grandes escalas envolvidas em seus estudos. Podem ser também beneficiados estudos feitos por meio de ensaios em escala reduzida, uma vez que a comparação de resultados com a escala real se torna possível ao obter-se informações do comportamento da embarcação sujeita a um certo estado de mar. Para tanto, devem ser obtidas informações detalhadas sobre o espectro de ondas ao qual uma determinada embarcação está sujeita, tais como a sua direção de incidência, período de pico e altura significativa das ondas.

Estas informações podem auxiliar também na operação de unidades de produção de petróleo, como, por exemplo, de FPSOs (Floating Production Storage and Offloading), pois sabendo-se as características do espectro de mar no local onde a embarcação está posicionada, podem ser tomadas decisões de reorientação desta com relação à direção média de incidência das ondas, buscando-se a redução da influência de tal espectro sobre os movimentos da embarcação e, consequentemente, reduzindo-se o tempo de parada da produção. Sendo possível a obtenção de tais informações em tempo real, estas podem ser utilizadas para alimentação de sistemas de posicionamento dinâmico de FPSOs e de outras embarcações.

Tanto em FPSOs quanto em outros tipos de embarcação, o conhecimento do espectro direcional de ondas também pode ser utilizado em situações de emergência, quando o mar se encontra em condições extremas, com o propósito de se garantir a segurança das instalações e da tripulação. Operações de risco como içamento de cargas, lançamento de dutos e cabos, também podem ser otimizadas ao existirem tais informações em tempo real, tornando-as mais eficientes e seguras.

Tradicionalmente, os espectros direcionais de onda são obtidos por meio dos dados coletados por bóias oceanográficas, utilizando-se suas séries temporais de movimento, como feito em (LONGUET-HIGGINS; CARTWRIGHT; SMITH, 1961), por exemplo. Entretanto, este tipo de equipamento é de difícil aplicação nas necessidades atuais de exploração de petróleo em alto mar, a qual tem sido realizada em águas cada vez mais profundas, sendo isto uma tendência das empresas exploradoras, em particular, da PETROBRAS.

Sendo complexa a instalação e manutenção das bóias oceanográficas em mares de grande profundidade, uma alternativa mais prática é a utilização de sistemas de registro das condições de mar localizados a bordo das embarcações. Comparando-se às bóias, existe maior facilidade 
de instalação e manutenção de sistemas de radares, sendo estes inclusive utilizados em algumas embarcações da PETROBRAS como, por exemplo, o FPSO P-50, embarcação empregada como modelo em estudos numéricos ao longo deste trabalho, apresentada na figura 1 .

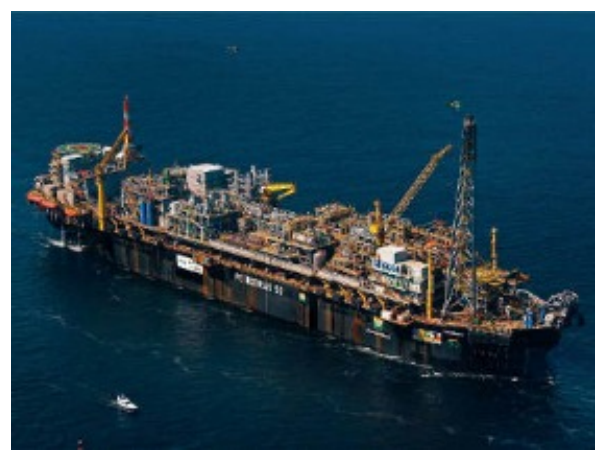

Figura 1: FPSO P-50 da PETROBRAS.

Dada a relativa facilidade de instalação e manutenção de sistemas de determinação de espectro direcional localizados a bordo, uma metodologia alternativa e complementar à utilização de radares vem sendo estudada desde o ano 2000, no Departamento de Engenharia Naval e Oceânica da Escola Politécnica da Universidade de São Paulo (EPUSP).

O trabalho aqui desenvolvido está inserido no contexto da continuação dos estudos realizados pelo grupo de pesquisa da EPUSP, sendo este apoiado pela PETROBRAS na forma de convênio de pesquisa, com o propósito de desenvolvimento de um software de estimação do espectro direcional de ondas a ser validado por meio de sua implantação em um FPSO da frota da empresa. Sendo a metodologia desenvolvida na EPUSP também baseada em um sistema localizado a bordo da embarcação, sua implementação operacional é relativamente simples, bastando-se a utilização de um computador conectado a acelerômetros e rate-gyros. Trata-se portanto de um sistema de baixo custo inicial, com fácil instalação e manutenção. Devido ao fato da PETROBRAS possuir embarcações munidas de sensores que realizam tais tarefas e estas serem também passíveis da instalação de tal sistema, torna-se viável o estudo com base nos registros dos movimentos, justificando a aplicabilidade de tal metodologia.

A metodologia para inferência de ondas aqui adotada é definida em (SIMOS et al., 2009) e se baseia na utilização dos movimentos de primeira-ordem de sistemas estacionários de grande porte, tais como FPSOs. Existem, na literatura especializada, outros trabalhos sobre a estimação de espectros, tais como (ISEKI; OHTSU, 2000), (ISEKI, 2009) e (NIELSEN, 2008), abordando um problema similar, porém nestes é considerado o uso de embarcações de pequeno porte com velocidade de avanço, implicando em uma modelagem diferenciada do problema de estimação de espectros.

Os estudos anteriores realizados pelo grupo de pesquisa da EPUSP, tais como (TANNURI et al., 2001) e (TANNURI et al., 2004), demonstraram, através de simulações numéricas, ser possível a estimação do espectro direcional com base no monitoramento dos movimentos da embarcação. Nestes trabalhos foram utilizados dois tipos de métodos de estimação: um paramétrico e um não-paramétrico. O primeiro era conhecido àquela época e utilizado em outras metodologias. Já o método não-paramétrico, denominado também método Bayesiano de estimação de espectros, 
proposto por (ISEKI; OHTSU, 2000), determinava uma nova abordagem sobre o problema de estimação espectral, utilizando inferência Bayesiana para a modelagem do problema e inserindo um termo de controle (também chamado de hiperparâmetro) para garantir a suavidade das estimativas ao longo das direções de incidência. Com ambos os métodos, foram obtidos bons resultados em simulações numéricas, os quais indicavam ser viável a implementação de um sistema a bordo que estimasse o espectro direcional de ondas, utilizando os sensores do próprio FPSO como forma de aquisição das séries temporais de movimento da embarcação.

Foi então sugerido em (NIELSEN, 2008) que o método Bayesiano poderia receber um segundo hiperparâmetro de controle, sendo este utilizado para suavização da estimativa ao longo das frequências. A influência de tal parâmetro foi testada para ensaios em escala reduzida por (TANNURI et al., 2007) para uma embarcação do tipo VLCC (Very Large Crude Carrier) e analisada mais profundamente em (SPARANO, 2008) utilizando-se ensaios também em escala do FPSO P-35 e da BGL-1 (Balsa Guindaste de Lançamento 1), sendo verificados novamente bons resultados dos espectros estimados, corroborando com o fato de que era possível a utilização das séries temporais de movimento da embarcação para a estimação do espectro direcional de ondas.

Encarando o sistema flutuante como um sensor por meio do qual pode-se medir o espectro de mar, é importante considerar a faixa de frequências sobre a qual o mesmo consegue operar, bem como o nível dos sinais gerados. Este sensor funciona também como um filtro, uma vez que existe uma determinada faixa de frequências na qual existe resposta do sensor, sendo descartadas as outras, dado que não podem ser medidas pelo mesmo. A faixa de operação do sensor é determinada pelo chamado período de corte, sendo que nas regiões abaixo de tal período, as funções de transferência da embarcação não apresentam níveis significativos de resposta, ou seja, são descartadas as altas frequências, uma vez que a embarcação, vista como sensor, não conseguirá medí-las.

Portanto, fica estabelecido que não se pode obter a mesma faixa de frequência de operação das bóias oceanográficas ou dos radares por meio deste sistema, o que se torna mais evidente com o uso de embarcações de grande porte, como FPSOs. Sendo esta uma desvantagem da metodologia adotada, existem problemas de estimação quando o período de pico do espectro estimado se encontra próximo ao período de corte. Uma vez que se busca relacionar os movimentos da embarcação com o espectro de mar, é crucial que exista uma resposta mensurável e limpa quando existe excitação do navio.

Uma hipótese fundamental na qual se baseia o estudo é a linearidade da resposta da embarcação às excitações de onda, ou seja, os movimentos do navio podem ser tratados sendo linearmente proporcionais à amplitude das ondas, o que equivale a dizer que estes movimento são analisados por meio dos RAOs (Response Amplitude Operators).

Tendo isto em mente, um terceiro hiperparâmetro foi introduzido por (SIMOS et al., 2009) como forma de redução da energia em períodos fora da faixa de estimação, pois considerando que os RAOs tem uma amplitude muito baixa e a resposta do navio também, qualquer espectro nesta faixa poderia causar esta resposta, o que não corresponde ao problema real. Isto resultou em um modelo completo de estimação, o qual é utilizado neste trabalho, onde são consideradas não apenas as aproximações do espectro direcional, mas também as suavizações nas direções e frequências, além da anulação da energia fora do domínio de resposta. 
Nos estudos realizados neste trabalho foram abordadas duas partes do processo de estimação: a calibração dos fatores de suavização mencionados (também chamados de hiperparâmetros) e o pós-processamento do espectro estimado, este segundo consistindo na extração de estatísticas de mar da estimativa encontrada, considerando-se, inclusive a possível bimodalidade dos espectros estimados.

Estas duas partes, embora distintas, estão interrelacionadas pelo método Bayesiano de estimação, pois, para a utilização correta do algoritmo Bayesiano é preciso uma calibração prévia dos hiperparâmetros e, após a estimação feita pelo algoritmo, é necessário que se traduza o espectro em quantidades mais "palpáveis", tais como as estatísticas de mar usualmente adotadas na engenharia naval: altura significativa $\left(H_{s}\right)$, período de pico $\left(T_{p}\right)$, direção média de incidência de ondas $\left(\theta_{m}\right)$ e espalhamento $(s)$.

O processo completo de estimação é apresentado na figura 2, onde são destacados pela linha pontilhada vermelha os principais assuntos tratados neste trabalho. A ligação entre os dois tópicos abordados é o próprio algoritmo Bayesiano de estimação, pois ao serem definidos valores adequados dos hiperparâmetros, tenta-se garantir um espectro suave para a indentificação de mares cruzados e posterior extração de suas estatísticas.

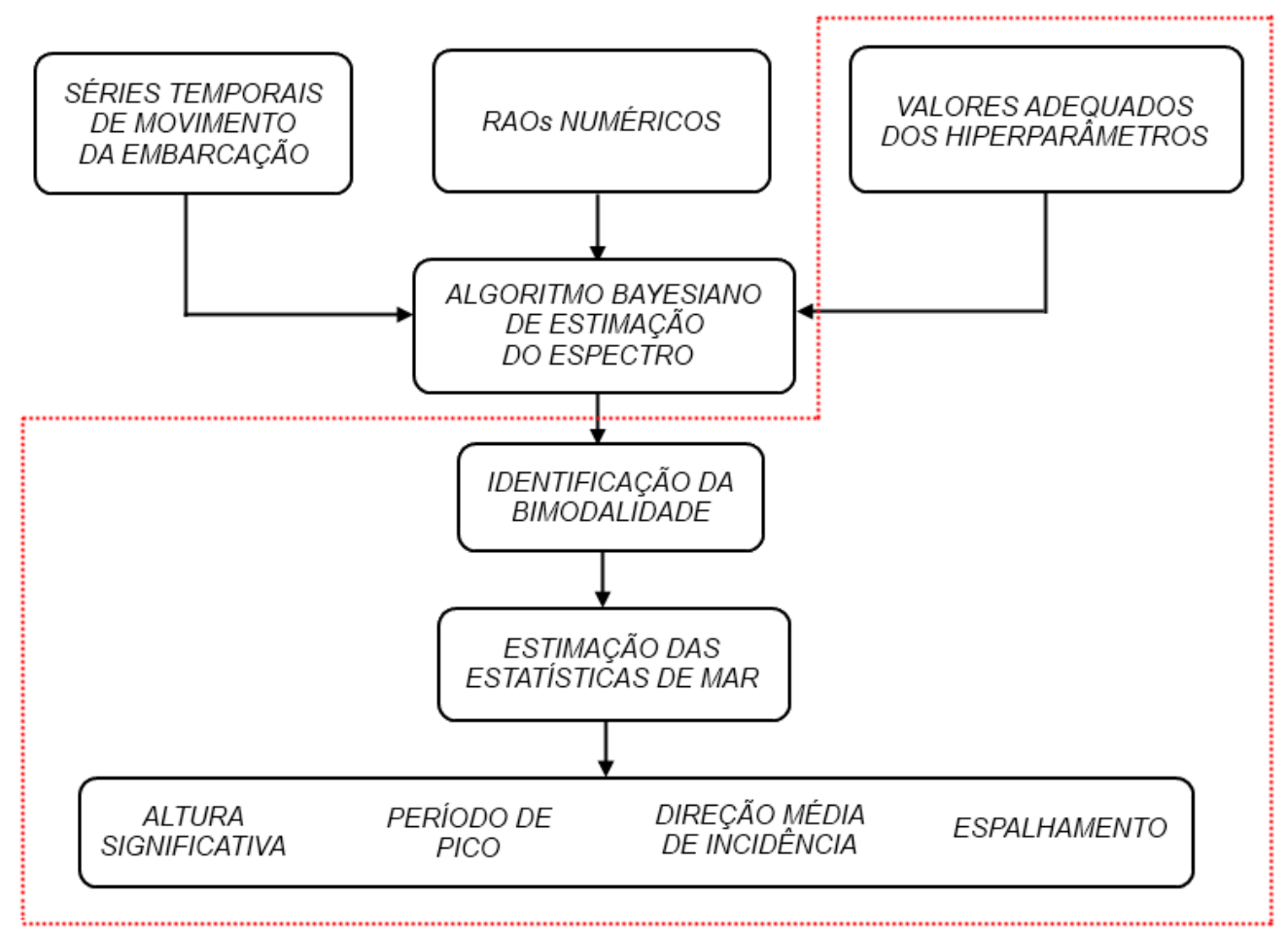

Figura 2: Representação esquemática do processo de estimação completo - em vermelho está destacada a parte principal da qual trata este trabalho.

A primeira parte do trabalho envolve uma compreensão básica da abordagem Bayesiana à estimação dos espectros direcionais e uma calibração dos hiperparâmetros de suavização derivados de tal abordagem, dado que existe influência dos mesmos sobre a estimação final. 
Os espectros direcionais estimados pelo método Bayesiano podem ter suas estatísticas comprometidas quando se faz uso de valores incorretos para os hiperparâmetros, como será mostrado no capítulo 4, pois, atentando-se ao fato de que estes termos são utilizados para suavizar a estimativa, valores muito altos podem ocasionar estatísticas subestimadas e, no caso contrário, podem ser superestimadas, dado que força-se a concentração de energia em uma determinada região.

A qualidade das estimativas geradas pelo método Bayesiano, introduzido inicialmente por (AKAIKE, 1980), depende diretamente dos valores dos hiperparâmetros utilizados para a suavização dos espectros estimados. Ao incluir tais termos, (AKAIKE, 1980) sugeriu também o uso do critério de informação ABIC (Akaike's Bayesian Information Criterion) como método de decisão de valores dos hiperparâmetros. Este critério foi desenvolvido com base na abordagem Bayesiana e classifica os modelos a serem utilizados para a estimação variando os hiperparâmetros por um processo de minimização, associando de maneira sistemática um valor de $A B I C$ a cada modelo, e definindo como ótimo o modelo que obteve o menor valor para tal critério.

Embora estudos anteriores indicassem estimações bem sucedidas com o uso do critério $A B I C$, este método tem se mostrado inviável em termos práticos. Primeiramente, este critério esbarra em limitações computacionais, pois espera-se que a estimação dos espectros seja feita em "tempo real" e, dada a necessidade de diversas estimativas de espectro para a busca do valor mínimo do critério $A B I C$, isto se torna impraticável, já que o tempo de execução requerido se aproxima de intervalvo típico de mudança do estado de mar. Em segundo lugar, embora estudos mais recentes indicam ser possível obter boas estimativas do espectro de mar utilizando-se valores fixos dos hiperparâmetros (ver, por exemplo, (SPARANO, 2008), (SIMOS et al., 2009) e (ISEKI; NIELSEN, 2010a)), o uso do critério $A B I C$ tem sido questionado, como é feito em (ISEKI, 2011) através de uma análise mais detalhada sobre o aspecto, concluindo que nem sempre as melhores estimativas são encontradas com o uso do $A B I C$.

Assim, considera-se a possibilidade do uso de valores pré-estabelecidos dos hiperparâmetros, de forma a simplificar o processo de estimação, mas levando-se em consideração que não pode haver grandes prejuízos às estimações. Para tanto, é necessária uma calibração prévia destes valores, sendo isto realizado neste trabalho por meio de uma metodologia de calibração, descrita no capítulo 4.

A metodologia de calibração consistiu no desenvolvimento de um processo sistemático no qual, necessitando-se a calibração de hiperparâmetros para uma outra embarcação, basta que sejam repetidos os passos do processo descrito no capítulo 4 para a obtenção de um conjunto de valores dos hiperparâmetros.

O processo de calibração se baseia no uso de espectros direcionais teóricos gerados numericamente como paradigma de comparação, buscando por meio da minimização do erro entre os espectros estimado e teórico, o par de hiperparâmetros que causa o menor erro, ou seja, que resulta na melhor estimação. As séries temporais de movimento da embarcação necessárias ao método de estimação foram geradas por meio de software de simulação da dinâmica da embarcação sujeita a um mar com parâmetros pré-determinados. Nestas simulações numéricas, utilizou-se como modelo o FPSO P-50 da PETROBRAS, variando-se o calado entre leve, intermediário e cheio, o que fez com que o mesmo se tornasse um parâmetro do problema de estimação, uma 
vez que a resposta da embarcação também varia sensivelmente de acordo com o carregamento.

Ao final do desenvolvimento da metodologia de calibração, foram obtidos valores dos hiperparâmetros dependentes do calado da embarcação e do período de pico dos espectros teóricos. Estes valores foram então testados nos diversos conjuntos de mares teóricos utilizados ao longo do desenvolvimento da metodologia, avaliando-se o erro em relação aos valores teóricos cometido pelas estatísticas finais que descrevem o mar. Os resultados destes testes foram considerados bons, considerando que os erros cometidos nas estimativas estavam dentro de uma faixa aceitável, o que justifica a utilização da metodologia proposta em aplicações reais do método de estimação.

Um último fator importante para que seja realizada a calibração dos hiperparâmetros é a necessidade de um espectro relativamente suave ao longo das direções e frequências para obtenção das estatísticas de mar finais, assunto este abordado na segunda parte do trabalho. Ao garantirse a suavidade do espectro estimado, sem prejudicar a energia contida no mesmo, aumenta-se a confiabilidade das estatísticas extraídas ao final do processo de estimação sejam confiáveis, pois serão facilitadas tanto a indentificação de mares cruzados quanto a estimação das estatísticas de cada mar.

Em posse dos espectros estimados, podem ser extraídas informações de estatísticas dos mares, sejam estes cruzados (combinação de dois mares com períodos e direções distintas) ou unimodais. Este tema é tratado na segunda parte do trabalho, no capítulo 5 , onde são considerados os modelos paramétricos de Hogben \& Cobb e JONSWAP combinados à função de espalhamento direcional, necessários à descrição do espectro direcional.

Dado que o espectro direcional fornecido pelo algoritmo Bayesiano é nada além de uma matriz com os valores de energia ao longo das direções e frequências, os estudos realizados na segunda parte podem ser feitos com espectros gerados por algum outro método, como, por exemplo, um espectro gerado pelas medições em um ensaio, como foi utilizado neste trabalho. É importante salientar que ao se basear em espectros medidos e não nos estimados para a elaboração da estimação paramétrica, evita-se criar um método tendencioso, pois o algoritmo Bayesiano pode obter estimativas dos espectros com redução de sua energia real, por exemplo. Desta maneira, ao elaborar um método com base em espectros medidos, aumenta-se a chance de realizar com sucesso as estimativas dos espectros obtidos pelo método Bayesiano.

Não sendo conhecidas as características dos espectros a terem suas estatísticas estimadas, por vezes foram enfrentados problemas de estimação de espectros unimodais ao utilizar um modelo paramétrico bimodal de descrição do espectro direcional de onda. Devido a este fato, foi necessária a implementação de um critério de bimodalidade que indicasse previamente qual modelo usar com base na matriz do espectro.

Assim, foram estudados e comparados 4 diferentes critérios de bimodalidade, (KOBUNE; SASAKI; HASHIMOTO, 1985), (KUIK; VLEDDER; HOLTHUUSEN, 1988), (BESNARD; BENOIT, 1994) e (PISCOPIA; PANIZZO; GIROLAMO, 2004), optando-se pelo qual melhor atendia as exigências do método de estimação: encontrar corretamente os mares unimodais, dadas as estimações incorretas quando estes eram ajustados por um modelo paramétrico bimodal. Dessa maneira, adotou-se o critério proposto por (PISCOPIA; PANIZZO; GIROLAMO, 2004), sendo este o único capaz de ca- 
racterizar corretamente tais espectros em todos os casos testados.

Ao final, foram realizados testes do método de estimação paramétrica com dados de ensaios em escala, observando-se as estatísticas de cada modo do espectro para os casos de mares cruzados.

Dessa maneira, o texto deste trabalho está organizado da seguinte forma: no capítulo 2 é feita incialmente uma revisão bibliográfica sobre estatística Bayesiana e suas aplicações ao problema de estimação de espectros direcionais. Em seguida são apresentados os estudos feitos sobre o método Bayesiano de estimação, assim como do critério $A B I C$. Por fim, são abordados os estudos referentes aos critérios de bimodalidade testados e os tipos de modelos paramétricos utilizados para a estimação das estatísticas modais de onda.

Inicialmente são apresentadas no capítulo 3 a modelagem Bayesiana dos problemas de estimação da função de espalhamento e do espectro direcional, sendo este capítulo importante para a compreensão do funcionamento do método Bayesiano de estimação de espectros direcionais e do papel desempenhado pelos hiperparâmetros na modelagem Bayesiana.

No apêndice A é feita uma introdução básica à estatística Bayesiana, seguida de uma aplicação da modelagem Bayesiana ao problema de resolução de sistemas lineares de alta ordem, sendo esta aplicação utilizada para apresentar o critério $A B I C$ e o conceito fundamental dos hiperparâmetros. Desta maneira, os assuntos abordados neste apêndice precedem o método Bayesiano de estimação de espectros e servem de fundamentação teórica para as aplicações apresentadas no capítulo 3.

O capítulo 4 aborda a metodologia de calibração dos hiperparâmetros desenvolvida neste trabalho. Inicialmente é apresentada a motivação para uma análise de sensibilidade, justificando a metodologia de calibração aqui proposta. O desenvolvimento da metodologia é apresentado em seguida, com considerações sobre o método de cálculo dos erros entre espectros teóricos e estimados. Ao final é feita uma discussão dos resultados, analisando-se o método de escolha dos valores dos hiperparâmetros.

A estimação paramétrica é abordada no capítulo 5, onde são inicialmente apresentados os modelos paramétricos e suas variações utilizadas neste trabalho. É feita em seguida a apresentação dos critérios de bimodalidade e testes comparativos dos mesmos, finalizando-se com a aplicação da estimação paramétrica a espectros direcionais gerados a partir de dados de ensaios em escala reduzida.

Por fim, são apresentadas no capítulo 6 as conclusões finais deste trabalho, tecendo comentários sobre os resultados obtidos na metodologia de calibração dos hiperparâmetros, bem como sobre aqueles obtidos na estimação paramétrica das estatísticas de mares cruzados. Em ambos os casos foram verificados bons resultados, concluindo-se que tais métodos podem ser considerados para as devidas finalidades a que foram propostos, embora ainda haja, em ambos os casos, aspectos a serem estudados para maior refinamento dos métodos. 
São também feitas sugestões de trabalhos futuros advindas do desenvolvimento e dos resultados aqui obtidos. Neste capítulo são sugeridas continuações de estudos referentes aos parâmetros considerados no desenvolvimento da metodologia de calibração, além das discretizações utilizadas. Dois importantes aspectos são destacados neste capítulo, os quais ainda devem ser avaliados para uma conclusão final acerca da metodologia proposta: variações do espalhamento direcional do mar e análise de mares bimodais. São também feitas considerações sobre a calibração do terceiro hiperparâmetro, assunto não abordado neste texto.

Sugestões sobre a segunda parte do estudo são referentes, principalmente, ao limite heurístico adotado pelo critério de bimodalidade, pois existem evidências de que mais mares bimodais possam ser caracterizados com mais confiança pelo critério caso este parâmetro seja calibrado às condiç̃̃es da costa brasileira. Ao final, são sugeridos também testes relacionando-se as duas partes distintas do trabalho, ou seja, uma verificação das estatísticas obtidas pelo método paramétrico aplicado aos espectros direcionais obtidos ao final da metodologia de calibração. 


\section{Revisão Bibliográfica}

Apresenta-se neste capítulo a revisão bibliográfica necessária ao estudo dos temas abordados neste texto. As referências estudadas estão separadas por assunto, de forma a manter uma ordem lógica e complementar. Desta maneira, são mencionadas, primeiramente, as referências utilizadas para a parte de parametrização de espectros direcionais, uma vez que o presente trabalho faz uso de modelos paramétricos em grande parte do texto. Em seguida são considerados os trabalhos sobre critérios de identificação de mares cruzados que, embora não estejam diretamente ligados aos assuntos seguintes, são consequência dos estudos de estimação paramétrica. Na sequência são apresentadas as referências de estatística Bayesiana utilizadas para a compreensão de tal teoria de estimação, seguidas, por fim, dos trabalhos sobre as aplicações do método Bayesiano relacionadas à estimação espectral.

\subsection{Modelos paramétricos}

A hipótese fundamental em que se baseia o problema de estimação do espectro direcional é que tal espectro, denotado por $S(\omega, \theta)$, pode ser descrito como uma função dependente da frequência e da direção de propagação da onda, denotadas, respectivamente, por $\omega$ e $\theta$. Esta função é escrita através da clássica expressão:

$$
S(\omega, \theta)=S(\omega) D(\omega, \theta)
$$

onde $S(\omega)$ é o espectro de frequência e $D(\omega, \theta)$ é a função de espalhamento direcional (Directional Spreading Function - DSF), definida no intervalo $[0 ; 2 \pi]$ e tal que $D(\omega, \theta) \geq 0$. Estas funções devem obedecer ainda as seguintes relações ${ }^{1}$ :

$$
S(\omega)=\int_{0}^{2 \pi} S(\omega, \theta) \mathrm{d} \theta \quad \text { e } \quad \int_{0}^{2 \pi} D(\omega, \theta) \mathrm{d} \theta=1
$$

\footnotetext{
${ }^{1} \mathrm{~A}$ princípio bastam tais expressões para definição dos modelos, entretanto serão incluídas outras restrições a estas funções no capítulo 5
} 
O espectro de frequência $S(\omega)$ pode ser utilizado sob diversas formulações, tendo sido também adotada neste trabalho uma formulação muito próxima à clássica JONSWAP2.

$$
S(\omega)=2 \pi \beta_{J} \frac{H_{s}^{2} \omega_{p}^{4}}{\omega^{5}} \exp \left[\frac{-1,25 \omega_{p}^{4}}{\omega^{4}}\right] \gamma^{\exp \left[-\frac{\left(\omega-\omega_{p}\right)^{2}}{2 \sigma^{2} \omega_{p}^{2}}\right]}
$$

onde $H_{s}$ é a altura significativa de onda, $\omega_{p}$ é a frequência angular de pico relacionada ao período de pico por $T_{p}=2 \pi / \omega_{p}$ e $1 \leq \gamma \leq 7$. O parâmetro $\sigma$ define a largura do pico e $\beta_{J}$ é um parâmetro de forma do espectro (ver (GODA, 2000, p. 29) $)^{3}$ ).

Um outro modelo para o espectro de frequência também utilizado neste trabalho foi proposto em (OCHI; HUBBLE, 1976):

$$
S(\omega)=\frac{1}{4} \frac{\left(\frac{4 \lambda+1}{4} \omega_{p}^{4}\right)^{\lambda}}{\Gamma(\lambda)} \frac{H_{s}^{2}}{\omega^{4 \lambda+1}} \exp \left[-\frac{4 \lambda+1}{4}\left(\frac{\omega_{m}}{\omega}\right)^{4}\right]
$$

onde $\lambda$ é um parâmetro de controle da forma do espectro. O trabalho mostrou que esta formulação é capaz de representar uma variedade de formas de espectro, sendo inclusive possível utilizá-la com frequências de pico duplas (mares bimodais), bastando-se apenas somar duas representações de mares unimodais de tal modelo. Esta formulação é também encontrada em (GRAHAM; JUSZKO, 1993) no qual é feita uma análise comparativa da influência da parametrização do espectro na predição de movimentos de um navio.

Definido o espectro de frequências, resta a questão da escolha de funções para representação do espalhamento direcional que atendam aos critérios estabelecidos. Este problema foi extensamente estudado por diversos autores, envolvendo inicialmente o uso de séries de Fourier como forma de determinação de DSFs, utilizando registros de mar obtidos por bóias oceanográficas.

Dentre os primeiros trabalhos feitos no sentido de definir estas funções, foi realizado em (LONGUET-HIGGINS, 1957) um amplo estudo das características estatísticas de uma superfície em movimento, definindo-se um método para obtenção do espectro de energia.

Este estudo serve como referência para diversos outros, inclusive para (LONGUET-HIGGINS; CARTWRIGHT; SMITH, 1961), onde foi feito um estudo da DSF, sendo inclusive mostrado que o

\footnotetext{
${ }^{2}$ Foram feitas pequenas modificações pela PETROBRAS afim de adaptar o modelo aos mares da costa brasileira

${ }^{3}$ Este parâmetro é também apresentado na seção 5.4
} 
espalhamento da energia $(s)$ pode ser incluído como um parâmetro em modelos de descrição do espectro direcional. Por meio da análise de Fourier de dados obtidos por bóias oceanográficas, é proposta nesta referência uma função para descrever o espalhamento direcional, sendo que esta se tornou a base de diversas formulações propostas posteriormente:

$$
D(\omega, \theta)=\frac{1}{\pi} 2^{2 s-1} \frac{\Gamma^{2}(s+1)}{\Gamma(2 s+1)} \cos ^{2 s}\left(\frac{\theta-\theta_{m}}{2}\right)
$$

onde $\theta_{m}$ é a direção média de incidência de ondas e $\Gamma(s)=\int_{0}^{\infty} t^{s-1} \mathrm{e}^{-t} \mathrm{~d} t$.

Em (MITSUYASU et al., 1975) é feita uma análise do ajuste das séries de Fourier à função proposta em (LONGUET-HIGGINS; CARTWRIGHT; SMITH, 1961), sendo então desenvolvida uma formulação alternativa, tendo em vista aplicações práticas da mesma, incluindo uma variação de $s$ em função da frequência. Assim, o modelo da DSF é complementado por:

$$
s= \begin{cases}s_{\max }\left(\omega / \omega_{p}\right)^{5}, & \text { para } \omega \leq \omega_{p} \\ s_{\max }\left(\omega / \omega_{p}\right)^{2,5}, & \text { para } \omega>\omega_{p} .\end{cases}
$$

onde $s_{\max }$ adquire valores diferentes de acordo com o tipo de mar analisado. Para aplicações de engenharia, (GODA, 2000) define alguns valores básicos, os quais serão apresentados neste texto em momento oportuno.

\subsection{Critérios de bimodalidade}

Mares reais são melhor representados por modelos que considerem a existência de diferentes concentrações de energia com alturas, direções e frequências de onda próprias, sendo estes chamados de mares cruzados. Em aplicações práticas é frequente a necessidade de adotar modelos paramétricos de espectros direcionais capazes de representar este fenômeno, também denominado bimodalidade espectral.

Assim, para a correta representação de um espectro direcional medido ou mesmo estimado, faz-se necessária, primeiramente, a identificação do tipo de espectro a ser representado, classificando-o como uni ou bimodal.

Ao separar espectros bimodais e unimodais, é possível realizar de maneira correta a estimação das estatísticas descritivas dos espectros. Sem adotar tal critério, a representação de espectros unimodais por modelos bimodais pode ocorrer em implementações numéricas, resul- 
tando em estatísticas incorretas, como foi verificado ao longo do desenvolvimento deste trabalho. Desta maneira, buscou-se na literatura critérios que possibilitassem a classificação dos espectros conforme mencionado. São apresentados aqui apenas os conceitos destes critérios, já que no capítulo 5 são feitas as definições e formulações apropriadas.

Um dos primeiros parâmetros a fornecer informações sobre a direcionalidade das ondas que determinam um espectro foi introduzido por (LONGUET-HIGGINS, 1957), sendo chamado longcrestedness $(\Gamma)$, calculado através dos 4 primeiros coeficientes da série de Fourier utilizada na obtenção da DSF ${ }^{4}$, e tendo a propriedade de oscilar próximo a zero no caso de mares unimodais e próximo a 1 no caso contrário.

É afirmado em (GODA, 2000) que o parâmetro long-crestedness não define um critério de bimodalidade, e esta referência introduz um parâmetro alternativo, baseado em $\Gamma$, chamado direção média de espalhamento $\left(\theta_{k}\right)$, este variando entre zero e 0,5.

Em posse destes dois parâmetros, (KOBUNE; SASAKI; HASHIMOTO, 1985) propõem - após mostrar que sozinhos estes parâmetros não são critérios universais para identificação da bimodalidade - um critério alternativo através da combinação de $\Gamma$ e $\theta_{k}$, definindo em um plano $\theta_{k} \times \Gamma$ duas regiões separadas por uma curva limite $\left(\Gamma_{\text {lim }}\right)$. O critério é objetivo ao afirmar que espectros associados a valores $\Gamma<\Gamma_{\text {lim }}$ são considerados bimodais, sendo unimodais no caso contrário.

Também fazendo uso dos mesmos 4 coeficientes da série de Fourier no cálculo de seus parâmetros, (KUIK; VLEDDER; HOLTHUUSEN, 1988) definem um critério de identificação de mares cruzados utilizando os conceitos de skewness $(\gamma)$ e kurtosis $(\delta)$.

$\mathrm{O}$ parâmetro $\gamma$ fornece uma medida de assimetria da DSF em relação à média e $\delta$ indica o quão alto é o pico desta função. Consequentemente, a combinação destas informações fornece uma medida qualitativa da forma da DSF, o que naturalmente indica a possibilidade do uso destas informações na identificação de mares unimodais, uma vez que para estes deve existir simetria da DSF. Em teoria, um mar perfeitamente unimodal terá $\gamma=0$, pois não existe assimetria em relação à média dos valores da DSF. Este critério estabelece que se para um dado espectro direcional, estão associados valores de $\gamma$ e $\delta$ acima da curva limite definida por:

$$
\delta= \begin{cases}2+|\gamma| & \text { para }|\gamma| \leq 4 \\ 6 & \text { para }|\gamma|>4\end{cases}
$$

então o espectro é unimodal, caso contrário, podem existir 2 ou mais picos de energia. Este critério foi estabelecido sobre um bom número de testes numéricos, contando também com avaliações de registros reais de bóias oceanográficas.

\footnotetext{
${ }^{4}$ Embora neste trabalho não se tenha a informação das séries de Fourier, é apresentada uma forma de obtenção destes coeficientes utilizando a própria DSF.
} 
Após uma avaliação comparativa numérica dos critérios apresentados anteriormente, (BESNARD; BENOIT, 1994) apresentam um terceiro critério de bimodalidade, também utilizando os coeficientes da série de Fourier, baseado nas quantidades $r$ e $\Theta$, as quais indicam, respectivamente, a razão entre as amplitudes dos coeficientes da série de Fourier e o ângulo entre as direções média e principal da DSF. O critério proposto indica que para casos de bimodalidade, ambos os parâmetros recebem valores altos $\left(r>0,1\right.$ e $\left.\Theta>5^{\circ}\right)$, já no caso contrário, supõese a unimodalidade dos espectros, associando a estes valores baixos dos hiperparâmetros (se $0,1 \leq r \leq 10$ e $\Theta \leq 5^{\circ}$ ou se $\left.r \leq 0,1\right)$.

Um estudo comparativo dos métodos de identificação de mares cruzados propostos por (KOBUNE; SASAKI; HASHIMOTO, 1985) e (KUIK; VLEDDER; HOLTHUUSEN, 1988) é feito também em (BENASSAI; PORTA, 2000), utilizando registros de mares gerados por tempestades próximas à costa italiana, sendo estes obtidos por meio de bóias oceanográficas. Neste estudo conclui-se que o critério proposto por (KOBUNE; SASAKI; HASHIMOTO, 1985) é capaz de indentificar espectros bimodais e que (KUIK; VLEDDER; HOLTHUUSEN, 1988) é eficiente para alguns valores de kurtosis.

Por fim, um último estudo avaliado, conduzido por (PISCOPIA; PANIZZO; GIROLAMO, 2004) compara os 3 métodos apresentados anteriormente e propõe um último critério, o qual é utilizado neste trabalho. Este critério é consideravelmente mais simples que os anteriores, inferindo que a diferença absoluta entre a direção média de incidência das ondas $\left(\theta_{m}\right)$ e a direção média do fluxo de energia $\left(\theta_{m}^{D}\right)$ não deve ultrapassar $3^{\circ}$. Após comparar seus resultados com os demais critérios, (PISCOPIA; PANIZZO; GIROLAMO, 2004) afirma que seu critério de identificação encontra corretamente $100 \%$ dos casos de mares unimodais, mantendo uma performance próxima aos outros critérios quando avaliados os índices de acerto para mares bimodais.

Este é um fato muito importante na abordagem do presente trabalho, pois, como mencionado anteriormente, identificar corretamente os mares unimodais aumenta consideravelmente a taxa de estimações corretas das estatísticas de mar, uma vez que ao avaliar mares unimodais por meio de modelos bimodais causava erros consideráveis.

\subsection{Inferência Bayesiana}

O estudo de inferência Bayesiana se fez necessário devido à complexidade dos modelos adotados na abordagem Bayesiana ao problema de estimação dos espectros direcionais. Sendo este um tema diferenciado, no que diz respeito aos métodos da engenharia, um embasamento teórico era necessário para melhor compreensão da modelagem já realizada nos trabalhos anteriores.

A principal referência utilizada neste estudo foi (AKAIKE, 1980). O trabalho apresentado nesta referência embasa toda a estimação não-paramétrica de espectro direcional de ondas, sendo então uma importante leitura. No mencionado trabalho são levantadas diversas questões sobre inferência Bayesiana e sobre seu uso completo, sem adotar conceitos de estatística frequentista.

O principal assunto de interesse no referido trabalho é a modelagem Bayesiana utilizada para a resolução de sistemas lineares em problemas de ajuste de funções a conjuntos de dados, a qual é feita levando-se em consideração sistemas de grande ordem em que o número de coeficientes 
ultrapassa em muito o número de observações, sendo, portanto, sistemas difícies de resolver numericamente por métodos convencionais, tais como método dos mínimos quadrados, o qual se torna instável em situações como esta.

Introduzindo um termo de erro com propriedades Gaussianas, controlado por um certo (hiper)parâmetro $u$, afim de priorizar alguns coeficientes da aproximação, (AKAIKE, 1980) transforma o problema de ajuste em um problema de escolha do valor de $u$, pois assim é possível obter uma solução próxima da ótima, mas com garantia de ser uma função suave.

Ao propor tal método, o autor também determina uma maneira de resolver o problema da escolha deste parâmetro, o que é o grande diferencial do trabalho e utilidade da abordagem Bayesiana do ponto de vista da aplicabilidade. Define-se um critério de informação (Akaike's Bayesian Information Criterion - $A B I C$ ) que indica, por meio de diversas estimações, qual o melhor $u$ a ser utilizado, bastando encontrar o valor mínimo que este critério atinge. Assim, o critério $A B I C$ faz uso do próprio modelo Bayesiano para encontrar o modelo ótimo que leva à melhor estimativa.

Embora muito útil, este critério se mostrou custoso computacionalmente no problema de estimação espectral, uma vez que necessita diversas estimações para encontrar o melhor valor de $u$. Mesmo assim, tendo em vista o histórico de estudos do método Bayesiano de estimação de espectros, o qual fez uso do $A B I C$ por um considerável período de tempo, é importante destacar tal referência.

\subsection{Método Bayesiano de estimação de espectros direcio- nais}

Anteriormente ao método Bayesiano de estimação, os espectros direcionais eram obtidos, em sua grande maioria, por meio de séries temporais dos registros de bóias oceanográficas, utilizando especialmente os movimentos de Heave, Roll e Pitch. Para estimar o espectro direcional de ondas a partir dos movimentos de primeira ordem de sistemas oceânicos, devem ser feitas adaptações às formulações clássicas de forma a incluir a dinâmica própria da embarcação, a qual é descrita por meio de seus RAOs.

Em (HASHIMOTO; KOBUNE; KAMEYAMA, 2000) é proposta a abordagem Bayesiana ao problema de estimação de espectros, baseando-se em (AKAIKE, 1980) e ainda sem considerar os movimentos do sistema flutuante, apenas utilizando dados de ondas medidos por meio de probe arrays. O trabalho desenvolve uma formulação específica para a estimação da DSF, levando em consideração também o critério $A B I C$ como forma de encontrar valores ótimos para o hiperparâmetro de suavização. Nestes estudos era considerada a suavização apenas nas direções, utilizando-se apenas um parâmetro para controle entre o bom ajuste ou maior suavização.

O método Bayesiano proposto por (HASHIMOTO; KOBUNE; KAMEYAMA, 2000) foi então adaptado por (ISEKI; OHTSU, 2000) para estimar o espectro direcional de ondas baseado em três movimentos do sistema flutuante: Heave, Roll e Pitch. Este estudo considera um navio relativamente pequeno (em comparação aos FPSOs utilizados nos estudos aqui realizados) e em movimento, o que implica em um problema envolvendo a frequência de encontro. 
Os estudos realizados na EPUSP desde o ano 2000 foram inicialmente descritos em (TANNURI et al., 2001), o qual descreve um trabalho baseado na formulação descrita em (ISEKI; OHTSU, 2000), adotando-se a abordagem não-paramétrica, utilizando o método Bayesiano de estimação de espectros para um FPSO em situação estacionária. Neste trabalho são apresentados resultados de simulações numéricas para mares decenários e centenários da Bacia de Campos, obtidos com boa precisão. Sugere-se nesta referência a substituição do movimento Roll pelo movimento de Sway, pois este último movimento não apresenta não-linearidades em seu RAO na região de ressonância devido ao amortecimento viscoso, como acontece com Roll. Além disso, argumentase que o RAO também é uma função ímpar em relação à linha de centro da embarcação, o que fornece informação sobre a direção de incidência do espectro. Um outro fator considerado é que este movimento é menos sensível à variações de calado, sendo inclusive feita uma análise de sensibilidade às condições de carregamento da embarcação, concluindo que as estimativas obtidas não são afetadas significativamente por pequenas alterações dos RAOs causadas pela variação do calado.

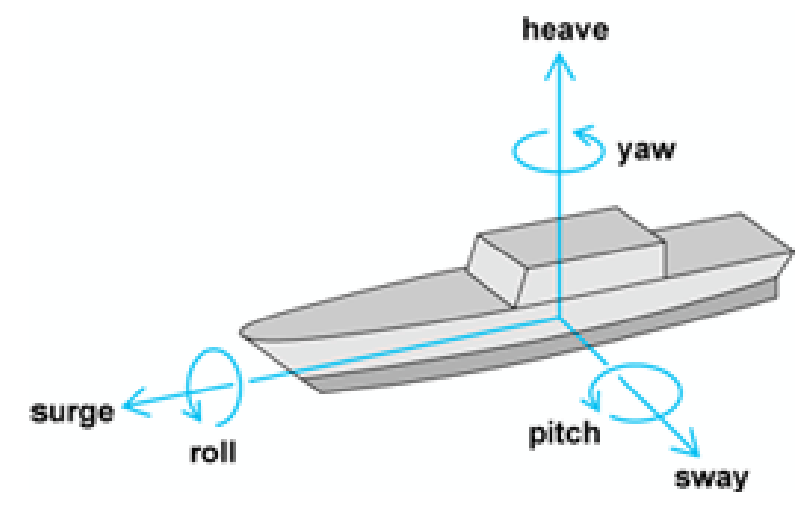

Figura 3: Graus de liberdade da embarcação.

Em (TANNURI et al., 2004) é abordado o método paramétrico de estimação de espectros de onda, utilizando a formulação de Hogben \& Cobb para o espectro direcional, assim como apresentada em (GRAHAM; JUSZKO, 1993). Neste trabalho apresenta-se um método que tenta minimizar o erro quadrático entre o espectro estimado e o medido de um FPSO em estado estacionário, através dos movimentos de Sway, Heave e Pitch. Neste estudo também são feitas simulações numéricas que mostraram bons resultados para a estimação paramétrica. Entretanto, são mencionadas limitações quanto à implementação deste método na prática, relacionadas ao alto custo computacional do algoritmo de estimação, dado que este se resume a um problema de programação não-linear.

São apresentadas em (TANNURI et al., 2007) estimativas de espectro direcional comparados a resultados de monitoramento em escala real, utilizando os métodos paramétrico e não-paramétrico para o cálculo das estimativas. Neste trabalho são utilizados cinco movimentos para a geração dos espectros: Surge, Sway, Heave, Pitch e Yaw. Esta nova abordagem gerou resultados ligeiramente melhores que os obtidos em estudos anteriores com apenas 3 movimentos. Entretanto, foi possível uma estimação melhor do espalhamento dos mares observados. A principal conclusão de (TANNURI et al., 2007) é que a abordagem Bayesiana leva a resultados consideravelmente melhores que o método paramétrico de estimação. 
Com base nestas conclusões, (SPARANO, 2008) utiliza a abordagem Bayesiana em uma série de ensaios em escala reduzida de duas embarcações: o FPSO P-35 e a BGL-1 (figuras 4(a) e 4(b)). Os resultados das estimações do FPSO são comparados a dados reais de carregamento, movimentos de primeira ordem e aproamento, obtidos por uma campanha de monitoramento realizada pelo MARIN (Maritime Research Institute Netherlands) na Bacia de Campos, na qual também foi instalada uma bóia oceanográfica no local, sendo esta utilizada como paradigma da estimação. Este estudo conclui que o método Bayesiano é bastante confiável, mas além disso introduz um novo hiperparâmetro no modelo Bayesiano, de modo a minimizar a energia estimada em faixas de frequência fora da região de estimação. Tanto este hiperparâmetro quanto o de controle da suavização são adotados fixos por calado, indicando que o método Bayesiano é pouco sensível a variações destes parâmetros.

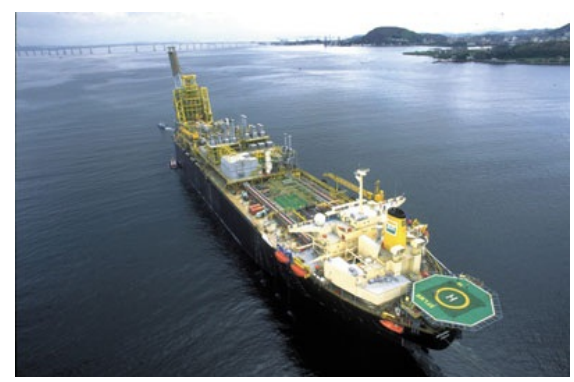

(a) P-35.

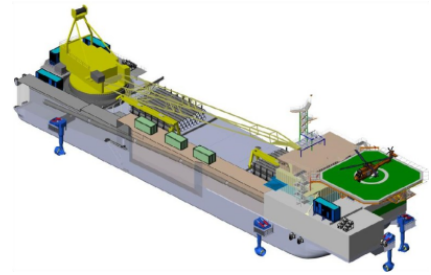

(b) BGL-1.

Figura 4: Embarcações utilizadas como referência para ensaios em escala em (SPARANO, 2008).

É introduzido por (NIELSEN, 2008) no modelo Bayesiano um segundo hiperparâmetro de controle de suavização, desta vez ao longo das frequências. Neste trabalho é reformulado o critério $A B I C$ e são feitas simulações numéricas de forma avaliar o efeito de tal modificação do modelo. São feitas também comparações com dados de radar, concluindo-se que as estimativas encontradas são razoáveis.

Através da implementação do método Bayesiano realizada por (ISEKI, 2009) para estimação de espectros em tempo real, foi possível verificar que o método é viável como um sistema onboard, dado que foram obtidos bons resultados das estimações em tempo real comparadas às estimações de registros realizados no mesmo período. Entretanto, nada é mencionado sobre o uso do critério $A B I C$ neste estudo.

O uso de um modelo Bayesiano com 3 hiperparâmetros fixos a cada calado é analisado em (SIMOS et al., 2009) após uma análise de sensibilidade dos mesmos para ensaios em escala realizados com um FPSO em estado estacionário. São feitas também comparações com os resultados gerados utilizando o critério $A B I C$, donde se conclui que as estimativas obtidas utilizando tal critério são sensivelmente melhores. Entretanto, é considerado também o problema do custo computacional da utilização deste critério, o que o torna inviável para aplicações práticas em tempo real.

Uma análise direta do uso de hiperparâmetros fixos foi feita em (ISEKI; NIELSEN, 2010a) com o propósito de verificar se as estimações são muito afetadas. Este estudo é justificado pelo aumento da eficiência computacional na estimação, uma vez que ao eliminar o critério $A B I C$, deixam de ser feitas diversas iterações da estimação pelo método Bayesiano. Através de simulações numéricas 
o trabalho indica que podem ser usados valores fixos para os hiperparâmetros de suavização, dado que neste estudo não foi adotado o hiperparâmetro de redução da energia.

Recentemente, em (ISEKI, 2011) foi feita uma análise da relação entre o mínimo do critério $A B I C$ e a melhor estimativa possível, indicando que nem sempre o critério $A B I C$ leva aos melhores resultados. Este fato é importante no que diz respeito às justificativas do presente trabalho, uma vez que é feita uma calibração dos hiperparâmetros de forma serem obtidos a priori, independentes do espectro estimado, mas em função de quantidades previamente mensuráveis, tais como $T_{p}$ e calado da embarcação. 


\section{Método Bayesiano}

\subsection{Estimação da função de espalhamento direcional}

Em (HASHIMOTO; KOBUNE; KAMEYAMA, 2000) é feita a aplicação do método Bayesiano à estimação da função de espalhamento dos espectros direcionais de onda, sendo tal fundamentação teórica apresentada nesta seção. A fundamentação teórica dos conceitos aqui utilizados é apresentada no apêndice $A$, onde é mostrado também o desenvolvimento primordial do critério $A B I C$, sendo este o diferencial da abordagem Bayesiana ao problema de estimação de espectros, uma vez que por meio deste se definem modelos ótimos de estimação utilizando conceitos de estatística Bayesiana.

Segundo (SPARANO, 2008), assume-se que a função de espalhamento direcional, $D(\theta \mid \omega)$, é composta por $K$ funções constantes, igualmente espaçadas no círculo [0;2 $\pi$ ], sendo esta encarada como uma função $D(\theta)$ para cada frequência $\omega$. Portanto, a função de espalhamento de energia é discretizada ao longo da direção $\theta$, sendo constante em cada intervalo $\Delta \theta_{k}, k=\{1, \ldots, K\}$ do círculo.

Como $D(\theta \mid \omega)>0$, pode-se fazer:

$$
\ln D\left(\theta_{k} \mid \omega\right)=x_{k}(\omega), k=\{1, \ldots, K\}
$$

e desta maneira, a função de espalhamento direcional é dada por

$$
D(\theta \mid \omega)=\sum_{k=1}^{K} e^{x_{k}(\omega)} I_{k}(\theta \mid \omega)
$$

onde 


$$
I_{k}(\theta \mid \omega)=\left\{\begin{array}{l}
1, \text { se }(k-1) \Delta \theta<\theta<k \Delta \theta \\
0, \text { caso contrário }
\end{array}\right.
$$

Fazendo uso da relação de dispersão $\omega^{2}=\mathbf{k} g \tanh \mathbf{k} h$, onde $\mathbf{k}, g$ e $h$ denotam, respectivamente, o número de onda, a gravidade e a profundidade, e supondo que existe linearidade entre os espectros de entrada e de saída, denotados respectivamente por $S(\omega, \theta)$ e $\Phi_{l, m}(\omega)$, pode ser escrita a matriz de espectros cruzados, por meio da função de transferência $H_{p}(\omega, \theta)$.

$$
\Phi_{l m}(\omega)=\int_{0}^{2 \pi} H_{p}(\omega, \theta) S(\omega, \theta) \mathrm{d} \theta
$$

onde $l$ e $m$ indicam certas propriedades da onda e $p$ denota o tipo de função de transferência utilizada com base nas propriedades $l$ e $m .{ }^{1}$ Assim, utilizando (3.1), tem-se que:

$$
\begin{aligned}
& S_{l m}(\omega)=\int_{0}^{2 \pi} H_{p}(\omega, \theta) S(\omega) D(\theta \mid \omega) \mathrm{d} \theta \Leftrightarrow \\
& S_{l m}(\omega)=S(\omega) \sum_{k=1}^{K} e^{x_{k}(\omega)} \int_{0}^{2 \pi} H_{p}(\omega, \theta) I_{k}(\theta \mid \omega) \mathrm{d} \theta \Leftrightarrow \\
& S_{l m}(\omega)=S(\omega) \sum_{k=1}^{K} \alpha_{j k}(\omega) e^{x_{k}(\omega)}
\end{aligned}
$$

onde ${ }^{2}$

$$
\alpha_{j k}(\omega)=\int_{0}^{2 \pi} H_{p}(\omega, \theta) I_{k}(\theta \mid \omega) \mathrm{d} \theta
$$

Sendo os espectros cruzados obtidos a partir de $n$ registros de movimento aquisitados, é natural pensar que existem erros associados aos mesmos. Estes erros, denotados por $\epsilon_{j}(\omega)$, $j=\{1, \ldots, 2 n\}^{3}$, são supostos independentes e tais que $\epsilon \sim \mathcal{N}\left(0, \sigma^{2}\right)$. Levando-se em consi-

\footnotetext{
${ }^{1}$ Ver (HASHIMOTO; KOBUNE; KAMEYAMA, 2000) para escolha do tipo de função. Este detalhe é irrelevante para o desenvolvimento da formulação.

${ }^{2}$ Note que (3.3) é válida pela suposição de suavidade e continuidade do integrando.

${ }^{3} \mathrm{O}$ número de registros dobra devido à separação em partes real e imaginária dos espectros
} 
deração tais erros de medição, pode-se re-escrever a função de espalhamento direcional como

$$
\varphi_{j}(\omega)=\sum_{k=1}^{K} \alpha_{j k}(\omega) e^{x_{k}(\omega)}+\epsilon_{j}(\omega)
$$

Sendo denotado por $\varphi$ o vetor que contém todas as $\varphi_{j}$, aplicando-se os conceitos introduzidos na seção A.3, a função de espalhamento direcional pode ter seus parâmetros estimados por meio da seguinte função de verossimilhança:

$$
L\left(x_{1}, \ldots, x_{k} ; \sigma^{2} \mid \boldsymbol{\varphi}\right)=\frac{1}{\left(2 \pi \sigma^{2}\right)^{n}} \exp \left\{-\frac{1}{2 \sigma^{2}} \sum_{j=1}^{2 n}\left[\varphi_{j}(\omega)-\sum_{k=1}^{K} \alpha_{j k}(\omega) e^{x_{k}(\omega)}\right]^{2}\right\}
$$

Lembrando que esta formulação apresentada foi baseada numa representação da função $D(\theta \mid \omega)$ como sendo constante por intervalos, destaca-se então o fato de que nenhuma análise da variação de energia em cada segmento $\Delta \theta_{k}$ foi feita. Levando em consideração que a análise direcional de onda é feita com base na teoria linear de ondas, pode-se assumir que esta variação entre cada segmento é independente. Entretanto, não é correto assumir que a distribuição de energia ao longo das direções de onda não é contínua, inclusive porque supõe-se a função de espalhamento direcional sendo suave e contínua. Portanto, deve ser adicionada uma condição de que a variação de $x_{k}$ deve ser bem aproximada localmente por uma função linear, a qual é a expressão matemática da continuidade e suavidade da função de espalhamento direcional, sendo isto equivalente a dizer que as segundas derivadas de $\ln D\left(\theta_{k} \mid \omega\right)$ devem ser próximas a zero. Isto implica que

$$
\sum_{k=1}^{K}\left(x_{k}-2 x_{k-1}+x_{k-2}\right)^{2}, \text { com } x_{0}=x_{K} \text { e } x_{-1}=x_{K-1}
$$

deve diminuir conforme aumente a suavização da estimativa da função de espalhamento direcional. Supõe-se então que esta estimativa maximize (3.6) e minimize (3.7) simultaneamente, sendo isto equivalente a maximizar a expressão

$$
L\left(x_{1}, \ldots, x_{k} ; \sigma^{2} \mid \boldsymbol{\varphi}\right) \exp \left[-\frac{u^{2}}{2 \sigma^{2}} \sum_{k=1}^{K}\left(x_{k}-2 x_{k-1}+x_{k-2}\right)^{2}\right]
$$


a qual pode ser considerada uma distribuição a posteriori, pois corresponde ao lado direito de (A.2), bastando a distribuição a priori de $\mathbf{x}=\left(x_{1}, x_{2}, \ldots, x_{K}\right)$ ser

$$
p\left(\mathbf{x} \mid u^{2}, \sigma^{2}\right)=\left(\frac{u}{\sqrt{2 \pi} \sigma}\right)^{K} \exp \left[-\frac{u^{2}}{2 \sigma^{2}} \sum_{k=1}^{K}\left(x_{k}-2 x_{k-1}+x_{k-2}\right)^{2}\right]
$$

Assim, para um conjunto de dados observados, a posteriori é dada pelo teorema de Bayes na seguinte forma:

$$
p_{\text {post }}\left(\mathbf{x} \mid u^{2}, \sigma^{2}\right) \propto L\left(\mathbf{x}, \sigma^{2} \mid \boldsymbol{\varphi}\right) p\left(\mathbf{x} \mid u^{2}, \sigma^{2}\right)
$$

Sendo conhecido o valor de $u$, a estimativa de $\mathbf{x}$ que maximiza a expressão (3.8) pode ser determinada pela minimização de

$$
\sum_{j=1}^{2 n}\left(\varphi_{j}-\sum_{k=1}^{K} \alpha_{j k} e^{x_{k}}\right)^{2}+u^{2} \sum_{k=1}^{K}\left(x_{k}-2 x_{k-1}+x_{k-2}\right)^{2}
$$

Os valores mais adequados do hiperparâmetro $u^{2}$ e da variância $\sigma^{2}$ podem ser obtidos por meio da determinação do valor mínimo do critério de informação $A B I C$, conforme (3.9)

$$
A B I C=-2 \ln \int L\left(\mathbf{x}, \sigma^{2} \mid \boldsymbol{\varphi}\right) p\left(\mathbf{x} \mid u^{2}, \sigma^{2}\right) \mathrm{d} \mathbf{x}
$$




\subsection{Estimação do espectro direcional a partir de movimen- tos de $1^{\mathrm{a}}$ ordem}

O modelo de estimação introduzido por (HASHIMOTO; KOBUNE; KAMEYAMA, 2000) e apresentado na seção 3.1 foi adaptado por (ISEKI; OHTSU, 2000) para utilização dos movimentos de primeira ordem da embarcação na estimação do espectro direcional de ondas. Esta adaptação consistiu na inserção dos RAOs da embarcação equivalentemente ao uso da função de transferência em (3.2) e na adoção de espectros cruzados dos movimentos do sistema. Embora nesta referência considere-se a embarcação em curso, a metodologia apresentada nesta seção segue a mesma abordagem estacionária vista em (TANNURI et al., 2004).

Além destas modificações, são inseridos 2 novos hiperparâmetros nesta nova formulação, bem como distribuições a priori distintas para cada um. O primeiro hiperparâmetro é usado para a suavização na frequência, conforme proposto por (NIELSEN, 2008), e o segundo para forçar energia nula em frequências fora do domínio de estimação, assim como descrito em (ISEKI; OHTSU, 2000), mantendo-se também o hiperparâmetro inicialmente proposto por (HASHIMOTO; KOBUNE; KAMEYAMA, 2000) para a suavização da estimativa ao longo das direções.

Assumindo linearidade na resposta da embarcação às excitações de onda, a relação que descreve os espectros cruzados resultantes das séries temporais de movimento do navio é dada pela integral (3.10) a seguir:

$$
\phi_{i j}(\omega)=\int_{-\pi}^{\pi} R A O_{i}(\omega, \theta) \overline{R A O_{j}(\omega, \theta)} S(\omega, \theta) \mathrm{d} \theta
$$

onde $R A O_{i}$ é o operador de resposta em amplitude (Response Amplitude Operator) do movimento $i$ na frequência $\omega$ e direção de incidência $\theta, \overline{R A O_{j}}$ denota o complexo conjugado do operador do movimento $j$ e $S(\omega, \theta)$ é o espectro direcional de onda.

Para escrever a expressão (3.10) discretizada nas direções, deve-se assumir que o integrando é constante em cada segmento $\Delta \theta=2 \pi / K$ do círculo. Usando $\theta_{k}=-\pi+(k-1) \Delta \theta$, $k=\{1, \ldots, K\}$. Escolhido um certo intervalo com $M$ frequências $\left(\omega_{1}, \ldots, \omega_{M}\right)$ nas quais espera-se resposta da embarcação às ondas, a equação (3.10) pode ser escrita como:

$$
\phi_{i j}\left(\omega_{m}\right)=\Delta \theta \sum_{k=1}^{K} R A O_{i}\left(\omega_{m}, \theta_{k}\right) \overline{R A O_{j}\left(\omega_{m}, \theta_{k}\right)} S\left(\omega_{m}, \theta_{k}\right)
$$

com $m=\{1, \ldots, M\}$. Matricialmente, para cada frequência $\omega_{m}$ de interesse, tem-se que a equação (3.11) fica: 


$$
\boldsymbol{\Phi}\left(\omega_{m}\right)=\Delta \theta \mathbf{R A O}\left(\omega_{m}\right) \cdot \mathbf{S}\left(\omega_{m}\right) \cdot{\overline{\mathbf{R A O}\left(\omega_{m}\right)}}^{T}
$$

onde, omitindo a dependência dos termos envolvidos às frequências $\omega_{m}$ para simplificar a notação, tem-se que

$$
\begin{aligned}
& \boldsymbol{\Phi}\left(\omega_{m}\right)=\left(\begin{array}{cccc}
\phi_{11} & \phi_{11} & \ldots & \phi_{16} \\
\phi_{21} & \phi_{22} & \ldots & \phi_{26} \\
\vdots & \vdots & \ddots & \vdots \\
\phi_{61} & \phi_{62} & \ldots & \phi_{66}
\end{array}\right) \quad, \quad \mathbf{S}\left(\omega_{m}\right)=\left(\begin{array}{cccc}
S\left(\theta_{1}\right) & 0 & \ldots & 0 \\
0 & S\left(\theta_{2}\right) & \ldots & 0 \\
\vdots & \vdots & \ddots & \vdots \\
0 & 0 & \ldots & S\left(\theta_{K}\right)
\end{array}\right) \\
& \operatorname{RAO}\left(\omega_{m}\right)=\left(\begin{array}{cccc}
R A O_{1}\left(\theta_{1}\right) & R A O_{1}\left(\theta_{2}\right) & \ldots & R A O_{1}\left(\theta_{K}\right) \\
R A O_{2}\left(\theta_{1}\right) & R A O_{2}\left(\theta_{2}\right) & \ldots & R A O_{2}\left(\theta_{K}\right) \\
\vdots & \vdots & \ddots & \vdots \\
R A O_{6}\left(\theta_{1}\right) & R A O_{6}\left(\theta_{2}\right) & \ldots & R A O_{6}\left(\theta_{K}\right)
\end{array}\right) \text { e } \\
& \overline{\mathbf{R A O}\left(\omega_{m}\right)}=\left(\begin{array}{cccc}
\overline{R A O_{1}\left(\theta_{1}\right)} & \overline{R A O_{1}\left(\theta_{2}\right)} & \ldots & \overline{R A O_{1}\left(\theta_{K}\right)} \\
\overline{R A O_{2}\left(\theta_{1}\right)} & \overline{R A O_{2}\left(\theta_{2}\right)} & \ldots & \overline{R A O_{2}\left(\theta_{K}\right)} \\
\vdots & \vdots & \ddots & \vdots \\
\overline{R A O_{6}\left(\theta_{1}\right)} & \overline{R A O_{6}\left(\theta_{2}\right)} & \ldots & \overline{R A O_{6}\left(\theta_{K}\right)}
\end{array}\right)
\end{aligned}
$$

Os índices $1, \ldots, 6$ correspondem aos graus de liberdade da embarcação na seguinte ordem: surge, sway, heave, roll, pitch e yaw.

Uma importante simplificação da expressão (3.12) pode ser feita devido ao fato da matriz $\Phi$ ser Hermitiana, ou seja, $\phi_{i j}=\overline{\phi_{j i}}$, pois através desta propriedade pode-se utilizar apenas os elementos da matriz triangular superior. Além disso, destaca-se o fato de que os espectros $\phi_{i i}$ da diagonal principal de $\boldsymbol{\Phi}$ são reais e os espectros $\phi_{i j}$ são complexos. Levando-se em consideração estes fatos, o seguinte sistema linear pode ser usado para representar (3.12):

$$
\mathbf{B}=\mathbf{A x}+\mathbf{U}
$$


onde $\mathbf{x}$ é um vetor de ordem $K \cdot M$ que contém o espectro direcional desconhecido avaliado nos pares $\left(\omega_{m}, \theta_{k}\right)$ :

$$
\mathbf{x}=\left[\begin{array}{c}
S\left(\omega_{1}, \theta_{1}\right) \\
S\left(\omega_{1}, \theta_{2}\right) \\
\vdots \\
S\left(\omega_{M}, \theta_{K-1}\right) \\
S\left(\omega_{M}, \theta_{K}\right)
\end{array}\right]
$$

o vetor B contém $N^{2} \cdot M$ espectros de movimento e espectros cruzados de movimento dos $N$ graus de liberdade utilizados:

$$
\mathbf{B}=\left[\begin{array}{c}
\mathbf{b}_{1} \\
\mathbf{b}_{2} \\
\vdots \\
\mathbf{b}_{M}
\end{array}\right], \operatorname{com} \mathbf{b}_{m}=\left[\begin{array}{c}
\phi_{i i}\left(\omega_{m}\right) \\
\vdots \\
\operatorname{Re}\left[\phi_{i j}\left(\omega_{m}\right)\right] \\
\vdots \\
\operatorname{Im}\left[\phi_{i j}\left(\omega_{m}\right)\right] \\
\vdots
\end{array}\right],
$$

A é a matriz de dimensão $\left(N^{2} \cdot M\right) \times(K \cdot M)$ dos RAOs, dada por:

$$
\begin{gathered}
\mathbf{A}=\left[\begin{array}{cccc}
\mathbf{A}_{1} & \mathbf{0} & \ldots & \mathbf{0} \\
\mathbf{0} & \mathbf{A}_{2} & \ldots & \mathbf{0} \\
\vdots & \vdots & \ddots & \vdots \\
\mathbf{0} & \mathbf{0} & \ldots & \mathbf{A}_{M}
\end{array}\right], \text { com } \\
\mathbf{A}_{m}=\left[\begin{array}{ccc}
\left|R A O_{i}\left(\omega_{m}, \theta_{1}\right)\right|^{2} & \ldots & \left|R A O_{i}\left(\omega_{m}, \theta_{K}\right)\right|^{2} \\
\vdots & \vdots & \vdots \\
\operatorname{Re}\left[R A O_{i}\left(\omega_{m}, \theta_{1}\right) \overline{R A O_{j}\left(\omega_{m}, \theta_{1}\right)}\right] & \ldots & \operatorname{Re}\left[R A O_{i}\left(\omega_{m}, \theta_{K}\right) \overline{R A O_{j}\left(\omega_{m}, \theta_{K}\right)}\right] \\
\vdots & \vdots & \vdots \\
\operatorname{Im}\left[R A O_{i}\left(\omega_{m}, \theta_{1}\right) \overline{R A O_{j}\left(\omega_{m}, \theta_{1}\right)}\right] & \ldots & \operatorname{Im}\left[R A O_{i}\left(\omega_{m}, \theta_{K}\right) \overline{R A O_{j}\left(\omega_{m}, \theta_{K}\right)}\right] \\
\vdots & \vdots & \vdots
\end{array}\right]
\end{gathered}
$$

Considerando que as medições de movimento para obtenção dos espectros possuem ruídos 
associados, o vetor $\mathbf{U}$ de dimensão $N^{2} \cdot M$ representa estes erros, os quais assume-se que sigam uma distribuição Normal de média 0 e variância $\sigma^{2}$, sendo chamado ruído branco Gaussiano.

Usando esta modelagem, pode-se então aplicar o método Bayesiano para estimação de $\mathbf{x}$. De acordo com (SIMOS et al., 2009) e com base em (ISEKI; OHTSU, 2000), pode-se mostrar que a função de verossimilhança do modelo (3.13) é dada pela expressão (3.14) abaixo:

$$
L(\mathbf{x} \mid \mathbf{B})=\left(\frac{1}{2 \pi \sigma^{2}}\right)^{\frac{N^{2}}{2}} \exp \left(-\frac{1}{2 \sigma^{2}}\|\mathbf{B}-\mathbf{A} \mathbf{x}\|^{2}\right)
$$

Fazendo a mesma suposição descrita na seção 3.1 de que o espectro estimado é suave ao longo das direções e frequências, são definidas em (3.16) as diferenças de segunda ordem $\epsilon_{1_{m k}} \mathrm{e}$ $\epsilon_{2_{m k}}$ para direção e frequência, respectivamente.

$$
\begin{aligned}
& \epsilon_{1_{m k}}=S\left(\omega_{m}, \theta_{k-1}\right)-2 S\left(\omega_{m}, \theta_{k}\right)+S\left(\omega_{m}, \theta_{k+1}\right) \\
& \epsilon_{2_{m k}}=S\left(\omega_{m-1}, \theta_{k}\right)-2 S\left(\omega_{m}, \theta_{k}\right)+S\left(\omega_{m+1}, \theta_{k}\right)
\end{aligned}
$$

De acordo com (NIELSEN, 2008), esta suposição é equivalente a minimizar os seguintes funcionais:

$$
\begin{aligned}
& \sum_{k=1}^{K} \sum_{m=1}^{M} \epsilon_{1_{m k}}^{2}=\mathbf{x}^{T} \mathbf{H}_{1} \mathbf{x}, \operatorname{com} S\left(\omega_{m}, \theta_{0}\right)=S\left(\omega_{m}, \theta_{K}\right) \text { e } S\left(\omega_{m}, \theta_{K+1}\right)=S\left(\omega_{m}, \theta_{1}\right) \\
& \sum_{k=1}^{K} \sum_{m=1}^{M} \epsilon_{2_{m k}}^{2}=\mathbf{x}^{T} \mathbf{H}_{2} \mathbf{x}
\end{aligned}
$$

onde as matrizes $\mathbf{H}_{1}$ e $\mathbf{H}_{2}$ podem ser facilmente construídas, levando-se em consideração a própria estrutura do funcional, conforme feito em (NIELSEN, 2008).

Segundo (ISEKI; OHTSU, 2000), dado um espectro de energia no intervalo de frequências $\left(\omega_{1}, \ldots, \omega_{M}\right)$, existem infinitas possibilidades de comportamento fora das fronteiras, o que pode influenciar a estimação, pois a energia estimada estará correta, mas com a distribuição errada. Sabendo que fora do intervalo, tanto a resposta do navio, quanto o RAO são nulos, é necessário evitar este tipo de estimativa. Assim, força-se a minimização do espectro de potência em baixas e altas frequências $\left(\omega_{1}, \ldots, \omega_{L}, \omega_{H}, \ldots, \omega_{M}\right)$ pré especificadas, por meio da inserção de um 
terceiro hiperparâmetro no modelo Bayesiano.

Dessa maneira, busca-se minimizar o seguinte funcional:

$$
\sum_{k=1}^{K} \sum_{m=1}^{L} S\left(\omega_{m}, \theta_{k}\right)^{2}+\sum_{k=1}^{K} \sum_{m=H}^{M} S\left(\omega_{m}, \theta_{k}\right)^{2}=\mathbf{x}^{T} \mathbf{H}_{3} \mathbf{x}
$$

onde $\mathbf{H}_{3}$ é uma matriz obtida pelo mesmo procedimento das matrizes $\mathbf{H}_{1}$ e $\mathbf{H}_{2}$.

Considerando-se então que $\epsilon_{1_{m k}} \sim \mathcal{N}\left(0, \sigma^{2} / u_{1}^{2}\right)$ e $\epsilon_{2_{m k}} \sim \mathcal{N}\left(0, \sigma^{2} / u_{2}^{2}\right)$, onde $u_{1}$ e $u_{2}$ são os hiperparâmetros de suavização na direção e na frequência, respectivamente, e que a função minimizada em (3.17) também segue uma distribuição Gaussiana de média 0 e variância $\sigma^{2} / u_{3}^{2}$ em que $u_{3}$ é o hiperparâmetro de energia nula forçada, tem-se que a distribuição a priori destes termos é expressa por:

$$
p(\mathbf{x})=\prod_{i=1}^{3}\left(\frac{u_{i}^{2}}{2 \pi \sigma^{2}}\right)^{\frac{K}{2}} \exp \left(-\frac{u_{i}^{2}}{2 \sigma^{2}} \mathbf{x}^{T} \mathbf{H}_{i} \mathbf{x}\right)
$$

Assim, pelo teorema de Bayes, a distribuição a posteriori é dada pela seguinte expressão:

$$
\begin{aligned}
& p_{\text {post }}\left(\mathbf{x} \mid u_{1}, u_{2}, u_{3}, \sigma^{2}, \mathbf{B}\right) \propto L(\mathbf{x} \mid \mathbf{B}) p(\mathbf{x}) \\
& =C \exp \left\{-\frac{1}{2 \sigma^{2}}\left[\|\mathbf{B}-\mathbf{A} \mathbf{x}\|^{2}+\mathbf{x}^{T}\left(u_{1}^{2} \mathbf{H}_{1}+u_{2}^{2} \mathbf{H}_{2}+u_{3}^{2} \mathbf{H}_{3}\right) \mathbf{x}\right]\right\}
\end{aligned}
$$

onde $C$ é um fator de normalização que não depende da variável estimada $\mathbf{x}$.

Portanto, assim como foi feito na seção 3.1, a estimativa de $\mathbf{x}$ é encontrada pela maximização da distribuição a posteriori (3.19). Entretanto, sendo esta função uma exponencial, sua maximização equivale à minimização do funcional

$$
\mathbf{J}(\mathbf{x})=\|\mathbf{B}-\mathbf{A} \mathbf{x}\|^{2}+\mathbf{x}^{T}\left(u_{1}^{2} \mathbf{H}_{1}+u_{2}^{2} \mathbf{H}_{2}+u_{3}^{2} \mathbf{H}_{3}\right) \mathbf{x}
$$


Os valores dos hiperparâmetros $u_{1}, u_{2}$ e $u_{3}$ podem ser encontrados por meio da busca do valor mínimo da estatística $A B I C$, conforme visto anteriormente. No caso deste modelo, uma aproximação da integral utilizada no cálculo do critério é sugerida por (NIELSEN, 2008), dadas as altas ordens das matrizes envolvidas. Assim, deve ser minimizada a expressão:

$$
A B I C=P \cdot \ln \mathbf{J}(\mathbf{x})-\ln \left|\operatorname{det}\left(u_{1}^{2} \mathbf{H}_{1}+u_{2}^{2} \mathbf{H}_{2}\right)\right|+\ln \left|\operatorname{det}\left(\mathbf{A} \mathbf{A}^{T}+u_{1}^{2} \mathbf{H}_{1}+u_{2}^{2} \mathbf{H}_{2}\right)\right|
$$

Assim como descrito no capítulo 4, neste trabalho foi desenvolvida uma metodologia alternativa para a busca de valores dos hiperparâmetros $u_{1}$ e $u_{2}$, pois existia o espectro numérico como paradigma, sendo possível calcular o erro entre a estimação encontrada e o valor real. Assim, o uso da estatística $A B I C$ não foi necessário, mas destaca-se novamente a importância desta abordagem dado o histórico de trabalhos do grupo da EPUSP e de outros autores envolvendo tal critério, sendo inevitável a comparação dos resultados aqui obtidos com os de trabalhos anteriores. 


\section{Análise de sensibilidade: calibração dos hiperparâmetros}

\subsection{Introdução}

Neste capítulo apresenta-se uma metodologia a ser aplicada para determinação, a priori, dos hiperparâmetros $u_{1}$ e $u_{2}$ vistos na seção 3.2 como parte de um funcional a ser minimizado. Por meio de uma análise de sensibilidade, buscou-se definir um procedimento aplicável a qualquer embarcação em que se desejar utilizar o sistema de estimação de espectro direcional de ondas, sendo necessário basicamente repetir os passos aqui apresentados para obtenção de valores destes hiperparâmetros condizentes com o comportamento de tal embarcação.

A idéia principal é encontrar valores de $u_{1}$ e $u_{2}$ que possam ser tabelados para parâmetros observáveis antes da estimação, tais como calado e período de pico $\left(T_{p}\right)$. Esta abordagem foi adotada com base em estudos recentes sobre a influência dos hiperparâmetros na estimação dos espectros direcionais de onda, tais como (SIMOS et al., 2009), (ISEKI; NIELSEN, 2010a), (ISEKI; NIELSEN, 2010b) e (ISEKI, 2011), onde são sugeridos valores fixos dos hiperparâmetros a cada calado, sendo também mostrado que a estimação é pouco sensível a variações dos mesmos. Portanto, ao final da aplicação da metodologia de calibração, obtém-se duas tabelas referentes à $u_{1}$ e $u_{2}$ em função de $T_{p}$ e calado da embarcação, donde podem ser retirados valores intermediários por meio de interpolação.

Inicialmente são apresentados neste capítulo alguns problemas da abordagem atual por meio do critério de informação $A B I C$, assim como outras evidências que estimulam o desenvolvimento da metodologia de calibração. Em seguida, é apresentada a metodologia desenvolvida propriamente dita, abordando-se as características do FPSO P-50 da PETROBRAS, utilizado por meio de um modelo numérico, para a geração de séries temporais de movimentos e RAOs em cada calado utilizado. Apresenta-se também a formulação do cálculo de erro necessário à calibração, incluindo e justificando a normalização dos espectros teórico e estimado, além da apresentação da minimização da soma destes erros. Ao final, são apresentados resultados comparativos que embasam a tomada de decisão do uso de hiperparâmetros variáveis por $T_{p}$ e calado.

Os métodos aqui apresentados foram todos desenvolvidos em MATLAB ${ }^{\circledR}$ 7.9.0. Para maiores detalhes sobre a implementação numérica do algoritmo Bayesiano utilizado nesta seção, recomenda-se a leitura da seção 3.4 de (SPARANO, 2008), uma vez que no trabalho aqui apresentado, utiliza-se tal implementação apenas como ferramenta de testes para obtenção dos valores do hiperparâmetros, bem como dos espectros direcionais estimados. 


\subsection{Motivação}

Na seção 3.2 foi mostrado que o problema de estimação do espectro direcional de ondas é resolvido através da minimização de

$$
\mathbf{J}(\mathbf{x})=\|\mathbf{B}-\mathbf{A} \mathbf{x}\|^{2}+\mathbf{x}^{T}\left(u_{1}^{2} \mathbf{H}_{1}+u_{2}^{2} \mathbf{H}_{2}+u_{3}^{2} \mathbf{H}_{3}\right) \mathbf{x}
$$

no qual o vetor $\mathrm{x}$ que minimiza este funcional é composto por valores do espectro direcional de onda que, combinados linearmente com as funções de transferência, aproximam um conjunto de respostas da embarcação às excitações de onda.

Este funcional é derivado de um modelo Bayesiano que leva em consideração não apenas a combinação linear dos espectros desconhecidos contidos em x com as funções de transferência, mas envolve também um compromisso entre o ajuste e a suavidade desta aproximação, sendo isto realizado por meio da escolha correta de valores para os hiperparâmetros $u_{1}$ e $u_{2}$. Além disso, tem-se a utilização de um terceiro hiperparâmetro, $u_{3}$, para forçar energia mínima em baixas e altas frequências, pois este é o comportamento esperado no espectro teórico fora das frequências onde se realiza a estimação.

O que torna a abordagem Bayesiana interessante no caso da estimação do espectro direcional, além de definir uma classe de funcionais para a minimização, é a busca sistemática de uma função ótima nesta classe. Dentre as diversas funções contidas numa família de funcionais pode-se encontrar, por meio dos critérios de informação, um modelo ótimo representado por uma função que tem o melhor compromisso entre a suavização da aproximação e o ajuste dos dados, sendo necessário apenas utilizar os valores dos hiperparâmetros correspondentes ao modelo que atende à especificação de tal critério.

Segundo o critério de informação $A B I C$ apresentado neste trabalho, a melhor função $\mathbf{J}(\mathbf{x})$ a ser minimizada é aquela correspondente ao valor mínimo obtido na expressão (3.21), variando-se os hiperparâmetros $u_{1}, u_{2}$ e $u_{3}$. Ou seja, dado um conjunto de observações dos movimentos da embarcação, a melhor estimativa do espectro direcional de onda, unindo suavização e aderência desta estimativa aos dados, é encontrada pela minimização de um funcional definido como ótimo ao se encontrar valores de seus parâmetros que fazem o valor de $A B I C$ ser também mínimo.

Assim, evidencia-se que os valores destes hiperparâmetros influenciam a estimativa final do espectro direcional de onda, pois caso a escolha dos mesmos seja feita de maneira arbitrária ou equivocada, mesmo obedecendo a algum critério, podem ser encontradas estimativas que priorizem demasiadamente a suavização, perdendo-se informação sobre a energia contida no espectro, ou que ajam da maneira contrária, desprezando a suavidade da aproximação mas mantendo-a 
com certa aderência aos dados.

\section{Exemplo 1}

No exemplo apresentado a seguir ficam evidentes as afirmações feitas a respeito da escoIha correta de valores dos hiperparâmetros. Considerando um espectro direcional teórico com espectro de potência $S$ (omega) com as seguintes características ${ }^{1}$ :

- Altura significativa, $H_{s}=4 m$;

- Período de pico, $T_{p}=10 s$;

- Direção média relativa à popa do navio, $\theta_{m}=135^{\circ} \mathrm{e}$;

- Espalhamento, $s=150$

A representação do espectro direcional de energia de onda, $S(\omega, \theta)$, é feita por meio de uma superfície tridimensional em função das frequências e direções, sendo possivel ver nesta a disposição dos picos de energia e suas respectivas magnitudes. O mapa do espectro é uma representação polar de $S(\omega, \theta)$ por meio de curvas de nível, onde pode-se ver claramente o posicionamento do pico do espectro em relação à embarcação, além do espalhamento ao longo das direções e frequências.

Para este exemplo, mapa e espectro direcional teóricos podem ser vistos nas figuras 6(a) e 7(a), respectivamente, indicando a concentração da energia a $135^{\circ}$ em relação à popa da embarcação no sentido anti-horário, em um período de pico de $10 \mathrm{~s}$.

\begin{tabular}{|l|cc|}
\hline Suavização & $u_{1}$ & $u_{2}$ \\
\hline Ótima & 0,00208 & 0,00564 \\
Baixa & 0,0001 & 0,0009 \\
Alta & 0,1 & 0,8 \\
\hline
\end{tabular}

Tabela 1: Exemplo de valores de $u_{1}$ e $u_{2}$

Fazendo-se $u_{3}=0,07$ e utilizando os pares $\left(u_{1}, u_{2}\right)$ conforme a tabela 1 , fica claro, pelo espectro de potência apresentado na figura 5, que existe uma certa discrepância entre as estimativas obtidas para cada par apresentado na tabela.

A questão da diferença de suavização em cada caso é ilustrada pelas figuras 6 e 7, ficando evidente no caso de alta suavização a perda de energia, conforme pode ser visto na figura $7(\mathrm{c})$, onde o pico principal do espectro direcional é praticamente dez vezes menor que o teórico. Já no caso de baixa suavização, a estimativa fica extremamente ruidosa, e o mapa do espectro direcional, mostrado na figura $6(\mathrm{~d})$, indica que a aproximação encontrada não mantém a forma do espectro teórico, uma vez que o compromisso com a suavização foi bastante reduzido.

\footnotetext{
${ }^{1}$ Sendo apenas um exemplo com uma mesma embarcação, os dados dimensionais do navio são irrelevantes para a compreensão do problema apresentado.
} 


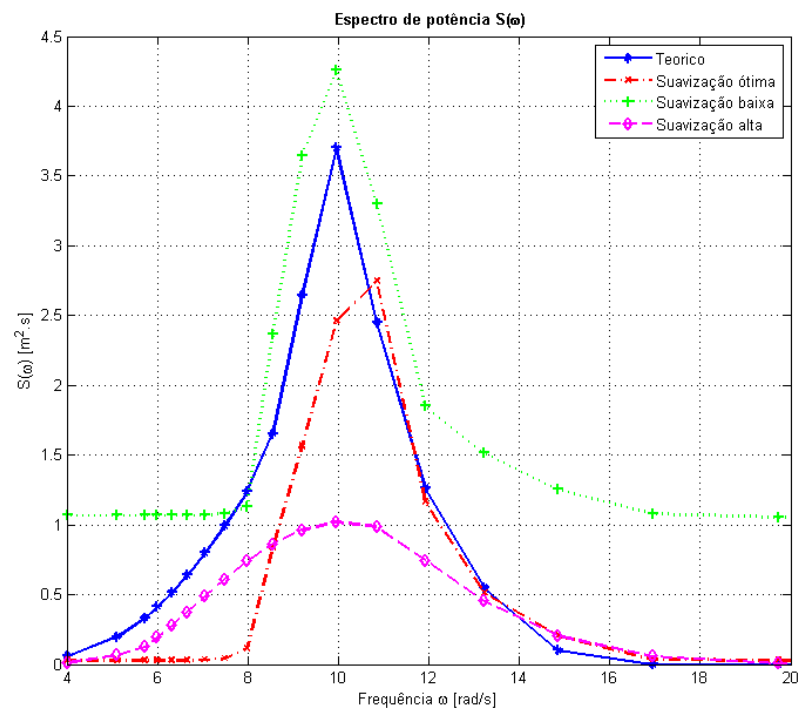

Figura 5: Comparação entre espectros de potência teórico e estimados.

Ao se considerar valores altos dos dois hiperparâmetros, a suavização tem um peso maior na estimação, fazendo com que ocorra menor aderência da aproximação aos dados e consequentemente, verifica-se uma perda da energia no espectro de potência estimado, conforme pode ser visto na figura 5 , pela curva tracejada cor-de-rosa.

No caso oposto, onde a suavização é muito baixa, indicada pela curva pontilhada de cor verde na mesma figura, ao utilizar-se valores pequenos de $u_{1}$ e $u_{2}$, o terceiro hiperparâmetro tem maior importância na estimação, causando um acúmulo de energia em altas e baixas frequências, dado que este foi tomado como sendo constante. Evidencia-se neste exemplo que a escolha de $u_{3}$ não é a mais adequada para o par de $u_{1}$ e $u_{2}$ utilizado. Já no caso ótimo ocorre um balanceamento destas características, resultando em uma estimativa de espectro direcional relativamente suave e com energia mais próxima do espectro teórico esperado, sendo este caso representado pela curva pontilhada-tracejada de cor vermelha.

Este exemplo ilustra claramente a necessidade da calibração do modelo a ser minimizado, encontrando-se valores de $u_{1}$ e $u_{2}$ que levem a um funcional ótimo para executar a minimização em busca de $\mathbf{x}$, uma vez que podem ocorrer diversos casos como o apresentado acima.

Embora o critério $A B I C$ resolva a questão da busca de um modelo ótimo em diversos problemas de ajuste de curvas a conjuntos de dados, ou seja, indica valores dos hiperparâmetros a serem utilizados nestes problemas, existem evidências de que este critério não é aplicável na prática, pois a proposta do método de estimação on-board pressupõe certa rapidez na obtenção das estatísticas de mar, dado que o próprio pode mudar caso o intervalo de tempo de espera seja prolongado ${ }^{2}$.

Em resumo, o mar no qual se tem interesse deve ter suas estatísticas extraídas o mais rápido possível, pois muito provavelmente, em um curto intervalo de tempo, a embarcação estará sujeita

\footnotetext{
${ }^{2} \mathrm{O}$ que se espera que aconteça em situações de mar relevantes, pois em, por exemplo, 1 hora, o mar pode mudar muito suas características.
} 


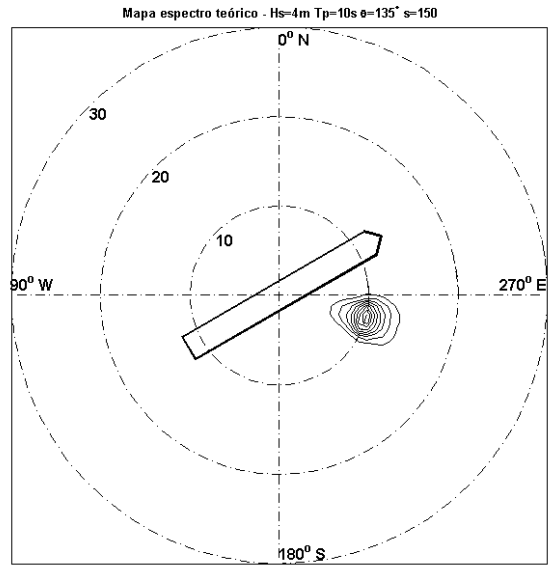

(a) Mapa teórico.

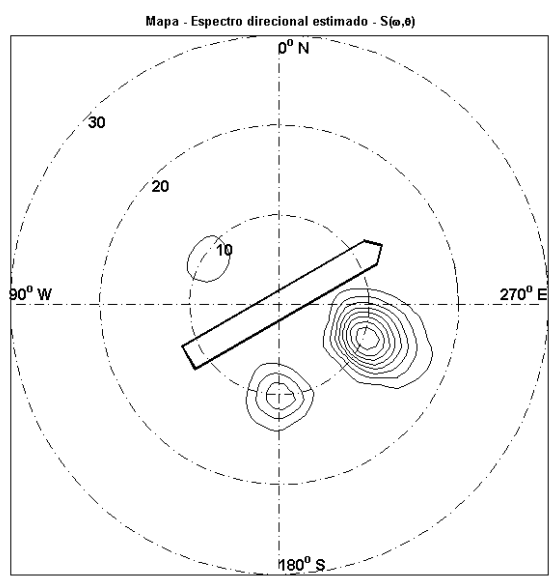

(c) Mapa estimado $u_{1}$ e $u_{2}$ superestimados.

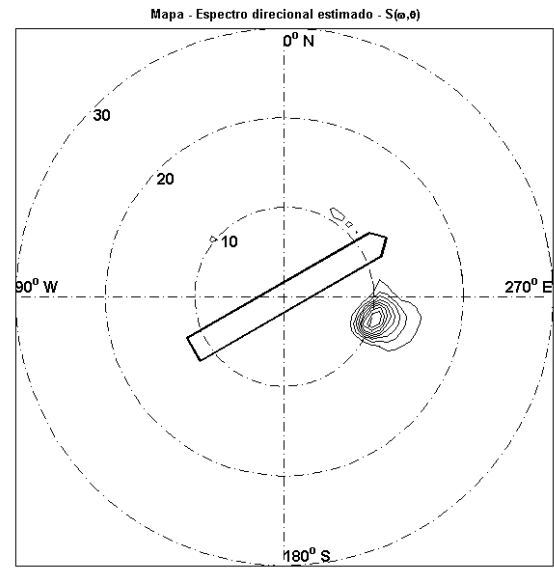

(b) Mapa estimado $u_{1}$ e $u_{2}$ ótimos.

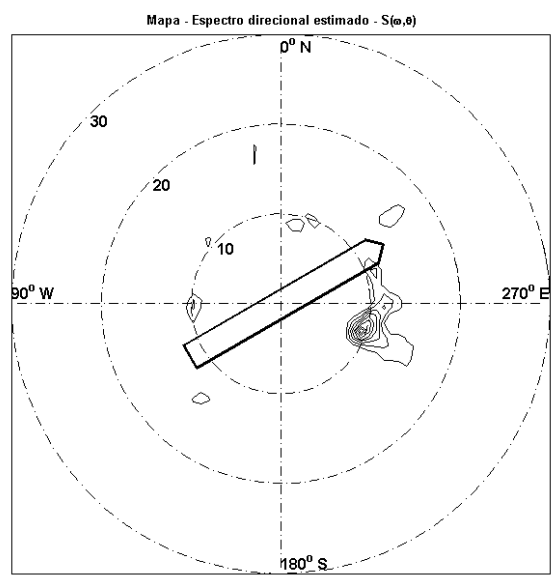

(d) Mapa estimado $u_{1}$ e $u_{2}$ subestimados.

Figura 6: Mapas dos espectros direcionais teórico e estimados para os casos da tabela 1.

a um espectro de mar diferente. Testes realizados indicam tempos de execução de um algoritmo de minimização de $A B I C$ da ordem de 1 hora e 30 minutos, tempo este totalmente incompatível com os pré-requisitos do método de estimação.

Tendo em vista estudos recentes sobre este aspecto particular da estimação do espectro direcional, foi proposto em (TANNURI et al., 2004) a utilização de valores fixos de $u_{1}$, $u_{2}$ e $u_{3}$ em cada calado em que a embarcação se encontra. Este procedimento foi baseado na avaliação da eficiência do método Bayesiano com base em uma série de ensaios, com modelos em escala reduzida, realizados em tanque de provas. Posteriormente, em (ISEKI; NIELSEN, 2010a) e (ISEKI; NIELSEN, 2010b) são feitas menções ao uso dos hiperparâmetros com valores fixos, mostrando que existe pouca variação no valor ótimo da função objetivo. Nestes dois últimos trabalhos são inclusive feitas afirmações de que a busca do mínimo valor de $A B I C$ não é fundamental para que seja encontrada uma estimativa aceitável do espectro. Em particular, em (ISEKI, 2011) é feita uma análise mais específica sobre os resultados dados pelo critério $A B I C$, indicando que nem sempre a melhor estimativa é encontrada do ponto de vista da estimação do espectro direcional de onda. 


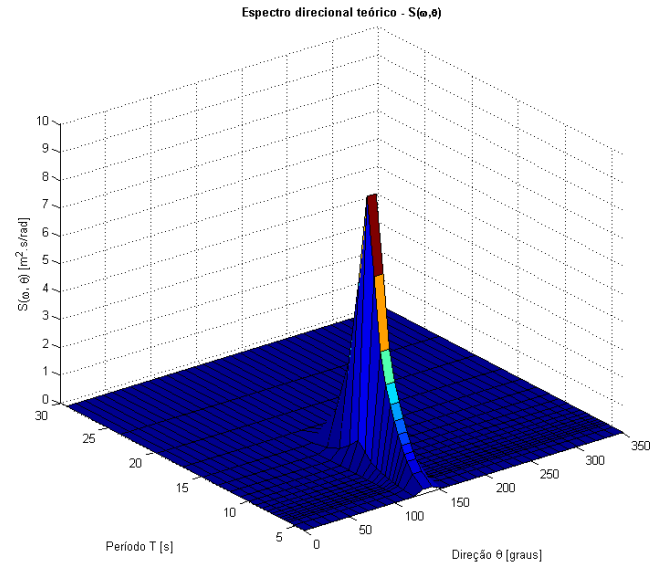

(a) Espectro direcional teórico.

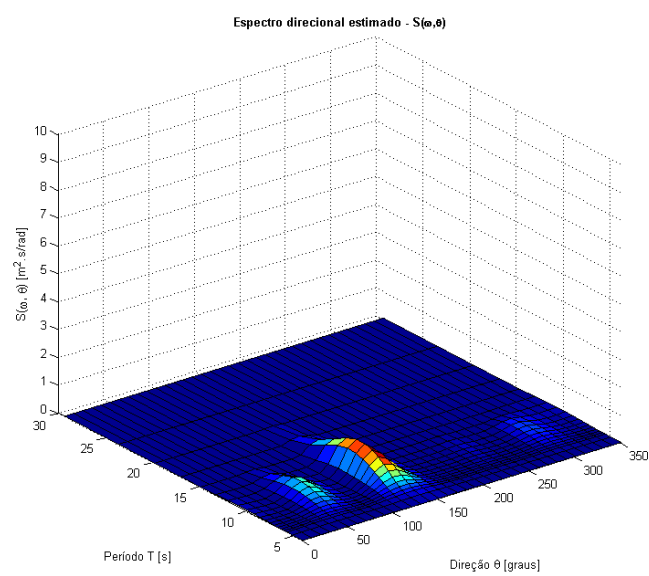

(c) Espectro estimado $u_{1}$ e $u_{2}$ grandes.

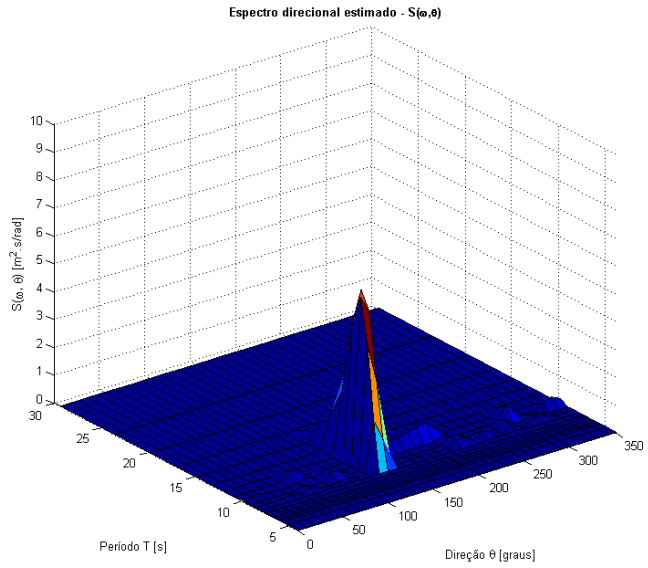

(b) Espectro estimado $u_{1}$ e $u_{2}$ ótimos.

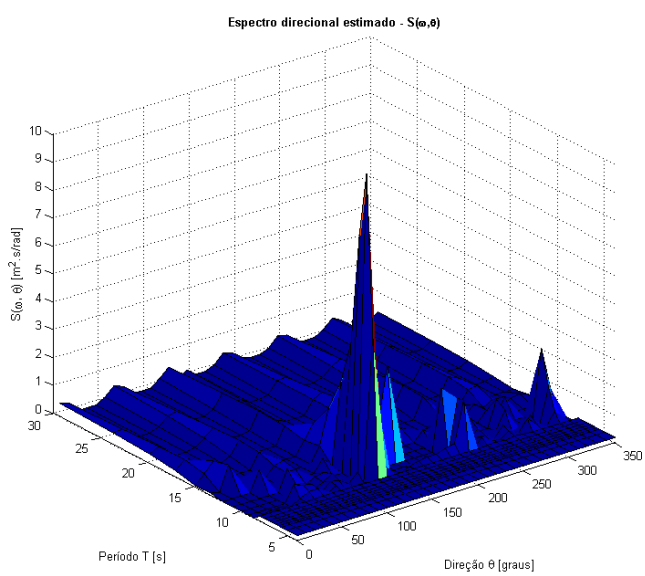

(d) Espectro estimado $u_{1}$ e $u_{2}$ pequenos.

Figura 7: Espectros direcionais teórico e estimados para os casos da tabela 1.

Seguindo a abordagem de emprego de valores fixos, faz-se então necessário que os valores destes hiperparâmetros sejam definidos a priori, dadas as dificuldades apresentadas para sua obtenção no momento da estimação do espectro e a incerteza que tem sido apresentada recentemente sobre a utilidade prática do critério $A B I C$.

Isto pode ser feito por uma metodologia de calibração prévia dos hiperparâmetros, tabelandose valores para determinadas condições passíveis de serem conhecidas independentemente da estimação dos movimentos, tais como calado do navio (no caso de um FPSO) e o período médio.

Sendo possível a simulação computacional de todo o processo envolvido, desde a dinâmica da embarcação sujeita a um determinado estado de mar, até o cálculo das estatísticas do mesmo, propõe-se neste trabalho, em vista dos fatos apresentados, uma metodologia de calibração dos hiperparâmetros, de modo que possam ser decididos os valores de $u_{1}$ e $u_{2}$ previamente para uma dada estimação. 
Dada a complexidade do problema e os tempos envolvidos no processamento numérico, esse estudo fará uma primeira análise com base em algumas simplificações, buscando-se definir uma metodologia de calibração de $u_{1}$ e $u_{2}$ de maneira sistemática, utilizando valores fixos de $u_{3}$ propostos em estudos anteriores, tal como em (SIMOS et al., 2009). O estudo deste terceiro hiperparâmetro não foi incluído neste trabalho devido à natureza do mesmo. Não sendo um termo de suavização nas dimensões especificadas, mas sim de minimização da energia, compreende um aspecto diferente do estudo realizado e não será considerado nesta primeira abordagem do problema. Serão portanto utilizados valores fixos de $u_{3}$ em cada calado considerado do FPSO P-50, com $u_{3}=0,07$ para calado cheio, $u_{3}=0,053$ para intermediário e $u_{3}=0,035$ em calado leve. Estes valores são definidos com base nos utilizados em (SIMOS et al., 2009).

\subsection{Metodologia de calibração dos hiperparâmetros}

A idéia básica da metodologia proposta é encontrar valores de $u_{1}$ e $u_{2}$ no caso em que se possui o conhecimento prévio do espectro de mar. Assim, tendo como paradigma o espectro teórico calculado pelo modelo JONSWAP direcional, pode-se procurar valores destes hiperparâmetros que sejam adequados para que a estimação seja a mais próxima possível do espectro teórico, bastando-se minimizar a diferença entre este e o espectro estimado. Para tanto, porém, deve-se definir como esta diferença deve ser quantificada e a forma como a busca dos melhores valores de $u_{1}$ e $u_{2}$ será feita.

Definindo-se alguns espectros de mar pelo modelo JONSWAP, resultantes de combinações de $H_{s}, T_{p}, \theta_{m}$ e $s$, obtém-se por um processo exaustivo, a cada par de hiperparâmetros um valor de erro entre o espectro teórico e o estimado, resultando em uma superfície de erros em função de $u_{1}$ e $u_{2}$ para cada combinação de parâmetros de mar. Nesta superfície de erros escolhe-se o par de hiperparâmetros correspondente ao valor mínimo dos erros, sendo este par considerado o ótimo e utilizando-se as estatísticas deste espectro estimado como referência.

Após a definição de tais superfícies, são somados os erros para todas as direções, ou seja, fixando-se outros parâmetros, obtém-se uma nova superfície, referente à soma dos erros, realizando-se nesta uma busca pelo valor mínimo, tomando-se os valores de $u_{1}$ e $u_{2}$ correspondentes. Estes valores dos hiperparâmetros são então utilizados em uma nova estimação, a qual tem suas estatísticas extraídas e comparadas com os resultados obtidos para o par considerado ótimo. Estando estas estatísticas dentro de uma margem de erro aceitável em relação ao espectro teórico para todas as incidências de onda, devem ser adotados tais hiperparâmetros como referência para definir uma tabela dos mesmos em função de $T_{p}$ e calado.

Para que seja possível simular o processo completo, desde a obtenção dos dados de movimento até o cálculo das estatísticas globais do espectro, é necessária a definição ou obtenção dos seguintes itens:

1. Espectros teóricos de mar definidos pelo modelo JONSWAP para um conjunto de combinações de $H_{s}, T_{p}, \theta_{m}$ e $s$;

2. Um conjunto de valores para a discretização do calado, bem como os modelos da embarcação em cada um; 
3. Séries temporais dos movimentos da embarcação sujeita aos mares definidos pelo conjunto de parâmetros, para cada calado;

4. RAOs dos movimentos da embarcação para incidência de onda e cada calado;

5. Malha para a discretização do plano $u_{1} \times u_{2}$;

Os valores de $H_{s}$ e $T_{p}$ utilizados neste trabalho são apresentados na tabela 2, onde para cada um destes mares, foram calculados os erros mínimos para os espectros teóricos relativos às direções médias $\theta_{m}=\{0,30,45,60,90,120,135,150,180\}$, dadas em graus, conforme a figura 8 , na qual as linhas vermelhas com setas indicam as direções em que as ondas estão incidindo sobre a embarcação em cada caso, convencionando-se que a onda vem de uma destas direções e adotando-se o sentido positivo de popa para proa.

\begin{tabular}{|c|c|c|}
\cline { 2 - 3 } \multicolumn{1}{c|}{} & $H_{s}[\mathrm{~m}]$ & $T_{p}[\mathrm{~s}]$ \\
\hline Mar 1 & 2 & 10 \\
Mar 2 & 4 & 8,5 \\
Mar 3 & 4 & 10 \\
Mar 4 & 4 & 12 \\
Mar 5 & 4 & 14 \\
\hline
\end{tabular}

Tabela 2: Valores de $H_{s}$ e $T_{p}$ utilizados para geração de espectros direcionais de onda.

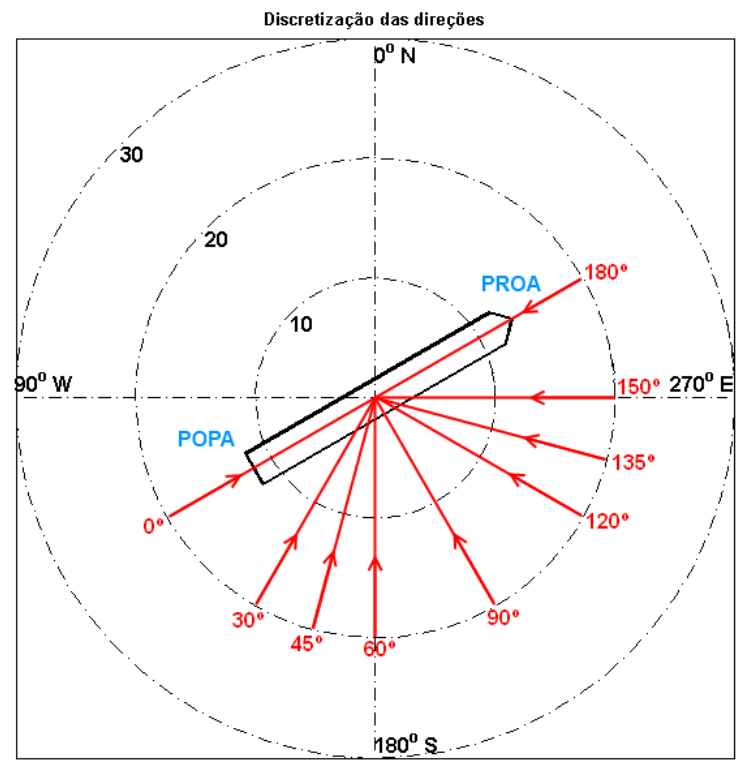

Figura 8: Discretização das direções médias de incidência de ondas.

Dado que quanto maior o calado em que a embarcação se encontra, menor é a resposta, deve ser definida uma faixa discretizada dos calados para analisar tal sensibilidade do processo, pois as séries temporais serão diferentes a cada valor da discretização. A metodologia de calibração desenvolvida foi baseada nos calados cheio $(21 \mathrm{~m})$, intermediário $(14,5 \mathrm{~m})$ e leve $(9 \mathrm{~m})$. 
O valor de $s$ foi considerado constante e igual a 150, dadas as limitações existentes de software para a geração de espectros com espalhamento. Assim, o número de testes inicial é dado pelo número de mares da tabela 2 multiplicado pelo número de incidências de onda e pelo número de calados, resultando em $5 \times 9 \times 3=135$ condições às quais a embarcação esteve sujeita.

Utilizou-se o modelo numérico do FPSO P-50 da PETROBRAS, apresentado na figura 9, para a geração dos RAOs e das séries temporais de movimento.

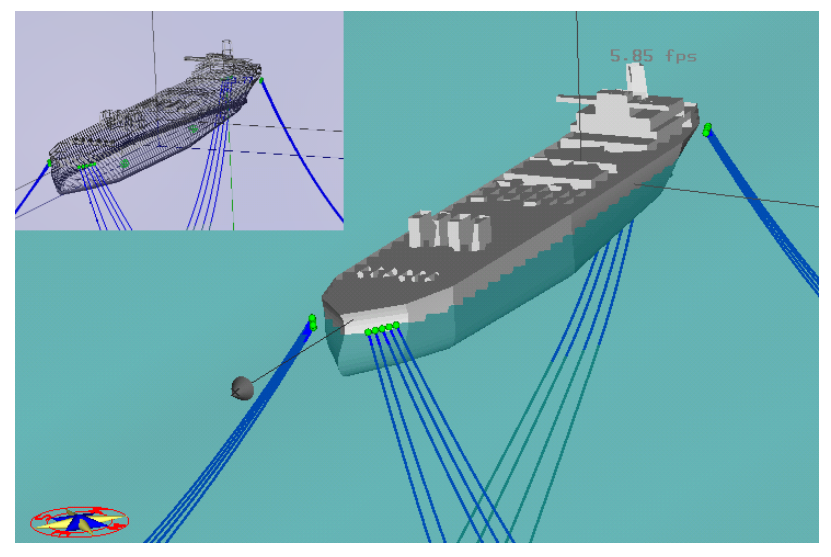

Figura 9: Modelo do FPSO P-50 utilizado no Dynasim.

Os principais dados dimensionais desta embarcação são apresentados na tabela 3 em função dos calados utilizados, onde $I_{x x}, I_{y y}$ e $I_{z z}$ indicam as inércias nos respectivos eixos.

\begin{tabular}{|r|r|r|r|}
\hline \multicolumn{1}{|c|}{ Dados } & \multicolumn{3}{|c|}{ Calado } \\
\cline { 2 - 4 } & Lastro $(9 \mathrm{~m})$ & Intermediário $(14,5 \mathrm{~m})$ & Cheio $(21 \mathrm{~m})$ \\
\hline Deslocamento [t] & $1,24.10^{5}$ & $2,09.10^{5}$ & $3,11.10^{5}$ \\
Trim [ $\left.{ }^{\circ}\right]$ & $-0,663$ & $-0,015$ & 0,002 \\
LCG [m] & 6,92 & 13,52 & 10,48 \\
VCG [m] & 18,78 & 14,03 & 14,30 \\
$I_{x x}\left[\mathrm{tm}^{2}\right]$ & $5,87.10^{7}$ & $9,23.10^{7}$ & $1,19.10^{8}$ \\
$I_{y y}\left[\mathrm{tm}^{2}\right]$ & $9,96.10^{8}$ & $1,40.10^{9}$ & $1,85.10^{9}$ \\
$I_{z z}\left[\mathrm{tm}^{2}\right]$ & $9,98.10^{8}$ & $1,41.10^{9}$ & $1,89.10^{9}$ \\
Amortecimento [t/s] & $7,25.10^{6}$ & $7,73.10^{6}$ & $9,05.10^{6}$ \\
\hline
\end{tabular}

Tabela 3: Principais dados do FPSO P-50.

As séries temporais de movimento do navio nos 6 graus de liberdade foram geradas por meio do software Dynasim ${ }^{\circledR}$, o qual, simula a dinâmica da embarcação sujeita a um certo mar definido pelo usuário, gerando séries temporais de movimento nos 6 graus de liberdade: Surge, Sway, Heave, Roll, Pitch e Yaw.

O modelo numérico do FPSO P-50 utilizado no Dynasim deve ser ajustado a cada calado a ser analisado, pois as séries temporais dos movimentos são dadas em relação ao centro de gravidade da embarcação. 
Na figura 10 tem-se um exemplo das séries temporais geradas pelo Dynasim para os movimentos da $P-50$ em calado leve, sujeita a um mar com parâmetros $H_{s}=4 \mathrm{~m}, T_{p}=10 \mathrm{~s}$, $\theta_{m}=135^{\circ}$ e $s=150$.
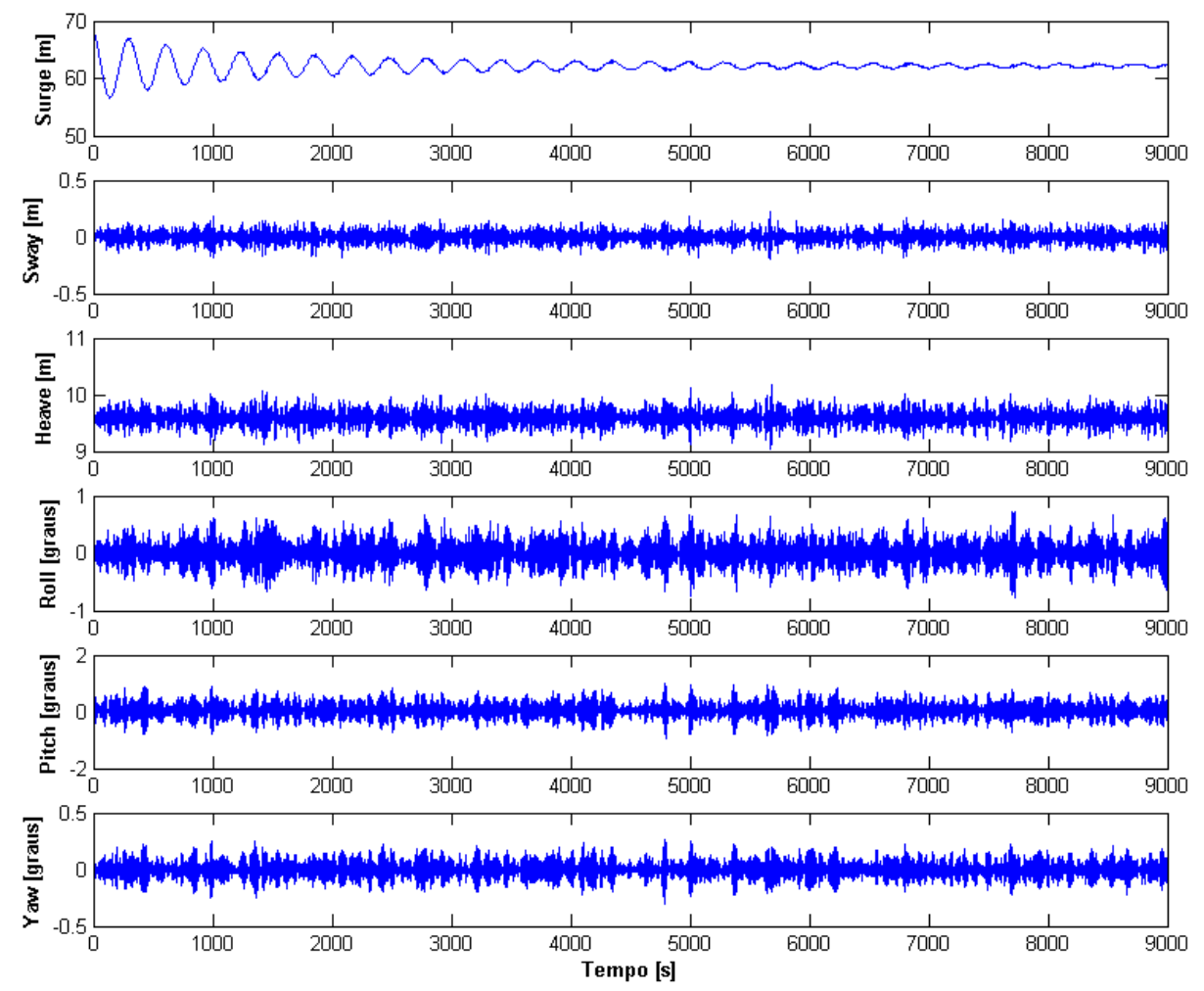

Figura 10: Exemplo de séries temporais dos movimentos geradas pelo Dynasim para os 6 graus de liberdade do FPSO P-50 em calado leve.

Os RAOs utilizados foram gerados por meio do WAMIT ${ }^{\circledR}$, software conhecido e amplamente usado na indústria naval e em pesquisas da área. Estes serviram tanto para a rotina de calibração quanto para uso no Dynasim, dado que o mesmo necessita destas informações para simulação da dinâmica. No sistema final de estimação do espectro direcional são também adotados estes mesmos RAOs, os quais são apresentados no apêndice $C$.

É importante destacar que, embora sejam apresentados aqui os RAOs e séries temporais de Roll estes dados não serão utilizados ao longo do processo de estimação bem como do desenvolvimento da metodologia. Isto se faz necessário devido às incertezas inerentes envolvidas no processo de obtenção dos RAOs para este grau de liberdade, resultantes dos efeitos viscosos nãolineares, uma vez que se supõe linearidade entre o movimento da embarcação e a onda incidente.

Para a definição de uma malha de discretização de $u_{1}$ e $u_{2}$, foram realizados testes com diversos valores para definir uma região preferencial de busca. Entretanto, dados os resultados obtidos em (TANNURI et al., 2004), (SPARANO, 2008) e (SIMOS et al., 2009), a região limite foi determinada com base nos valores dos hiperparâmetros citados nestes estudos, realizando-se um estudo preliminar para verificação do comportamento da superfície de erro encontrada. 
Os valores máximos de $u_{1}$ e $u_{2}$ utilizados nestas referências são, 0,07 e 0,21, respectivamente, sem menção a valores limitantes inferiores. Devido aos valores utilizados nestes estudos, a malha gerada neste trabalho é fortemente influenciada, sendo limitada por valores próximos a estes máximos mencionados e fazendo-se as seguintes discretizações para os hiperparâmetros:

$$
u_{1}=\left\{\begin{array}{c}
0,0001 \\
0,00208 \\
0,00406 \\
0,00604 \\
0,00802 \\
0,01 \\
0,015 \\
0,02 \\
0,025 \\
0,03 \\
0,035 \\
0,05
\end{array}\right\} \quad u_{2}=\left\{\begin{array}{c}
0,0001 \\
0,00564 \\
0,01119 \\
0,01673 \\
0,02228 \\
0,02782 \\
0,03337 \\
0,03891 \\
0,04446 \\
0,05 \\
0,06 \\
0,07625 \\
0,0925 \\
0,10875 \\
0,125 \\
0,15 \\
0,175 \\
0,2
\end{array}\right\}
$$

A malha de discretização de $u_{1}$ e $u_{2}$ foi necessária para a observação de tendências dos valores de erro. Poderia ter-se adotado um processo de otimização, buscando-se o valor mínimo do erro, mas neste caso não seria possível observar tais tendências, apenas valores mais precisos dos hiperparâmetros obtidos.

Embora testes de minimização do erro por um processo de otimização tenham sido realizados, tornou-se inviável a utilização deste método devido à falta de conhecimento que se tinha do resultado esperado e da impossibilidade de usar a soma dos erros ao final deste processo, uma vez que eram obtidos apenas valores para 1 ponto da malha. Isto fez com que a análise dos valores dos hiperparâmetros se mostrasse extremamente complexa nesta abordagem.

Desta maneira, embora isso não tenha sido considerado neste estudo, tal processo de minimização pode ser utilizado para o refinamento dos resultados, encontrando valores independentes da discretização da malha para os hiperparâmetros. 


\subsubsection{Processo exaustivo de cálculo de erros mínimos}

Para a determinação dos erros entre o espectro estimado e o real foi adotada a seguinte formulação de erro, sendo detalhada a escolha desta formulação no apêndice B:

$$
\text { erro }_{a b s}=\sum_{k=1}^{K} \sum_{m=1}^{M} \Delta \theta_{k} \Delta \omega_{m}\left|\frac{S^{*}\left(\omega_{m}, \theta_{k}\right)}{\max \left[S^{*}(\omega, \theta)\right]}-\frac{S\left(\omega_{m}, \theta_{k}\right)}{\max [S(\omega, \theta)]}\right|
$$

onde $\Delta \theta=2 \pi / K$. Os valores $\max \left[S^{*}(\omega, \theta)\right]$ e $\max [S(\omega, \theta)]$ são, respectivamente, os máximos dos espectros teórico e estimado, nos intervalos discretos de $\omega$ e $\theta$, e $\Delta \omega_{m}$ é dado por:

$$
\Delta \omega_{m}=\left\{\begin{array}{l}
\omega_{2}-\omega_{1}, \text { se } m=1, \\
\frac{\omega_{m}-\omega_{m-1}}{2}, \text { se } 1<m<M \text { e } \\
\omega_{M}-\omega_{M-1}, \text { se } m=M .
\end{array}\right.
$$

Uma vez definidos os dados e formulações necessários ao processo de simulação e à metodologia de calibração dos hiperparâmetros, tem-se todo o aparato necessário a uma esquematização do processo de cálculo dos erros mínimos, bem como para a apresentação de resultados da calibração.

O processo exaustivo consiste no cálculo dos erros para todos os pares $\left(u_{1}, u_{2}\right)$ contidos na malha, sendo que ao final, obtém-se o par destes hiperparâmetros correspondente ao valor mínimo de erro. Apresentado na figura 11, o fluxo deste processo de busca do menor erro é bastante simples:

1. Definidos os parâmetros de um conjunto de mares e a discretização dos calados, são geradas as séries temporais dos movimentos da embarcação;

2. Fornecendo tais séries de movimentos e os RAOs ao algoritmo Bayesiano de estimação, bem como um valor inicial de $u_{1}$ e $u_{2}$ (valores de $u_{3}$ só variam com o calado, mas são supostos conhecidos), obtém-se uma estimativa do espectro direcional de ondas;

3. Como os valores dos parâmetros de um espectro JONSWAP são dados a priori, calcula-se então o erro entre o espectro estimado e o teórico;

4. Repete-se o processo de estimação e cálculo de erro para diversos pares $\left(u_{1}, u_{2}\right)$ definidos na malha;

5. A melhor estimativa é aquela em que ocorreu menor erro, sabendo-se portanto os valores de $u_{1}$ e $u_{2}$ que geraram tal estimativa do espectro direcional. 


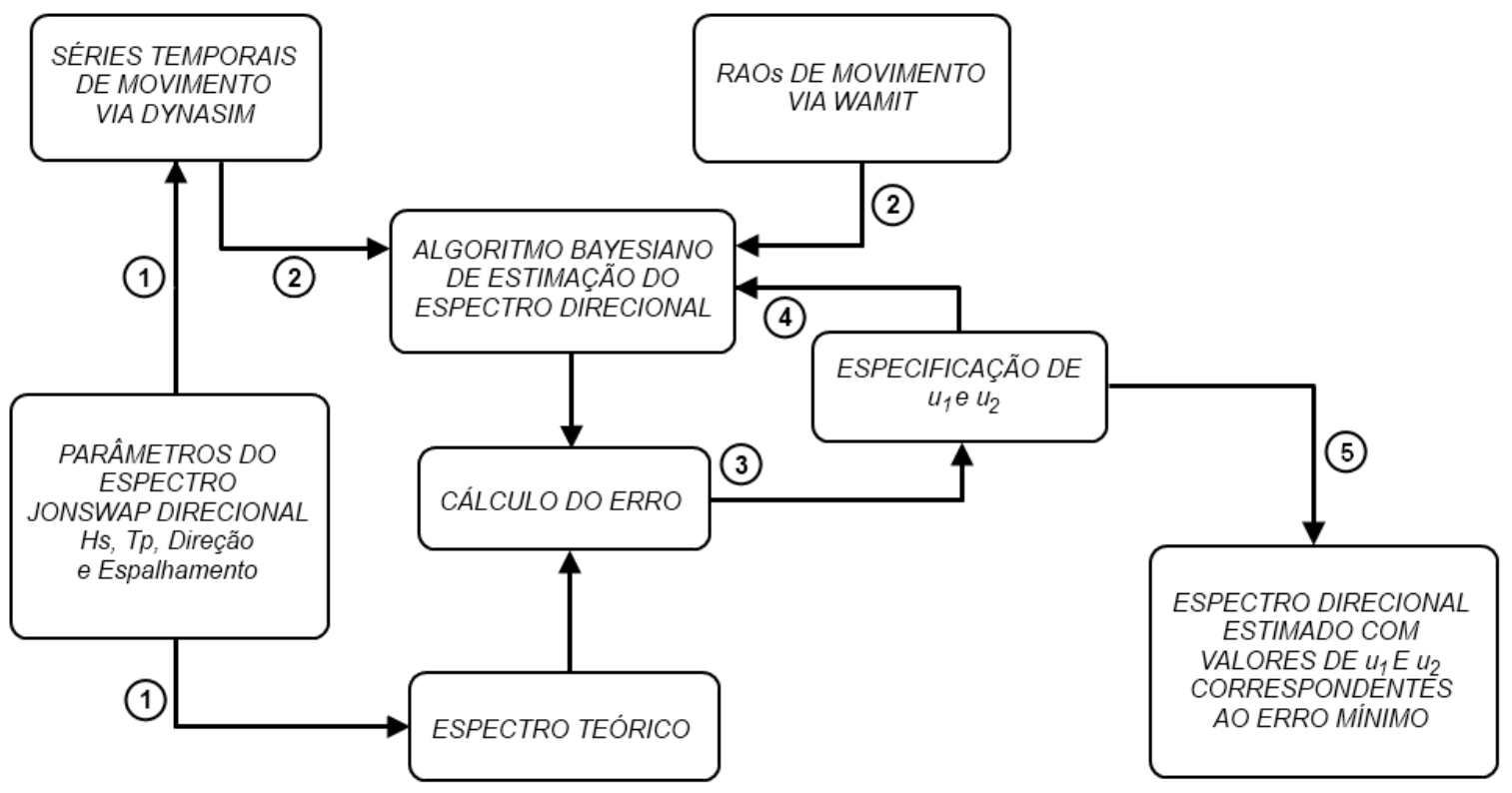

Figura 11: Representação esquemática do processo exaustivo de cálculo do melhor espectro estimado. 


\section{Exemplo 2}

Gerando-se numericamente um conjunto de séries temporais com base nos parâmetros $H_{s}=$ $4 m, T_{p}=10 \mathrm{~s}$ e $\theta_{m}=120^{\circ}$ para a embarcação P-50 em calado leve, ao aplicar-se o processo apresentado na figura 11 utilizando-se a malha definida anteriormente para os hiperparâmetros, obtém-se a superfície de erros da figura 12(a).

A superfície é definida pelos erros absolutos (pontos vermelhos) calculados utilizando-se a formulação B.3 em cada ponto da malha, ou seja, a cada par de hiperparâmetros foram executados os passos 2 e 3 do esquema da figura 11 .

Verifica-se claramente que o valor mínimo neste caso localiza-se não muito distante da origem da malha, mais especificamente no ponto definido por $u_{1}=0,00406$ e $u_{2}=0,02228$, resultando em um erro mínimo de erro $_{a b s}=2,4699$. Sendo este o ponto ótimo da malha para este caso, são obtidas as estatísticas referentes ao respectivo par de hiperparâmetros: $H_{s}^{e s t}=3,92 \mathrm{~m}$, $T_{p}^{e s t}=9,96 s$ e $\theta_{m}^{\text {est }}=118,99^{\circ}$. O mapa direcional estimado para este exemplo é apresentado na figura 12(b), a superfície do espectro direcional estimado e o espectro de potência são mostrados, respectivamente, nas figuras $12(\mathrm{~d})$ e $12(\mathrm{c})$.

Nota-se que alguns pontos da malha não possuem valores de erro indicados pelos pontos vermelhos. Isto foi feito propositalmente para a redução do tempo computacional na determinação das superfícies de erro. Dado que era conhecida a tendência dos valores dos hiperparâmetros, foram retirados alguns pontos da malha fora da região de interesse, priorizando-se a discretização ao redor do ponto de erro mínimo.

A estimação feita para o ponto ótimo da malha resultou em boas aproximações do espectro teórico, no que se refere às estatísticas calculadas, conforme apresentado acima. Entretanto, em alguns casos ocorrem estimações divergentes, resultando em espectros distantes (em termos do erro) do teórico e consequentemente, estatísticas incorretas são extraídas, mesmo mantendo-se a energia total do espectro próxima a do teórico. A seguir tem-se um exemplo deste tipo de estimação divergente, a qual foi verificada ser recorrente em casos de $\theta_{m}=45^{\circ}$ para calado intermediário e cheio. 


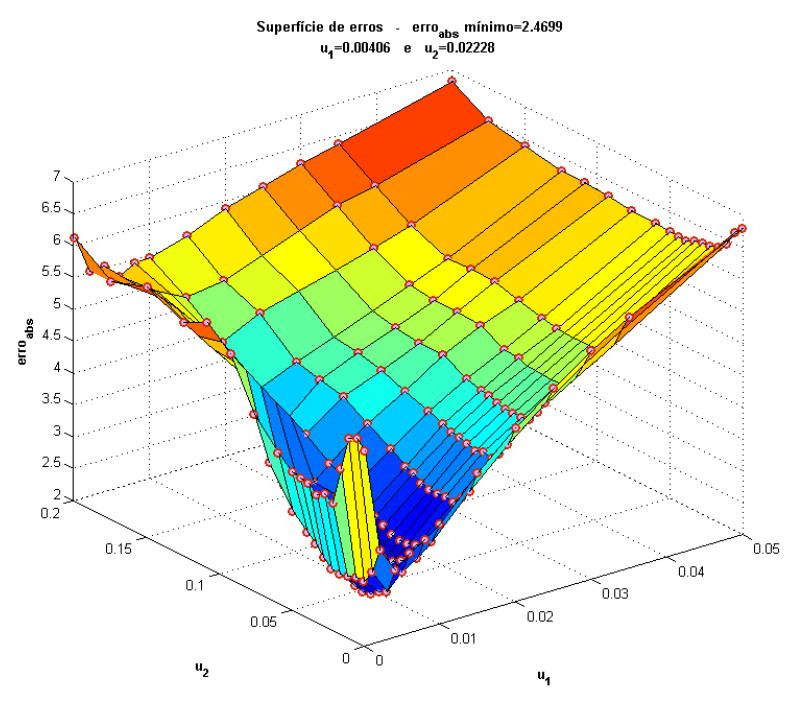

(a) Superfície de erroabs.

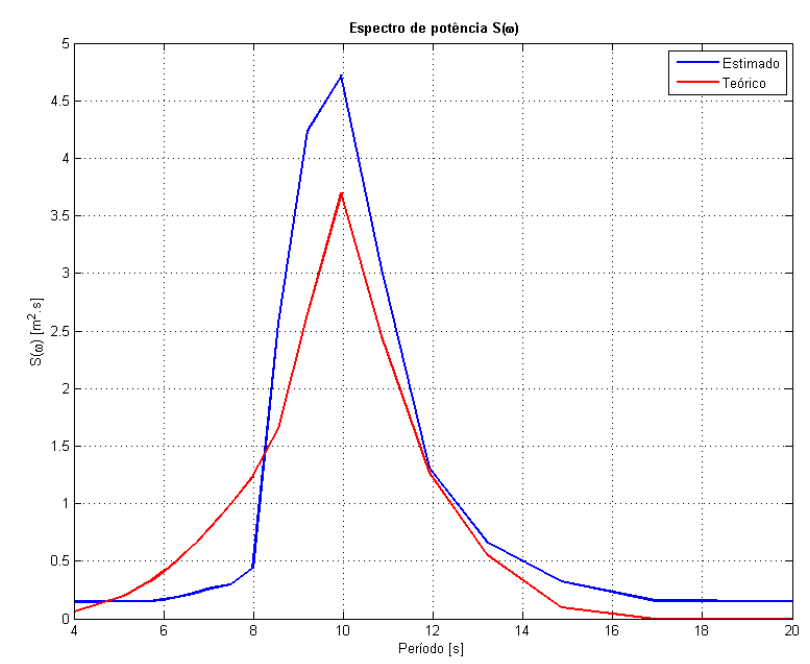

(c) Espectros de potência teórico e estimado.

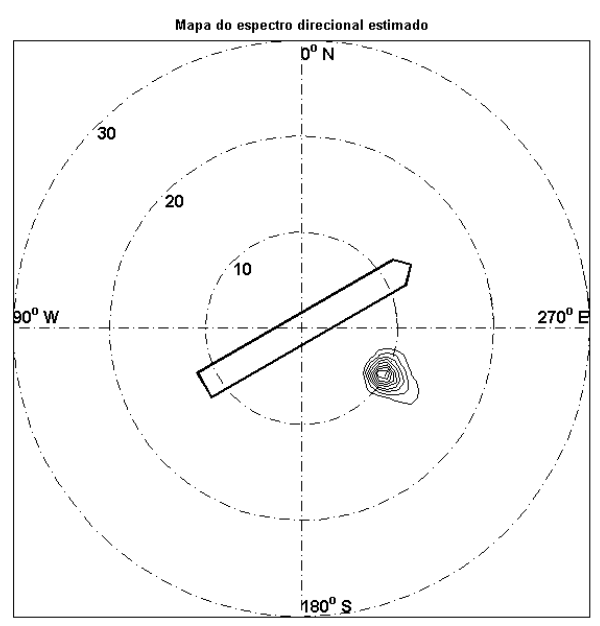

(b) Mapa do espectro direcional estimado.

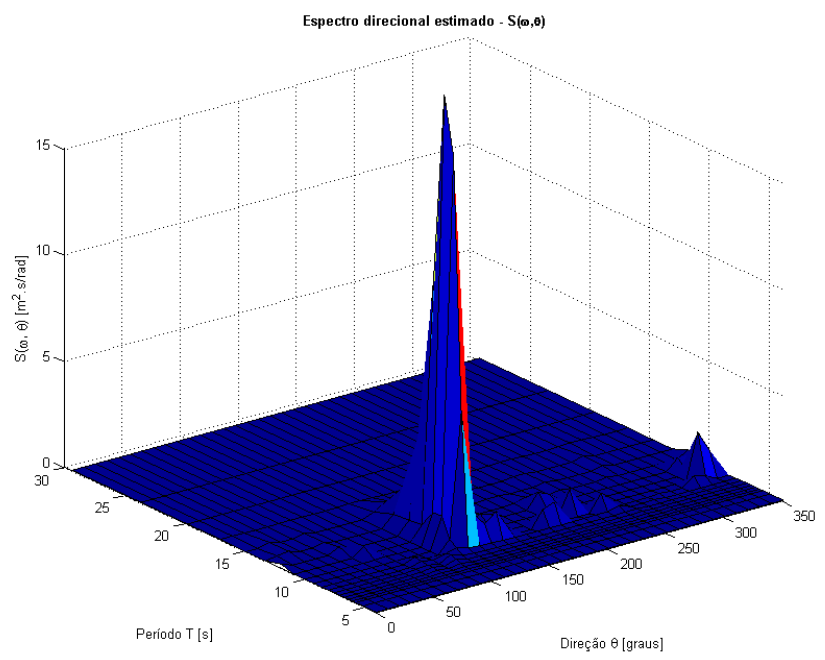

(d) Espectro direcional estimado

Figura 12: Resultados da estimação exaustiva com uso do erro $_{a b s}$ para espectro com parâmetros $H_{s}=4 m, T_{p}=10 \mathrm{~s}$ e $\theta_{m}=120^{\circ}$ com embarcação em calado leve. 


\section{Exemplo 3}

Este fato é exemplificado pela aplicação do mesmo procedimento descrito acima para um espectro gerado utilizando-se os seguintes parâmetros: $H_{s}=4 m, T_{p}=8,5 \mathrm{~s}$ e $\theta_{m}=45^{\circ} \mathrm{com}$ a embarcação em calado cheio. Apresentam-se na figura 13 os resultados obtidos na estimação, bem como a superfície de erros.

Verifica-se claramente pela figura 13(b) que a energia não foi mantida na direção correta, resultando em uma direção média estimada ${ }^{3} \theta_{m}^{\text {est }}=-72,23^{\circ}$, com $T_{p}^{\text {est }}=9,196 \mathrm{~s}$ e $H_{s}^{\text {est }}=3,538 \mathrm{~m}$ indicando que a energia total estimada se manteve relativamente próxima à teórica, conforme pode ser verificado no espectro de potência apresentado na figura 13(c), uma vez que as curvas possuem áreas relativamente próximas.

Sendo os valores dos hiperparâmetros $u_{1}=0,00208$ e $u_{2}=0,0001$, compreende-se que houve tentativa de forçar uma baixa suavização da estimativa do espectro, uma vez que tais valores são muito próximos à origem da malha. $\mathrm{O}$ algoritmo não encontrou valores que priorizassem a forma do espectro como propõe a formulação do erro abs nos intervalos considerados. Este tipo de estimação incorreta ainda necessita maior investigação para determinar as causas possíveis de tais erros.

\footnotetext{
${ }^{3}$ Embora os resultados sejam apresentados no intervalo $\left[0^{\circ} ; 360^{\circ}\right]$, as estatísticas de direção são sempre dadas entre $-180^{\circ}$ e $180^{\circ}$.
} 


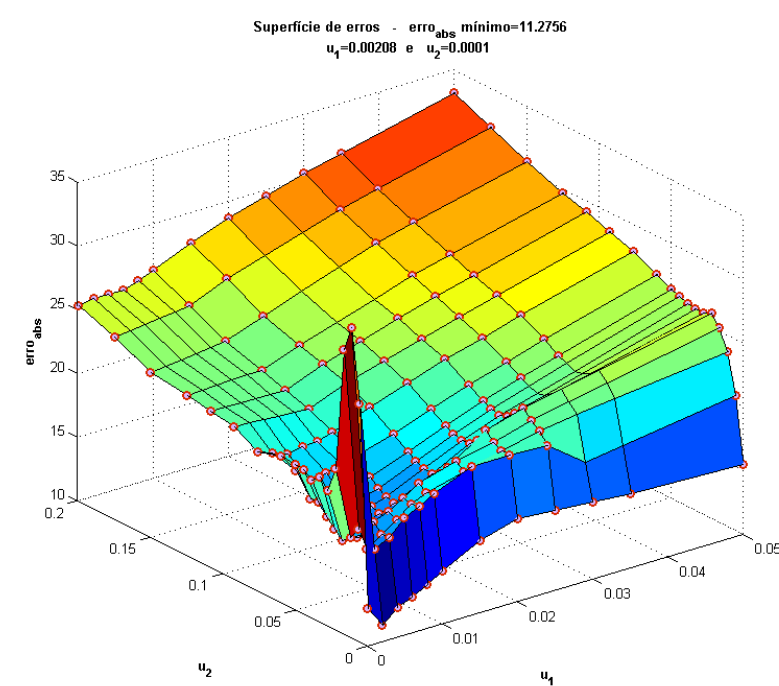

(a) Superfície de erro $a b s$.

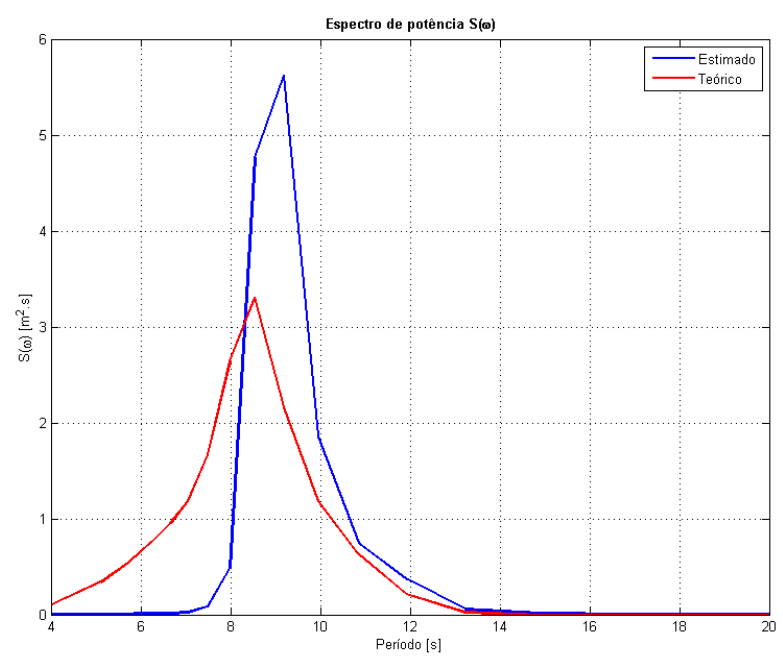

(c) Espectros de potência teórico e estimado.

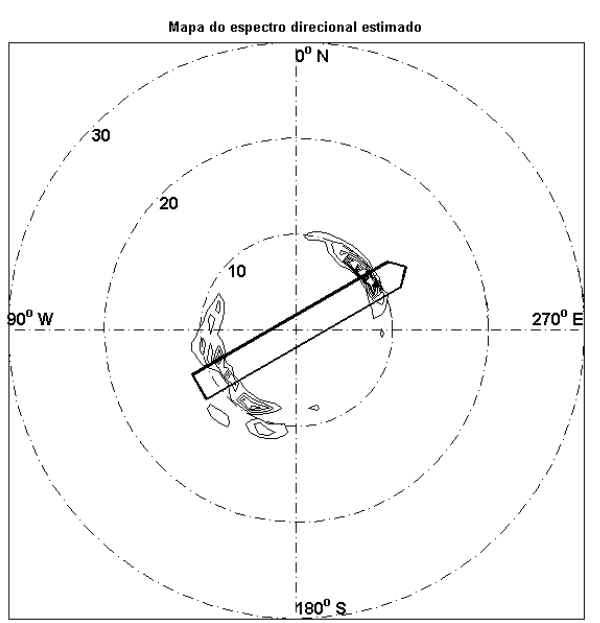

(b) Mapa do espectro direcional estimado.

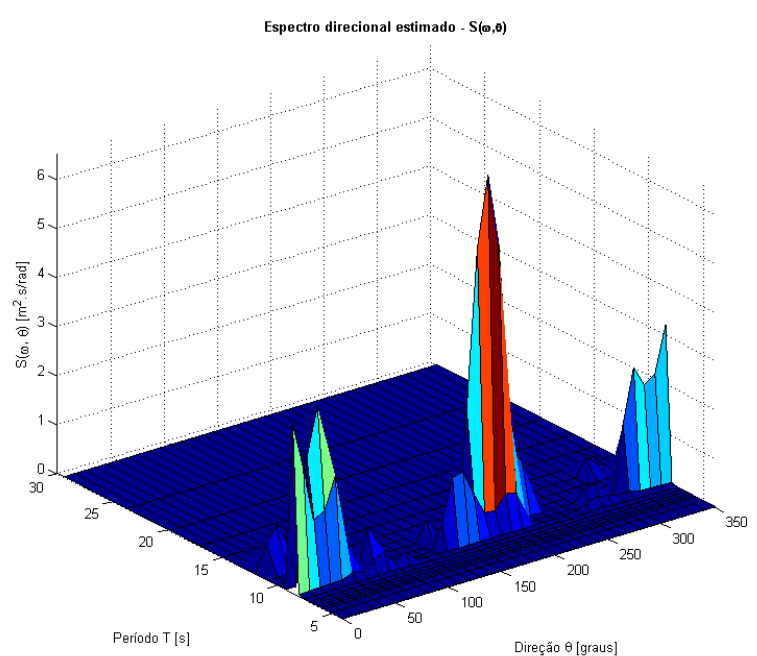

(d) Espectro direcional estimado

Figura 13: Resultados da estimação exaustiva com uso do erro $_{a b s}$ para espectro com parâmetros $H_{s}=4 m, T_{p}=8,5 \mathrm{~s}$ e $\theta_{m}=45^{\circ}$ com embarcação em calado cheio. 
Tendo em vista os exemplos apresentados, foi executado este processo para todos os mares definidos na tabela 2 combinados às incidências de onda $\theta_{m}$ mencionadas anteriormente, para cada um dos 3 calados. Assim, foram obtidas 135 estimativas de espectros direcionais de onda, assim como de superfícies de erro, sendo que a cada mar da tabela mencionada haviam 9 incidências de onda.

Os resultados obtidos nos testes de minimização pelo processo exaustivo são apresentados nas tabelas de 29 a 33 no apêndice D, onde podem ser vistas as estatísticas globais obtidas e a comparação percentual com os valores teóricos. Nestas tabelas valores negativos do percentual indicam estimativas menores que os teóricos e positivos, o contrário, indicando superestimação da energia contida no espectro.

Sabendo-se que casos com incidência de $45^{\circ}$ e $135^{\circ}$ são comprometidos pelo próprio processo de estimação, a desconsiderar-se tais estimativas que são tidas como incorretas, o maior erro obtido é uma variação de $38 \%$ a menos na estimativa de $H_{s}$ para o mar 2 com incidência $\theta_{m}=120^{\circ}$, sendo que para este período de onda a estimação é sabida ser mais difícil de se realizar.

Um fato a ser destacado é que um período de pico $T_{p}=8,5 \mathrm{~s}$ é baixo, o que torna as amplitudes das respostas da embarcação muito pequenas. Isto dificulta o processo de estimação, uma vez que são utilizadas as séries temporais destas respostas para a geração dos espectros cruzados de movimento. Como a energia do espectro é filtrada pelo próprio navio, não causando movimentos significativos, perde-se informação útil à estimação, o que resulta em valores de $H_{s}$ menores que o real, isso explica a ocorrência de diversos $\Delta H_{s}<0$.

Com exceção dos casos mencionados, as estatísticas obtidas estão em uma faixa aceitável de erro, sendo que os valores de $T_{p}^{e s t}$ são diretamente influenciados pela discretização utilizada na frequência ${ }^{4}$.

\footnotetext{
${ }^{4}$ Vale lembrar que o aumento da discretização implica diretamente no aumento da ordem dos sistemas a serem resolvidos pelo método Bayesiano, comprometendo a eficiência computacional do algoritmo.
} 


\subsubsection{Critério de escolha dos hiperparâmetros $u_{1}$ e $u_{2}$}

Como se pretende encontrar uma relação entre os hiperparâmetros e quantidades observáveis como $T_{p}$ e calado, é interessante observar algumas tendências. Na figura 14 pode ser vista a variação das superfícies de erro em função dos calados.

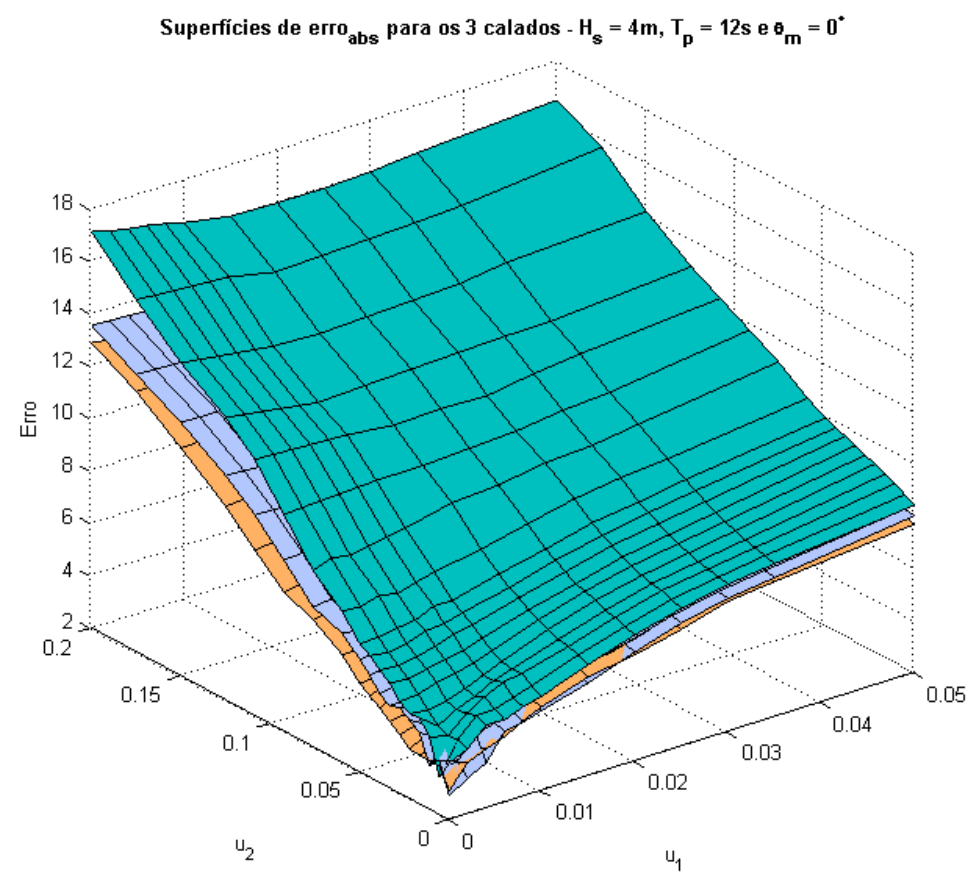

Figura 14: Superfícies de erro $_{a b s}$ para os 3 calados $-H_{s}=4 m, T_{p}=12 s$ e $\theta_{m}=0^{\circ}$.

As cores verde, violeta e laranja das superfícies indicam, respectivamente, calados vazio, intermediário e cheio. Observa-se nesta figura uma clara tendência de erros menores para suavizações menores, independente dos calados. Isso indica que a variação dos hiperparâmetros em função dos calados não é tão significativa.

Um outro exemplo é dado na figura 15, onde observam-se as tendências das superfícies variando-se a direção média de incidência de ondas e mantendo outros parâmetros fixos.

Verifica-se que neste caso as superfícies de $0^{\circ}$ e $180^{\circ}$ tem tendências parecidas, com baixa suavização, dado que o erro mínimo é encontrado para valores baixos dos hiperparâmetros. No caso de $90^{\circ}$ esta tendência não acontece, encontrando-se valores de $u_{1}$ e $u_{2}$ que permitam maior suavização.

Estes fatos ocorrem devido à dinâmica da embarcação. Quando as ondas incidem de través, existe maior movimentação em Sway e Heave, resultando em maiores amplitudes dos espectros de movimento, o que fornece mais informação ao algoritmo de estimação. Já nos casos de proa e popa, acontece movimentação em graus de liberdade menos significativos e de menor amplitude, como Surge e Pitch, existindo menos informação à estimação. 


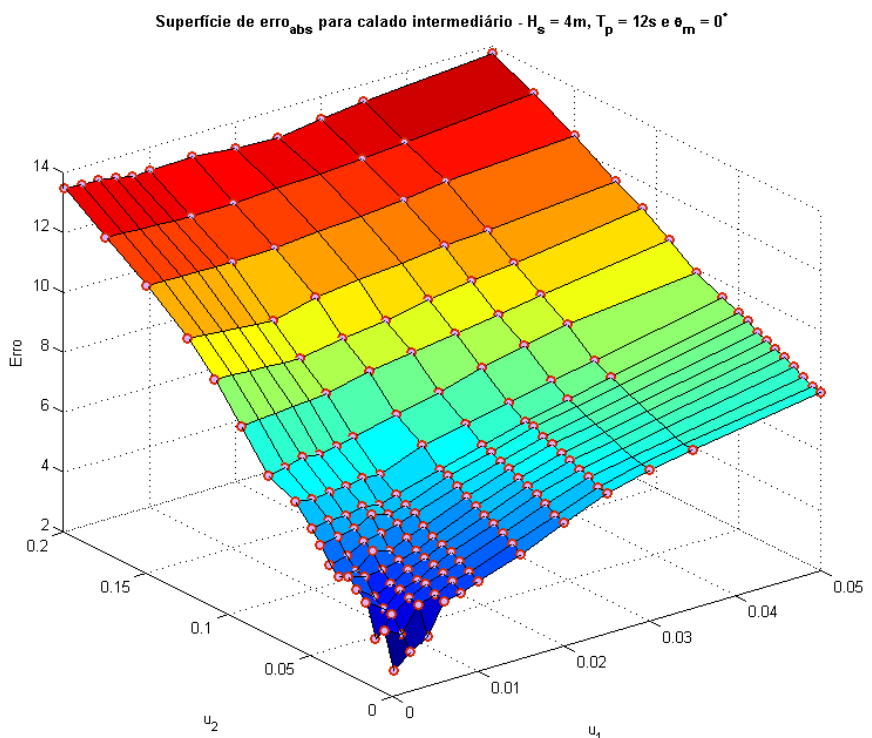

(a) $H_{s}=4 m, T_{p}=12 s$ e $\theta_{m}=0^{\circ}$.

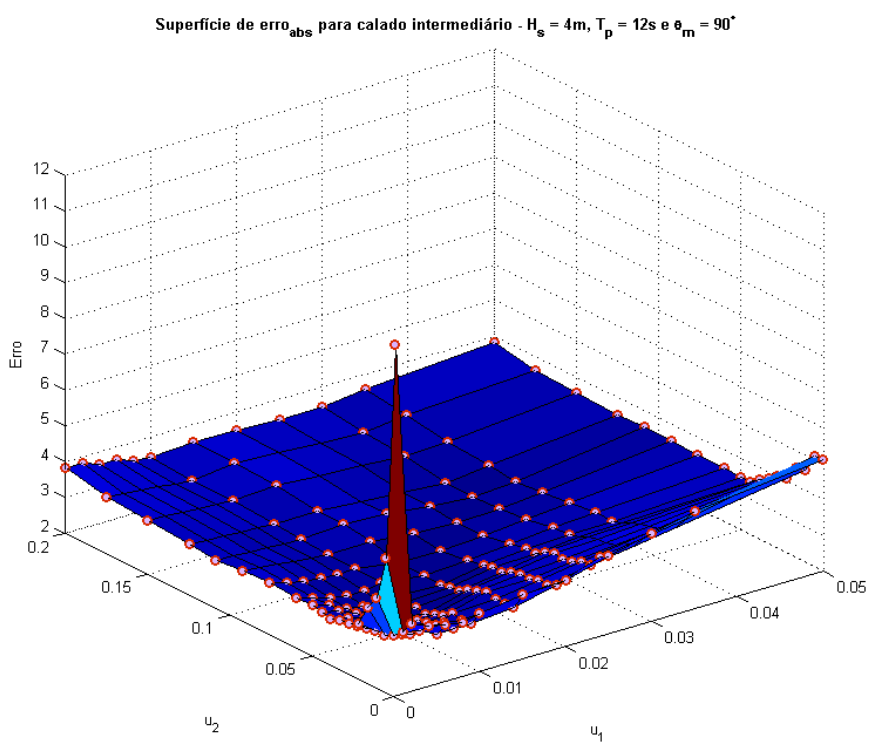

(b) $H_{s}=4 m, T_{p}=12 s$ e $\theta_{m}=90^{\circ}$.

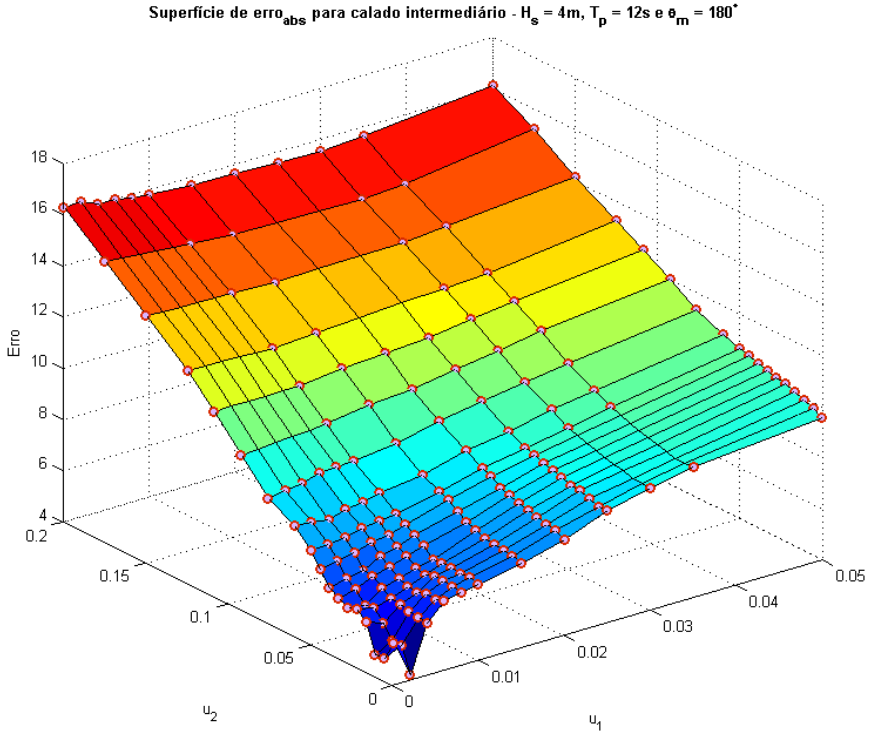

(c) $H_{s}=4 m, T_{p}=12 s$ e $\theta_{m}=180^{\circ}$.

Figura 15: Superfícies de erro $_{a b s}$ para o mar $H_{s}=4 m, T_{p}=12 \mathrm{~s}$ com direções $\theta_{m}=0^{\circ}, \theta_{m}=90^{\circ}$ e $\theta_{m}=180^{\circ}$ - Calado intermediário. 
Para a decisão de qual direção priorizar em relação à escolha dos hiperparâmetros para a simplificação e não dependência destes nas direções, opta-se pelos valores de estimativas mais suscetíveis a erros, no caso, proa e popa são um bom exemplo pois, como se possui mais informação nos casos de través, estas estimações suportam melhor a não suavização.

Embora o processo exaustivo atenda aos requisitos de estimação, este é inviável para a utilização em tempo real, pois para a malha proposta os tempos de execução deste algoritmo chegam a atingir duas horas de processamento em um computador Intel ${ }^{\circledR}$ Core $^{\mathrm{TM}} 2$ Quad Q2800, com processamento de $2,66 \mathrm{GHz}$ e $3 G b$ de memória $R A M$.

Neste trabalho, optou-se pela minimização da soma dos erros ao longo das direções, obtendose então valores de $u_{1}$ e $u_{2}$ variáveis em função do calado e do período de pico. Considerando-se que ao fixar valores de $u_{1}$ e $u_{2}$ nas direções e que podendo variar a cada calado e a cada período de pico dos espectros teóricos, as estimativas obtidas ainda estarão dentro de uma faixa de erro tolerável, é possível então encontrar tais valores através dos mínimos das somas dos erros, tomando-se o par de hiperparâmetros correspondente a tal valor.

Sendo este um processo simples, bastando-se apenas somar os valores dos erros em cada coordenada da malha para os 9 casos de incidências de cada mar apresentado na tabela 2, serão então obtidas 15 superfícies de soma dos erros, uma em cada calado para cada mar considerado.

Um exemplo de superfície de soma dos valores de erro $_{a b s}$ em cada coordenada da malha $u_{1} \times u_{2}$ ao longo das direções é apresentado na figura 16 para o mar 3 , o qual é definido por $H_{s}=4 m$ e $T_{p}=10 s$, com a embarcação em calado leve.

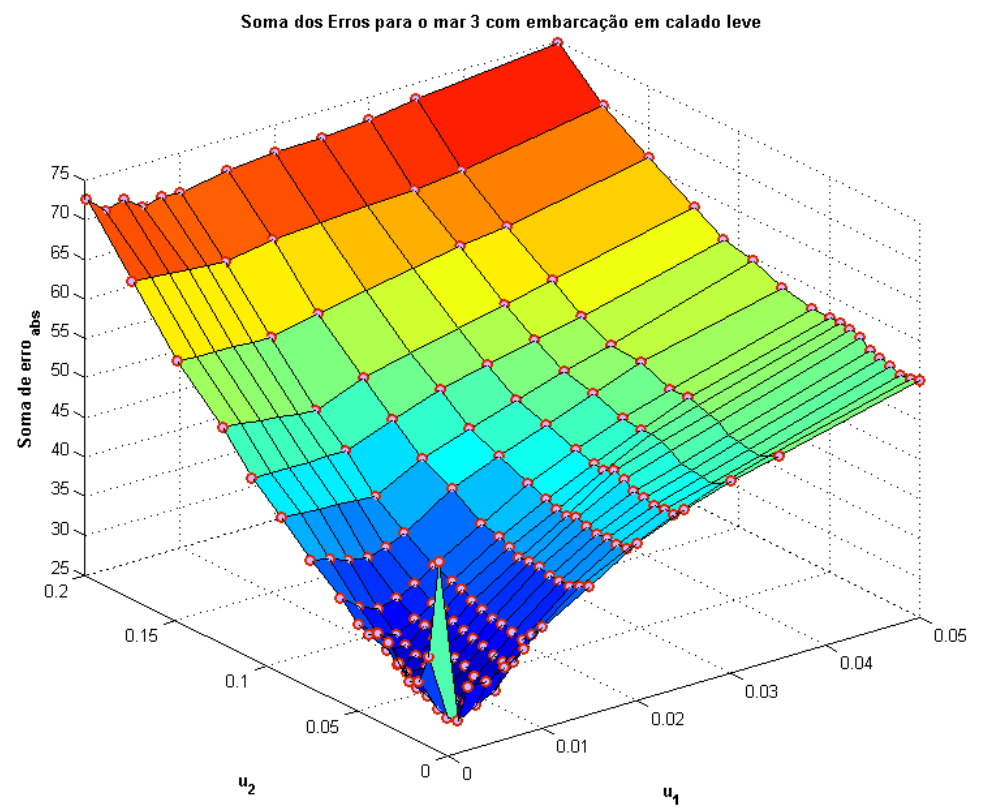

Figura 16: Soma dos valores de erro $_{a b s}$ nas direções para o caso de mar 3 com embarcação em calado $9 \mathrm{~m}$.

Para este caso, obtém-se o valor mínimo da superfície igual a 27,7818 , localizado nas coor- 
denadas $u_{1}=0,00208$ e $u_{2}=0,01119$. Assim, conforme definido pela metodologia, devem ser calculadas as novas estimativas para todas as direções no caso do mar 3 com a embarcação no calado leve, utilizando-se estes novos valores de hiperparâmetros e verificando-se os erros obtidos nas estatísticas finais.

Note que alguns pontos da superfície obtida não foram calculados, dado que nas superfícies originais tais pontos da malha não possuiam um valor de erro associado, uma vez que se buscou maior desempenho computacional, portanto, a superfície é definida novamente apenas pelos pontos vermelhos nos quais efetivamente existe um valor de erro calculado.

Um aspecto importante de destacar é o descarte do primeiro ponto da malha, localizado na origem. Observando-se que nesta coordenada força-se ao máximo a não suavização da estimativa, existem dois casos opostos de valores de erro: mínimos ou máximos. Ou seja, ou a estimativa ajusta-se muito bem ao espectro teórico ou ocorre o exato oposto, ocasionando altos erros na direção estimada.

Ao longo dos estudos, notou-se o padrão de que para incidências de través estes pontos tendiam a valores máximos de erro, em contraste aos mares incidentes de proa e popa, os quais tendiam ao mínimo. Intuitivamente, isto leva a crer que ao tomar-se uma coordenada mais avançada em relação à origem, serão atendidos ambos os casos, mesmo que isto resulte em erros levemente maiores. Assim, optou-se pela não utilização deste ponto, pois caso ocorresse valor mínimo de erro nesta coordenada, os mares de través poderiam ser demasiadamente penalizados. Já no caso oposto, os mares de proa e popa não sofrem tanto prejuízo ao adotar-se valores levemente maiores de $u_{1}$ e $u_{2}$.

\section{Exemplo 4}

Tomando-se o caso apresentado no exemplo 3, ao adotar os novos valores $u_{1}=0,00208$ e $u_{2}=0,01119$ obtidos pelo mínimo da soma dos erros apresentada acima, dado que o período de pico e calado são os mesmos, as estatísticas do espectro estimado permanecem dentro de uma faixa aceitável de erro, sendo estas $H_{s}^{e s t}=4,146 m, T_{p}^{e s t}=9,95 \mathrm{~s}$ e $\theta_{m}^{e s t}=119,026^{\circ}$. Comparativamente, houve uma variação de $\Delta H_{s}=4 \%$, sendo que no exemplo anterior esta variação era de $-2 \%$, ambos em relação ao valor teórico. No caso da direção estimada, em ambos os casos o erro é de aproximadamente $1^{\circ}$.

Os mapas dos espectros direcionais teórico e estimado para este caso são apresentados na figura 17, onde fica claro que houve pouca sensibilidade do modelo à pequenas variações nos hiperparâmetros, comparando-se aos resultados obtidos para o teste equivalente de exaustão.

Para todos os mares da tabela 2 são apresentados no apêndice $E$ as tabelas com os resultados das estimações, utilizando-se valores fixos dos hiperparâmetros como mostrado nesta seção. São também apresentados no apêndice $F$ os mapas dos espectros direcionais estimados, os quais foram obtidos utilizando-se os pares de hiperparâmetros encontrados pela minimização da soma dos erros. Tais resultados são dispostos de acordo com cada estado de mar da tabela 2 combinado às direções médias $\theta_{m}$ e separados por calado em que se encontra o FPSO P-50. São discutidos na seção seguinte os resultados obtidos pela minimização da soma dos erros e pelo processo de exaustão. 


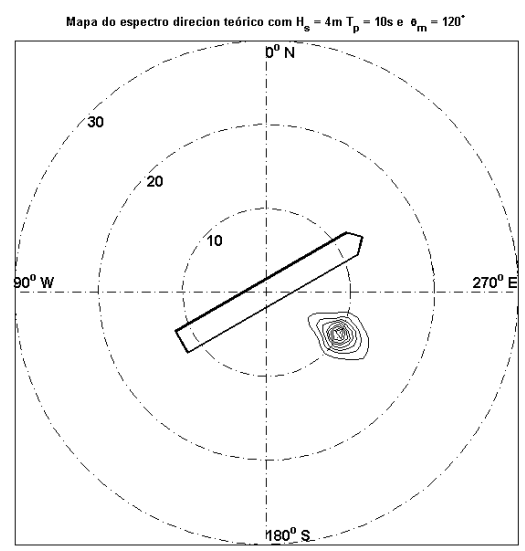

(a) Mapa do espectro direcional teórico.

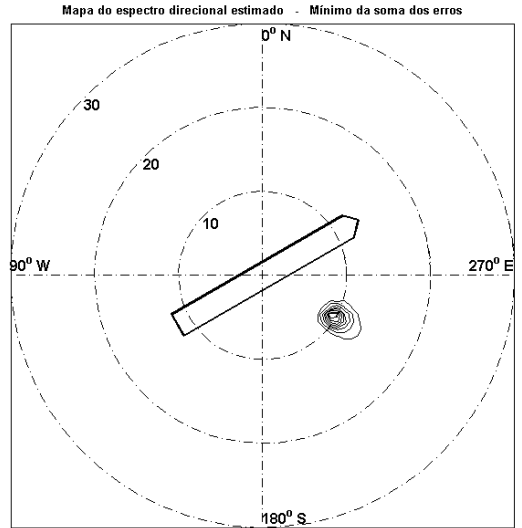

(b) Mapa do espectro direcional estimado.

Figura 17: Resultados da estimação utilizando valores dos hiperparâmetros referentes ao mínimo da soma - Espectro com parâmetros $H_{s}=4 \mathrm{~m}, T_{p}=10 \mathrm{~s}$ e $\theta_{m}=120^{\circ}$ com embarcação em calado leve.

\subsection{Discussão dos resultados}

Com a finalidade de se poder comparar os resultados aqui obtidos com os de referências como, por exemplo, (ISEKI, 2011), foram adotados os valores fixos globais $u_{1}=0,00208$ e $u_{2}=0,0001$ para um último teste de estimação. Estes valores foram escolhidos com base nos obtidos pelo mínimo da soma dos erros no calado intermediário e em $T_{p}=10 \mathrm{~s}$, dado serem estas condições mais prováveis para o FPSO P-50 estar sujeito na Bacia de Campos.

Esta verificação final serve para analisar a influência de valores fixos globais nas estimativas finais. Os resultados obtidos nestes testes são apresentados apenas na forma de erros percentuais das estatísticas nos gráficos, uma vez que não foram obtidas boas aproximações, conforme mostrado a seguir.

Afim de se concluir sobre o uso de hiperparâmetros variáveis em função do calado da embarcação e do período de pico, foram comparados os percentuais de erro em $H_{s}^{\text {est }}$, dado que este parâmetro está diretamente relacionado à energia contida no espectro estimado, ou seja, se a estimativa não conseguiu se manter com energia próxima à contida no espectro direcional teórico, os outros parâmetros dificilmente estarão corretos, dado que se supõe a capacidade do algoritmo Bayesiano em manter a quantidade de energia próxima à real.

Assim como feito anteriormente, desconsideram-se os casos em que a incidência de onda é $\theta_{m}=45^{\circ}$ ou $\theta_{m}=135^{\circ}$, pois nestes casos não se sabe a origem dos erros da estimação, existindo a possibilidade de não estarem relacionados à escolha correta dos hiperparâmetros.

Conforme apresentado nas figuras $18(\mathrm{a})$ até $22(\mathrm{c})$, os percentuais de erro $\left(\Delta H_{s}\right)$ nos casos 
de $u_{1}$ e $u_{2}$ ótimos obtidos pelo processo de minimização (curva pontilhada na cor azul), atigem variação máxima de $38 \%$ abaixo do teórico, isto em casos de $T_{p}=8,5 \mathrm{~s}$, sendo estes de difícil aplicação do método de estimação. Para os outros mares, desconsiderando-se os casos críticos de incidência, verifica-se que a variação dos percentuais de erro não ultrapassa os $15 \%$, ou seja, em mares com $H_{s}=4 m$, obtém-se valores de $H_{s}^{\text {est }}$ entre 3,4 e 4,6 metros de onda, o que é considerado um ótimo resultado em termos de estimação do espectro direcional de onda.

Entretanto, para a aplicação real sugerida pela metodologia, são utilizados os valores fixos de $u_{1}$ e $u_{2}$ em cada calado e $T_{p}$, obtidos por meio da minimização da soma dos erros absolutos (curva tracejada cor-de-rosa). Neste caso, também desconsiderando-se os casos críticos, tanto da direção de incidência, quanto do mar 2 , os percentuais de erro ficam limitados a variações máximas de $20 \%$, o que implica em estimativas de $H_{s}$ variando entre 3,2 e 4,8 metros, sendo estes valores aceitáveis de erro.

No caso de hiperparâmetros fixos globais (curva pontilhada-tracejada na cor verde), ocorre uma penalização maior nos mares 4 e 5 , o que é considerado como não aceitável no âmbito da estimação, dado que estes tipos de mar são mais fáceis de estimar, uma vez que excitam mais a embarcação, gerando respostas com maior amplitude. Neste caso, existem variações de erro acima de $35 \%$ positivos, o que implica em superestimação além do tolerável, pois um mar de $H_{s}=4 m$ teria uma estimativa de $H_{s}^{e s t}=5,4 m$, sendo esta totalmente incoerente com o estado de mar verdadeiro. Isto ocorre em parte pela escolha dos valores de $u_{1}$ e $u_{2}$ destes testes, pois os mesmos são mais adequados a períodos mais baixos. 


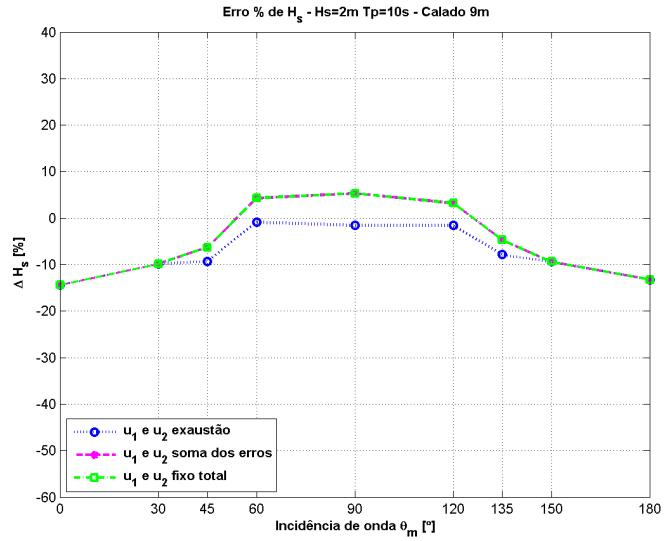

(a) $H_{s}=2 m, T_{p}=10 \mathrm{~s}$ e calado $9 \mathrm{~m}$.

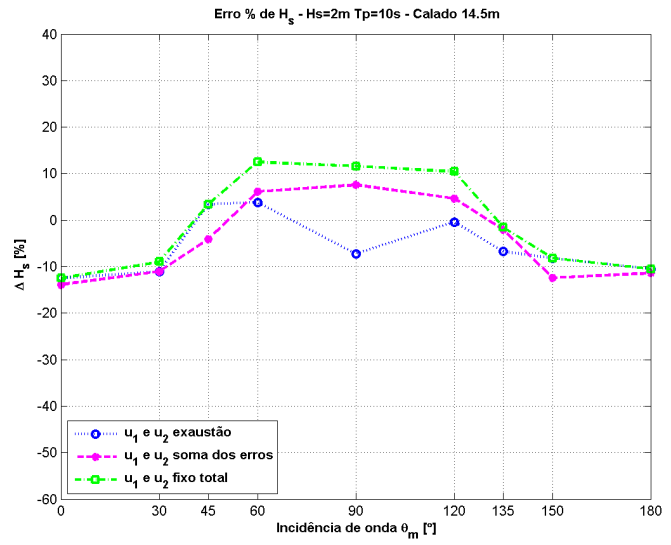

(b) $H_{s}=2 m, T_{p}=10 \mathrm{~s}$ e calado $14,5 \mathrm{~m}$.

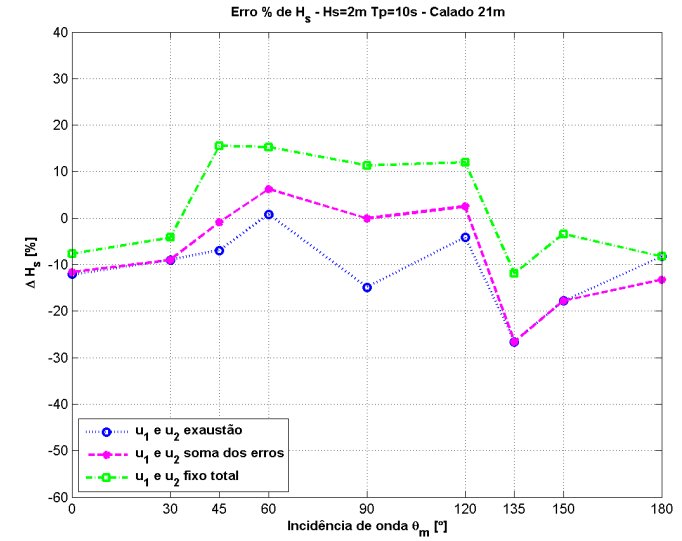

(c) $H_{s}=2 m, T_{p}=10 \mathrm{~s}$ e calado $21 \mathrm{~m}$

Figura 18: Erros percentuais $\Delta H_{s}$ em relação ao teórico do mar 1, em cada calado - Curvas: Exaustão; Soma dos erros e; Hiperparâmetros fixos globalmente. 


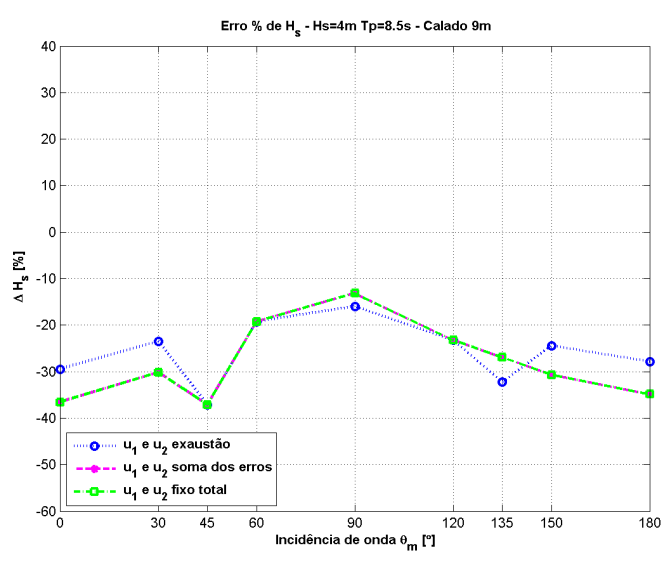

(a) $H_{s}=4 m, T_{p}=8,5 s$ e calado $9 \mathrm{~m}$.

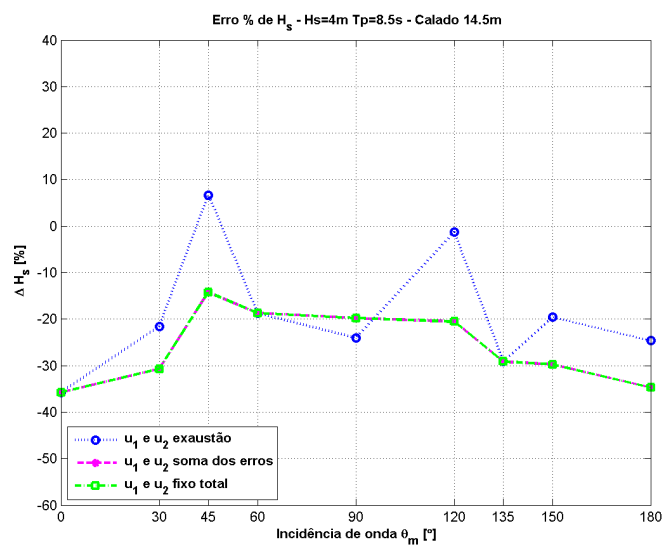

(b) $H_{s}=4 m, T_{p}=8,5 \mathrm{~s}$ e calado $14,5 \mathrm{~m}$.

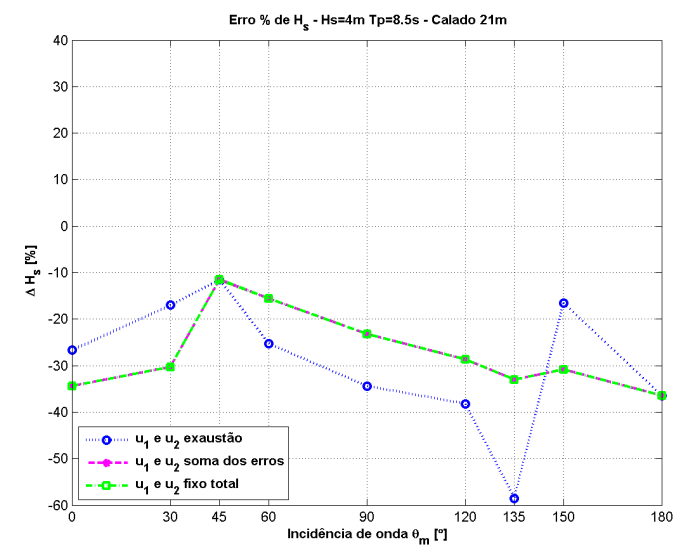

(c) $H_{s}=4 \mathrm{~m}, T_{p}=8,5 \mathrm{~s}$ e calado $21 \mathrm{~m}$.

Figura 19: Erros percentuais $\Delta H_{s}$ em relação ao teórico do mar 2, em cada calado - Curvas: Exaustão; Soma dos erros e; Hiperparâmetros fixos globalmente.

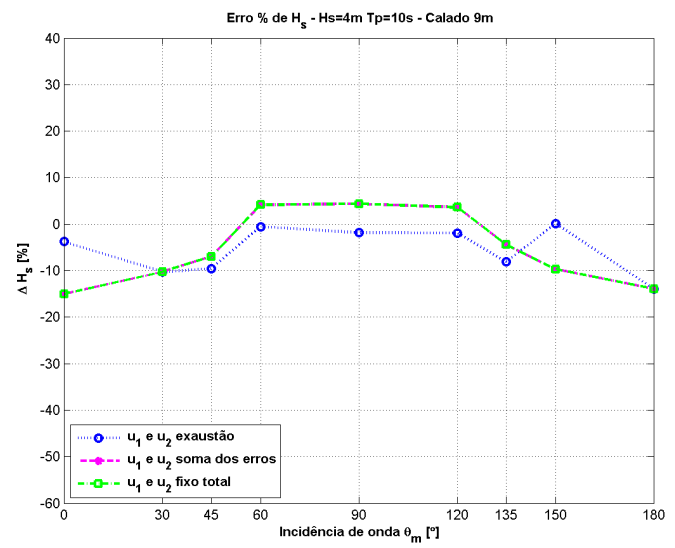

(a) $H_{s}=4 m, T_{p}=10 \mathrm{~s}$ e calado $9 \mathrm{~m}$.

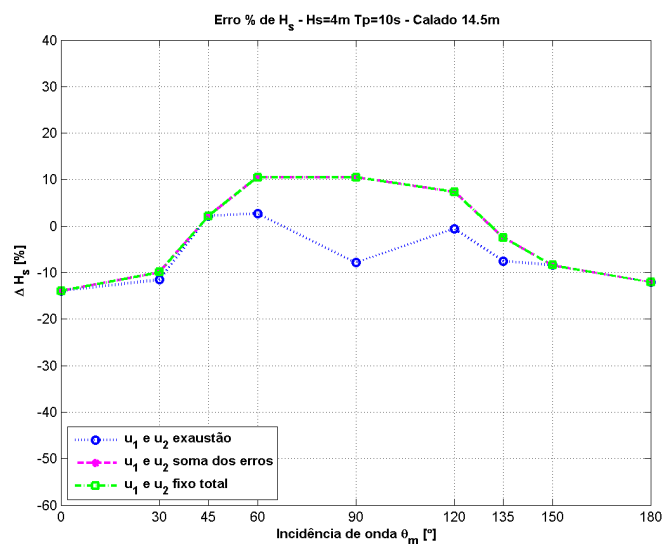

(b) $H_{s}=4 m, T_{p}=10 \mathrm{~s}$ e calado $14,5 \mathrm{~m}$.

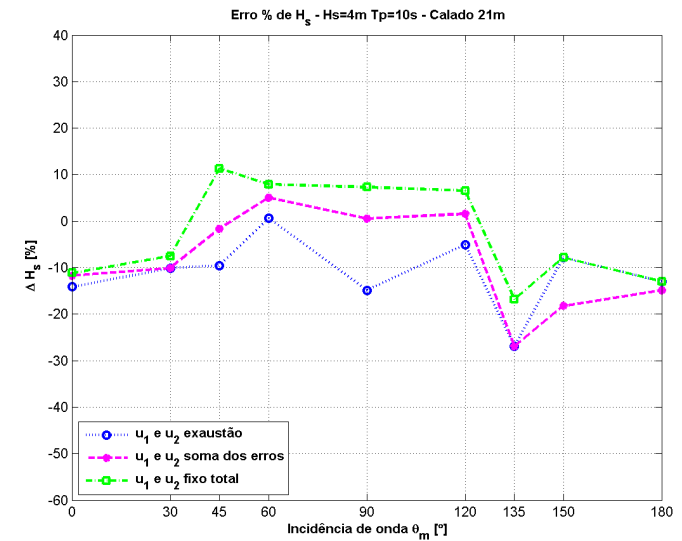

(c) $H_{s}=4 m, T_{p}=10 \mathrm{~s}$ e calado $21 \mathrm{~m}$

Figura 20: Erros percentuais $\Delta H_{s}$ em relação ao teórico do mar 3, em cada calado - Curvas: Exaustão; Soma dos erros e; Hiperparâmetros fixos globalmente. 


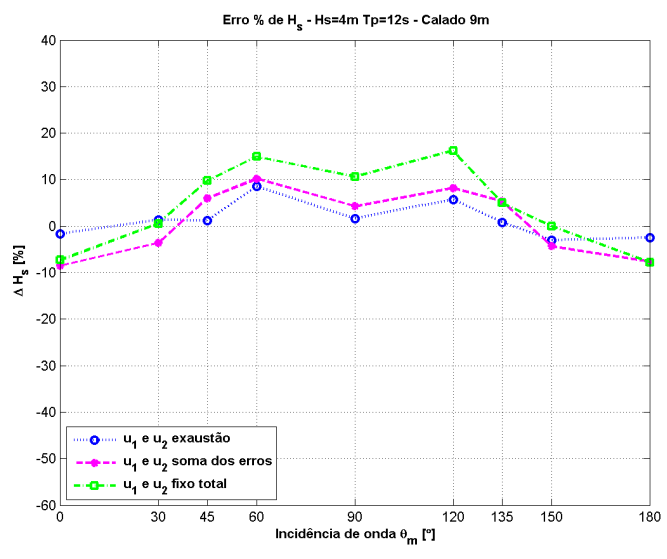

(a) $H_{s}=4 m, T_{p}=12 \mathrm{~s}$ e calado $9 \mathrm{~m}$.

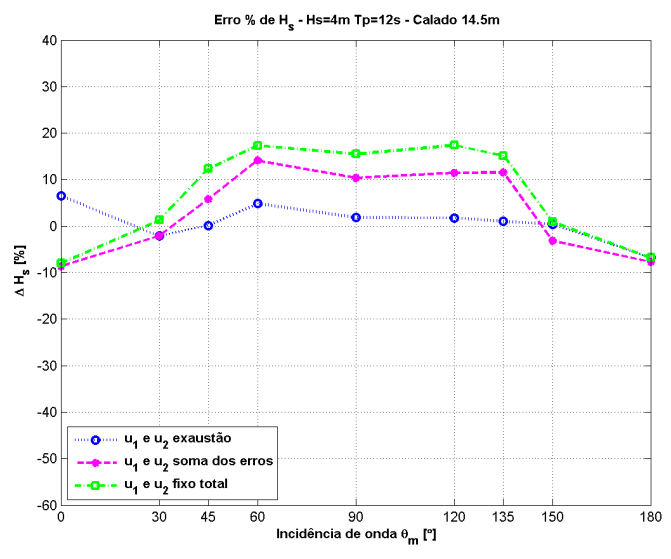

(b) $H_{s}=4 m, T_{p}=12 \mathrm{~s}$ e calado $14,5 \mathrm{~m}$.

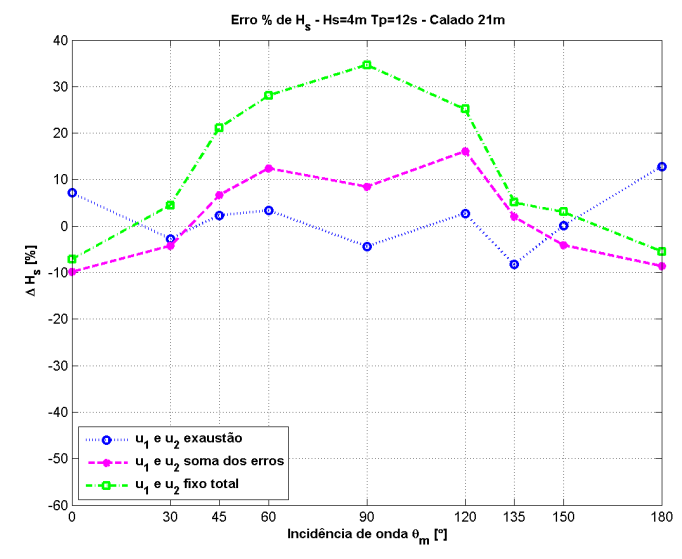

(c) $H_{s}=4 m, T_{p}=12 \mathrm{~s}$ e calado $21 \mathrm{~m}$.

Figura 21: Erros percentuais $\Delta H_{s}$ em relação ao teórico do mar 4, em cada calado - Curvas: Exaustão; Soma dos erros e; Hiperparâmetros fixos globalmente.

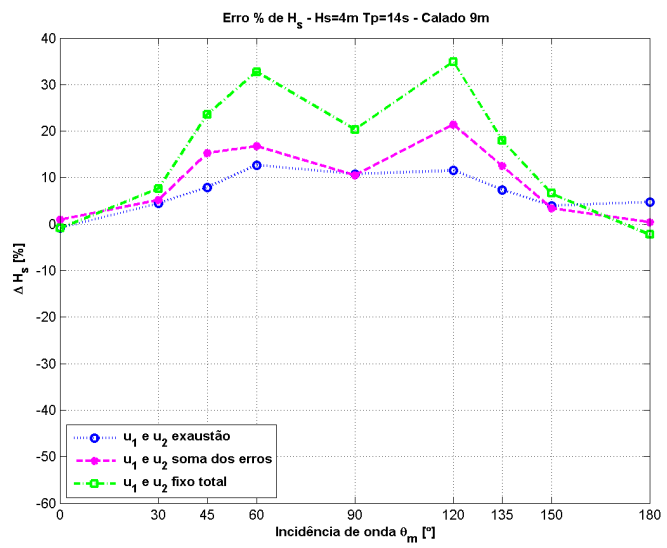

(a) $H_{s}=4 m, T_{p}=14 s$ e calado $9 \mathrm{~m}$.

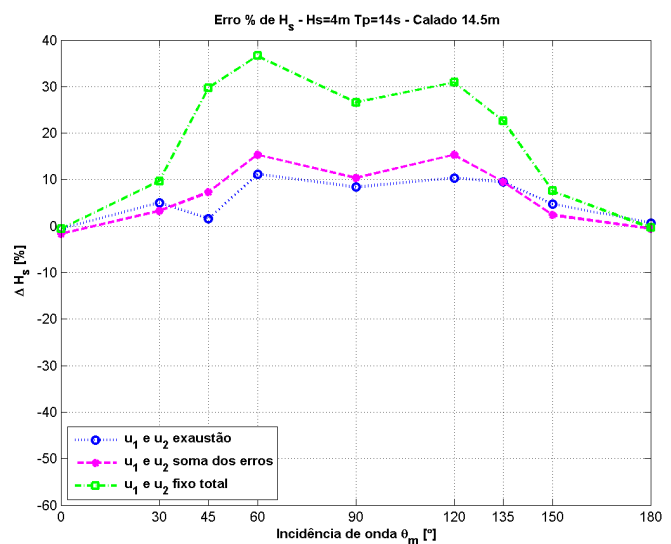

(b) $H_{s}=4 m, T_{p}=14 \mathrm{~s}$ e calado $14,5 \mathrm{~m}$.

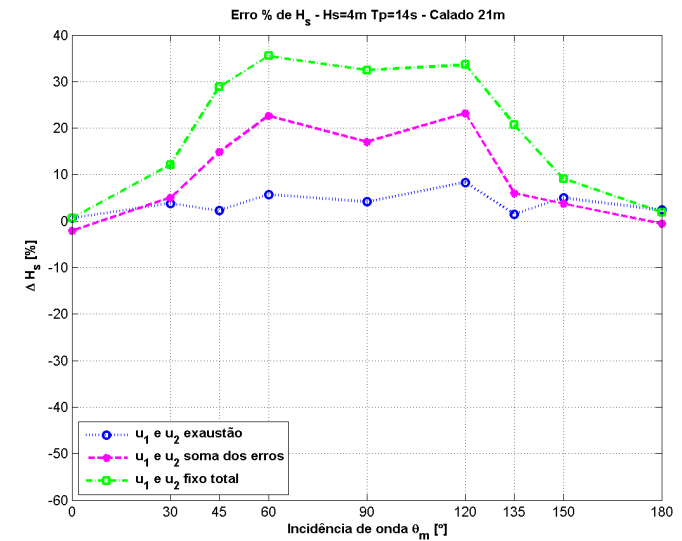

(c) $H_{s}=4 m, T_{p}=14 \mathrm{~s}$ e calado $21 \mathrm{~m}$

Figura 22: Erros percentuais $\Delta H_{s}$ em relação ao teórico do mar 5, em cada calado - Curvas: Exaustão; Soma dos erros e; Hiperparâmetros fixos globalmente. 
Desta maneira, os resultados indicam que ao tomar valores de $u_{1}$ e $u_{2}$ em função do calado e do período de pico, os erros cometidos na estimação da quantidade de energia contida no espectro teórico, ainda não prejudicam a estimação como um todo, ou seja, aceitam-se tais erros com o propósito de simplificar o processo de obtenção de modelos ótimos (ou próximos destes) para a estimação do espectro direcional de onda.

Portanto, uma maneira de utilizar-se os valores obtidos para os hiperparâmetros é por meio de uma interpolação dos dados apresentados nas tabelas 4 e 5.

\begin{tabular}{|r|cccc|}
\hline \multirow{2}{*}{ Calado [m] } & \multicolumn{4}{|c|}{$T_{p}[\mathrm{~s}]$} \\
\cline { 2 - 5 } & 8,5 & 10 & 12 & 14 \\
\hline 9 & 0,00208 & 0,00208 & 0,00208 & 0,00208 \\
14,5 & 0,00208 & 0,00208 & 0,00208 & 0,00406 \\
21 & 0,00208 & 0,00208 & 0,00406 & 0,00406 \\
\hline
\end{tabular}

Tabela 4: Valores de $u_{1}$ em função dos períodos de pico e dos calados.

\begin{tabular}{|r|cccc|}
\hline \multirow{2}{*}{ Calado [m] } & \multicolumn{4}{|c|}{$T_{p}[\mathrm{~s}]$} \\
\cline { 2 - 5 } & 8,5 & 10 & 12 & 14 \\
\hline 9 & 0,00010 & 0,00010 & 0,01119 & 0,01119 \\
14,5 & 0,00010 & 0,00010 & 0,00564 & 0,01119 \\
21 & 0,00010 & 0,00564 & 0,01119 & 0,00564 \\
\hline
\end{tabular}

Tabela 5: Valores de $u_{2}$ em função dos períodos de pico e dos calados.

Isto é equivalente a encontrar valores intermediários para calados e períodos de pico diferentes dos tabelados em uma superfície como as apresentadas nas figuras 23(a) e 23(b).

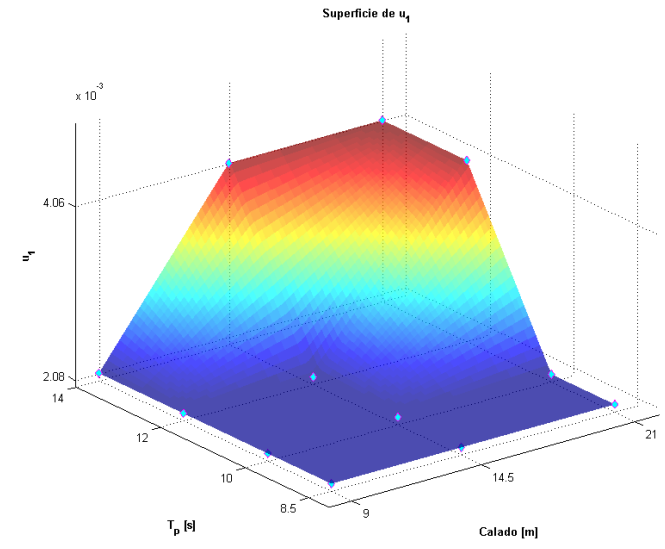

(a) Superfície de $u_{1}$ em função de calado e $T_{p}$.

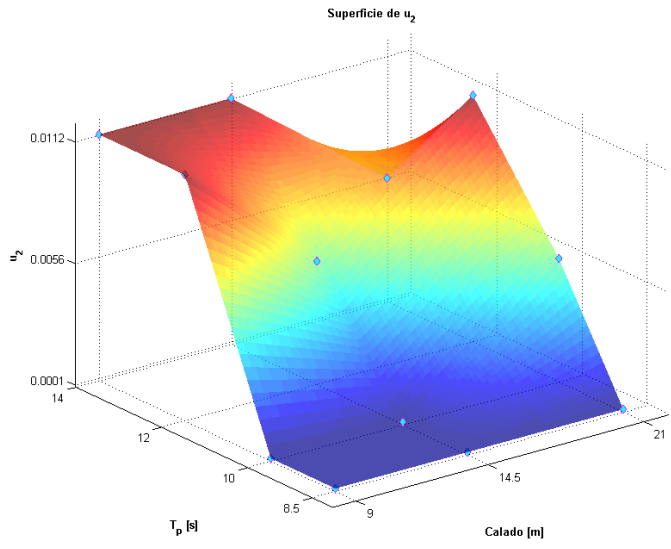

(b) Superfície de $u_{2}$ em função de calado e $T_{p}$.

Figura 23: Superfícies de $u_{1}$ e $u_{2}$ em função dos calados e dos períodos de pico $T_{p}$.

É importante destacar que estas superfícies foram obtidas com valores vizinhos na discretização da malha $u_{1} \times u_{2}$ e, portanto, quaisquer outros valores intermediários não foram analisados. Além disso, é interessante notar que em uma região pequena como esta existem variações consideráveis das estimativas obtidas conforme pode ser visto na análise de erros percentuais de $H_{s}$. 
Dado que este procedimento determina valores dos hiperparâmetros em função de $T_{p}$ é necessário estimar este parâmetro de alguma maneira. Uma opção para isto seria o uso do período médio de algum movimento da embarcação, por exemplo, o de Heave, dada sua resposta linear às excitações de onda.

Vale lembrar também que os testes aqui realizados contaram com apenas um valor do espalhamento $s$, uma vez que não foi possível incluí-lo na metodologia de calibração devido a limitações de software. Este fato é importante pois os mares considerados não possuem espaIhamento de energia, ou seja, a energia dos espectros direcionais teóricos fica extremamente concentrada em uma região pequena de direções e frequências. Isto força baixas suavizações dos espectros estimados, implicando em baixos valores dos hiperparâmetros durante o processo de calibração dos mesmos. 


\section{Pós-processamento}

\subsection{Introdução}

Neste capítulo é apresentado o pós-processamento do espectro direcional, introduzindo modelos paramétricos baseados em estatísticas de mar para descrição do espectro em função da frequência e da direção. Possuindo-se apenas o espectro direcional é difícil saber a que tipo de mar o mesmo corresponde, dado que o espectro não está descrito por meio de uma parametrização, mas sim por uma matriz com dados de energia em função das frequências e direções. Do ponto de vista da aplicabilidade dos espectros direcionais de energia, é necessária a "tradução" dos mesmos em quantidades compreensíveis e manipuláveis, tais como as estatísticas globais de mar: $H_{s}, T_{p}, \theta_{m}$ e $s$, amplamente utilizadas em Engenharia Naval.

Estas estatísticas globais podem ser facilmente calculadas com a finalidade de se compreender melhor qual tipo de mar está sendo representado pelo espectro direcional. Entretanto, a extração destas informações dos espectros torna-se muitas vezes complexa ao serem considerados estados de mares cruzados (Crossed-Sea States), em que dois mares $(i=\{1,2\})$ de diferentes alturas significativas $\left(H_{s_{i}}\right)$, vindos de diferentes direções médias $\left(\theta_{m_{i}}\right)$, com dois períodos de pico $\left(T_{p_{i}}\right)$ e respectivos espalhamentos de energia $\left(s_{i}\right)$, influenciam nos movimentos da embarcação.

Estes parâmetros estatísticos modais $\left(H_{s_{i}}, T_{p_{i}}, \theta_{m_{i}}\right.$ e $\left.s_{i}\right)$ fornecem, através de modelos espectrais direcionais, uma função dependente da frequência e da direção que se aproxima do espectro direcional discreto (como, por exemplo, da matriz obtida pelo método Bayesiano). Assim, é necessário extrair deste espectro discreto os valores dos parâmetros estatísticos através de algum tipo de estimação, a qual será aqui chamada de estimação paramétrica.

A estimação paramétrica é feita através da minimização do erro total calculado por meio das diferenças entre a matriz que representa o espectro direcional e a função $S(\omega, \theta)$ que representa o espectro estimado. Devido a isto, é necessária a escolha de um modelo para a representação de $S(\omega, \theta)$, a qual deve levar em consideração alguns fatores importantes, tais como o ajuste aos tipos de espectro a serem estimados e a difusão na literatura.

Neste trabalho, foram utilizados os modelos de espectro de energia de Hogben \& Cobb, proposto por (HOGBEN; COBB, 1986), e JONSWAP, modelo clássico de representação espectral, ambos compostos à parcela direcional $D(\omega, \theta)$. A escolha destes modelos é justificada na seção 5.2. As formulações destes dois modelos são apresentadas neste capítulo juntamente a alguns exemplos comparativos para ilustrar as principais diferenças dos modelos. 
Verificou-se que para a realização do processo de estimação paramétrica é necessária a identificação prévia da bimodalidade ou unimodalidade espectral. Isto se deve ao fato de existirem dificuldades de convergência ao estimar os parâmetros de um espectro com apenas um pico através de um modelo bimodal, como foi constatado ao longo do estudo realizado. Desta maneira, tornou-se necessário o estudo e implementação de um critério de bimodalidade, o qual também é discutido e apresentado neste capítulo, na seção 5.5.

O emprego do critério de bimodalidade garante que um espectro de apenas um pico de energia seja estimado por uma versão unimodal do modelo de espectro direcional. Esperava-se que ao fazer a estimação de um mar unimodal por um modelo bimodal, as componentes do modelo relativas a um pico inexistente fossem muito próximas a zero. Entretanto, verificou-se ao longo do desenvolvimento do processo de estimação que isto nem sempre ocorre, pois o algoritmo atribui valores incoerentes a um suposto segundo pico de energia, inclusive penalizando o pico correto com a diminuição de sua energia.

Portanto, tornou-se necessária uma forma de classificar os espectros a serem estimados em duas classes: uni ou bimodais. Ao aplicar tal processo, aumenta-se a confiabilidade das estatísticas extraídas dos espectros, uma vez que adota-se o modelo correto para a estimação, ao menos para mares unimodais.

No caso oposto, em que um mar bimodal é modelado por um unimodal, o problema é o de perda da energia real do espectro direcional, dado que um dos picos não é contabilizado no momento da estimativa das estatísticas. Neste trabalho foram aceitas estimativas deste tipo, pois embora seja perdido um dos picos de energia, verificou-se ao longo dos testes que o modo principal sempre permanece, sendo encontradas as estatísticas do mar de maior influência. Além disso, foi verificado também que este tipo de erro ocorre somente em mares bimodais em que o primeiro pico de energia é significativamente maior que o segundo. Ou seja, em mares bimodais de picos contendo energias próximas, obtém-se as estimativas corretas para os dois picos.

Esta classificação dos espectros foi feita por meio dos chamados critérios de bimodalidade, sendo que neste trabalho foram estudados 4 métodos de identificação, comparando-os por meio de testes com os espectros a serem estimados e adotando-se o critério que atendia melhor aos requisitos: identificar todos os mares unimodais. Considerou-se que a identificação incorreta de mares bimodais não traria grandes prejuízos ao trabalho realizado.

Assim, adotou-se o critério proposto por (PISCOPIA; PANIZZO; GIROLAMO, 2004), pois este foi o único capaz de atender ao requisito estabelecido, identificando corretamente todos os mares unimodais testados. Entretanto, a restrição imposta pelo critério penaliza demasiadamente os mares bimodais, forçando estimativas unimodais para mares em que seria perfeitamente realizável a estimação bimodal dos parâmetros. Uma das sugestões feitas ao final deste trabalho é um estudo mais criterioso deste fator limitante.

Juntos, os processos de identificação da bimodalidade e estimação paramétrica formam o chamado pós-processamento, sendo este destacado pela linha pontilhada vermelha do diagrama apresentado na figura 24 , onde é feita uma representação esquemática do fluxo do algoritmo implementado para o pós-processamento, relacionando-o ao algoritmo Bayesiano de estimação 
de espectros.

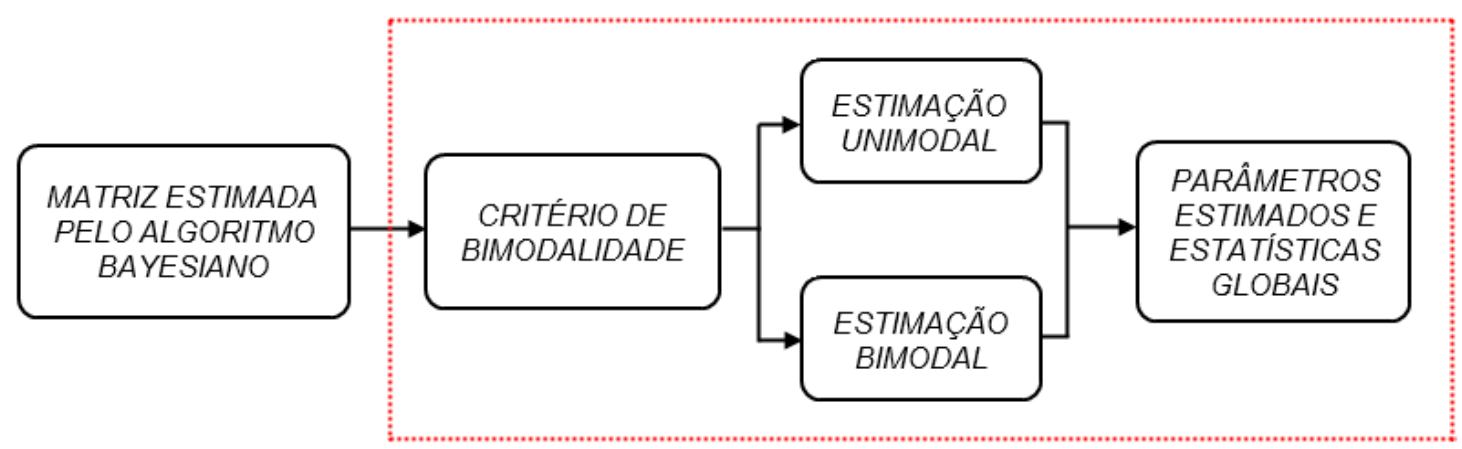

Figura 24: Representação esquemática do algoritmo de pós-processamento.

É importante salientar que, embora o espectro direcional discreto a ter suas estatísticas extraídas possa ser gerado pelo algoritmo Bayesiano, neste capítulo foram utilizados mares medidos de ensaios em escala. Isto foi feito levando-se em consideração o fato de que ao gerar o espectro, o algoritmo Bayesiano pode gerar estimativas incorretas, o que poderia levar ao desenvolvimento de um método de pós-processamento tendencioso. Além disso, utilizando-se informações medidas, aumenta-se a confiabilidade do método, podendo então adotar-se os procedimento de pós-processamento aos espectros gerados pelo método Bayesiano com maior segurança.

As rotinas utilizadas para o pós-processamento foram implementadas em ambiente MATLAB ${ }^{\circledR}$ por meio de um conjunto de rotinas que envolvem os passos do algoritmo representados pelo diagrama.

Neste capítulo é levantada também a questão da variação do parâmetro de espalhamento $(s)$ em função da frequência, abordagem um tanto comum na literatura clássica. A análise feita durante os testes mostra que as estimativas dos parâmetros estatísticos não tem alteração significativa ao adotar-se uma formulação com $s$ fixo. Entretanto, é importante frisar que os ensaios utilizados como base foram gerados por meio de um modelo com $s$ fixo.

Os espectros aqui utilizados para a validação do pós-processamento são resultantes dos ensaios elaborados em (SPARANO, 2008) e (SIMOS et al., 2009). Estes ensaios foram realizados no tanque de provas do LabOceano da COPPE/UFRJ utilizando escalas 1:48 e 1:70. Para a medição das amplitudes de onda em pontos determinados foram utilizados wave-probes (sensores de onda) e a frequência de amostragem é de $25 \mathrm{~Hz}$ (escala de modelo), conforme mencionado ${ }^{1}$ em (SPARANO, 2008, p.41-42).

Ao final do capítulo são apresentados resultados obtidos pela estimação paramétrica, comparando-os com os valores teóricos que serviram de base para os ensaios realizados no tanque de provas. Através destas comparações são feitas as considerações finais para a escolha do modelo JONSWAP com $s$ fixo para a representação dos espectros direcionais, tendo em vista a precisão das estimativas e o tempo de processamento para obtenção de resultados.

\footnotetext{
${ }^{1}$ Maiores detalhes sobre as instalações e equipamentos usados nos experimentos podem ser encontrados em (SPARANO, 2008) e (SIMOS et al., 2009).
} 


\subsection{Espectro Direcional de Energia}

Existem diversos modelos de espectro de energia (também chamados espectro de frequência ou ainda, espectro de potência) conhecidos na literatura clássica. Alguns podem ser destacados por serem mais comumente utilizados, tais como Pierson-Moskowitz, Bretschneider e JONSWAP. Outros menos difundidos na literatura, como no caso do espectro de Hogben \& Cobb, têm sua relevância devido ao histórico dos estudos que servem de base para o desenvolvimento deste trabalho, principalmente em (SIMOS et al., 2009).

Estas formulações de espectro de energia, denotado aqui por $S(\omega)$, onde $\omega$ é a frequência angular em $[\mathrm{rad} / \mathrm{s}]$, possuem em comum os parâmetros $H_{s}$ e $T_{p}$, diferindo-se na forma do espectro, mas mantendo a mesma área e frequência de pico, ou seja, todos contém a mesma energia. Para fins de ilustração é apresentado na figura 25 um exemplo de espectro de potência para os modelos JONSWAP e Hogben \& Cobb.

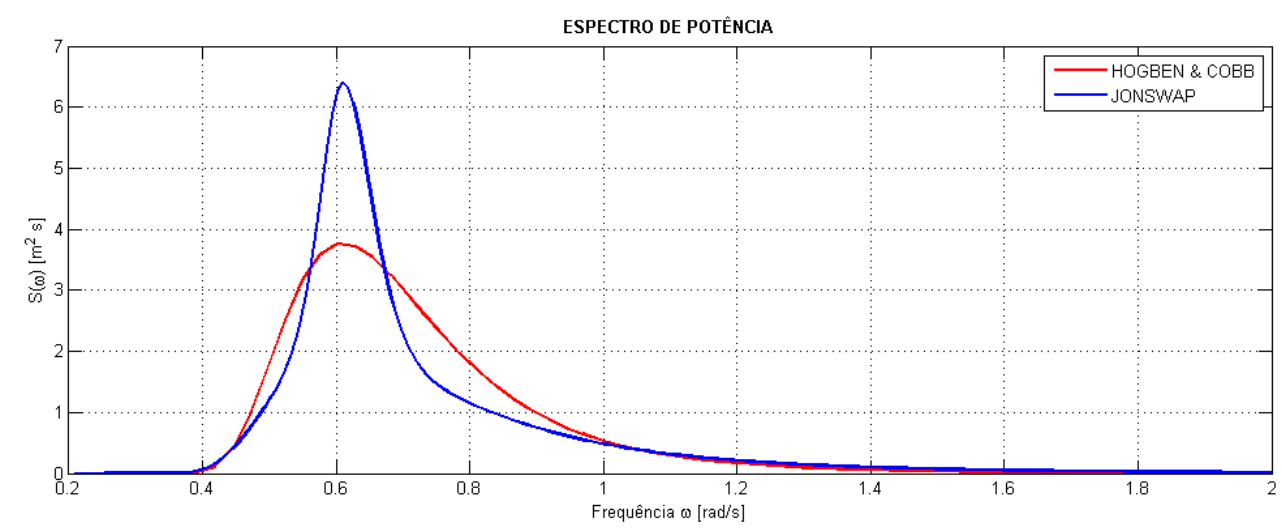

Figura 25: Exemplo de espectros de potência utilizando os modelos de JONSWAP e Hogben $\&$ Cobb com $H_{s}=4,5 m$ e $T_{p}=10,3 s-\lambda=1,5$ para Hogben \& Cobb e $\gamma=3,3$ para JONSWAP.

Sabendo que para mesmos $H_{s}$, a energia contida em $S(\omega)$ é igual para diferentes parametrizações, dado que $H_{s}=4 \sqrt{m_{0}}$, onde $m_{0}$ é a área abaixo da curva de $S(\omega)$. Ao se fazer a composição do espectro de frequência com a parcela direcional $D(\omega, \theta)$, onde $\theta$ é a direção, o espectro direcional de energia de onda, denotado por $S(\omega, \theta)$ terá a mesma energia para diferentes parametrizações. A diferença entre parametrizações está ligada a forma que esta energia está distribuida, dependendo do espalhamento,$s$, e de algum parâmetro de forma ou de amplificação de pico, estes variando a cada modelo espectral.

Um espectro direcional de energia é, basicamente, uma função multivariada que descreve como a energia das ondas por metro quadrado de superfície do mar está distribuída ao longo das frequências e direções. Este espectro é dado de maneira que a área limitada pelos intervalos de frequência e direção é proporcional à energia total por metro quadrado de superfície do mar.

A expressão (5.1) a seguir descreve um espectro direcional de energia de onda, através do uso de funções adequadas e da escolha dos valores de seus parâmetros: 


$$
S(\omega, \theta)=S(\omega) D(\omega, \theta)
$$

no qual $\omega$ é a frequência angular $(\omega=2 \pi f, f$ é a frequência em $[H z]), \theta$ é direção, $D(\omega, \theta)$ é uma função de espalhamento direcional e $S(\omega)$ é o espectro de frequência, ou ainda, espectro de potência, dado pela expressão (5.2):

$$
S(\omega)=\int_{0}^{2 \pi} S(\omega, \theta) d \theta
$$

Para que uma função seja utilizada como parte direcional do espectro, esta deve possuir as seguintes propriedades:

\section{Propriedade 1:}

$$
\left.\begin{array}{l}
D(\omega, \theta) \geq 0 \\
D(\omega, \theta+2 \pi)=D(\omega, \theta)
\end{array}\right\} \text { para } \theta \in \mathbb{R}
$$

\section{Propriedade 2:}

$$
\int_{\alpha-\pi}^{\alpha+\pi} D(\omega, \theta) d \theta=1, \text { para } \alpha \in \mathbb{R}
$$

Uma expressão deste tipo muito utilizada na literatura, tendo sido proposta por (LONGUETHIGGINS; CARTWRIGHT; SMITH, 1961), é dada em (5.3):

$$
D(\omega, \theta)=\frac{1}{\pi} 2^{2 s-1} \cos ^{2 s}\left(\frac{\theta-\theta_{m}}{2}\right) \frac{\Gamma^{2}(s+1)}{\Gamma(2 s+1)}
$$

Onde $s$ é o parâmetro de espalhamento e $\theta_{m}$ é a direção média da energia. A função $\Gamma$ é dada pela expressão (5.4):

$$
\Gamma(s)=\int_{0}^{\infty} t^{s-1} e^{-t} d t
$$


e para fins de implementação numérica, é interessante destacar a propriedade desta função dada pela expressão (5.5).

\section{Propriedade 3:}

$$
\Gamma(s+1)=s \Gamma(s), \text { para } s \in \mathbf{R}_{*}^{+} .
$$

Esta propriedade é importante para a eficiência computacional no cálculo de $D(\omega, \theta)$, pois através da mesma é possível calcular a função $\Gamma$ de maneira recursiva para valores tabelados de $s$, usando interpolação linear para valores intermediários deste parâmetro. Do ponto de vista computacional esta abordagem é menos custosa que o cálculo da integral dada em (5.4) e suficientemente precisa.

Neste trabalho foram adotados dois tipos de espectros de frequência, Hogben \& Cobb e JONSWAP, sendo que ambos foram utilizados juntamente com a parte direcional dada por (5.3). A escolha destes modelos foi feita considerando-se com os seguintes fatores:

- O modelo de Hogben \& Cobb já havia sido utilizado em trabalhos anteriores (ver (SIMOS et al., 2009) e (SPARANO, 2008)) e como o estudo aqui realizado é uma continuação destes, naturalmente optou-se pela utilização do mesmo modelo.

- Este modelo de espectro é feito já levando-se em consideração a parte direcional, assim como a soma dos dois picos de energia no caso bimodal, sendo uma combinação dos modelos propostos por (OCHI; HUBBLE, 1976) e (LONGUET-HIGGINS; CARTWRIGHT; SMITH, 1961). Devido a isto, a sua utilização para a estimação dos parâmetros de espectros direcionais de energia era mais direta.

- A PETROBRAS utiliza o modelo de espectro de frequência JONSWAP, portanto o uso desta parametrização juntamente à parte direcional é justificada pelo histórico de estudos da modelagem feita à Bacia de Campos.

- Utilizou-se inicialmente o modelo de Hogben \& Cobb e dada a necessidade da estimação do parâmetro de amplificação do pico, $\gamma$, adotou-se também o modelo JONSWAP. 0 parâmetro $\gamma$ é necessário devido ao uso histórico feito pela PETROBRAS. Dado que não existiram diferenças significativas nas estimativas dos outros parâmetros comuns aos dois modelos, optou-se também pelo uso deste segundo modelo.

- O espectro JONSWAP foi utilizado na geração dos ensaios em escala feitos no LabOceano, os quais serviram como teste e foram usados na validação da estimação aqui implementada. 


\subsection{Modelo proposto por Hogben \& Cobb}

O modelo de espectro direcional aqui apresentado é uma combinação dos modelos propostos por (OCHI; HUBBLE, 1976) e (LONGUET-HIGGINS; CARTWRIGHT; SMITH, 1961), os quais tratam, respectivamente, do espectro de potência, $S(\omega)$, e da função de distribuição de energia, $D(\omega, \theta)$. Neste texto não será detalhado o desenvolvimento dos dois modelos citados, mas apenas do espectro direcional de energia como foi proposto por (HOGBEN; COBB, 1986), o qual é definido pela expressão (5.6) a seguir:

\section{Definição 1:}

$$
\begin{aligned}
S(\omega, \theta)= & \frac{1}{4} \sum_{i=1}^{2} \frac{\left(\frac{4 \lambda_{i}+1}{4} \omega_{m_{i}}^{4}\right)^{\lambda_{i}}}{\Gamma\left(\lambda_{i}\right)} \frac{H_{s_{i}}^{2}}{\omega^{4 \lambda_{i}+1}} A\left(s_{i}\right) \\
& \times \cos ^{2 s_{i}}\left(\frac{\theta-\theta_{m_{i}}}{2}\right) \exp \left[-\frac{4 \lambda_{i}+1}{4}\left(\frac{\omega_{m_{i}}}{\omega}\right)^{4}\right]
\end{aligned}
$$

onde $H_{s}$ é a altura significativa de onda, $\omega_{m}$ é a frequência modal, a qual está relacionada com o período de pico por $T_{p}=2 \pi / \omega_{m}, \theta_{m}$ é a direção média, $s$ é o espalhamento e $\lambda$ é um parâmetro de controle da forma do espectro, de modo a torná-lo mais pontiagudo conforme tomam-se valores mais altos do mesmo.

Cada componente $i=1,2$ do somatório representa um dos modos do espectro, dessa maneira o modelo dado pela expressão (5.6) possibilita a representação de um estado de mar cruzado onde, por exemplo, uma componente é relativa a um swell e a outra relativa a um mar local. Este tipo de espectro direcional resultante da combinação de mares é chamado de bimodal.

O termo indicado por $A(s)$ é um fator de normalização para a área sob a curva de $\cos ^{2 s}$, sendo dado pela expressão (5.7).

$$
A(s)=\frac{2^{2 s-1} \Gamma^{2}(s+1)}{\pi \Gamma(2 s+1)}
$$

Ou seja, este termo é uma parte da função de distribuição de energia dada na expressão (5.3).

\section{Exemplos}

São apresentados a seguir alguns exemplos variando-se os valores dos parâmetros para o modelo dado por (5.6). Na tabela 6 são dados os valores adotados para os parâmetros dos espectros direcionais. 


\begin{tabular}{|c|c|c|c|c|c|c|c|c|c|c|}
\hline Exemplo & $H_{s_{1}}$ & $\omega_{m_{1}}$ & $\theta_{m_{1}}$ & $\lambda_{1}$ & $s_{1}$ & $H_{s_{2}}$ & $\omega_{m_{2}}$ & $\theta_{m_{2}}$ & $\lambda_{2}$ & $s_{2}$ \\
\hline $\mathbf{1}$ & 1,47 & $2 \pi / 5,35$ & $-\pi / 3$ & 1,3 & 85 & 0,63 & $2 \pi / 11,3$ & $\pi / 3$ & 2,2 & 85 \\
$\mathbf{2}$ & 2,02 & $2 \pi / 7,35$ & $-\pi / 4$ & 1,6 & 15 & 0,72 & $2 \pi / 9,3$ & 0 & 2,0 & 85 \\
$\mathbf{3}$ & 4,5 & $2 \pi / 10,3$ & 0 & 1,5 & 12 & 0 & 0 & 0 & 0 & 0 \\
\hline
\end{tabular}

Tabela 6: Valores adotados para os parâmetros nos exemplos do modelo de Hogben \& Cobb. $H_{s_{i}}$ em $[\mathrm{m}], \omega_{m_{i}}$ em $[\mathrm{rad} / \mathrm{s}]$ e $\theta_{m_{i}}$ em $[\mathrm{rad}]$.

Nas figuras de (26(a)) a (26(c)) tem-se as representações gráficas dos exemplos do espectro direcional dado pelo modelo (5.6). Pode-se perceber que o modelo também engloba o caso unimodal, dado no exemplo 3 ao se considerar os parâmetros de uma das componentes iguais a zero.

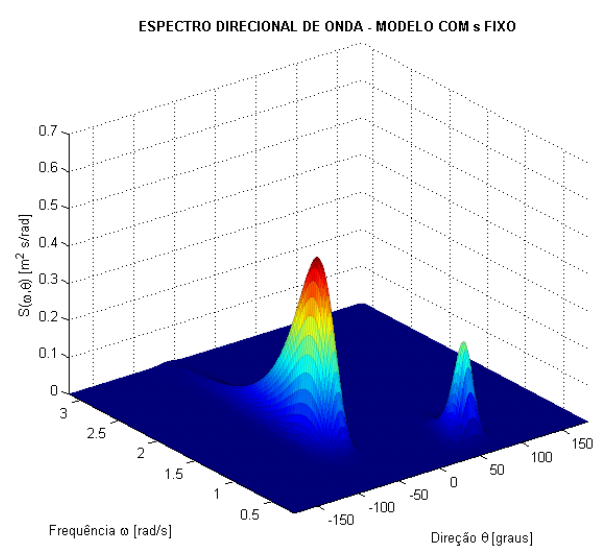

(a) Espectro direcional de onda - Exemplo 1.

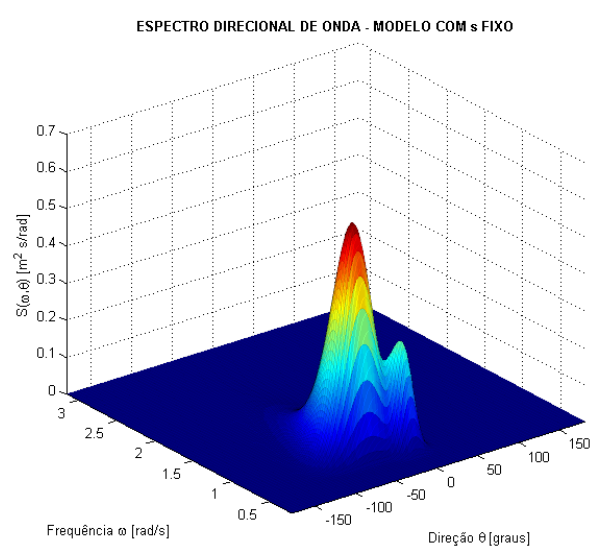

(b) Espectro direcional de onda - Exemplo 2.

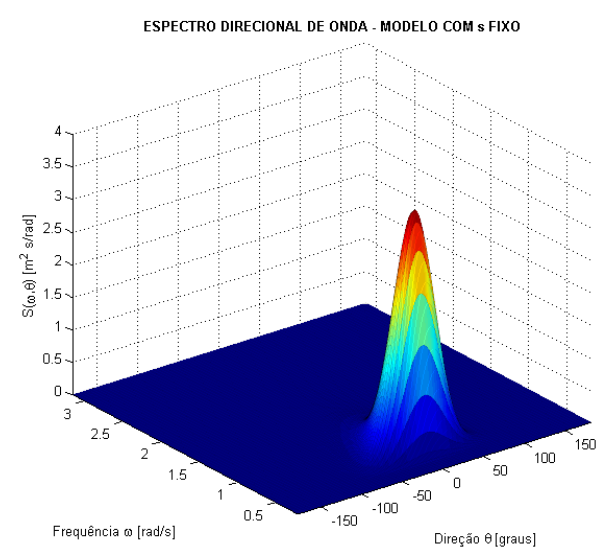

(c) Espectro direcional de onda - Exemplo 3 (caso unimodal).

Figura 26: Espectro teóricos dos exemplos apresentados na tabela 6.

Os exemplos mostrados levam em consideração o fato de que o modelo adota o parâmetro de espalhamento da energia, $s$, como sendo fixo. Entretanto, podem ser usados valores variáveis de $s$ de acordo com a frequência, sendo que, dessa forma, garante-se menos espalhamento nas direções relativas às frequências de pico do espectro, ou ainda próximas a estas. Segundo (GODA, 2000), a expressão (5.8) pode ser usada para relacionar o parâmetro $s$ às frequências de pico. 


$$
s= \begin{cases}s_{\max }\left(\omega / \omega_{p}\right)^{5}, & \text { para } \omega \leq \omega_{p} \\ s_{\max }\left(\omega / \omega_{p}\right)^{2,5}, & \text { para } \omega>\omega_{p} .\end{cases}
$$

onde $\omega$ é o intervalo de frequências e $\omega_{p}$ é a frequência de pico, ambos em $[\mathrm{rad} / \mathrm{s}]$, e $s_{\max }$ é uma constante de espalhamento de energia relacionada a um certo tipo de mar. Ainda segundo (GODA, 2000), alguns valores a serem adotados para $s_{\max }$ podem ser vistos na tabela 7 .

\begin{tabular}{|c|c|}
\hline$s_{\max }$ & Tipos de onda \\
\hline 10 & Ondas geradas pelo vento \\
25 & Swell com decaimento curto \\
75 & Swell com decaimento longo \\
\hline
\end{tabular}

Tabela 7: Valores típicos de $s_{\max }$ para diferentes situações de mar.

\section{Exemplos}

São apresentados a seguir alguns exemplos variando-se os valores dos parâmetros para o modelo dado por (5.6) utilizando-se a formulação (5.8) para o parâmetro $s$ e comparando-se com os exemplos 1 a 3 . Na tabela 8 são dados os valores adotados para os parâmetros dos espectros direcionais.

\begin{tabular}{|c|c|c|c|c|c|c|c|c|c|c|}
\hline Exemplo & $H_{s_{1}}$ & $\omega_{m_{1}}$ & $\theta_{m_{1}}$ & $\lambda_{1}$ & $s_{\max _{1}}$ & $H_{s_{2}}$ & $\omega_{m_{2}}$ & $\theta_{m_{2}}$ & $\lambda_{2}$ & $s_{\max _{2}}$ \\
\hline $\mathbf{4}$ & 1,47 & $2 \pi / 5,35$ & $-\pi / 3$ & 1,3 & 85 & 0,63 & $2 \pi / 11,3$ & $\pi / 3$ & 2,2 & 85 \\
$\mathbf{5}$ & 2,02 & $2 \pi / 7,35$ & $-\pi / 4$ & 1,6 & 15 & 0,72 & $2 \pi / 9,3$ & 0 & 2,0 & 85 \\
$\mathbf{6}$ & 4,5 & $2 \pi / 10,3$ & 0 & 1,5 & 12 & 0 & 0 & 0 & 0 & 0 \\
\hline
\end{tabular}

Tabela 8: Valores adotados para os parâmetros nos exemplos do modelo de Hogben \& Cobb utilizando a formulação com $s$ variável. $H_{s_{i}}$ em $[\mathrm{m}], \omega_{m_{i}}$ em $[\mathrm{rad} / \mathrm{s}]$ e $\theta_{m_{i}}$ em $[\mathrm{rad}]$.

Nas figuras 27(b), 28(b) e 29(b) tem-se as representações gráficas dos exemplos do espectro direcional dado pelo modelo (5.6) adotando-se a formulação (5.8). Para comparação, são apresentados também os espectros direcionais dos exemplos de 1 a 3 do modelo (5.6) com $s$ fixo. 


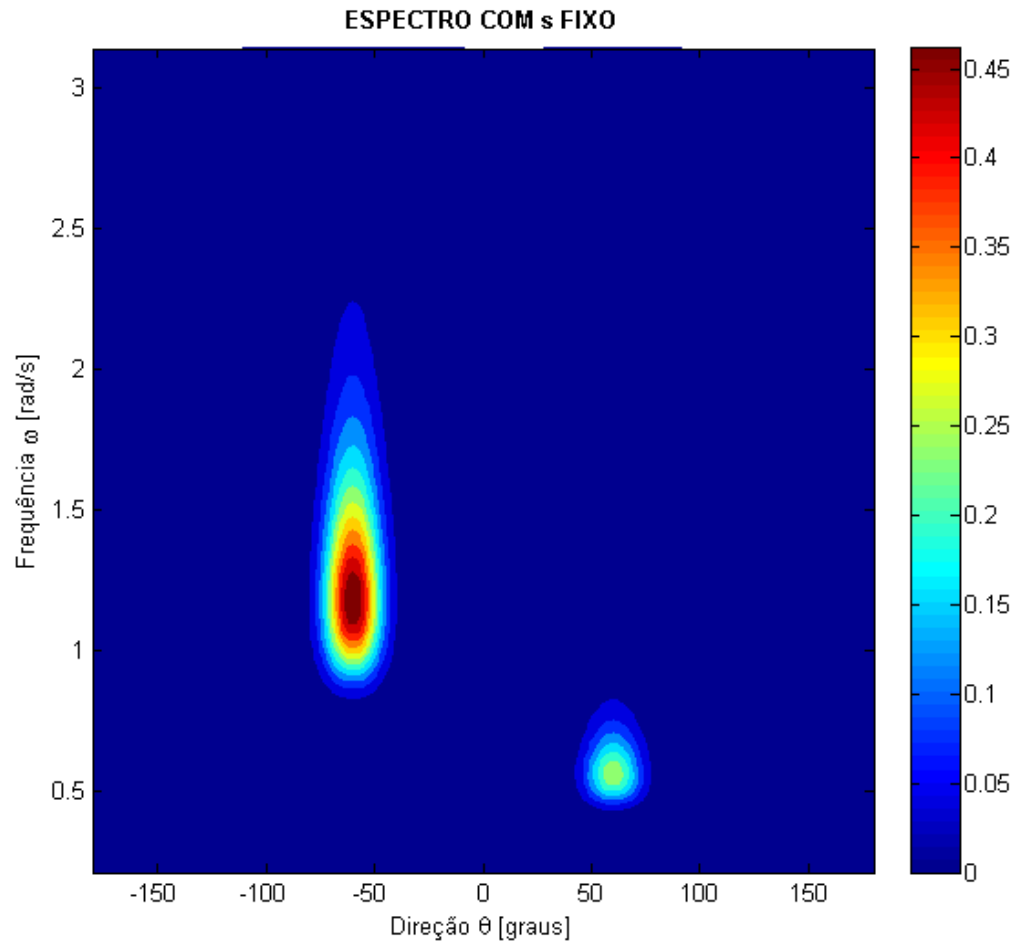

(a) Modelo com s fixo

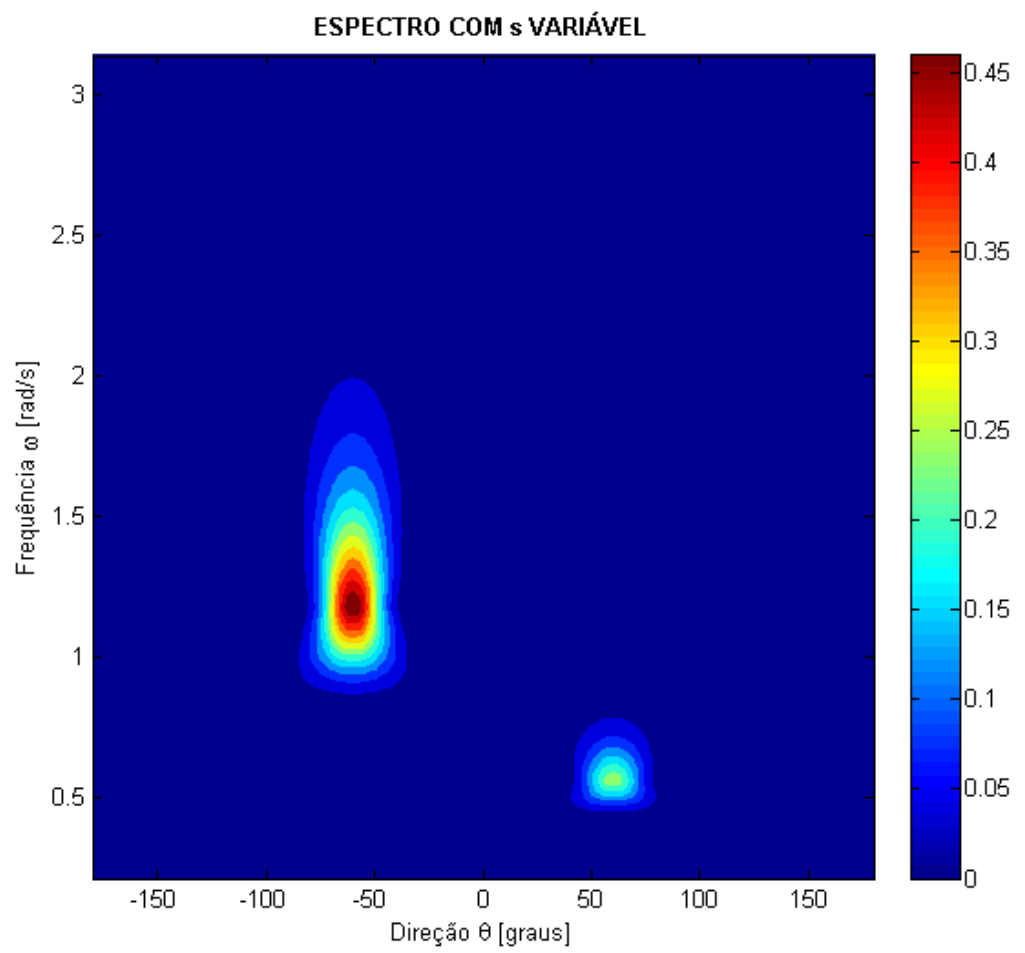

(b) Modelo com $s$ variável

Figura 27: Mapas do espectro direcional de onda para os casos com $s$ fixo e $s$ variável dos exemplos 1 e 4 . 


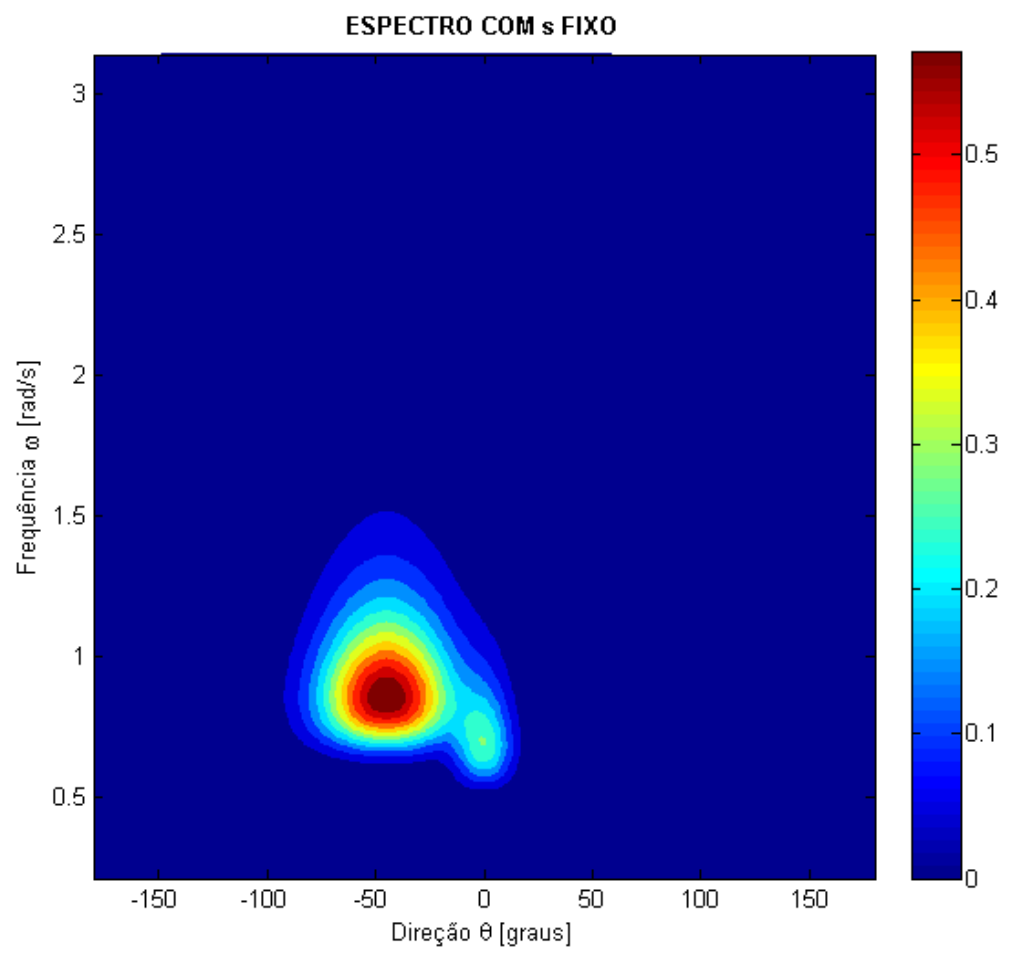

(a) Modelo com s fixo

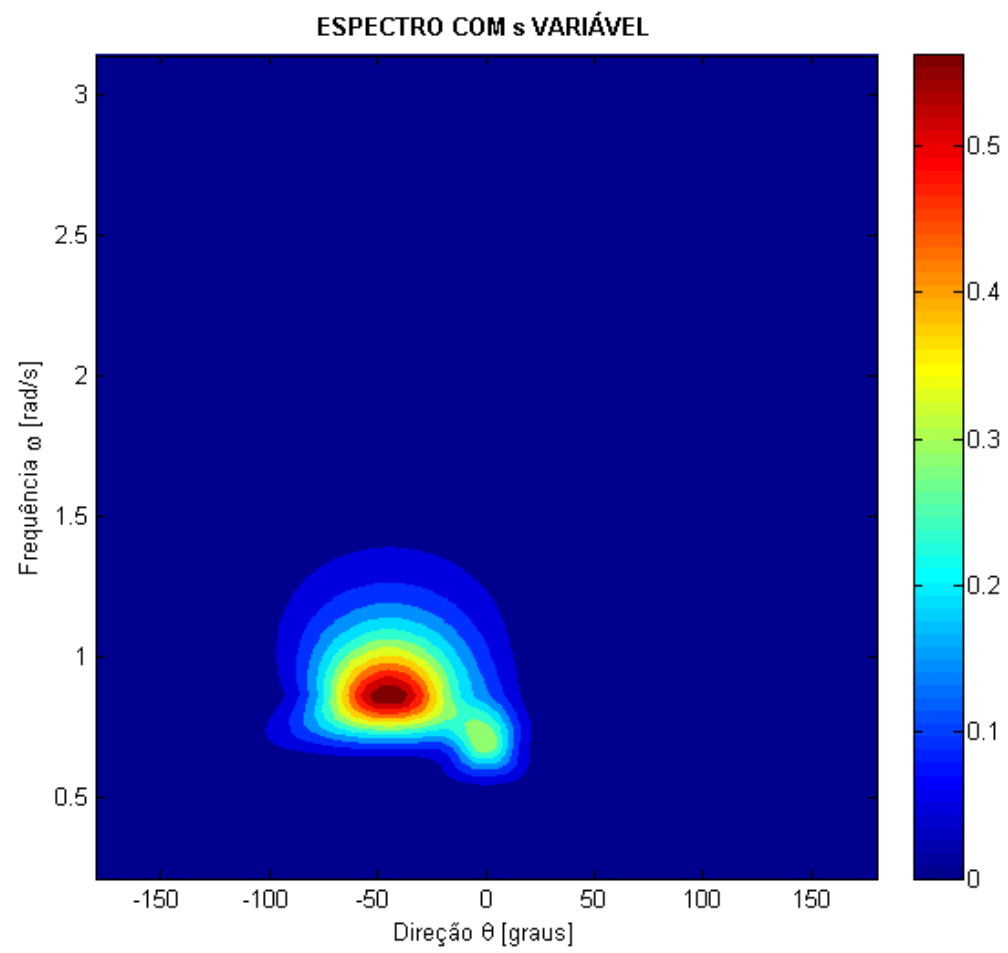

(b) Modelo com $s$ variável

Figura 28: Mapas do espectro direcional de onda para os casos com $s$ fixo e $s$ variável dos exemplos 2 e 5 . 


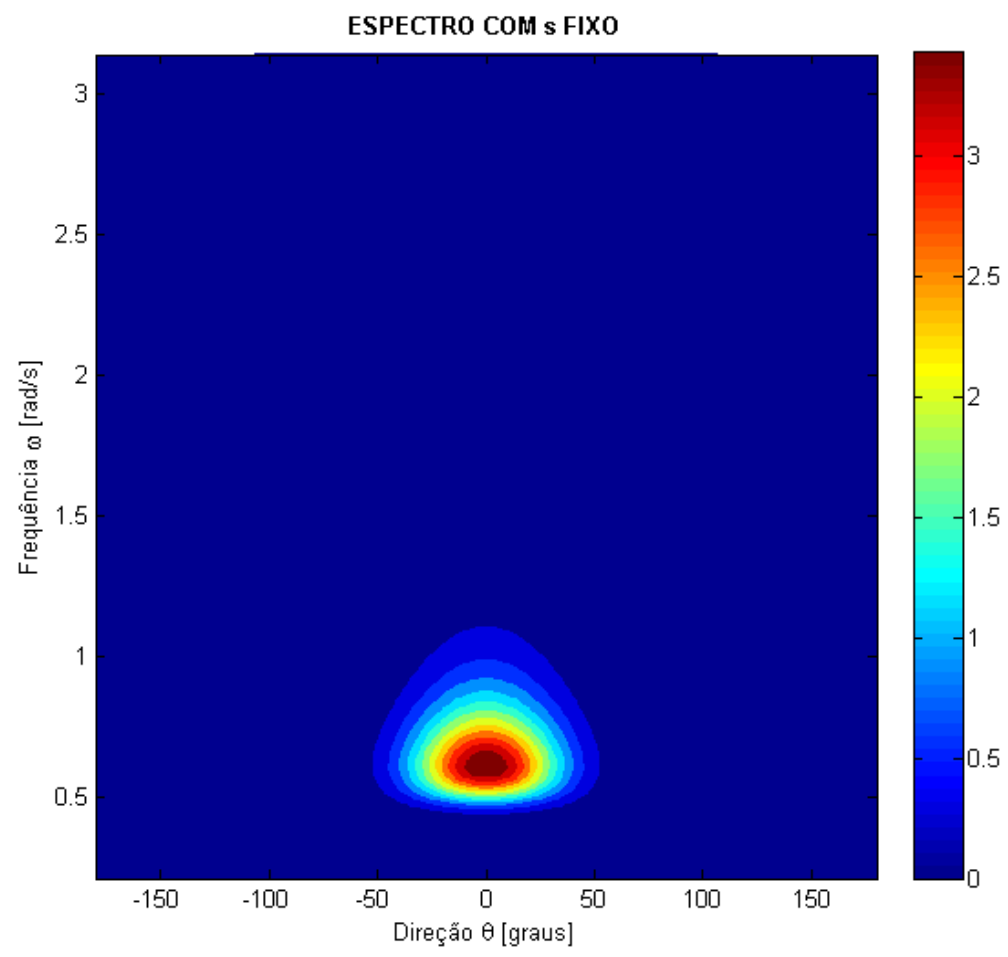

(a) Modelo com s fixo

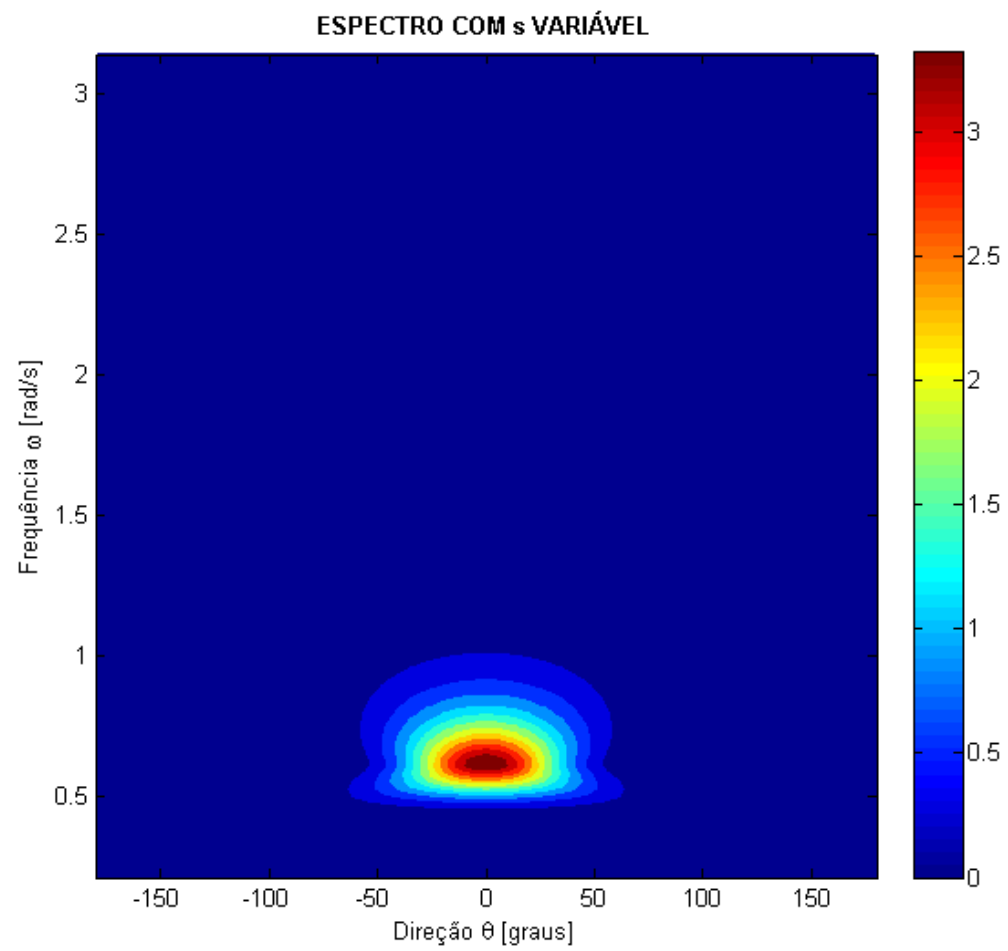

(b) Modelo com $s$ variável

Figura 29: Mapas do espectro direcional de onda para os casos com $s$ fixo e $s$ variável dos exemplos 3 e 6 . 
Integrando o espectro direcional de onda em todas as direções como na relação (5.2), encontra-se o espectro de potência, o qual é o mesmo para as duas variações do modelo, conforme pode ser observado na figura (30). Obviamente, uma vez que a função de espalhamento, dada por (5.1), não influencia a energia total contida no espectro, o espectro de potência se mantém igual em ambos os modelos de $s$ (fixo ou variável), alterando-se apenas a forma do espectro direcional.

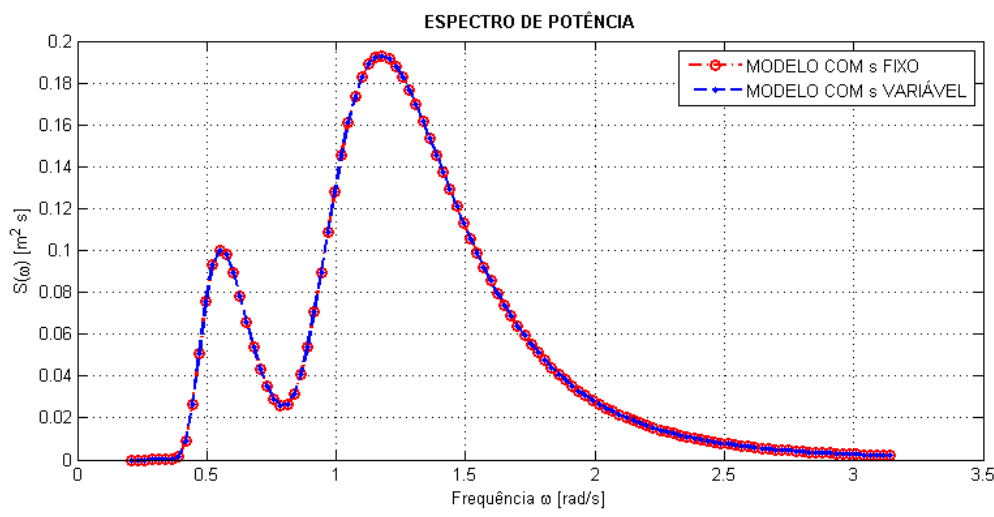

Figura 30: Espectro de potência com $s$ fixo e $s$ variável para os exemplos 1 e 4 .

O espectro de potência é uma ferramenta muito útil para a visualização do comportamento da energia contida no espectro direcional quando seus parâmetros não são conhecidos. Através deste é possível calcular estatísticas globais, como $H_{s}$ e $T_{p}$, ver (GODA, 2000). Embora estas estatísticas sejam importantes, não são suficientes no âmbito deste trabalho, dado que são necessárias estatísticas locais de cada pico no caso de um mar cruzado. Se for considerado um espectro unimodal, as estatísticas locais e globais são, obviamente, iguais. 


\subsection{Modelo JONSWAP}

O segundo modelo de espectro direcional utilizado neste trabalho é baseado no espectro de frequência conhecido na literatura como JONSWAP (Joint North Sea Wave Atmosphere Program), fazendo a composição deste com a função de distribuição de energia, como feito na expressão (5.1). O espectro de potência é descrito pela relação (5.9) a seguir, conforme (GODA, 2000):

$$
S(\omega)=2 \pi \beta_{J} \frac{H_{s}^{2} \omega_{p}^{4}}{\omega^{5}} \exp \left[\frac{-1,25 \omega_{p}^{4}}{\omega^{4}}\right] \gamma^{\exp \left[-\frac{\left(\omega-\omega_{p}\right)^{2}}{2 \sigma^{2} \omega_{p}^{2}}\right]}
$$

onde novamente $H_{s}$ é a altura significativa e $\omega_{p}$ é a frequência de pico relacionada ao período de pico, $T_{p}$. O parâmetro $\sigma$ define a largura do pico e $\beta_{J}$ é um parâmetro de forma, o qual, segundo (GODA, 2000), é calculado pela expressão (5.10).

$$
\beta_{J}=\frac{0,0624}{0,230+0,0336 \gamma-0,185(1,9+\gamma)^{-1}}(1,094-0,01915 \ln \gamma)
$$

O fator de amplificação de pico foi utilizado na literatura especializada durante muito tempo como sendo $\gamma=3,3$, o valor médio deste parâmetro para o Mar do Norte, podendo também variar entre 1 e 7, conforme (GODA, 2000). Neste estudo, o valor de $\gamma$ é sempre considerado no intervalo mencionado.

Embora esta seja uma formulação clássica na literatura, neste texto faremos uso de uma variação do espectro de potência dado em 5.9, a qual é apresentada na expressão (5.11). A diferença está apenas na constante multiplicadora, que varia levemente em relação ao modelo clássico. Esta escolha se baseia no fato de que a relação apresentada a seguir tem sido utilizada frequentemente para os mares da Bacia de Campos, tanto pela PETROBRAS quanto por pesquisadores da área de engenharia naval e oceanografia no Brasil.

$$
S(\omega)=2 \pi \alpha \frac{g^{2}}{\omega^{5}} \exp \left[\frac{-1,25 \omega_{p}^{4}}{\omega^{4}}\right] \gamma^{\exp \left[-\frac{\left(\omega-\omega_{p}\right)^{2}}{2 \sigma^{2} \omega_{p}^{2}}\right]}
$$

no qual $g$ é a aceleração da gravidade ao nível do mar e $\alpha$ é dado pela expressão (5.12). 


$$
\alpha=5,0609 \frac{H_{s}^{2} \omega_{p}^{4}}{(2 \pi)^{4}}(1-0,287 \ln \gamma)
$$

A largura do pico definida pelo parâmetro $\sigma$ é dada pela seguinte expressão:

$$
\sigma= \begin{cases}\sigma_{a}=0,07, & \text { para } \omega \leq \omega_{p} \\ \sigma_{b}=0,09, & \text { para } \omega>\omega_{p}\end{cases}
$$

Dessa maneira, o espectro direcional de onda (5.14) é obtido ao se multiplicar a expressão (5.11) pela parte direcional $D(\omega, \theta)$, dada por (5.3), e somando-se os dois modos.

\section{Definição 2:}

$$
S(\omega, \theta)=\frac{1}{4} \sum_{i=1}^{2} 2 \pi \alpha_{i} \frac{g^{2}}{\omega^{5}} A\left(s_{i}\right) \cos ^{2 s_{i}}\left(\frac{\theta-\theta_{m_{i}}}{2}\right) \exp \left[\frac{-1,25 \omega_{p_{i}}^{4}}{\omega^{4}}\right] \gamma_{i}^{\exp \left[-\frac{\left(\omega-\omega_{p_{i}}\right)^{2}}{2 \sigma_{i}^{2} \omega_{p_{i}}^{2}}\right]}
$$

Este modelo também pode sofrer a mesma variação apresentada na seção 5.3, expressão (5.8), através do uso do parâmetro $s$ como sendo uma função da frequência. 


\begin{tabular}{|c|c|c|c|c|c|c|c|c|c|c|}
\hline Exemplo & $H_{s_{1}}$ & $\omega_{m_{1}}$ & $\theta_{m_{1}}$ & $\gamma_{1}$ & $s_{1}$ & $H_{s_{2}}$ & $\omega_{m_{2}}$ & $\theta_{m_{2}}$ & $\gamma_{2}$ & $s_{2}$ \\
\hline $\mathbf{7}$ & 1,47 & $2 \pi / 5,35$ & $-\pi / 3$ & 1,0 & 85 & 0,63 & $2 \pi / 11,3$ & $\pi / 3$ & 4,0 & 85 \\
$\mathbf{8}$ & 2,02 & $2 \pi / 7,35$ & $-\pi / 4$ & 2,2 & 15 & 0,72 & $2 \pi / 9,3$ & 0 & 2,3 & 85 \\
$\mathbf{9}$ & 4,5 & $2 \pi / 10,3$ & 0 & 3,3 & 12 & 0 & 0 & 0 & 0 & 0 \\
\hline
\end{tabular}

Tabela 9: Valores adotados para os parâmetros nos exemplos do modelo JONSWAP. $H_{s_{i}}$ em $[\mathrm{m}], \omega_{p_{i}}$ em $[\mathrm{rad} / \mathrm{s}]$ e $\theta_{m_{i}}$ em $[\mathrm{rad}]$.

\begin{tabular}{|c|c|c|c|c|c|c|c|c|c|c|}
\hline Exemplo & $H_{s_{1}}$ & $\omega_{m_{1}}$ & $\theta_{m_{1}}$ & $\gamma_{1}$ & $s_{\max _{1}}$ & $H_{s_{2}}$ & $\omega_{m_{2}}$ & $\theta_{m_{2}}$ & $\gamma_{2}$ & $s_{\max _{2}}$ \\
\hline $\mathbf{1 0}$ & 1,47 & $2 \pi / 5,35$ & $-\pi / 3$ & 1,0 & 85 & 0,63 & $2 \pi / 11,3$ & $\pi / 3$ & 4,0 & 85 \\
$\mathbf{1 1}$ & 2,02 & $2 \pi / 7,35$ & $-\pi / 4$ & 2,2 & 15 & 0,72 & $2 \pi / 9,3$ & 0 & 2,3 & 85 \\
$\mathbf{1 2}$ & 4,5 & $2 \pi / 10,3$ & 0 & 3,3 & 12 & 0 & 0 & 0 & 0 & 0 \\
\hline
\end{tabular}

Tabela 10: Valores adotados para os parâmetros nos exemplos do modelo JONSWAP utilizando a formulação com $s$ variável. $H_{s_{i}}$ em $[\mathrm{m}], \omega_{p_{i}}$ em $[\mathrm{rad} / \mathrm{s}]$ e $\theta_{m_{i}}$ em $[\mathrm{rad}]$.

\section{Exemplos}

São apresentados nas figuras de $31(\mathrm{a})$ a $33(\mathrm{~b})$ alguns exemplos de espectros direcionais obtidos para os valores das tabelas 9 e 10 


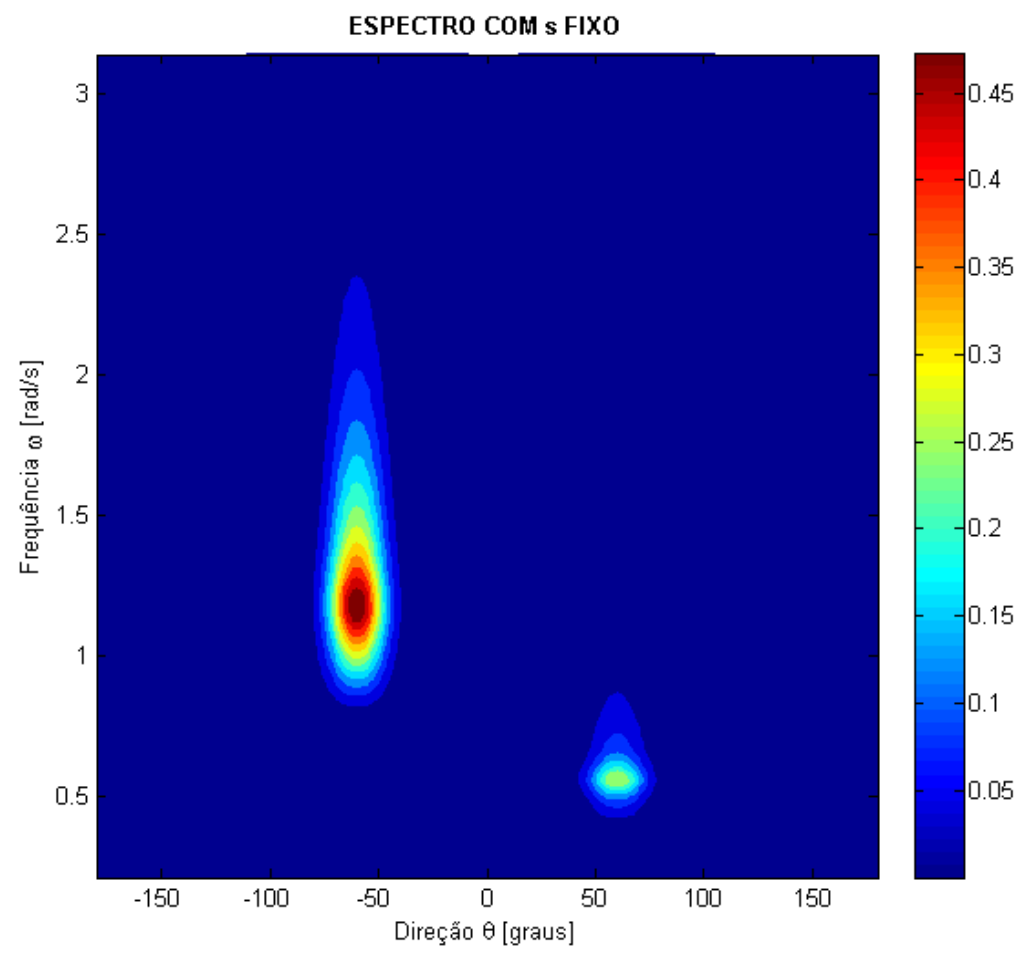

(a) Modelo com s fixo

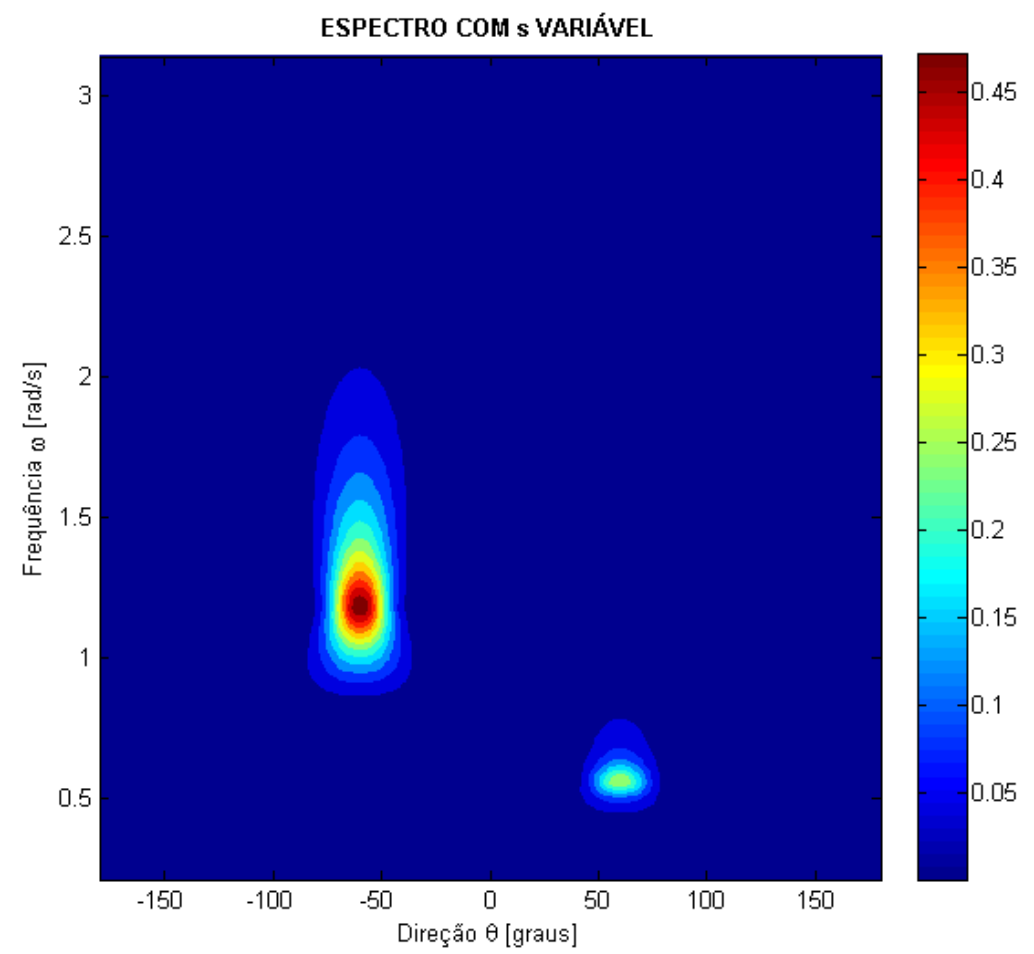

(b) Modelo com s variável

Figura 31: Mapas do espectro direcional de onda para os casos com $s$ fixo e $s$ variável dos exemplos 7 e 10 . 


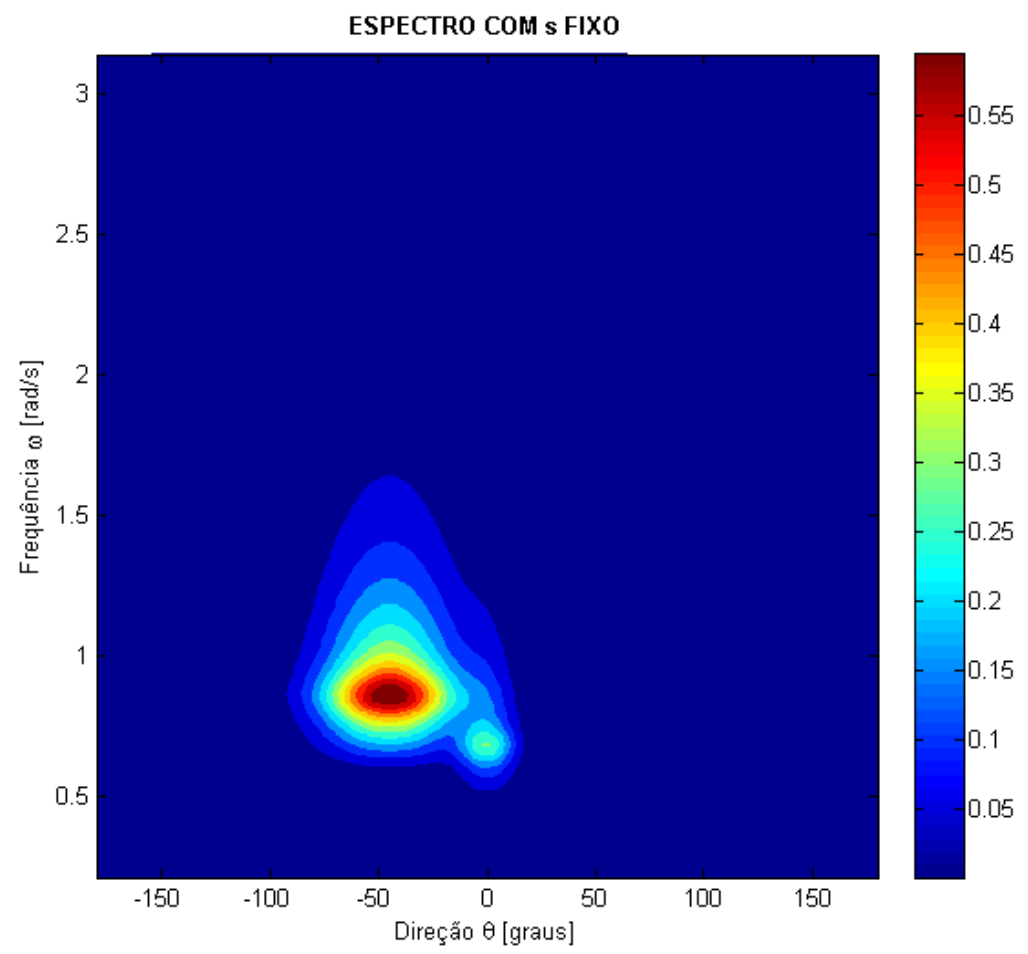

(a) Modelo com $s$ fixo

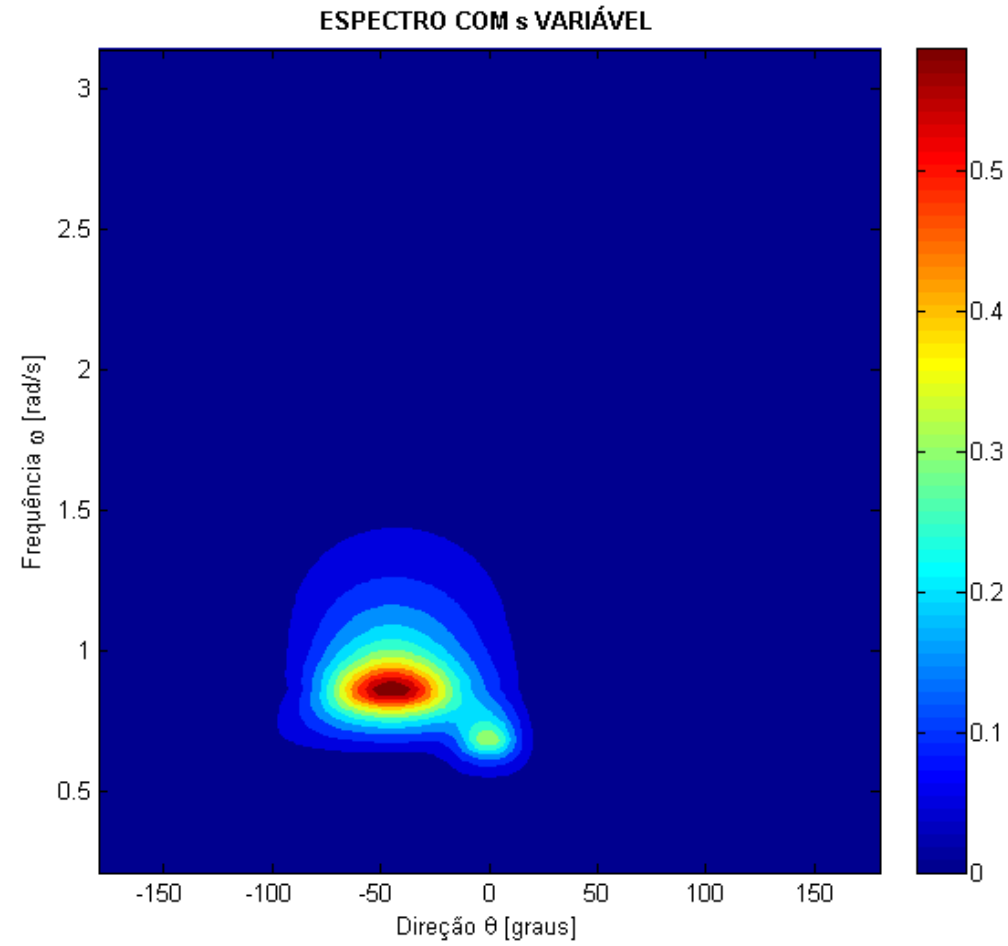

(b) Modelo com s variável

Figura 32: Mapas do espectro direcional de onda para os casos com $s$ fixo e $s$ variável dos exemplos 8 e 11 . 


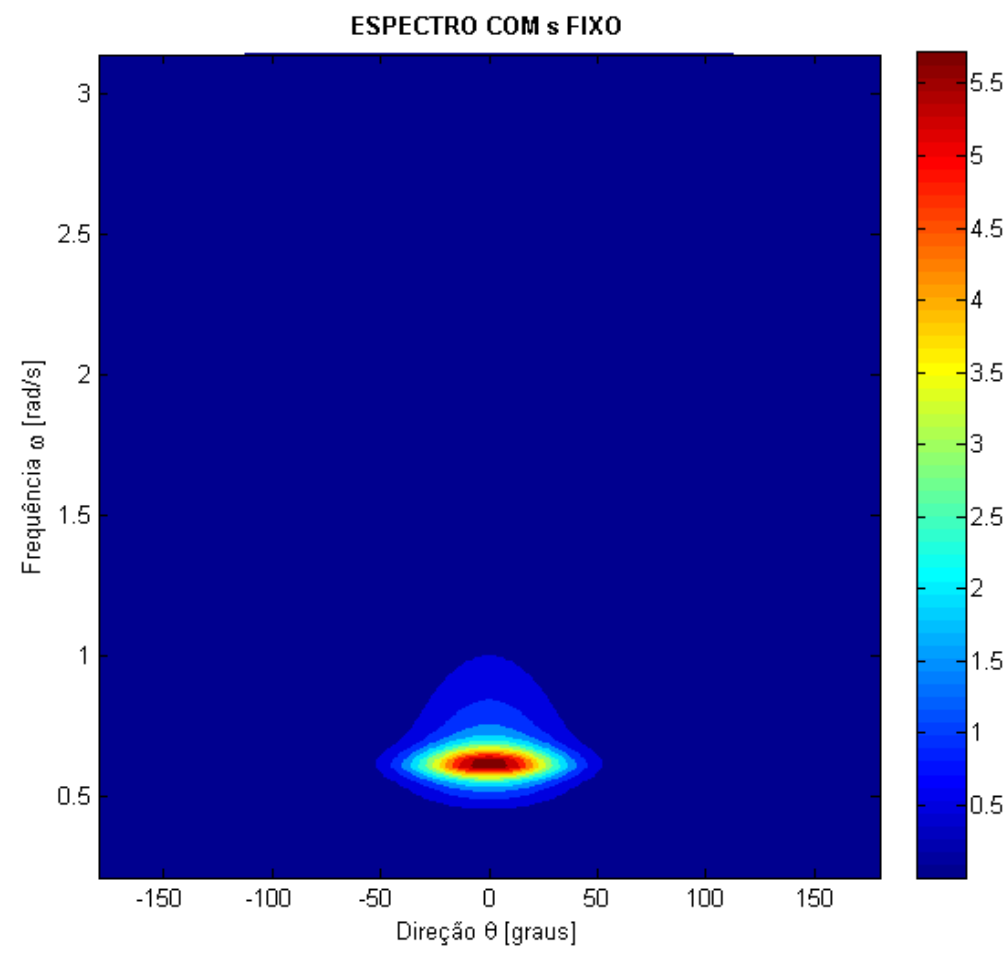

(a) Modelo com $s$ fixo

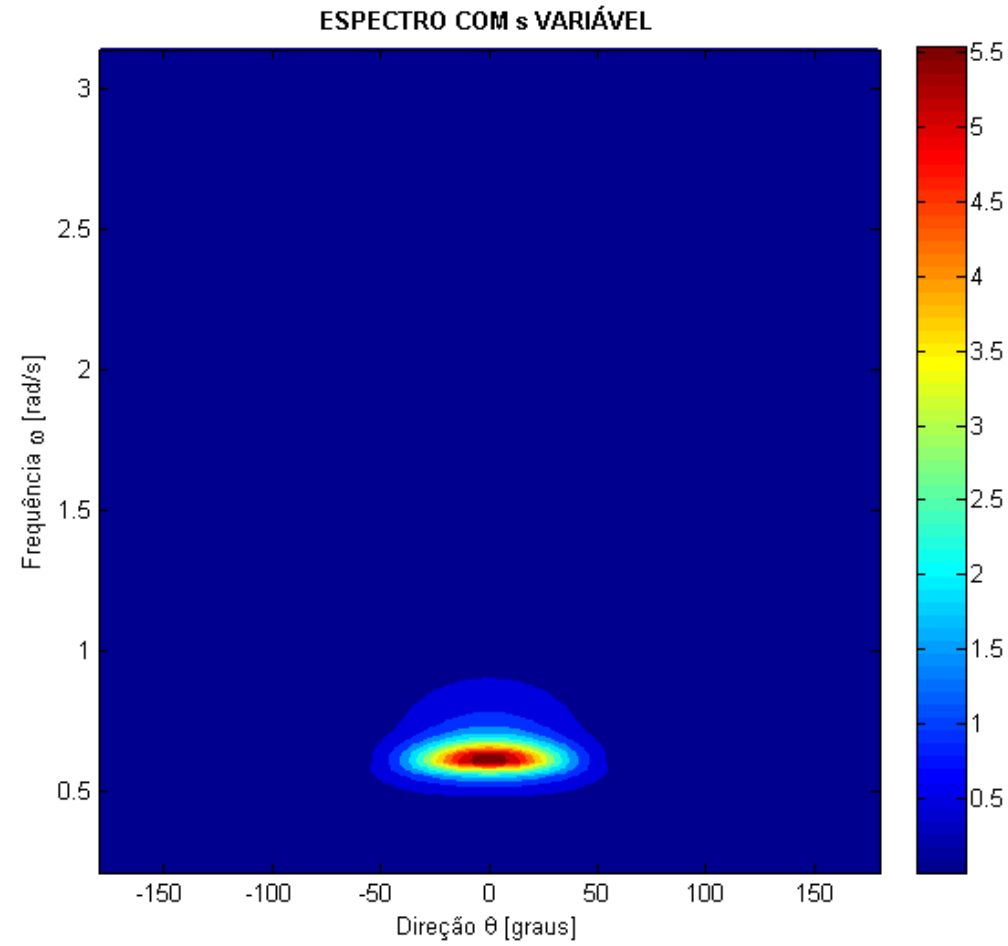

(b) Modelo com s variável

Figura 33: Mapas do espectro direcional de onda para os casos com $s$ fixo e $s$ variável dos exemplos 9 e 12 . 


\subsection{Critério de Bimodalidade}

O processo de estimação utilizado neste trabalho, como mencionado anteriormente, encontra valores para os parâmetros que descrevem o espectro direcional de energia de onda através de um modelo. Para a realização deste processo existe uma característica de extrema importância do espectro a ser estimado: o tipo de distribuição de sua energia.

Os espectros direcionais de onda podem ser divididos em duas categorias segundo a distribuição da energia:

- Unimodais, com apenas um pico de energia em uma dada frequência e direção média.

- Bimodais, com dois picos de energia, cada qual com uma direção média e frequência de pico próprias.

Esta definição é um tanto vaga, considerando-se que um pico poderia ser qualquer valor não nulo que existisse em um espectro. Entretanto, será considerado que deve existir energia significativa do segundo pico em relação ao de maior energia, para que o espectro seja tratado como sendo bimodal.

A questão da distinção entre espectros unimodais e bimodais é importante devido ao fato de ter sido verificado que a estimação de um espectro unimodal através de um modelo bimodal poderia não convergir para a solução esperada. Este fato foi constatado durante as primeiras estimativas realizadas neste trabalho, quando verificou-se que espectros unimodais, com parâmetros estimados através de modelos bimodais, possuiam valores incorretos para um segundo pico de energia. Esperava-se que, nestes casos, os valores dos parâmetros de um possível segundo pico fossem nulos ou com valores próximos a zero. Isto, entretanto, não ocorreu com nenhum espectro unimodal testado.

Portanto, devido aos erros encontrados nas estimações, ficou clara a necessidade da implementação de um método de classificação através da distribuição da energia do espectro, utilizando-se este critério para a tomada de decisão de qual modelo utilizar: unimodal ou bimodal, dado que ao serem feitas estimações através de modelos unimodais, para espectros também unimodais, foram obtidos bons resultados.

São apresentados a seguir 4 métodos de identificação da bimodalidade, os quais foram escoIhidos com base em uma pesquisa na bibliografia especializada. A principal referência é (PISCOPIA; PANIZZO; GIROLAMO, 2004), no qual é feita uma comparação entre os métodos aqui apresentados. Durante o estudo, esta comparação foi verificada com base em espectros gerados no tanque utilizados neste trabalho e em espectros gerados numericamente.

Nesta seção será adotada a notação $f$ para a frequência, dada em $[H z]$. 


\subsubsection{Espalhamento direcional}

O termo de espalhamento direcional $D(f, \theta)$ apresentado na seção 5.2, tem uma formulação proposta por (LONGUET-HIGGINS; CARTWRIGHT; SMITH, 1961) adotada frequentemente na literatura.

$$
D(f, \theta)=A(f) \cos ^{2 s}\left(\frac{\theta-\theta_{m}}{2}\right)
$$

onde $A(f)$ é uma constante de normalização, $\theta_{m}$ é a direção média de ondas e $s$ é o espaIhamento, ao qual podem ser feitas as mesmas considerações já mencionadas na seção 5.2

Um segundo modelo foi proposto por (MITSUYASU et al., 1975), dado na expressão a seguir:

$$
D(f, \theta)=G(s) \cos ^{2 s}\left(\frac{\theta-\theta_{m}}{2}\right)
$$

no qual:

$$
G(s)=\frac{1}{\pi} 2^{2 s-1} \frac{\Gamma^{2}(s+1)}{\Gamma(2 s+1)}
$$

É importante notar que neste caso a função de espalhamento dependerá da frequência $f$ somente no caso em que se adota o parâmetro $s$ como sendo também função de $f$, tal qual é feito na relação (5.8), caso contrário, dependerá apenas de $\theta_{m}$

Para ambos os modelos apresentados, uma maneira de se obter o espalhamento direcional é por meio da série de Fourier truncada nos dois primeiros termos dos coeficientes de Fourier, utilizando a série temporal das medições de onda, conforme (KUIK; VLEDDER; HOLTHUUSEN, 1988). Entretanto, neste texto será adotada outra abordagem, pois o espectro direcional é a única fonte de dados disponível.

Os 3 primeiros critérios necessitam de uma distribuição direcional da energia de onda, definida na expressão (5.15):

$$
D(\theta)=\int_{f_{\min }}^{f_{\max }} \frac{S(f, \theta)}{S(f)} d f
$$


Na qual $S(f)$ é dado pela expressão (5.2), apenas mantendo-se a relação $S(f)=2 \pi S(\omega)$.

Através da relação (5.15) acima, podem ser obtidos os quatro primeiros coeficientes de Fourier através das expressões (5.16) a (5.19) abaixo:

$$
\begin{aligned}
& a_{1}=\int_{0}^{2 \pi} D(\theta) \cos (\theta) d \theta \\
& a_{2}=\int_{0}^{2 \pi} D(\theta) \sin (\theta) d \theta \\
& b_{1}=\int_{0}^{2 \pi} D(\theta) \cos (2 \theta) d \theta \\
& b_{2}=\int_{0}^{2 \pi} D(\theta) \sin (2 \theta) d \theta
\end{aligned}
$$

Distribuições de probabilidade podem ser caracterizadas através do cálculos de seus momentos, os quais são geralmente considerados lineares. Entretanto, como a função de espalhamento direcional (ou distribuição direcional de energia) é definida sobre um círculo, devem ser considerados os equivalentes aos momentos lineares, os momentos circulares. Estes são definidos nas expressões (5.20), (5.21) e (5.22) a seguir, os quais podem ser calculados através dos coeficientes da série de Fourier truncada apresentados. Detalhes sobre as definições dos momentos circulares em analogia aos lineares podem ser encontrados em (KUIK; VLEDDER; HOLTHUUSEN, 1988).

$$
\begin{gathered}
m_{1}=\int_{0}^{2 \pi} D(\theta) \cos (\theta-\bar{\theta}) d \theta=\sqrt{a_{1}^{2}+b_{1}^{2}} \\
m_{2}=\int_{0}^{2 \pi} D(\theta) \cos [2(\theta-\bar{\theta})] d \theta=a_{2} \cos (2 \bar{\theta})+b_{2} \sin (2 \bar{\theta}) \\
n_{2}=\int_{0}^{2 \pi} D(\theta) \sin [2(\theta-\bar{\theta})] d \theta=b_{2} \cos (2 \bar{\theta})+a_{2} \sin (2 \bar{\theta})
\end{gathered}
$$


onde $\bar{\theta}=\arctan \left[b_{1} / a_{1}\right]$.

Fazendo uso dos parâmetros apresentados, podem ser definidos os 3 primeiros critérios de bimodalidade, propostos respectivamente por (KOBUNE; SASAKI; HASHIMOTO, 1985) , (KUIK; VLEDDER; HOLTHUUSEN, 1988) e (BESNARD; BENOIT, 1994).

O $4^{\circ}$ critério apresentado, proposto por (PISCOPIA; PANIZZO; GIROLAMO, 2004), não necessita dos parâmetros apresentados acima, pois é baseado apenas no cálculo de direções de energia e de fluxo de energia.

\subsubsection{Critério proposto por (KOBUNE; SASAKI; HASHIMOTO, 1985)}

Este critério utiliza um parâmetro $\Gamma$, chamado de long-crestedness e um segundo chamado ângulo médio de espalhamento da energia, $\theta_{k}$, o qual foi inicialmente proposto por (LONGUETHIGGINS; CARTWRIGHT; SMITH, 1961). Ambos são apresentados a seguir:

$$
\begin{gathered}
\Gamma=\sqrt{\frac{1-\sqrt{a_{2}^{2}+b_{2}^{2}}}{1+\sqrt{a_{2}^{2}+b_{2}^{2}}}} \\
\theta_{k}=\arctan \left[\frac{\sqrt{0,5 b_{1}^{2}\left(1+a_{2}\right) a_{1} b_{1} b_{2}+0,5 a_{1}^{2}\left(1-a_{2}\right)}}{a_{1}^{2}+b_{1}^{2}}\right]
\end{gathered}
$$

Os valores destes parâmetros são definidos, respectivamente, nos intervalos $[0 ; 1]$ e $[0 ; \pi / 2]$, sendo que ambos assumem valor zero para o caso de espectros com ondas em uma única direção e, $\Gamma=1$ e $\theta_{k}=p i / 2$ para o caso em que os picos de energia estão posicionados em direções opostas.

Os parâmetros utilizados neste critério, assim como no anterior, definem a forma da distribuição de energia do espectro. Dessa maneira, definindo-se um plano cartesiano com eixos $\theta_{k}$ e $\Gamma$, as regiões unimodais e bimodais são separadas pela curva $\Gamma_{l i m}$, ajustada pelo seguinte polinômio:

$$
\Gamma_{l i m}=a_{6} \theta_{k}^{6}+a_{5} \theta_{k}^{5}+a_{4} \theta_{k}^{4}+a_{3} \theta_{k}^{3}+a_{2} \theta_{k}^{2}+a_{1} \theta_{k}^{1}+a_{0}
$$


no qual tem-se, $a_{6}=-3,9193 \times 10^{-11}, a_{5}=7,5939 \times 10^{-9}, a_{4}=-6,2946 \times 10^{-7}$, $a_{3}=2,6708 \times 10^{-5}, a_{2}=-5,7428 \times 10^{-4}, a_{1}=2,2660 \times 10^{-2}$ e $a_{0}=-4,2152 \times 10^{-4}$.

Assim, quando $\theta_{k}>65^{\circ}$ a distribuição de energia direcional é sempre bimodal. Entretanto, quando $\theta_{k} \leq 65^{\circ}$ a distribuição será bimodal se $\Gamma<\Gamma_{\text {lim }}$, e unimodal caso contrário. As regiões deste critério são ilustradas pela figura 34 .

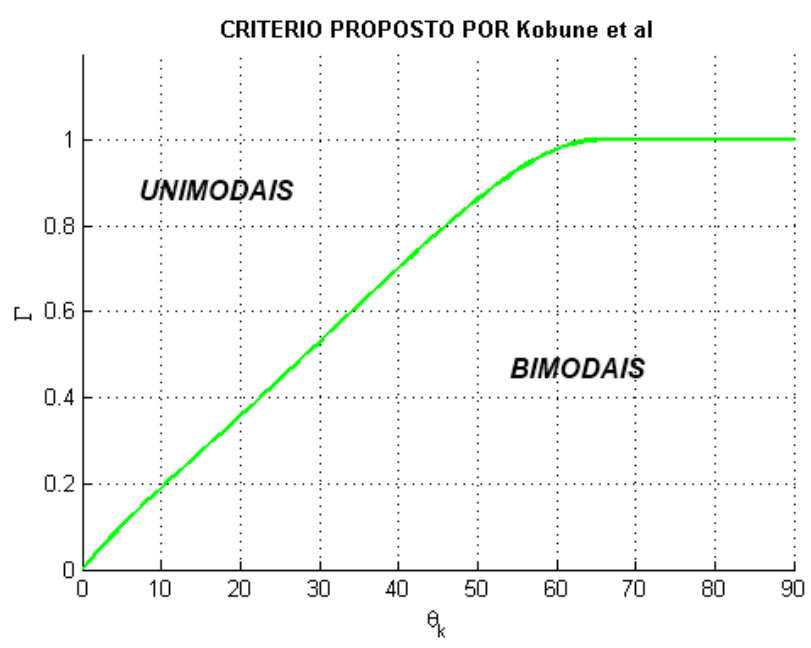

Figura 34: Esquema ilustrativo: Critério proposto por (KOBUNE; SASAKI; HASHIMOTO, 1985).

\subsubsection{Critério proposto por (KUIK; VLEDDER; HOLTHUUSEN, 1988)}

Este critério faz uso dos conceitos de skewness $(\gamma)$ e kurtosis $(\delta)$, normalmente definidos para uma distribuição de probabilidade. Neste caso, estes parâmetros são utilizados para a distribuição direcional de energia dada por (5.15), o que é feito com base na semelhança entre esta e uma distribuição de probabilidades. Os detalhes de como estes parâmetros podem ser definidos para uma distribuição direcional de energia definida sobre um círculo são encontrados em (KUIK; VLEDDER; HOLTHUUSEN, 1988), entretanto vale destacar que as propriedades 1 e 2 apresentadas na seção 5.2 são as semelhanças consideradas entre uma distribuição direcional de energia e uma de probabilidades.

O parâmetro skewness $(\gamma)$ é definido na Teoria de Probabilidade como sendo uma medida de assimetria da distribuição de probabilidade em relação à média, sendo que o valor desta medida pode ser positivo, negativo ou até mesmo indefinido. Qualitativamente, um valor negativo indica que a cauda esquerda de uma distribuição é mais alongada que a direita, sendo que no caso inverso, tem-se um valor positivo de $\gamma$. Para uma distribuição com tendência relativamente simétrica com relação à média, $\gamma$ assume valor zero, embora isso não implique em uma distribuição exatamente simétrica.

Também da Teoria de Probabilidade, utiliza-se o conceito de kurtosis $(\delta)$ da distribuição direcional de energia. Novamente fazendo-se a analogia com uma distribuição de probabilidades, este parâmetro é uma medida do quão alto é o pico de uma distribuição, sendo definido como 
uma forma normalizada do quarto momento central desta distribuição.

Estes dois parâmetros são definidos nas expressões (5.25) e (5.26) a seguir, em termos dos momentos circulares apresentados anteriormente:

$$
\begin{gathered}
\gamma=\frac{-n_{2}}{\sqrt{0,125\left(1-m_{2}\right)^{3}}} \\
\delta=\frac{6-8 m_{1}+2 m_{2}}{4\left(1-m_{1}\right)^{2}}
\end{gathered}
$$

Dado que estes parâmetros definem a forma da distribuição direcional de energia, é natural utilizar pares de valores destes parâmetros para definir se um espectro é bimodal ou unimodal, definindo regiões através destes pares. O critério estabelece que dado um sistema cartesiano com abcissa $\gamma$ e ordenada $\delta$, podem ser definidas as seguintes regiões para a análise:

$$
\delta= \begin{cases}2+|\gamma| & \text { para }|\gamma| \leq 4 \\ 6 & \text { para }|\gamma|>4\end{cases}
$$

Assim, quando $|\gamma|>4$, a distribuição direcional de energia é bimodal se $\delta \leq 6$, caso contrário é unimodal. Se $|\gamma| \leq 4$, a distribuição direcional de energia é bimodal se $\delta \leq 2+|\gamma|$, e unimodal caso contrário. Na figura 35 tem-se um esquema ilustrativo destas regiões.

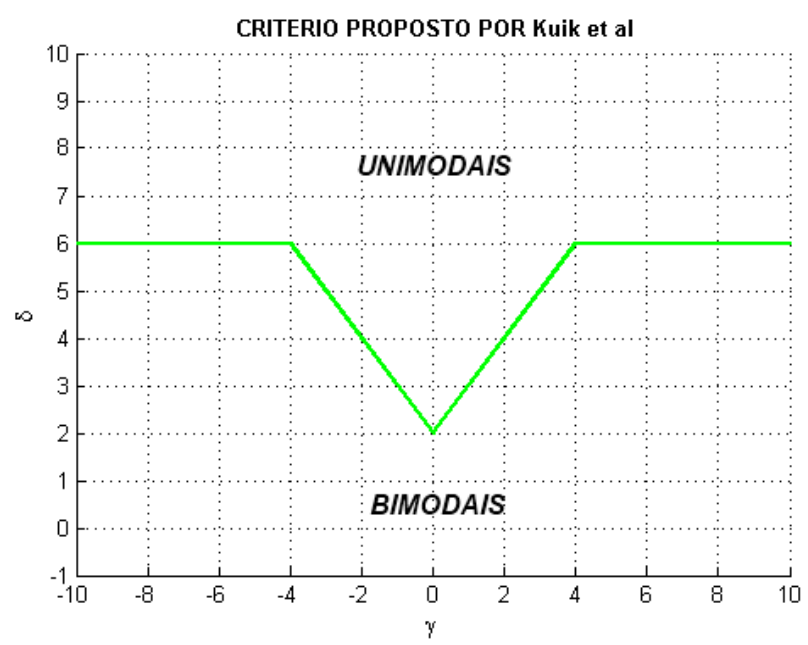

Figura 35: Esquema ilustrativo: Critério proposto por (KUIK; VLEDDER; HOLTHUUSEN, 1988). 


\subsubsection{Critério proposto por (BESNARD; BENOIT, 1994)}

Para este critério, é necessária a definição dos seguintes dois parâmetros:

$$
r=\frac{\sqrt{a_{2}^{2}+b_{2}^{2}}}{\sqrt{a_{1}^{2}+b_{1}^{2}}}
$$

e

$$
\Theta=\min \left\{\left|\bar{\theta}-\theta_{p}\right|,\left|\bar{\theta}-\theta_{p}-180\right|\right\}
$$

onde $\bar{\theta}=\arctan \left[b_{1} / a_{1}\right]$ é a direção média e $\theta_{p}=0,5 \arctan \left[b_{2} / a_{2}\right]$ é a direção principal.

O parâmetro $r$ é uma razão entre as amplitudes das duas primeiras componentes da série de Fourier. Já o parâmetro $\Theta$ é uma medida da abertura entre os picos destas duas componentes. Segundo (BESNARD; BENOIT, 1994), supõe-se que casos de espectros bimodais sejam caracterizados por altos valores de ambos os parâmetros, enquanto os casos unimodais tendem a ter valores baixos para os mesmos. Assim, definindo-se um plano cartesiano com eixos $r$ e $\Theta$, podem ser delimitadas as seguintes regiões de acordo com a separação de valores altos e baixos:

$$
\begin{cases}r=10 & \text { para } \Theta \leq 5^{\circ} \\ \Theta=5^{\circ} & \text { para } 0,1 \leq r \leq 10 \\ r=0,1 & \text { para } \Theta>5^{\circ}\end{cases}
$$

Desta maneira, o critério estabelece que quando $r>10$, a distribuição direcional de energia é sempre bimodal. No caso em que $r<0,1$, a distribuição é unimodal. Considerando-se o caso intermediário, com $0,1 \leq r \leq 10$, a distribuição direcional é unimodal se $\Theta \leq 5^{\circ}$ e bimodal caso contrário. Podem ser vistas na figura 36 um esquema ilustrativo destas regiões. 


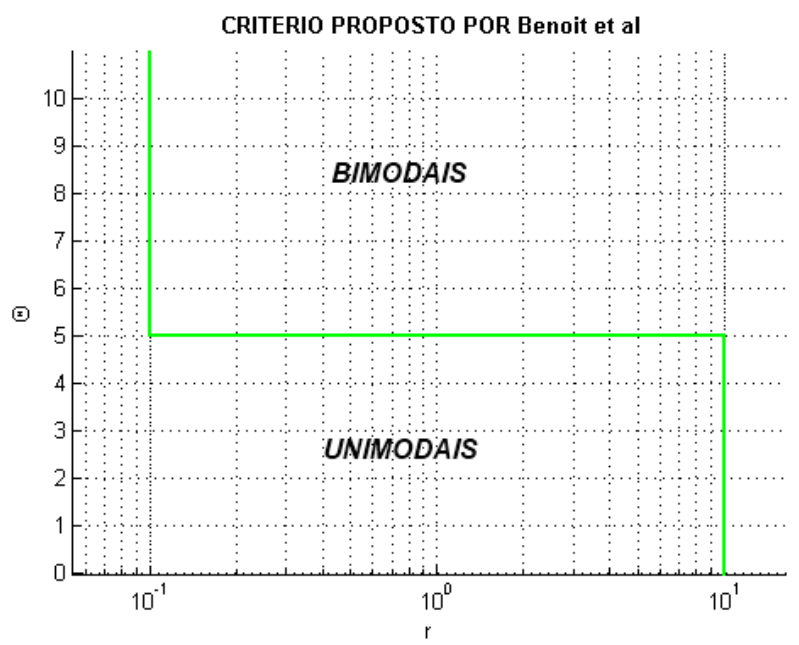

Figura 36: Esquema ilustrativo: Critério proposto por (BESNARD; BENOIT, 1994).

\subsubsection{Critério proposto por (PISCOPIA; PANIZZO; GIROLAMO, 2004)}

O critério foi proposto em (PISCOPIA; PANIZZO; GIROLAMO, 2004), sendo este o método utilizado neste trabalho para a classificação da modalidade dos mares. Optou-se pelo uso deste método através da comparação com os outros apresentados e por meio de uma pesquisa bibliográfica. Observou-se que embora este critério não tenha sido capaz de identificar a bimodalidade de todos os espectros bimodais testados, foi o único capaz de identificar com precisão todos os espectros unimodais. Este fato é importante pois, tomou-se como aceitável a estimação por um modelo unimodal de um espectro já sabido bimodal, dado que muitas vezes o segundo pico de energia pode ser desprezado sem grande prejuízo para a energia total do espectro.

Um dos parâmetros utilizados é o cálculo clássico da direção média $\theta_{m}^{L}$, proposto por (LONGUETHIGGINS, 1957) e dado na expressão (5.29) a seguir:

$$
\theta_{m}^{L}=\arctan \left[\frac{\int_{0}^{\infty} \int_{0}^{2 \pi} S(f, \theta) \sin \theta d \theta d f}{\int_{0}^{\infty} \int_{0}^{2 \pi} S(f, \theta) \cos \theta d \theta d f}\right]
$$

Outra formulação de uma direção relacionada à energia do espectro, proposta por (GIROLAMO, 2004) mais recentemente, é dada pela relação (5.30) abaixo:

$$
\theta_{m}^{D}=\arctan \left[\frac{\int_{0}^{\infty} \int_{0}^{2 \pi} C_{g}(f) S(f, \theta) \sin \theta d \theta d f}{\int_{0}^{\infty} \int_{0}^{2 \pi} C_{g}(f) S(f, \theta) \cos \theta d \theta d f}\right]
$$

onde $C_{g}(f)$ é a velocidade de grupo (da onda linear de frequência $f$ ), sendo utilizada a relação $C_{g}(f)=g /(4 \pi f)$ quando se considera águas profundas. 
Fisicamente, o parâmetro $\theta_{m}^{L}$ representa a direção média da energia contida no espectro direcional e o parâmetro $\theta_{m}^{D}$ representa a direção média do fluxo de energia deste mesmo espectro. O critério estabelece que se o índice dado por $\chi=\left|\theta_{m}^{L}-\theta_{m}^{D}\right|$ é tal que $\chi \leq \chi_{\text {lim }}$, então o espectro direcional de onda é considerado unimodal (assim como a respectiva distribuição direcional de energia), caso contrário, o espectro é considerado bimodal. Assim, o critério se baseia na diferença absoluta entre as direções médias da energia e do fluxo da mesma, indicando, através disso, uma tendência da modalidade espectral.

Em teoria, espectros unimodais devem ter $\chi=0$ e bimodais, $\chi>0$, entretanto para mares reais isso não é verdade. Nesta mesma referência é sugerido o valor de $\chi_{\text {lim }}=3^{\circ}$, sendo este obtido pelos autores considerando-se dados do Italian Sea Wave monitoring Network (SWaN). Sabendo que os mares cruzados são, no geral, bem ajustados por modelos bimodais, supondo uma distribuição não muito desigual da energia dentre os picos, ao calibrar o valor limitante para os mares da costa brasileira, serão consideradas mais fontes de estatísticas bimodais, pois mais mares cruzados serão modelados pela formulação bimodal. Assim, um estudo posterior importante seria a calibração de $\chi_{l i m}$.

É importante também destacar que este critério possui limitações na identificação de espectros bimodais nos casos em que ambos os picos possuem mesma direção, direções exatamente opostas ou ainda, as mesmas frequências de pico. Embora estes sejam fatores importantes do ponto de vista teórico, dificilmente ocorrem na prática, sendo portanto desconsiderados dos espectros possíveis sob os quais a unidade estará sujeita.

\subsubsection{Comparação dos critérios}

Os métodos apresentados foram aplicados aos espectros direcionais medidos por meio de wave-probes nos ensaios em escala. Estes espectros têm os valores de seus parâmetros teóricos apresentados nas tabelas 11 e 12 abaixo, separadas em espectros unimodais e bimodais, respectivamente.

Representados nos ensaios estão 4 mares unimodais e 5 bimodais, ensaiados em duas escalas: 1:48 e 1:70. A nomenclatura com prefixo W06-10 é referente aos espectros bimodais na escala 1:48, enquanto que W06-20 é relativo aos bimodais em escala 1:70, ou seja, os 10 espectros aqui apresentados são os mesmos espectros reais ensaiados em escalas diferentes. Da mesma maneira tem-se o prefixo W07-10 denotando espectros unimodais em escala 1:48 e W07-20 relativo aos unimodais em escala 1:70. Alturas significativas, $H_{s_{i}}$, são dadas na escala real, em metros. Períodos de pico, $T_{p_{i}}$, em segundos e direções médias, $\theta_{m_{i}}$, em graus.

Na tabela 13 a seguir, é apresentada a classificação dos espectros direcionais ensaiados segundo cada critério de bimodalidade. 


\begin{tabular}{|c|c|c|c|c|c|}
\hline \multicolumn{6}{|c|}{ ESPECTROS UNIMODAIS - ESCALA REAL } \\
\hline ESPECTRO & $H_{s_{1}}$ & $T_{p_{1}}$ & $\gamma_{1}$ & $s_{1}$ & $\theta_{m_{1}}$ \\
\hline W07-10102 & 4.48 & 10.29 & 1.51 & $\infty$ & 0 \\
W07-10202 & 7.77 & 15.31 & 1.7 & $\infty$ & 0 \\
W07-10301 & 4.48 & 10.29 & 1.51 & 60 & 0 \\
W07-10401 & 4.48 & 10.29 & 1.51 & 12 & 0 \\
W07-20104 & 4.51 & 10.32 & 1.51 & $\infty$ & 0 \\
W07-20203 & 7.82 & 15.38 & 1.7 & $\infty$ & 0 \\
W07-20301 & 4.51 & 10.32 & 1.51 & 60 & 0 \\
W07-20401 & 4.51 & 10.32 & 1.51 & 12 & 0 \\
\hline
\end{tabular}

Tabela 11: Valores teóricos dos espectros direcionais unimodais gerados no ensaio em escala.

\begin{tabular}{|c|c|c|c|c|c|c|c|c|c|c|}
\hline \multicolumn{10}{|c|}{ ESPECTROS BIMODAIS - ESCALA REAL } \\
\hline ESPECTRO & $H_{s_{1}}$ & $T_{p_{1}}$ & $\gamma_{1}$ & $s_{1}$ & $\theta_{m_{1}}$ & $H_{s_{2}}$ & $T_{p_{2}}$ & $\gamma_{2}$ & $s_{2}$ & $\theta_{m_{2}}$ \\
\hline W06-10109 & 1.47 & 11.55 & 1.4 & 85 & 150 & 0.98 & 6.61 & 0.9 & 85 & 210 \\
W06-10200 & 2.03 & 7.28 & 1.6 & 85 & 150 & 0.7 & 9.29 & 2 & 85 & 195 \\
W06-10300 & 1.47 & 5.35 & 1.3 & 85 & 150 & 0.63 & 11.29 & 2.2 & 85 & 210 \\
W06-10400 & 2.03 & 11.46 & 1.5 & 85 & 150 & 0.98 & 11.46 & 1.2 & 85 & 210 \\
W06-10500 & 1.47 & 11.55 & 1.4 & 85 & 150 & 0.98 & 6.61 & 0.9 & 85 & 150 \\
W06-20100 & 1.49 & 11.57 & 1.4 & 85 & 150 & 1.01 & 6.65 & 0.9 & 85 & 210 \\
W06-20200 & 2.02 & 7.34 & 1.6 & 85 & 150 & 0.72 & 9.28 & 2 & 85 & 195 \\
W06-20300 & 1.49 & 5.33 & 1.3 & 85 & 150 & 0.62 & 11.29 & 2.2 & 85 & 210 \\
W06-20400 & 2.02 & 11.43 & 1.5 & 85 & 150 & 1.01 & 11.43 & 1.2 & 85 & 210 \\
W06-20500 & 1.49 & 11.57 & 1.4 & 85 & 150 & 1.01 & 6.65 & 0.9 & 85 & 150 \\
\hline
\end{tabular}

Tabela 12: Valores teóricos dos espectros direcionais bimodais gerados no ensaio em escala. 


\begin{tabular}{|c|c|c|c|c|}
\hline ESPECTRO & Kobune-et-al & Kuik-et-al & Benoit-et-al & Piscopia-et-al \\
\hline W06-10109 & BIMODAL & BIMODAL & UNIMODAL & UNIMODAL \\
W06-10200 & BIMODAL & BIMODAL & UNIMODAL & UNIMODAL \\
W06-10300 & BIMODAL & BIMODAL & UNIMODAL & BIMODAL \\
W06-10400 & BIMODAL & BIMODAL & UNIMODAL & UNIMODAL \\
W06-10500 & BIMODAL & BIMODAL & BIMODAL & UNIMODAL \\
W06-20100 & BIMODAL & BIMODAL & UNIMODAL & UNIMODAL \\
W06-20200 & BIMODAL & BIMODAL & UNIMODAL & UNIMODAL \\
W06-20300 & BIMODAL & BIMODAL & UNIMODAL & BIMODAL \\
W06-20400 & BIMODAL & BIMODAL & BIMODAL & UNIMODAL \\
W06-20500 & BIMODAL & BIMODAL & BIMODAL & UNIMODAL \\
\hline W07-10102 & BIMODAL & BIMODAL & UNIMODAL & UNIMODAL \\
W07-10202 & BIMODAL & BIMODAL & UNIMODAL & UNIMODAL \\
W07-10301 & BIMODAL & BIMODAL & UNIMODAL & UNIMODAL \\
W07-10401 & BIMODAL & BIMODAL & UNIMODAL & UNIMODAL \\
W07-20104 & BIMODAL & BIMODAL & UNIMODAL & UNIMODAL \\
W07-20203 & BIMODAL & BIMODAL & UNIMODAL & UNIMODAL \\
W07-20301 & BIMODAL & BIMODAL & BIMODAL & UNIMODAL \\
W07-20401 & BIMODAL & BIMODAL & BIMODAL & UNIMODAL \\
\hline
\end{tabular}

Tabela 13: Classificação dos espectros direcionais gerados no ensaio em escala de acordo com cada critério.

Ao serem aplicados os métodos de identificação da bimodalidade nos espectros direcionais baseados nos parâmetros das tabelas 11 e 12, pode ser observada a eficiência de cada método através das figuras de 37 a 40.

Como mencionado anteriormente, devido à correta identificação dos espectros unimodais pelo critério proposto por (PISCOPIA; PANIZZO; GIROLAMO, 2004), este será utilizado na implementação final. Na tabela 14 a seguir, são apresentados os valores de $\chi$ calculados para os espectros dos ensaios. Pode-se notar que apenas dois deles satisfazem o critério de bimodalidade.

É importante destacar também que os espectros W06-10400 e W06-20400 possuem a mesma frequência de pico para os dois modos, e que W06-10500 e W06-20500 possuem a mesma direção média para ambos os picos, estando assim estes 4 espectros fora do alcance deste critério. Nota-se inclusive, que estes espectros possuem valores de $\chi$ muito menores que os outros originalmente bimodais.

Outro dado interessante de se destacar nos testes em espectros reais é a diferença da ordem de grandeza entre os valores de $\chi$ dos espectros bimodais W06, os quais são praticamente 10 vezes maiores que os valores dos unimodais W07. Isto sugere que $\chi_{\text {lim }}$ pode ser reajustado para valores mais baixos, entretanto, necessita-se de uma base de dados de espectros maior para realização de testes que confirmem tal tendência. 


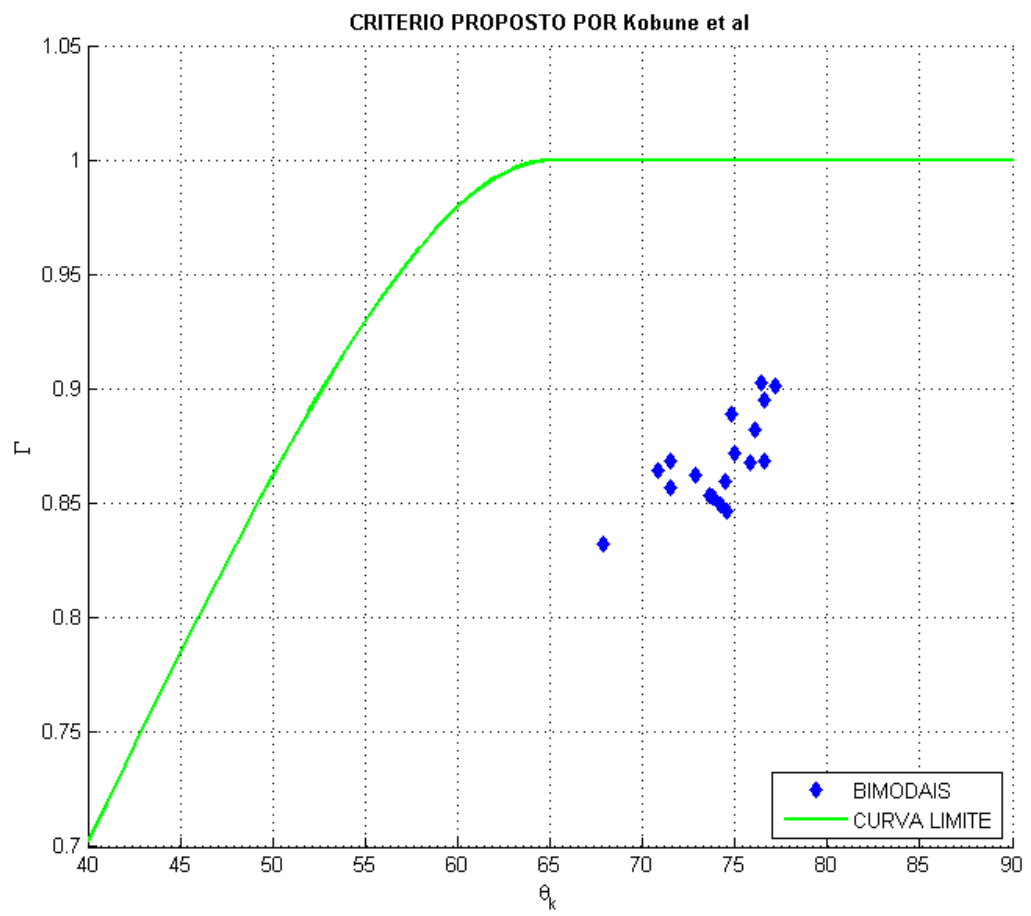

Figura 37: Critério proposto em (KOBUNE; SASAKI; HASHIMOTO, 1985) - Resultados para espectros direcionais dos ensaios.

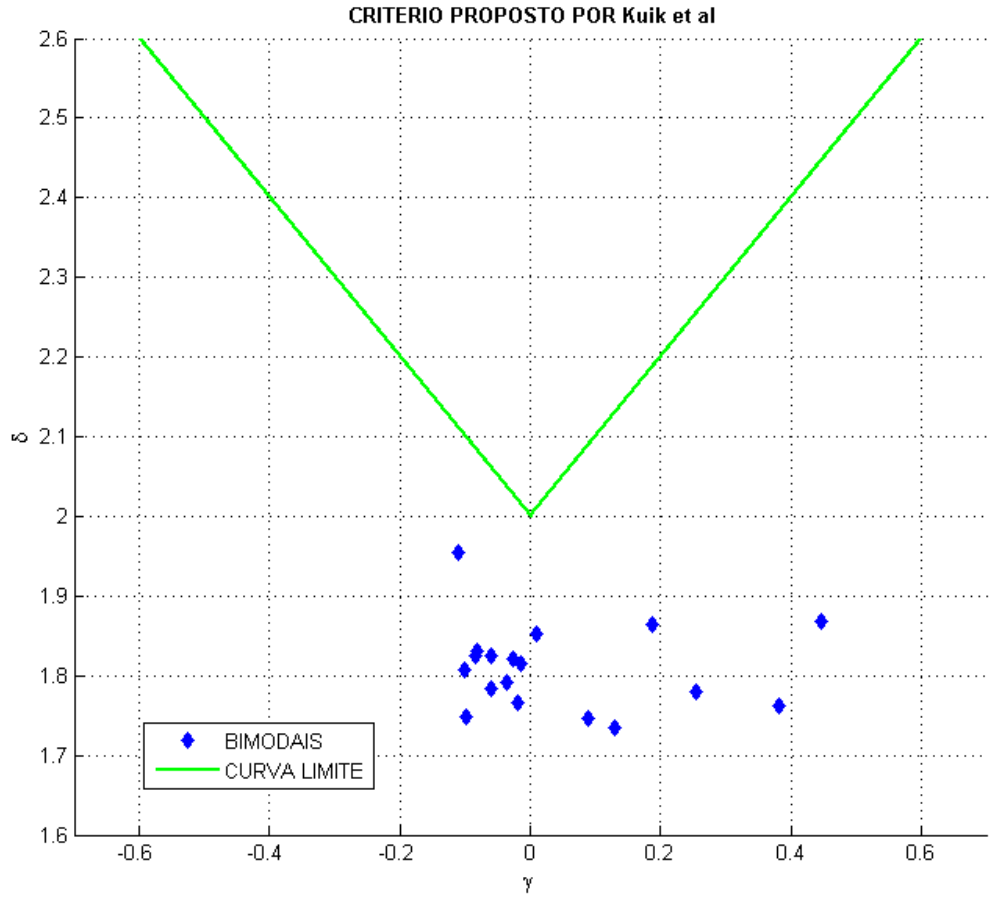

Figura 38: Critério proposto em (KUIK; VLEDDER; HOLTHUUSEN, 1988) - Resultados para espectros direcionais dos ensaios. 


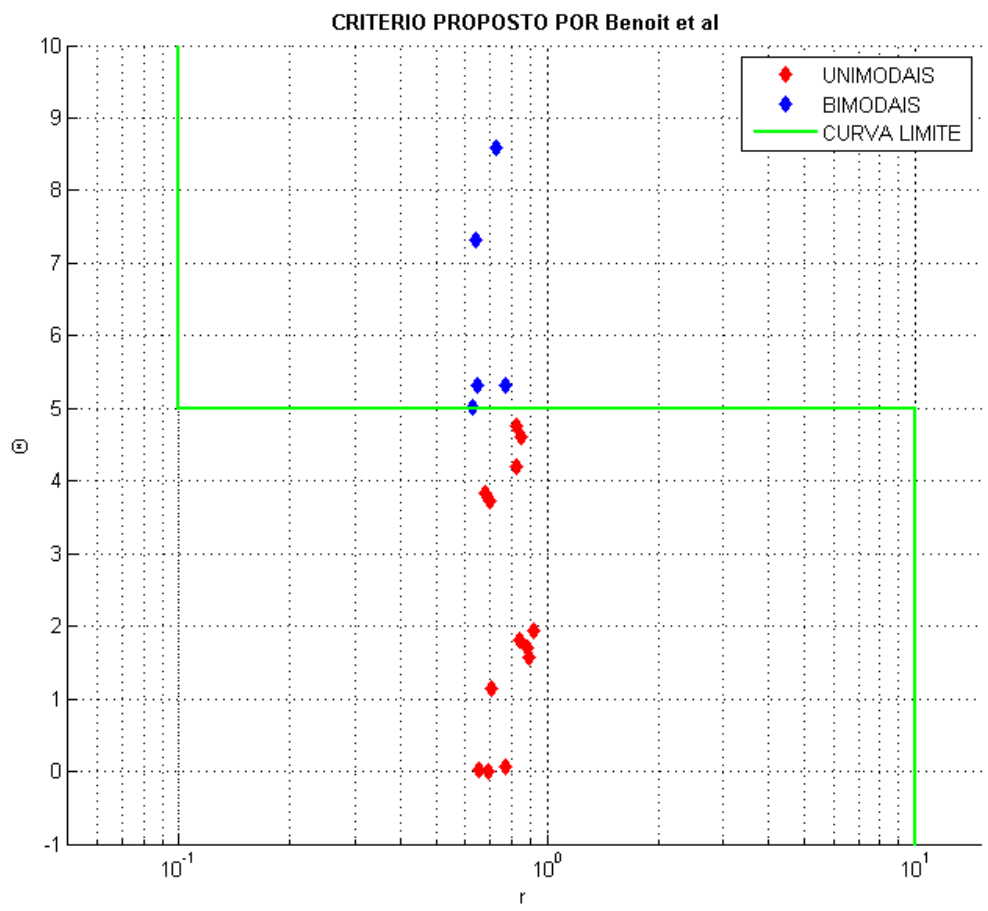

Figura 39: Critério proposto em (BESNARD; BENOIT, 1994) - Resultados para espectros direcionais dos ensaios.

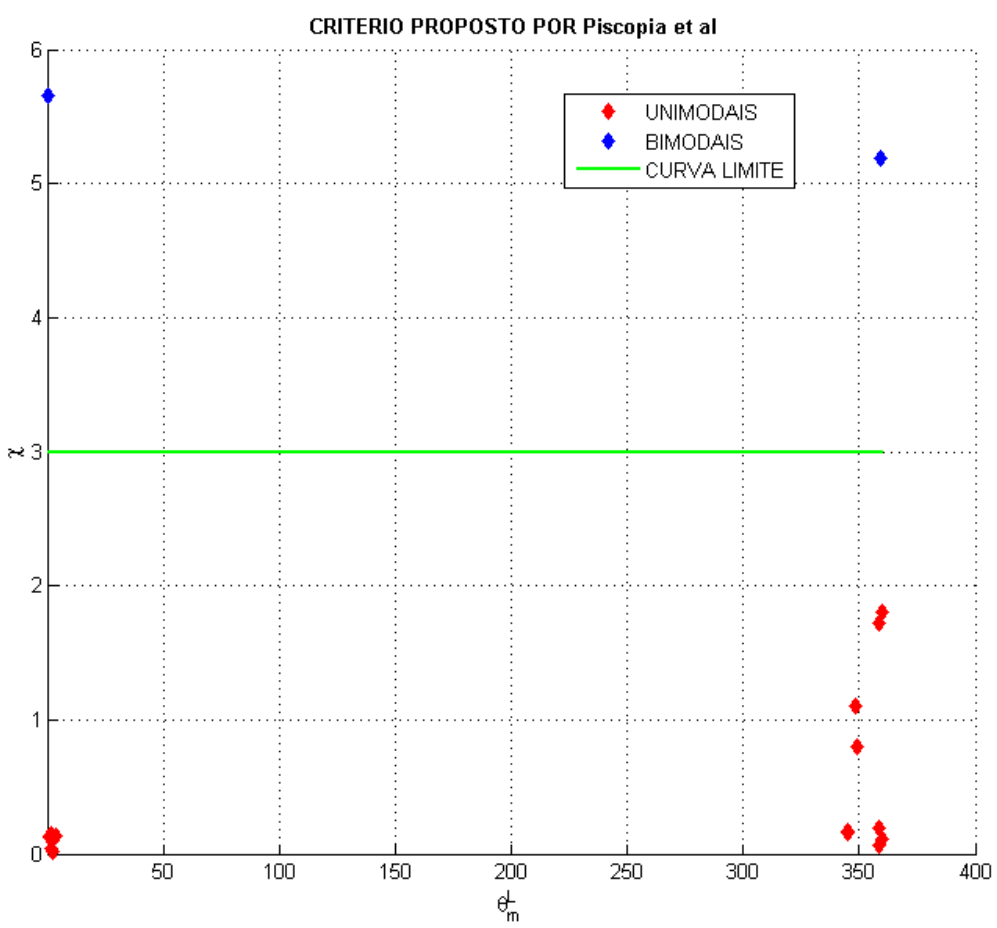

Figura 40: Critério proposto em (PISCOPIA; PANIZZO; GIROLAMO, 2004) - Resultados para espectros direcionais dos ensaios. 


\begin{tabular}{|c|c|}
\hline ESPECTRO & $\chi$ \\
\hline W06-10109 & 1,72030859 \\
W06-10200 & 1,09865121 \\
W06-10300 & 5,65271155 \\
W06-10400 & 0,06734282 \\
W06-10500 & 0,16482470 \\
W06-20100 & 1,80163355 \\
W06-20200 & 0,79379961 \\
W06-20300 & 5,18847045 \\
W06-20400 & 0,19434921 \\
W06-20500 & 0,16112978 \\
W07-10102 & 0,10795505 \\
W07-10202 & 0,14745289 \\
W07-10301 & 0,12164832 \\
W07-10401 & 0,13016250 \\
W07-20104 & 0,04299755 \\
W07-20203 & 0,02050760 \\
W07-20301 & 0,13126673 \\
W07-20401 & 0,10865414 \\
\hline
\end{tabular}

Tabela 14: Valores de $\chi$ para os espectros dos ensaios em escala. 


\subsection{Estimação Paramétrica}

Os tópicos abordados anteriormente neste capítulo foram necessários para detalhar o processo e definir as hipóteses necessárias à chamada estimação paramétrica. Nesta seção é feita uma breve descrição do algoritmo de estimação, bem como são apresentados os parâmetros a serem estimados em cada modelo e os intervalos de valores considerados para cada parâmetro. Ao final, são apresentados os resultados das estimações, obtidos para os modelos espectrais considerados. É feita também a justificativa, com base nos resultados e em outros aspectos, da escolha do modelo JONSWAP com $s$ fixo para a implementação final.

\subsubsection{Algoritmo de estimação}

Como mencionado anteriormente, o espectro discreto gerado pelo algoritmo Bayesiano deve ainda passar por um processo de estimação de seus parâmetros. Para isso deve-se, entretanto, identificar a uni ou bimodalidade espectral, com a finalidade de garantir o ajuste por meio de um modelo adequado. Após este processo de identificação de mares cruzados, a estimação pode ser feita a partir da escolha do modelo adequado, por meio de um processo de minimização com restrições que visa encontrar os valores dos parâmetros necessários para descrever o espectro utilizando o modelo escolhido.

A estimação paramétrica é feita ajustando-se uma função bivariada, dependente da frequência e da direção, ao conjunto de dados gerado pelo algoritmo Bayesiano. Este ajuste é feito por meio de um algoritmo de otimização, buscando-se valores para os parâmetros da função bivariada de maneira que esta seja a melhor descrição do conjunto de dados por meio de um dos modelos apresentados até o momento.

O processo de otimização busca valores mínimos de uma função de "distância"entre duas matrizes, sendo a primeira dada pelo algoritmo Bayesiano e a segunda a cada iteração da otimização, por meio do modelo espectral com seus parâmetros sendo ajustados. Esta "distância"será chamada de função erro, a qual, na terminologia usual de otimização, é chamada função objetivo, sendo dada pela expressão (5.31) a seguir:

$$
\text { erro }=100 \times \sqrt{\sum_{k=1}^{n} \sum_{l=1}^{m}\left(S\left(\omega_{k}, \theta_{l}\right)-\bar{S}\left(\omega_{k}, \theta_{l}\right)\right)^{2}}
$$

onde $S\left(\omega_{k}, \theta_{l}\right)$ é o espectro discreto dado pelo algoritmo Bayesiano e $\bar{S}\left(\omega_{k}, \theta_{l}\right)$ é gerado a cada iteração da estimação, este último variando conforme os parâmetros são ajustados. Os valores $n$ e $m$ são dados, respectivamente, pela discretização da frequência e da direção.

Para o processo de otimização é utilizada uma rotina chamada FMINCON.m, a qual é parte integrante do $M A T L A B^{\circledR}$, estando presente na Optimization Toolbox deste software. Esta rotina 
possui diversos ajustes possíveis tais como, o método de otimização a ser utilizado, o número máximo de iterações ou de avaliações da função objetivo, ou ainda, a variação máxima na diferenciação das variáveis, além de diversas outras opções que não foram relevantes para este trabalho. É necessário também que sejam definidos os valores mínimos e máximos de cada variável que compõe a função objetivo, assim como um valor inicial para cada uma destas variáveis.

Existem alguns métodos de otimização disponíveis nesta rotina, sendo que a mesma possui identificação automática do tipo de problema a ser otimizado, relacionando com o melhor método a ser usado. Optou-se por esta escolha automática, pois estava fora do escopo do trabalho o aprofundamento teórico na relação do problema com os métodos de otimização e, além disso, o próprio software manteve a escolha de método constante para diferentes espectros.

Obviamente os valores iniciais (ou ainda, a condição inicial) devem estar nos intervalos definidos para a otimização. Para cada espectro são então geradas 5 condições iniciais aleatórias, limitadas aos valores dos intervalos definidos para cada variável. A otimização é então feita para estas 5 condicões iniciais, escolhendo-se os valores dos parâmetros relativos à condição inicial que gerou resultados com menor valor da função objetivo. Verificou-se que 5 condições iniciais eram suficientes para que o algoritmo sempre encontrasse uma solução. Além disso, a variação dentre os resultados das 5 condições iniciais era sempre muito pequena.

Outro aspecto importante do algoritmo é o fato da distinção entre estimações unimodais ou bimodais ser feita através do uso de um modelo, respectivamente, uni ou bimodal. Isto é feito por meio da atribuição dos valores $i=\{1\}$ ou $i=\{1,2\}$ nas expressões (5.6) e (5.14). Além disso, como são estimados sempre 10 parâmetros, ao final da estimação unimodal são atribuidos valores nulos aos parâmetros relativos a um segundo pico, ou seja, no vetor de parâmetros estimados, as 5 últimas componentes serão sempre iguais a zero no caso de estimação unimodal.

\subsubsection{Parâmetros e limites}

Os espectros medidos em tanque de provas disponíveis para testar o algoritmo de otimização foram gerados a partir do modelo JONSWAP, composto à parte direcional com $s$ fixo, como apresentado na seção 5.4. Entretanto, os testes da estimação paramétrica foram feitos utilizando-se os dois modelos apresentados, com as respectivas variações na formulação do parâmetro $s$, conforme apresentado anteriormente. Assim, existe sempre algum parâmetro diferente entre cada modelo, embora se mantenha a maioria deles. Estes parâmetros são apresentados na tabela 15 para cada respectivo modelo.

\begin{tabular}{|c|l|c|c|c|c|c|c|c|c|c|c|}
\hline \multicolumn{10}{|c|}{ Modelos } & \multicolumn{10}{|c|}{ Parâmetros } \\
\hline \multirow{2}{*}{ JONSWAP } & $s$ fixo & $H_{s_{1}}$ & $T_{p_{1}}$ & $s_{1}$ & $\gamma_{1}$ & $\theta_{m_{1}}$ & $H_{s_{2}}$ & $T_{p_{2}}$ & $s_{2}$ & $\gamma_{2}$ & $\theta_{m_{2}}$ \\
\cline { 2 - 11 } & $s$ variável & $H_{s_{1}}$ & $T_{p_{1}}$ & $s_{\max _{1}}$ & $\gamma_{1}$ & $\theta_{m_{1}}$ & $H_{s_{2}}$ & $T_{p_{2}}$ & $s_{m_{2 a x}}$ & $\gamma_{2}$ & $\theta_{m_{2}}$ \\
\hline \multirow{2}{*}{ Hogben \& Cobb } & $s$ fixo & $H_{s_{1}}$ & $T_{p_{1}}$ & $s_{1}$ & $\lambda_{1}$ & $\theta_{m_{1}}$ & $H_{s_{2}}$ & $T_{p_{2}}$ & $s$ & $\lambda_{2}$ & $\theta_{m_{2}}$ \\
\cline { 2 - 11 } & $s$ variável & $H_{s_{1}}$ & $T_{p_{1}}$ & $s_{\max _{1}}$ & $\lambda_{1}$ & $\theta_{m_{1}}$ & $H_{s_{2}}$ & $T_{p_{2}}$ & $s_{\text {max }_{2}}$ & $\lambda_{2}$ & $\theta_{m_{2}}$ \\
\hline
\end{tabular}

Tabela 15: Parâmetros a serem estimados para cada modelo.

Dessa maneira fica clara a necessidade de um passo a mais para a estimação do parâmetro 
$\gamma$ caso fosse utilizado o modelo de Hogben \& Cobb para a estimação paramétrica, dado que a representação final seria efetivamente feita por meio de JONSWAP.

Os valores limitantes que definem os intervalos para a estimação foram determinados com base em valores possíveis de serem obtidos fisicamente ou através de pesquisa na literatura especializada ${ }^{2}$. Na tabela 16 são apresentados os valores máximo e mínimo dos intervalos de otimização para todos os parâmetros considerados ${ }^{3}{ }^{4}$.

\begin{tabular}{|c|c|c|}
\hline Parâmetro & Mínimo & Máximo \\
\hline$H_{s}[\mathrm{~m}]$ & 0,2 & 10 \\
$T_{p}[\mathrm{~s}]$ & 4 & 20 \\
$s$ ou $s_{\max }$ & 1 & 150 \\
$\gamma$ & 1 & 3,5 \\
$\lambda$ & 0,1 & 5 \\
$\theta_{m}$ [graus] & -180 & 180 \\
\hline
\end{tabular}

Tabela 16: Intervalos de otimização para cada parâmetro.

Dessa maneira, tanto os valores iniciais de cada parâmetro quanto suas respectivas estimativas, estarão limitadas aos intervalos apresentados. É importante salientar que no caso do algoritmo não convergir, nota-se que sempre algum parâmetro atinge um dos limites do intervalo em que o mesmo está contido. Um exemplo é o parâmetro $s$, o qual precisou ser ajustado de modo a abranger espectros mais dispersos gerados pelo algoritmo Bayesiano, ou seja, seu limite inferior precisou de um valor mais baixo.

\subsubsection{Resultados das estimações}

Em razão do critério de bimodalidade adotado, as estimações realizadas foram em sua maioria unimodais, pois a distribuição de energia dos espectros direcionais obtidos nos ensaios não possui grande distinção entre os picos de energia. Isto se deve em parte à imprecisão na geração dos mares e também à questão do limiar $\chi=3^{\circ}$ utilizado no critério de bimodalidade.

São apresentados nas tabelas 17 a 25 os resultados das estimações paramétricas. Pode-se notar que a estimação bimodal só foi feita para os casos W06-10300 e W06-20300, os quais são relativos a ensaios dos mesmos mares teóricos, tendo sido gerados em escalas diferentes. Conforme mencionado anteriormente, isto ocorre devido ao valor do limiar adotado no critério de bimodalidade, que faz com que as estimativas sejam feitas por meio do modelo unimodal.

As estimativas globais de $H s$ e $T p$ para todos os ensaios são apresentadas, respectivamente, nas tabelas 17 e 18. Observa-se que os valores estimados são muito próximos aos do ensaio para ambos os parâmetros, o que indica que a estimação paramétrica consegue ajustar bem o valor

\footnotetext{
${ }^{2}$ As principais referências utilizadas foram (GODA, 2000), (HOGBEN; COBB, 1986) e (OCHI; HUBBLE, 1976)

${ }^{3} \mathrm{O}$ valor máximo de $s$ ou $s_{\max }$ utilizado nestas estimações foi definido de acordo com os testes, pois em teoria pode-se tomar $s \rightarrow \infty$.

${ }^{4}$ Valores de $\gamma$ definidos com base em (GODA, 2000), sendo que para o caso $\gamma=1$ o modelo se resume ao de Pierson-Moskowitz
} 
total da energia, independente da modalidade do espectro, além de aproximar com certa precisão o período de pico médio.

\begin{tabular}{|c|c|c|c|c|c|}
\hline \multirow{2}{*}{ MODELO } & \multicolumn{4}{|c|}{$H_{s}$} \\
\cline { 2 - 5 } & \multicolumn{2}{|c|}{ JONSWAP } & \multicolumn{2}{c|}{ HOGBN } & \multirow{2}{*}{ ENSAIO } \\
\hline W06-10109 & fixo & variável & fixo & variável & \\
\hline W06-10200 & 1,66 & 1,33 & 1,26 & 1,37 & 1,47 \\
W06-10400 & 2,04 & 2,10 & 1,47 & 1,53 & 1,79 \\
W06-10500 & 1,36 & 1,36 & 1,44 & 1,54 & 2,12 \\
W06-20100 & 1,50 & 1,51 & 1,50 & 1,60 & 1,49 \\
W06-20200 & 1,81 & 1,86 & 1,69 & 1,79 & 1,93 \\
W06-20400 & 2,10 & 2,14 & 2,01 & 2,07 & 2,14 \\
W06-20500 & 1,43 & 1,44 & 1,48 & 1,57 & 1,59 \\
\hline W07-10102 & 4,70 & 4,77 & 4,48 & 4,65 & 4,59 \\
W07-10202 & 7,95 & 8,07 & 7,79 & 8,04 & 8,05 \\
W07-10301 & 4,68 & 4,77 & 4,46 & 4,63 & 4,67 \\
W07-10401 & 4,76 & 4,81 & 4,56 & 4,73 & 4,64 \\
W07-20104 & 4,37 & 4,44 & 4,22 & 4,35 & 4,34 \\
W07-20203 & 7,72 & 7,91 & 7,18 & 7,47 & 8,04 \\
W07-20301 & 4,71 & 4,66 & 4,73 & 4,97 & 4,62 \\
W07-20401 & 4,59 & 4,64 & 4,35 & 4,51 & 4,54 \\
\hline
\end{tabular}

Tabela 17: Resultados das estimações de $H_{s}$ em [m] na escala real para casos considerados unimodais.

A comparação dos valores estimados de $H_{s}$ e $T_{p}$ de cada pico é feita com valores teóricos, uma vez que não se sabe os valores obtidos nos ensaios destes parâmetros para cada pico, mas apenas o valor global de cada um.

A tabela 19 apresenta os resultados das estimações de $H_{s}$ para cada pico. Verifica-se que para os picos de menor energia são encontrados valores próximos ao $H_{s}$ teórico de cada pico. Já para o pico de maior energia, existe um erro associado. Este erro pode estar associado à geração do mar no ensaio e não somente ser um problema da estimação, uma vez que para o pico menor houve uma boa aproximação, assim como da energia total do espectro, conforme apresentado na tabela 17.

Já para os valores de $T_{p}$ de cada pico foram obtidas estimativas muito boas, conforme pode ser visto na tabela 20 , sendo que isto era esperado do algoritmo, uma vez que o período de pico é de fácil estimação. 


\begin{tabular}{|c|c|c|c|c|c|}
\hline \multirow{2}{*}{ MODELO } & \multicolumn{4}{|c|}{$T_{p}$} \\
\cline { 2 - 5 } & \multicolumn{2}{|c|}{ JONSWAP } & \multicolumn{2}{c|}{ HOGBEN } & \multirow{2}{*}{ ENSAIO } \\
\hline W06-10109 & 11,47 & 11,51 & 11,42 & 11,51 & 11,40 \\
W06-10200 & 7,36 & 7,40 & 7,43 & 7,45 & 7,30 \\
W06-10400 & 11,54 & 11,60 & 11,50 & 11,58 & 11,40 \\
W06-10500 & 11,31 & 11,32 & 11,29 & 11,26 & 11,40 \\
W06-20100 & 11,29 & 11,38 & 11,22 & 11,27 & 11,43 \\
W06-20200 & 7,30 & 7,32 & 7,38 & 7,36 & 7,48 \\
W06-20400 & 11,38 & 11,46 & 11,32 & 11,42 & 11,43 \\
W06-20500 & 11,29 & 11,41 & 11,11 & 11,20 & 12,06 \\
\hline W07-10102 & 10,21 & 10,23 & 10,24 & 10,26 & 10,12 \\
W07-10202 & 15,47 & 15,54 & 15,40 & 15,61 & 14,56 \\
W07-10301 & 10,38 & 10,44 & 10,38 & 10,47 & 10,12 \\
W07-10401 & 10,33 & 10,42 & 10,34 & 10,45 & 10,12 \\
W07-20104 & 10,45 & 10,49 & 10,37 & 10,43 & 10,88 \\
W07-20203 & 15,42 & 15,52 & 15,44 & 15,55 & 15,49 \\
W07-20301 & 10,30 & 10,42 & 10,29 & 10,38 & 9,87 \\
W07-20401 & 10,25 & 10,35 & 10,27 & 10,34 & 10,32 \\
\hline
\end{tabular}

Tabela 18: Resultados das estimações de $T_{p}$ em [s] na escala real para casos considerados unimodais. 


\begin{tabular}{|c|c|c|c|c|c|c|c|c|c|c|}
\hline \multirow{3}{*}{$\frac{\text { MODELO }}{s}$} & \multicolumn{5}{|c|}{$H_{s_{1}}$} & \multicolumn{5}{|c|}{$H_{s_{2}}$} \\
\hline & \multicolumn{2}{|c|}{ JONSWAP } & \multicolumn{2}{|c|}{ HOGBEN } & \multirow{2}{*}{ TEÓRICO } & \multicolumn{2}{|c|}{ JONSWAP } & \multicolumn{2}{|c|}{ HOGBEN } & \multirow{2}{*}{ TEÓRICO } \\
\hline & fixo & variável & fixo & variável & & fixo & variável & fixo & variável & \\
\hline W06-10300 & 0,85 & 0,81 & 0,77 & 0,74 & 1,47 & 0,63 & 0,64 & 0,58 & 0,61 & 0,63 \\
\hline W06-20300 & 0,99 & 0,99 & 0,93 & 0,60 & 1,49 & 0,62 & 0,64 & 0,57 & 0,59 & 0,62 \\
\hline
\end{tabular}

Tabela 19: Resultados das estimações de $H_{s_{1}}$ e $H_{s_{2}}$ em [m] na escala real para casos considerados bimodais.

\begin{tabular}{|c|c|c|c|c|c|c|c|c|c|c|}
\hline \multirow{3}{*}{$\frac{\text { MODELO }}{s}$} & \multicolumn{5}{|c|}{$T_{p_{1}}$} & \multicolumn{5}{|c|}{$T_{p_{2}}$} \\
\hline & \multicolumn{2}{|c|}{ JONSWAP } & \multicolumn{2}{|c|}{ HOGBEN } & \multirow{2}{*}{ TEÓRICO } & \multicolumn{2}{|c|}{ JONSWAP } & \multicolumn{2}{|c|}{ HOGBEN } & \multirow{2}{*}{ TEÓRICO } \\
\hline & fixo & variável & fixo & variável & & fixo & variável & fixo & variável & \\
\hline W06-10300 & 5,71 & 5,82 & 5,75 & 5,83 & 5,35 & 11,21 & 11,18 & 11,26 & 11,26 & 11,29 \\
\hline W06-20300 & 5,68 & 5,75 & 5,64 & 5,68 & 5,33 & 11,20 & 11,25 & 11,17 & 11,25 & 11,29 \\
\hline
\end{tabular}

Tabela 20: Resultados das estimações de $T_{p_{1}}$ e $T_{p_{2}}$ em [s] na escala real para casos considerados bimodais. 
O aproamento do modelo não era conhecido, o que implicava no desconhecimento do ângulo de incidência das ondas em relação à embarcação. Entretanto, existia a informação da abertura entre os dois picos, ou seja, a diferença absoluta em graus entre os dois picos nos casos dos ensaios bimodais. Como a maioria dos mares estimados foi considerado unimodal durante a estimação, a comparação dos resultados obtidos nas estimativas das direções ficou comprometida, uma vez que não existe mais um paradigma de comparação, ou seja, não era mais possível comparar as aberturas, com exceção apenas para os casos em que a estimativa foi feita utilizando-se um modelo bimodal. Na tabela 21 são apresentadas as direções médias de incidência obtidas pela estimação e a título de comparação, para os casos bimodais estimados a abertura teórica entre picos é de $60^{\circ}$.

\begin{tabular}{|c|c|c|c|c|c|c|c|c|}
\hline \multirow{3}{*}{$\frac{\text { MODELO }}{s}$} & \multicolumn{4}{|c|}{$\theta_{m_{1}}$} & \multicolumn{4}{|c|}{$\theta_{m_{2}}$} \\
\hline & \multicolumn{2}{|c|}{ JONSWAP } & \multicolumn{2}{|c|}{ HOGBEN } & \multicolumn{2}{|c|}{ JONSWAP } & \multicolumn{2}{|c|}{ HOGBEN } \\
\hline & fixo & variável & fixo & variável & fixo & variável & fixo & variável \\
\hline W06-10109 & $-20,01$ & $-20,06$ & $-20,09$ & $-19,89$ & & & & \\
\hline W06-10200 & $-25,13$ & $-25,14$ & $-25,18$ & $-25,16$ & & & & \\
\hline W06-10300 & $-21,46$ & $-22,89$ & $-21,00$ & $-22,23$ & 23,05 & 22,75 & 22,62 & 22,53 \\
\hline W06-10400 & $-14,05$ & $-13,47$ & $-13,90$ & $-13,42$ & & & & \\
\hline W06-10500 & $-23,16$ & $-22,86$ & $-23,27$ & $-23,14$ & & & & \\
\hline W06-20100 & $-10,40$ & $-11,11$ & $-10,29$ & $-11,01$ & & & & \\
\hline W06-20200 & $-23,92$ & $-24,04$ & $-23,92$ & $-24,02$ & & & & \\
\hline W06-20300 & $-21,64$ & $-22,21$ & $-21,60$ & $-22,11$ & 24,07 & 23,56 & 23,38 & 23,54 \\
\hline W06-20400 & $-4,94$ & $-5,14$ & $-4,91$ & $-5,06$ & & & & \\
\hline W06-20500 & $-20,70$ & $-20,58$ & $-20,82$ & $-20,84$ & & & & \\
\hline W07-10102 & $-0,19$ & $-0,26$ & $-0,16$ & $-0,24$ & & & & \\
\hline W07-10202 & 1,33 & 1,21 & 1,40 & 1,27 & & & & \\
\hline W07-10301 & 1,19 & 1,29 & 1,16 & 1,26 & & & & \\
\hline W07-10401 & 3,14 & 3,18 & 3,17 & 3,18 & & & & \\
\hline W07-20104 & 1,23 & 1,31 & 1,09 & 1,23 & & & & \\
\hline W07-20203 & 3,82 & 4,00 & 3,79 & 3,96 & & & & \\
\hline W07-20301 & 0,53 & 0,53 & 0,53 & 0,52 & & & & \\
\hline W07-20401 & 2,44 & 2,50 & 2,48 & 2,51 & & & & \\
\hline
\end{tabular}

Tabela 21: Resultados das estimações de $\theta_{m_{1}}$ e $\theta_{m_{2}}$ em [graus] na escala real.

Para a comparação com valores mais próximos aos obtidos nos ensaios, são apresentadas na tabela 22 as estatísticas globais calculadas através das estimações paramétricas, assim como os valores das medições feitas nos ensaios. Em casos de estimação bimodal, são apresentados os valores teóricos como paradigma de comparação, dado que não se possui os valores dos parâmetros para cada pico. 


\begin{tabular}{|c|c|c|c|c|c|c|c|c|c|c|c|c|c|c|}
\hline \multirow{3}{*}{$\frac{\text { MODELO }}{s}$} & \multicolumn{5}{|c|}{$H_{s}$} & \multicolumn{5}{|c|}{$T_{p}$} & \multicolumn{4}{|c|}{$\theta_{m}$} \\
\hline & \multicolumn{2}{|c|}{ JONSWAP } & \multicolumn{2}{|c|}{ HOGBEN } & \multirow{2}{*}{ ENSAIO } & \multicolumn{2}{|c|}{ JONSWAP } & \multicolumn{2}{|c|}{ HOGBEN } & \multirow{2}{*}{ ENSAIO } & \multicolumn{2}{|c|}{ JONSWAP } & \multicolumn{2}{|c|}{ HOGBEN } \\
\hline & fixo & variável & fixo & variável & & fixo & variável & fixo & variável & & fixo & variável & fixo & variável \\
\hline W06-10109 & 1,29 & 1,32 & 1,26 & 1,37 & 1,48 & 11,47 & 11,51 & 11,42 & 11,51 & 11,40 & 20,01 & 20,06 & 20,09 & 19,89 \\
\hline W06-10200 & 1,66 & 1,72 & 1,47 & 1,53 & 1,79 & 7,36 & 7,40 & 7,43 & 7,45 & 7,30 & 25,13 & 25,14 & 25,18 & 25,16 \\
\hline W06-10300 & 1,05 & 1,03 & 0,96 & 0,96 & 0,97 & 11,42 & 11,41 & 11,41 & 11,41 & 11,40 & 4,71 & 4,80 & 5,92 & 5,18 \\
\hline W06-10400 & 2,04 & 2,10 & 1,96 & 2,05 & 2,11 & 11,54 & 11,60 & 11,50 & 11,58 & 11,40 & 14,05 & 13,47 & 13,90 & 13,42 \\
\hline W06-10500 & 1,36 & 1,36 & 1,44 & 1,54 & 1,49 & 11,31 & 11,32 & 11,29 & 11,26 & 11,40 & 23,16 & 22,86 & 23,27 & 23,14 \\
\hline W06-20100 & 1,50 & 1,51 & 1,50 & 1,60 & 1,62 & 11,29 & 11,38 & 11,22 & 11,27 & 11,43 & 10,40 & 11,11 & 10,29 & 11,01 \\
\hline W06-20200 & 1,81 & 1,86 & 1,69 & 1,79 & 1,93 & 7,30 & 7,32 & 7,38 & 7,36 & 7,48 & 23,92 & 24,04 & 23,92 & 24,02 \\
\hline W06-20300 & 1,17 & 1,18 & 1,09 & 1,12 & 1,22 & 5,50 & 5,53 & 5,47 & 5,53 & 5,33 & 9,87 & 10,08 & 10,38 & 10,51 \\
\hline W06-20400 & 2,10 & 2,14 & 2,00 & 2,07 & 2,14 & 11,38 & 11,46 & 11,32 & 11,42 & 11,43 & 4,94 & 5,14 & 4,91 & 5,06 \\
\hline W06-20500 & 1,43 & 1,44 & 1,48 & 1,57 & 1,59 & 11,29 & 11,41 & 11,11 & 11,20 & 12,06 & 20,70 & 20,58 & 20,82 & 20,84 \\
\hline W07-10102 & 4,70 & 4,77 & 4,48 & 4,66 & 4,59 & 10,21 & 10,23 & 10,24 & 10,26 & 10,12 & 0,19 & 0,26 & 0,16 & 0,24 \\
\hline W07-10202 & 7,95 & 8,07 & 7,80 & 8,04 & 8,05 & 15,47 & 15,54 & 15,40 & 15,61 & 14,56 & 1,33 & 1,21 & 1,40 & 1,27 \\
\hline W07-10301 & 4,68 & 4,77 & 4,46 & 4,64 & 4,67 & 10,38 & 10,44 & 10,38 & 10,47 & 10,12 & 1,19 & 1,29 & 1,16 & 1,26 \\
\hline W07-10401 & 4,76 & 4,81 & 4,57 & 4,74 & 4,63 & 10,33 & 10,42 & 10,34 & 10,45 & 10,12 & 3,14 & 3,18 & 3,17 & 3,18 \\
\hline W07-20104 & 4,37 & 4,44 & 4,23 & 4,35 & 4,34 & 10,45 & 10,49 & 10,37 & 10,43 & 10,88 & 1,23 & 1,31 & 1,09 & 1,23 \\
\hline W07-20203 & 7,72 & 7,91 & 7,18 & 7,48 & 8,04 & 15,42 & 15,52 & 15,44 & 15,55 & 15,49 & 3,82 & 4,00 & 3,79 & 3,96 \\
\hline W07-20301 & 4,71 & 4,66 & 4,73 & 4,98 & 4,63 & 10,30 & 10,42 & 10,29 & 10,38 & 9,87 & 0,53 & 0,53 & 0,53 & 0,52 \\
\hline W07-20401 & 4,59 & 4,64 & 4,35 & 4,52 & 4,54 & 10,25 & 10,35 & 10,27 & 10,34 & 10,32 & 2,44 & 2,50 & 2,48 & 2,51 \\
\hline
\end{tabular}

Tabela 22: Estatísticas globais em escala real - $H_{s}$ em [m], $T_{p}$ em [s] e $\theta_{m}$ em [graus]. 
Os parâmetros de forma dos modelos JONSWAP e Hogben \& Cobb são apresentados, respectivamente, nas tabelas 23 e 24 . Verifica-se que os valores encontrados para $\gamma$ são estimativas razoáveis quando comparadas aos valores teóricos. É importante destacar que não foram feitas estimativas de $\gamma_{i}$ para os modelos baseados no espectro de frequência de Hogben \& Cobb e que não existiam valores teóricos para comparação, pois os espectros dos ensaios em escala foram gerados a partir do modelo direcional do espectro JONSWAP.

\begin{tabular}{|c|c|c|c|c|c|c|}
\hline \multirow{2}{*}{ MODELO } & \multicolumn{3}{|c|}{$\gamma_{1}$} & \multicolumn{3}{|c|}{$\gamma_{2}$} \\
\cline { 2 - 6 } & JONSWAP & \multirow{2}{*}{ TEÓRICO } & \multicolumn{2}{|c|}{ JONSWAP } & \multirow{2}{*}{ TEÓRICO } \\
\cline { 2 - 6 } & fixo & variável & & fixo & variável & \\
\hline W06-10109 & 1,27 & 1,05 & 1,40 & & & 0,90 \\
W06-10200 & 1,98 & 1,62 & 1,60 & & & 2,00 \\
W06-10300 & 1,59 & 1,53 & 1,30 & 2,18 & 1,85 & 2,20 \\
W06-10400 & 1,47 & 1,23 & 1,50 & & & 1,20 \\
W06-10500 & 1,01 & 1,01 & 1,40 & & & 0,90 \\
W06-20100 & 1,29 & 1,08 & 1,40 & & & 0,90 \\
W06-20200 & 1,99 & 1,47 & 1,60 & & & 2,00 \\
W06-20300 & 1,78 & 1,69 & 1,30 & 2,32 & 1,92 & 2,20 \\
W06-20400 & 1,67 & 1,42 & 1,50 & & & 1,20 \\
W06-20500 & 1,27 & 1,10 & 1,40 & & & 0,90 \\
\hline W07-10102 & 1,46 & 1,23 & 1,51 & & & \\
W07-10202 & 1,68 & 1,45 & 1,70 & & & \\
W07-10301 & 1,71 & 1,42 & 1,51 & & & \\
W07-10401 & 1,40 & 1,17 & 1,51 & & & \\
W07-20104 & 1,70 & 1,48 & 1,51 & & & \\
W07-20203 & 1,70 & 1,41 & 1,70 & & & \\
W07-20301 & 1,01 & 1,01 & 1,51 & & & \\
W07-20401 & 1,53 & 1,29 & 1,51 & & & \\
\hline
\end{tabular}

Tabela 23: Resultados das estimações de $\gamma_{1}$ e $\gamma_{2}$ - apenas para JONSWAP.

Os espalhamentos estimados fixos, $s$, e os variáveis, dependentes de $s_{m} a x$, são apresentados na tabela 25. Em teoria, os mares deveriam ter espalhamento muito baixo, ou seja, valores altos de $s$ teórico. Observa-se na tabela que os valores teóricos são dificilmente atingidos, sendo em sua maioria obtidos valores menores de espalhamento. Um dos fatores que influencia nisto é o próprio ensaio, uma vez que é difícil garantir que os valores simulados sejam iguais aos teóricos. Além disso, o próprio algoritmo se mostrou irregular quanto às estimativas do espalhamento, sendo este um dos parâmetros com maior variação de valores estimados. 


\begin{tabular}{|c|c|c|c|c|}
\hline \multirow{2}{*}{ MODELO } & \multicolumn{2}{|c|}{$\lambda_{1}$} & \multicolumn{2}{c|}{$\lambda_{2}$} \\
\cline { 2 - 5 } & \multicolumn{2}{|c|}{ JONSWAP } & \multicolumn{2}{c|}{ JONSWAP } \\
\hline W & fixo & variável & fixo & variável \\
\hline W06-10109 & 1,18 & 0,84 & & \\
W06-10200 & 2,86 & 2,29 & & \\
W06-10300 & 2,09 & 2,12 & 2,32 & 1,72 \\
W06-10400 & 1,47 & 1,21 & & \\
W06-10500 & 0,73 & 0,55 & & \\
W06-20100 & 1,12 & 0,82 & & \\
W06-20200 & 1,80 & 1,39 & & \\
W06-20300 & 2,34 & 2,01 & 2,83 & 2,27 \\
W06-20400 & 1,69 & 1,39 & & \\
W06-20500 & 0,93 & 0,72 & & \\
\hline W07-10102 & 1,49 & 1,21 & & \\
W07-10202 & 1,41 & 1,18 & & \\
W07-10301 & 1,67 & 1,34 & & \\
W07-10401 & 1,43 & 1,14 & & \\
W07-20104 & 1,59 & 1,36 & & \\
W07-20203 & 1,97 & 1,57 & & \\
W07-20301 & 0,97 & 0,74 & & \\
W07-20401 & 1,59 & 1,28 & & \\
\hline
\end{tabular}

Tabela 24: Resultados das estimações de $\lambda_{1}$ e $\lambda_{2}$ - apenas para Hogben \& Cobb. 


\begin{tabular}{|c|c|c|c|c|c|c|c|c|c|c|}
\hline \multirow{3}{*}{ MODELO } & \multicolumn{5}{|c|}{$1^{\circ}$ pico } & \multicolumn{5}{|c|}{$2^{\circ}$ pico } \\
\hline & \multicolumn{2}{|c|}{ JONSWAP } & \multicolumn{2}{|c|}{ HOGBEN } & \multirow{2}{*}{ TEÓRICO } & \multicolumn{2}{|c|}{ JONSWAP } & \multicolumn{2}{|c|}{ HOGBEN } & \multirow{2}{*}{ TEÓRICO } \\
\hline & $s_{1}$ & $s_{\max _{1}}$ & $s_{1}$ & $s_{\max _{1}}$ & & $s_{2}$ & $s_{\max _{2}}$ & $s_{2}$ & $s_{\max _{2}}$ & \\
\hline W06-10109 & 15,79 & 21,10 & 16,21 & 21,23 & \multirow{10}{*}{85,00} & & & & & \multirow{10}{*}{85,00} \\
\hline W06-10200 & 83,21 & 105,56 & 83,76 & 107,01 & & & & & & \\
\hline W06-10300 & 51,18 & 73,61 & 48,97 & 69,84 & & 21,37 & 29,93 & 22,80 & 30,88 & \\
\hline W06-10400 & 10,28 & 13,30 & 10,05 & 13,33 & & & & & & \\
\hline W06-10500 & 27,73 & 39,00 & 29,20 & 45,27 & & & & & & \\
\hline W06-20100 & 7,07 & 10,46 & 7,06 & 10,87 & & & & & & \\
\hline W06-20200 & 55,79 & 81,20 & 55,21 & 80,36 & & & & & & \\
\hline W06-20300 & 64,76 & 88,00 & 66,29 & 84,72 & & 22,85 & 28,38 & 21,50 & 27,68 & \\
\hline W06-20400 & 6,69 & 9,17 & 6,64 & 9,17 & & & & & & \\
\hline W06-20500 & 12,77 & 17,51 & 13,30 & 19,34 & & & & & & \\
\hline W07-10102 & 91,00 & 127,88 & 91,80 & 129,43 & \multirow{8}{*}{85,00} & & & & & \\
\hline W07-10202 & 41,42 & 55,58 & 40,99 & 56,84 & & & & & & \\
\hline W07-10301 & 53,30 & 73,30 & 53,12 & 73,99 & & & & & & \\
\hline W07-10401 & 12,15 & 17,82 & 12,12 & 17,90 & & & & & & \\
\hline W07-20104 & 47,21 & 64,64 & 46,31 & 64,90 & & & & & & \\
\hline W07-20203 & 44,51 & 61,64 & 43,86 & 61,07 & & & & & & \\
\hline W07-20301 & 26,64 & 40,32 & 26,64 & 41,25 & & & & & & \\
\hline W07-20401 & 12,99 & 18,33 & 13,04 & 18,56 & & & & & & \\
\hline
\end{tabular}

Tabela 25: Resultados das estimações de $s_{1}, s_{2}, s_{\max _{1}}$ e $s_{\text {max }_{2}}$. 
O tempo de cálculo de cada da estimativa é apresentado na tabela 26 a seguir, para que seja possível uma análise da eficiência do algoritmo. Os testes foram realizados em um computador Intel ${ }^{\circledR}$ Core $^{\mathrm{TM}} 2$ Quad Q2800, com processamento de 2,66GHz e $3 G b$ de memória RAM.

Destaca-se o fato de que devido à geração aleatória de condições iniciais, o tempo de execução pode variar a cada novo teste realizado. Portanto, os valores aqui apresentados servem apenas para ilustrar a ordem de grandeza e a diferença do tempo de execução para estimações unimodais e bimodais, dado que a segunda é mais custosa computacionalmente.

\begin{tabular}{|c|c|c|c|c|}
\hline \multirow{2}{*}{ MODELO } & \multicolumn{4}{|c|}{ Tempo de Execução } \\
\cline { 2 - 5 } & \multicolumn{2}{|c|}{ JONSWAP } & \multicolumn{2}{c|}{ HOGBN } \\
\hline W06-10109 & 29,047 & 3,703 & 6,188 & 10,875 \\
W06-10200 & 25,266 & 42,641 & 6,906 & 13,953 \\
W06-10300 & 82,453 & 125,875 & 45,422 & 64,438 \\
W06-10400 & 26,641 & 5,109 & 5,672 & 12,703 \\
W06-10500 & 19,563 & 41,156 & 8,609 & 11,500 \\
W06-20100 & 11,953 & 7,594 & 8,109 & 12,547 \\
W06-20200 & 29,234 & 135,469 & 6,797 & 18,453 \\
W06-20300 & 94,031 & 29,250 & 55,250 & 107,344 \\
W06-20400 & 33,547 & 49,531 & 5,078 & 17,594 \\
W06-20500 & 31,375 & 5,750 & 7,422 & 16,078 \\
\hline W07-10102 & 3,375 & 114,516 & 7,594 & 91,609 \\
W07-10202 & 29,797 & 183,266 & 7,906 & 16,797 \\
W07-10301 & 47,031 & 82,266 & 7,953 & 87,938 \\
W07-10401 & 45,016 & 44,203 & 7,250 & 11,344 \\
W07-20104 & 40,125 & 97,234 & 8,125 & 14,313 \\
W07-20203 & 38,578 & 91,750 & 75,109 & 21,156 \\
W07-20301 & 22,734 & 4,156 & 9,156 & 16,609 \\
W07-20401 & 34,656 & 90,906 & 8,125 & 14,453 \\
\hline
\end{tabular}

Tabela 26: Tempo de execução das estimações paramétricas em segundos.

Os espectros direcionais obtidos para cada modelo testado, assim como o espectro medido juntamente ao respectivo espectro de potência são apresentados nas figuras de 62(a) a 79 de apêndice $G$.

\subsubsection{Conclusões sobre a estimação}

Embora a maioria dos mares tenha passado pelo processo de estimação por meio de um modelo unimodal, as estatísticas globais foram satisfatórias, pois a energia total dos espectros foi mantida em boa parte dos testes, além da precisão obtida para o posicionamento do pico de energia no plano $\omega \times \theta$. Posto este fato, conclui-se que a perda de um dos picos não prejudica a estimação de maneira geral, dadas as estimativas de $H_{s}$ global próximas às medições, mesmo para estes casos. Em alguns casos em que ocorre a perda de um pico, nota-se também a diminuição da energia total do espectro de potência gerado na estimação. Pretende-se corrigir este tipo de 
estimação através do ajuste do parâmetro $\chi_{\text {lim }}$, conforme mencionado anteriormente, evitando a perda do pico de menor energia, mas com energia ainda assim significativa.

Visualmente, o ajuste dos espectros foi considerado bom, principalmente no que diz respeito aos mares unimodais, onde o espectro de frequência esteve sempre muito próximo ao do ensaio. Nas estimativas bimodais os resultados foram satisfatórios, mas fica claro que mais testes devem ser realizados, especialmente após a calibração de $\chi_{\text {lim }}$.

A escolha do modelo de espectro de frequência JONSWAP, composto à parte direcional com $s$ fixo conforme já apresentado, foi feita devido aos seguintes fatores:

- O uso corrente deste modelo tanto por parte da PETROBRAS, quanto na literatura clássica do assunto faz com que seu uso seja recomendado.

- Ao utilizar este modelo, deixa de ser necessária a estimação do parâmetro $\gamma$ por meio de um segundo ajuste paramétrico, o qual poderia dispersar erros da primeira estimação feita pelo modelo de Hogben \& Cobb.

- A título de esclarecimento, os mapas dos espectros direcionais utilizando-se $s$ fixo são visualmente mais próximos dos mapas originais, bem como a forma do espectro de potência obtido pelos parâmetros estimados. Isso ocorre devido ao uso de $s$ fixo para a geração das ondas nos ensaios.

Os resultados obtidos foram, de maneira geral, considerados satisfatórios, dado que principalmente os valores estimados de $H_{s}$ e $T_{p}$ de cada modo espectral foram muito próximos aos teóricos, assim como $\phi$, mesmo considerando-se os erros inerentes ao processo de geração do mar no tanque de provas, bem como de suas medições. 


\section{Conclusão e sugestões de trabalhos futuros}

Este capítulo versa sobre as conclusões a respeito dos resultados obtidos ao longo do trabaIho para as estimações dos espectros direcionais e as estatísticas de mar retiradas dos espectros. São também feitas considerações sobre a metodologia de calibração desenvolvida, assim como sobre o critério de bimodalidade implementado na segunda parte do trabalho. Sugestões são feitas a respeito de trabalhos futuros sobre diversos aspectos não considerados neste trabalho, por limitações de software ou por priorização de determinados aspectos a serem abordados.

No capítulo 4 foi descrita em detalhes a metodologia de calibração dos hiperparâmetros, a qual foi desenvolvida para analisar a sensibilidade das estimações dos espectros a estes parâmetros, utilizando-se o FPSO P-50 em três diferentes calados e sujeito a diversos estados de mar. Os testes de aplicação desta metodologia de calibração indicam que os valores dos hiperparâmetros podem ser obtidos previamente, por meio de simulações numéricas, adotando-se os pares $\left(u_{1}, u_{2}\right)$ em função do calado e do período médio, sem causar grandes erros nas estimativas de $H_{s}$. Verifica-se nestes resultados uma tendência clara: em períodos de onda maiores devem ser adotados valores maiores de $u_{1}$ e $u_{2}$.

Os percentuais de erro em $H_{s}$ obtidos pela aplicação da metodologia, representados pelas curvas cor-de-rosa nas figuras 18 a 22, indicam claramente que com o aumento dos períodos e a diminuição dos calados os erros tendem a ser menores. Esta é uma conclusão que vai de encontro ao comportamento realmente esperado da estimação, pois em períodos maiores espera-se maior resposta da embarcação, o que facilita o processo de estimação. O interessante nestes casos é perceber que os valores dos hiperparâmetros obtidos pela metodologia garantem a conservação destas boas características, deixando os percentuais de erro muito próximos àqueles obtidos com o uso dos valores ótimos dos hiperparâmetros.

Uma importante conclusão é que na abordagem atual, utilizada em (ISEKI, 2011) e (SIMOS et al., 2009), os valores dos hiperparâmetros são fixos por calado, o que pode levar a erros desnecessários nas estimações.

Casos com mares de períodos de pico baixos, como $T_{p}=8,5 \mathrm{~s}$, possuem maiores erros devido às próprias limitações do método Bayesiano de estimação, dadas as baixas amplitudes das respostas da embarcação utilizada como modelo numérico. Utilizando-se uma embarcação menor, com diferentes características, é provável que se aumente a faixa de frequências de aplicação do método Bayesiano. No entanto, para o caso do FPSO a estimativa de mares com períodos próximos ao período de corte fica comprometida. 
Vale lembrar que esta é apenas uma análise de sensibilidade preliminar desta metodologia, pois existem importantes fatores a serem considerados, tais como calibração do hiperparâmetro de energia $u_{3}$, discretização mais refinada da região preferencial da malha $u_{1} \times u_{2}$ e maiores variações dos parâmetros de definição dos espectros teóricos. Portanto, embora os resultados indiquem boas perspectivas, toma-se a prudente atitude de sugerir mais testes variando-se outros parâmetros do espectro direcional antes de uma conclusão final a respeito do uso da metodologia de calibração desenvolvida.

Devido à própria definição do hiperparâmetro $u_{3}$, relacionada ao acúmulo de energia em frequências onde não ocorrer resposta da embarcação, sugere-se também uma análise de sensibilidade mais ampla que a atual, envolvendo também este termo. Principalmente em mares de través observa-se uma superestimação da energia, o que pode ter sido ocasionado pelo uso incorreto de valores para este hiperparâmetro. Não sendo este um termo de suavização, talvez seja necessária uma abordagem diferenciada, verificando-se inicialmente uma tendência das estimações com outros parâmetros fixos e variação de $u_{3}$ e $\theta_{m}$, afim de perceber se existe uma relação entre estes termos, dada a tendência de erros maiores em $\theta_{m}=90^{\circ}$.

Os mares bimodais não foram testados nesta abordagem, mas esta é uma recomendação feita neste momento, uma vez que os estudos iniciais da metodologia de calibração indicam bons resultados, necessitando-se avaliar outros casos. Espera-se que exista predominância dos valores de $u_{1}$ e $u_{2}$ para os picos de maior energia, mas é complexo afirmar tal tendência, uma vez que nenhum teste foi feito neste sentido. Podem também ocorrer valores altos dos hiperparâmetros quando os picos de energia forem relativamente próximos, forçando maior suavização nas frequências e direções.

Outro aspecto importante de ser abordado é o uso de valores diferentes de espalhamento, dado que neste trabalho utilizou-se $s=150$, o que implica em alta concentração de energia. Intuitivamente, parece existir uma tendência de que para mares mais espalhados (valores menores de $s$ ) ocorram valores maiores dos hiperparâmetros, forçando maior suavização. Embora a suavização do espectro seja diferente do espalhamento e não necessariamente uma propriedade implique na outra, estas duas características parecem estar relacionadas de alguma maneira, (conforme figuras $6(c)$ e 7 (c) do primeiro exemplo do capítulo 4) e, portanto, sugere-se um estudo mais aprofundado dos valores de $u_{1}$ e $u_{2}$ a serem obtidos pela repetição do processo de calibração para mares mais espalhados.

As estimações paramétricas feitas na segunda parte do trabalho, no capítulo 5, obtiveram bons resultados para os casos testados. Entretanto, ao considerar que apenas dois mares de ensaios foram estimados por modelos bimodais afirma-se, com certa cautela, que este método pode ser utilizado em termos práticos para a estimação das estatísticas de mares bimodais. A limitação do método, no entanto, não se encontra no modelo paramétrico, sendo este funcional, mas sim no critério de bimodalidade. Verifica-se que a estimação das estatísticas ao utilizar o modelo paramétrico unimodal atingiu resultados muito bons, quando comparados às estatísticas globais dos espectros medidos nos ensaios, sendo este método de estimação considerado aplicável na prática. 
Em relação ao critério de bimodalidade implementado, recomenda-se fortemente uma calibração do valor de $\chi_{\text {lim }}$, ajustando-o aos mares da costa brasileira, dado o fato de que o valor limite sugerido e utilizado até o momento foi encontrado com base em testes no mar mediterrâneo, em locais próximos à costa italiana.

Após ser feita a calibração deste parâmetro definidor da bimodalidade, sugere-se novos testes com os mesmos mares, verificando um possível aumento do número de mares cruzados. Além de novos casos com picos de energia em diferentes direções e períodos de pico, evitando-se recair sobre as limitações do método apresentado.

O estudo mais aprofundado do método Bayesiano no que diz respeito aos casos de ondas incidentes a $45^{\circ}$ é um assunto a ser revisado. Talvez uma reformulação deste método utilizando as séries temporais e os RAOs do movimento de Roll, verificando a influência do mesmo nas estimativas, corrija as estimativas divergentes. Uma segunda alternativa é a discretização exata dos RAOs dos outros graus de liberdade utilizados, pois é feita uma interpolação entre RAOs de $40^{\circ}$ e $50^{\circ}$.

Por fim, uma última sugestão é um processo restrito a poucas iterações buscando-se calibrar os pares de $u_{1}$ e $u_{2}$ em função do calado, período e também da direção, estimando a cada iteração um novo $\theta_{m}$ e utilizando-se esta informação para uma busca na tabela de erros mínimos, interpolando quando necessário. 


\section{APÊNDICE A - Conceitos básicos de estatística Bayesiana}

\section{A.1 Introdução}

Quando se realiza algum estudo estatístico de um determinado fenômeno, buscando-se conhecer as características das variáveis e parâmetros envolvidos no sistema, é frequente a utilização do termo inferência estatística para referir-se ao ato de se fazer certas afirmações sobre um conjunto de observações, baseando-se nas informações extraídas do mesmo por processos estatísticos. Entretanto, este termo depende em muito do tipo de abordagem estatística considerada, pois pode-se inferir estatísticamente sobre um conjunto de dados de diferentes maneiras. As principais escolas de inferência estatística são conhecidas como frequentista e Bayesiana.

A inferência frequentista tem por característica o uso de distribuições de probabilidade com parâmetros estimados por meio de amostragem, estando estes sujeitos aos métodos clássicos desta teoria, tais como intervalos de confiança e testes de hipóteses. Assim, o que está sendo avaliado é como um determinado estimador de um parâmetro constante e de valor desconhecido aproxima bem o valor "real" desta constante. O nome desta abordagem advém da definição frequentista de probabilidade, na qual a probabilidade de um evento é o limite de sua frequência relativa em um número grande de ensaios.

No caso da inferência Bayesiana, faz-se uso de evidências para estimar a probabilidade de uma hipótese ser verdadeira, sendo que este conhecimento é utilizado iterativamente para modificar o nível de crença que se tem sobre a verdade de uma hipótese. Assim, a incerteza que se tem sobre o valor de uma determinada quantidade é dada por um modelo probabilístico que pode ser (e de fato é numa abordagem totalmente Bayesiana) alterado com base em informações adquiridas ao longo do tempo. Por este motivo, não existe diferença entre um parâmetro e uma variável aleatória na abordagem Bayesiana, pois o nível de crença, ou ainda, o grau de incerteza de ambos é dado por modelos probabilísticos para a quantidade que se deseja obter mais informações. Esta abordagem recebe este nome devido ao teorema que define tais probabilidades, o teorema de Bayes, criado por Thomas Bayes próximo à metade do século XVIII. 


\section{A.2 Conceitos básicos de estatística Bayesiana}

\section{A.2.1 O teorema de Bayes}

Considere uma quantidade de interesse desconhecida $\theta$ (tipicamente não observável). A informação da qual se dispõe sobre tal quantidade, resumida probabilisticamente por $p(\theta)$, pode ser aumentada (ou seja, pode ter sua incerteza reduzida) observando-se uma quantidade aleatória $X$ relacionada a $\theta$. A função densidade de probabilidade conjunta, $p(x, \theta)$, pode ser relacionada à função densidade de probabilidade condicional, $p(x \mid \theta)$, da seguinte maneira:

$$
p(x, \theta)=p(x \mid \theta) p(\theta)=p(\theta \mid x) p(x) \Longleftrightarrow p(\theta \mid x)=\frac{p(x \mid \theta) p(\theta)}{p(x)}
$$

Dado que $1 / p(x)$ não depende de $\theta$, este termo funciona como uma constante normalizadora. Se $x$ corresponde a valores amostrais (e portanto fixos) e $\theta$ corresponde a parâmetros da função densidade de probabilidade condicional, $p(x \mid \theta)$ pode ser vista como função de $\theta$, a qual fornece a plausibilidade, ou ainda, a verossimilhança de cada um dos valores possíveis de $\theta$, utilizando-se a notação $L(\theta \mid x)=p(x \mid \theta)$ para esta função.

As distribuições $p(\theta)$ e $p(\theta \mid x)$ são chamadas, respectivamente, priori e posteriori. A distribuição a priori reflete a natureza estatística do fenômeno, sendo definida sem a informação fornecida pelos dados colhidos. Já a posteriori contém a tanto a informação da priori, quanto a informação da verossimilhança, sendo esta relacionada aos dados observados.

Quando a amostra de dados $x$ é conhecida, a relação (A.1) pode então ser escrita como:

$$
p(\theta \mid x) \propto L(\theta \mid x) p(\theta)
$$

A equação (A.2) acima é a forma mais usual do teorema de Bayes, sendo esta a base de toda a abordagem Bayesiana de inferência estatística. Note que a igualdade foi substituida pela proporcionalidade, uma vez que o denominador em (A.1) é apenas uma constante normalizadora.

Tendo em vista o teorema de Bayes, é intuitivo pensar que se a distribuição a priori ou a verossimilhança forem pequenas, a posteriori também será, ou seja, existindo pouca crença na ocorrência de um fenômeno, ou uma baixa plausibilidade do mesmo, a probabilidade associada a posteriori será também pequena, independente da informação fornecida pelos dados observados. Este fato leva ao problema da escolha adequada da distribuição a priori e da função de verossimilhança a serem usadas para encontrar uma posteriori adequada, uma vez que a escolha da 
priori é subjetiva (ver (BOLSTAD, 2007), (LEE, 1997) e (EHLERS, 2003)).

Pela própria definição da verossimilhança apresentada anteriormente, pode-se compreender o princípio da verossimilhança, o qual postula que, para inferir sobre uma quantidade de interesse $\theta$ importa apenas o que foi realmente observado, e não o que poderia ter acontecido mas efetivamente não aconteceu, ou seja, para se definir, por exemplo, a distribuição de probabilidade de uma quantidade $\theta$, deve-se basear nas observações feitas sobre esta e não se basear em todos os valores possíveis de $\theta$, pois estes nunca serão conhecidos (em termos práticos).

Um exemplo clássico do uso deste princípio em inferência estatística, é o método da máxima verossimilhança, no qual toma-se o ponto de vista em que os parâmetros $\theta$ da função densidade de probabilidade condicional $p(x \mid \theta)$ são as variáveis da verossimilhança $L(\theta \mid x)$, utilizando-se então os valores observados $x$ para ajustar as variáveis $\theta$ da função a esta amostra, encontrando a função de verossimilhança que melhor descreve as observações.

\section{A.3 Abordagem Bayesiana à solução de sistemas lineares de alta ordem}

A abordagem Bayesiana ao problema de ajuste de um conjunto de dados por uma função de coeficientes desconhecidos é abordada em diversas referências. Em (AKAIKE, 1980) esta é utilizada como uma ferramenta de tratamento deste tipo de problema quando o número de parâmetros a serem estimados é muito maior que o número de dados da amostra.

A seguir são apresentadas as linhas gerais do desenvolvimento desta abordagem, de maneira muito próxima à apresentada em (HASHIMOTO; KOBUNE; KAMEYAMA, 2000), com alguma considerações baseadas em (AKAIKE, 1980). Inicialmente é apresentada a modelagem Bayesiana e em seguida, introduz-se a necessidade e apresenta-se um critério de informação para a determinação de valores de hiperparâmetros de um modelo Bayesiano. O critério de informação apresentado é chamado ABIC (Akaike's Bayesian Information Criterion) e, embora não seja efetivamente utilizado neste trabalho como um método de calibração dos hiperparâmetros do modelo Bayesiano, foi estudado durante o desenvolvimento da metodologia de calibração e utilizado em comparações iniciais com os resultados deste trabalho, conforme descrito no capítulo 4. Além disso, destaca-se a importância de tal critério na bibliografia especializada, dado que todas as referências utilizadas neste trabalho mencionam ou utilizam este critério.

Assumindo que uma variável y pode ser descrita como uma regressão linear de um vetor de variáveis independentes $\mathrm{x}$ conforme a relação a seguir:

$$
y=\mathbf{x} \boldsymbol{\alpha}+\epsilon
$$

em que $\boldsymbol{\alpha}$ é um vetor de coeficientes desconhecidos e $\epsilon$ é uma variável aleatória tal que segue uma distribuição Normal de média 0 e variância $\sigma^{2}$, denotado por $\epsilon \sim \mathcal{N}\left(0, \sigma^{2}\right)$. Uma importante 
definição a ser utilizada posteriormente para construir a priori e a verossimilhança, é a função densidade de probabilidade (f.d.p.) de uma variável aleatória contínua $X$. Se $X \sim \mathcal{N}\left(\mu, \sigma^{2}\right)$, sua f.d.p. é dada por:

$$
f(x)=\frac{1}{\sqrt{2 \pi} \sigma} \exp \left[\frac{-1}{2 \sigma^{2}}(x-\mu)^{2}\right] \quad, \text { para }-\infty<x<\infty
$$

É fácil ver que a integral desta função indica a probabilidade de $X$, já que a sua integral sobre os reais resulta em 1 .

Dada uma amostra $\left(y_{i}, \mathbf{x}_{i}\right), \operatorname{com} i=\{1, \ldots, n\}$, os coeficientes $\boldsymbol{\alpha}$ podem ser estimados pelo método dos mínimos quadrados, ou ainda, pelo método da máxima verossimilhança, bastando-se minimizar a relação (A.3):

$$
\sum_{i=1}^{n}\left|y_{i}-\mathbf{x}_{i}^{t} \boldsymbol{\alpha}\right|^{2}=\|\mathbf{y}-\mathbf{X} \boldsymbol{\alpha}\|^{2}
$$

onde $\mathbf{y}=\left(y_{1}, \ldots, y_{n}\right)^{t}, \mathbf{X}=\left(\mathbf{x}_{1}, \ldots, \mathbf{x}_{n}\right)^{t}$ e $\|\cdot\|^{2}$ denota uma norma dada por uma matriz definida positiva.

Quando a ordem do vetor $\boldsymbol{\alpha}$ dos coeficientes é muito maior que o número de observações $n$ (se for maior que $2 \sqrt{n}$ ) ou a matriz $\mathbf{X}$ dos dados observados é mal condicionada, o modelo torna-se instável ou os coeficientes não podem ser calculados por métodos tradicionais, tal como o método dos mínimos quadrados. Sendo este um problema clássico de análise numérica, para contornar tal situação encontra-se frequentemente na literatura a técnica de introdução de uma preferência nos parâmetros a serem calculados, levando-se em consideração um balanceamento entre uma aproximação bem ajustada e a suavidade da função utilizada para este ajuste. Dessa maneira, tenta-se minimizar a seguinte expressão:

$$
\|\mathbf{y}-\mathbf{X} \boldsymbol{\alpha}\|^{2}+u^{2}\left\|\mathbf{D}\left(\boldsymbol{\alpha}-\boldsymbol{\alpha}_{\mathbf{0}}\right)\right\|^{2}
$$

Assumindo que $\boldsymbol{\alpha}_{0}$ é conhecido e próximo de $\boldsymbol{\alpha}$, e que para uma certa matriz $\mathbf{D}$ utilizada para discretização das diferenças de segunda ordem ${ }^{1}$, o termo $\left|\mathbf{D}\left(\boldsymbol{\alpha}-\boldsymbol{\alpha}_{\mathbf{0}}\right)\right|^{2}$ é pequeno o suficiente,

\footnotetext{
1 (AKAIKE, 1980) define alguns tipos de matrizes D em cada exemplo apresentado, mas para uma melhor compreensão da definição recomenda-se a leitura de (SHILLER, 1973) ou (SPARANO, 2008) para um exemplo de aplicação
} 
tem-se que o vetor de parâmetros que minimiza a expressão (A.4) varia de acordo com a escolha de $u$ e, portanto, determinar um valor adequado deste parâmetro é o atual problema.

Para solucionar este novo problema, (AKAIKE, 1980) propôs que a minimização de (A.4) é equivalente à maximização da expressão (A.5) a seguir:

$$
\exp \left(\frac{-1}{2 \sigma^{2}}\|\mathbf{y}-\mathbf{X} \boldsymbol{\alpha}\|^{2}\right) \exp \left(\frac{-u^{2}}{2 \sigma^{2}}\left\|\mathbf{D}\left(\boldsymbol{\alpha}-\boldsymbol{\alpha}_{\mathbf{0}}\right)\right\|^{2}\right)
$$

Onde tem-se que o primeiro termo é proporcional à verossimilhança de $\boldsymbol{\alpha}$ e $\sigma^{2}$ para uma dada amostra $\left(y, \mathbf{x}_{i}\right)$, e o segundo termo é a distribuição a priori de $\boldsymbol{\alpha}$ :

$$
\begin{aligned}
& L\left(\boldsymbol{\alpha}, \sigma^{2} \mid \mathbf{y}\right) \propto \exp \left(\frac{-1}{2 \sigma^{2}}\|\mathbf{y}-\mathbf{X} \boldsymbol{\alpha}\|^{2}\right) \\
& p\left(\boldsymbol{\alpha} \mid u^{2}, \sigma^{2}\right)=\exp \left(\frac{-u^{2}}{2 \sigma^{2}}\left\|\mathbf{D}\left(\boldsymbol{\alpha}-\boldsymbol{\alpha}_{\mathbf{0}}\right)\right\|^{2}\right)
\end{aligned}
$$

Pode-se ver que a distribuição a posteriori do vetor de coeficientes $\boldsymbol{\alpha}$ é proporcional à expressão (A.5), sendo uma implicação direta da relação (A.2). Desta maneira, segundo (HASHIMOTO; KOBUNE; KAMEYAMA, 2000), o vetor que minimiza (A.4) é dado pela moda estatística da distribuição a posteriori, ou seja, é o vetor que maximiza $(A .5)^{2}$. Resumidamente, o processo implica em aumentar a probabilidade de ocorrência do conjunto de dados observados, por meio da "meIhor escolha" dos parâmetros desta função densidade de probabilidade.

De acordo com (AKAIKE, 1980), o problema fundamental na aplicação destes modelos a dados reais é a escolha do valor de $u^{2}$, sendo esta equivalente à decisão da distribuição a priori de $\boldsymbol{\alpha}$, supondo conhecidos os valores das outras constantes. Se $\boldsymbol{\alpha}_{\mathbf{0}}$ não é exatamente igual à $\boldsymbol{\alpha}$, conforme $u^{2}$ aumenta, o viés da estimativa também aumenta, mas a variância diminui. Nota-se então que é interessante encontrar um equilíbrio entre estes dois fatores e isto pode ser feito utilizando a informação fornecida pela própria verossimilhança do modelo, bastando-se considerar $u^{2}$ como um hiperparâmetro, uma vez que este possui distribuição a priori própria.

Portanto, pela própria abordagem Bayesiana, uma mudança no modelo (variação do valor de $u^{2}$ ) é ajustada pelos próprios dados observados (por meio da verossimilhança), assim justificando a afirmação de que a escolha do valor de $u^{2}$ pode ser interpretada como a de um parâmetro da distribuição a priori de $\boldsymbol{\alpha}$.

\footnotetext{
${ }^{2}$ Para uma distribuição de probabilidades contínua, a moda é o valor no qual a função densidade de probabilidade atinge seu valor máximo.
} 
Para o cálculo de valores de $u^{2}$ e $\sigma^{2}$ que levassem em consideração os fatos apresentados acima, (AKAIKE, 1980) propôs o uso da verossimilhança marginal dada por:

$$
\int L\left(\boldsymbol{\alpha}, \sigma^{2} \mid \mathbf{y}\right) p\left(\boldsymbol{\alpha} \mid u^{2}, \sigma^{2}\right) \mathrm{d} \boldsymbol{\alpha}
$$

Entretanto, ao invés de desenvolver uma distribuição a priori para $\left(u^{2}, \sigma^{2}\right)$, foi utilizado um procedimento de escolha do modelo por meio do método da máxima verossimilhança. Assim, um par $\left(u^{2}, \sigma^{2}\right)$ é escolhido de modo que o valor máximo de (A.6) é atingido, o que intuitivamente significa encontrar valores para este par mais prováveis de terem gerado o conjunto de dados. Levando-se em consideração o histórico desenvolvido em estudos anteriores, (AKAIKE, 1980) propôs então um critério de informação que indicasse a adequação do modelo dado um par $\left(u^{2}, \sigma^{2}\right)$ com base na expressão (A.6) por meio do método da máxima verossimilhança, mas transformando-o em um problema de minimização:

$$
A B I C=-2 \ln \int L\left(\boldsymbol{\alpha}, \sigma^{2} \mid \mathbf{y}\right) p\left(\boldsymbol{\alpha} \mid u^{2}, \sigma^{2}\right) \mathrm{d} \boldsymbol{\alpha}
$$

Assim, buscam-se valores de $u^{2}$ e $\sigma^{2}$ tais que a estatística $A B I C$ definida na equação (A.7), seja mínima. Neste caso, é utilizada a função log-verossimilhança, a qual possui uma relação muito próxima à entropia, sendo esta última a base para o uso de critérios de informação na busca por modelos concisos e preferencialmente de poucos parâmetros. 


\section{APÊNDICE B - Cálculo do erro do método de calibração e normalização dos espectros}

Para que seja definido o melhor espectro estimado e consequentemente se saiba o par de hiperparâmetros que definiu tal estimativa por meio da minimização do funcional (3.20), adota-se um processo iterativo sobre um plano $u_{1} \times u_{2}$ discretizado, em que a cada par $\left(u_{1}, u_{2}\right)$ é calculada uma medida que indique o quão adequada é a respectiva aproximação do espectro direcional teórico.

Conhecidos os espectros direcionais teórico e estimado discretizados nas frequências e direções, denotados respectivamente por $S^{*}\left(\omega_{m}, \theta_{k}\right)$ e $S\left(\omega_{m}, \theta_{k}\right)$, onde $m=\{1, \ldots, M\}$ e $k=\{1, \ldots, K\}$, os dois tipos de medidas qualitativas utilizadas neste trabalho são definidos nas expressões (B.1) e (B.3) denotando, respectivamente, o erro quadrático e o erro absoluto:

$$
\begin{aligned}
\text { erro }_{\text {quad }} & =\sum_{k=1}^{K} \sum_{m=1}^{M} \Delta \theta \Delta \omega_{m}\left[S^{*}\left(\omega_{m}, \theta_{k}\right)-S\left(\omega_{m}, \theta_{k}\right)\right]^{2} \\
\text { erro }_{a b s} & =\sum_{k=1}^{K} \sum_{m=1}^{M} \Delta \theta \Delta \omega_{m}\left|\frac{S^{*}\left(\omega_{m}, \theta_{k}\right)}{\max \left[S^{*}(\omega, \theta)\right]}-\frac{S\left(\omega_{m}, \theta_{k}\right)}{\max [S(\omega, \theta)]}\right|
\end{aligned}
$$

onde $\Delta \theta=2 \pi / K$. Os valores $\max \left[S^{*}(\omega, \theta)\right]$ e $\max [S(\omega, \theta)]$ são, respectivamente, os máximos dos espectros teórico e estimado, nos intervalos discretos de $\omega$ e $\theta$, e $\Delta \omega_{m}$ é dado por:

$$
\Delta \omega_{m}=\left\{\begin{array}{l}
\omega_{2}-\omega_{1}, \text { se } m=1 \\
\frac{\omega_{m}-\omega_{m-1}}{2}, \text { se } 1<m<M \text { e } \\
\omega_{M}-\omega_{M-1}, \text { se } m=M .
\end{array}\right.
$$

Intuitivamente, a diferença entre estas duas formas de medir a qualidade da aproximação reside no fato de que a primeira faz uma comparação das energias contidas nos espectros teórico 
e estimado, sendo equivalente a uma comparação indireta dos valores de $H_{s}$ global destes dois espectros, dado que $H_{s}=4 \sqrt{m_{0}}$, onde $m_{0}$ é o momento de ordem 0 do espectro de potência ${ }^{1}$. Já no segundo método de cálculo compara-se a forma e a disposição das energias. Embora seja perdida a informação da quantidade de energia real contida nos espectros devido à normalização feita por meio da divisão pelo valor máximo, por este método verifica-se o quão distante estão os picos de energia e quão dispersos estão ao longo de $\omega$ e $\theta$. Esta segunda forma de cálculo equivale à comparação das funções de espalhamento dos espectros teórico e estimado.

O erro quadrático foi adotado inicialmente como forma de verificação da melhor estimativa. Entretanto, como mostrado a seguir, esta abordagem possui deficiências na distinção de casos que são próximos em termos da quantidade de energia, mas muito distantes do ponto de vista da distribuição da mesma.

Um caso em que se tem o espectro teórico com somente um pico de energia, concentrado em uma certa coordenada $\left(\omega_{m}, \theta_{k}\right)$, e o estimado com a mesma quantidade de energia, mas muito espalhada ao longo das direções e frequências, é considerado muito próximo (ou até mesmo igual) a um caso onde o estimado possui a mesma distribuição de energia do teórico, em uma posição diferente do plano $(\omega, \theta)$, mas relativamente próxima do pico teórico.

Assim, um espectro com alta suavização e picos baixos, muito espalhados ao longo das direções e frequências pode ser considerado, erroneamente, como uma boa aproximação de um espectro teórico com alta concentração de energia em uma coordenada qualquer. Ocasionalmente, isso pode favorecer valores dos hiperparâmetros que resultem em alta suavização da estimativa, uma vez que estes casos também podem ser tidos como boas aproximaç̃ões.

\section{Exemplo 13}

Este fato pode ser ilustrado pelo exemplo dado na figura 41 a seguir, onde são apresentados para os parâmetros $H_{s}=4 \mathrm{~m}, T_{p}=10 \mathrm{~s}$ e $\theta_{m}=135^{\circ}$ os espectros teórico e estimados para níveis de suavização ótima e baixa, onde a estimativa ótima é encontrada pelo uso do erro tipo erro $_{\text {quad }}$ para as séries temporais do FPSO P-50 em calado cheio. A suavização destes casos é determinada pelo uso dos hiperparâmetros dados pela tabela 27.

\begin{tabular}{|l|c|c|}
\hline Suavização & $u_{1}$ & $u_{2}$ \\
\hline Ótima & 0,0001 & 0,004 \\
Baixa & 0,0003 & 0,008 \\
\hline
\end{tabular}

Tabela 27: Valores de $u_{1}$ e $u_{2}$ utilizados na comparação das formulações de erro.

Fica claro que o espectro com baixa suavização dado na figura 41(c), ao menos visualmente, aparenta aproximar melhor o espectro teórico apresentado na figura 41(a). A estimativa ótima dada pela figura 41(b) é altamente ruidosa, mas mesmo assim, pelo método de cálculo de erro adotado, obteve menor valor de erro em relação ao espectro teórico, conforme a tabela 28.

Ao observar as superfícies das diferenças absolutas dos espectros teórico e estimados para suavizações ótima e baixa dadas pela figura 42, fica mais evidente o problema encontrado. Embora

\footnotetext{
${ }^{1} \mathrm{O}$ momento de $k$-ésima ordem é dado por $m_{k}=\int_{0}^{\infty} S(\omega) \omega^{k} \mathrm{~d} \omega$ onde $S(\omega)$ é o espectro de potência.
} 


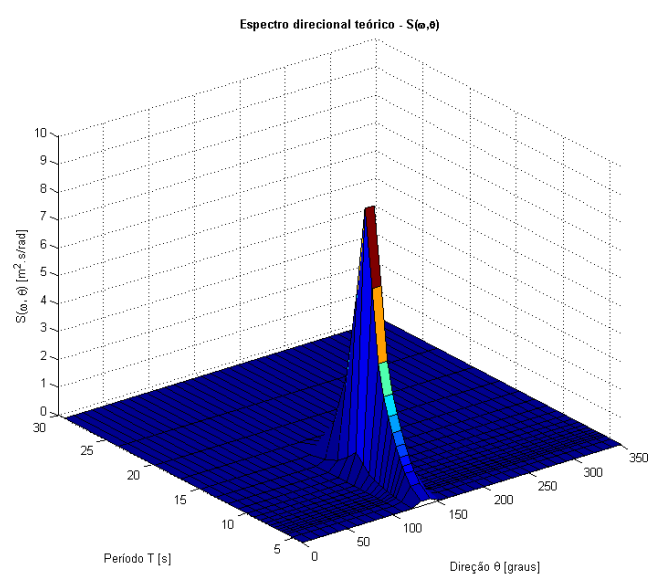

(a) Espectro direcional teórico.

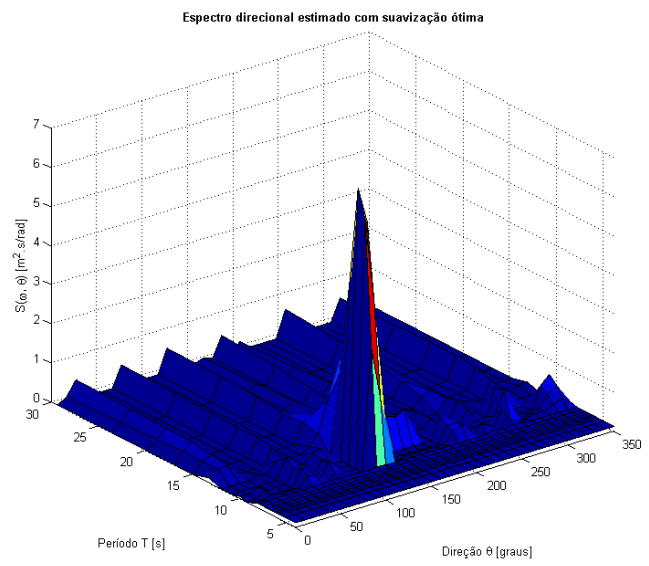

(b) Estimativa ótima por menor erro quad.

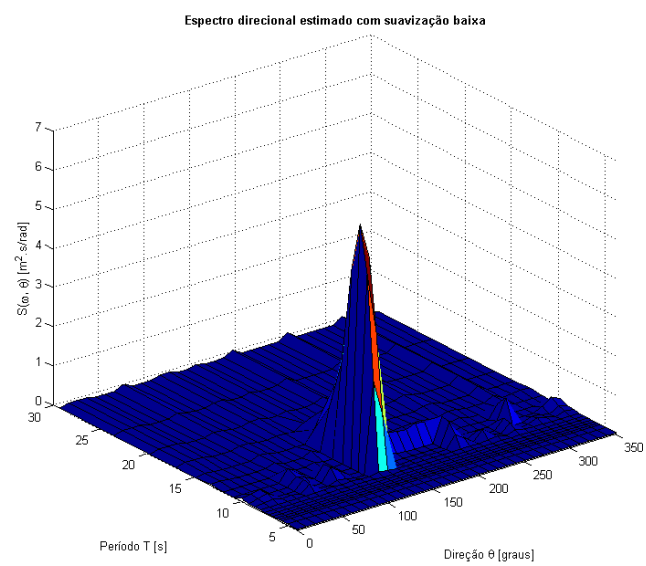

(c) Estimativa com baixa suavização.

Figura 41: Espectros teórico e estimados com diferentes valores de $u_{1}$ e $u_{2}$ com cálculo de erro pelo modelo erro $_{\text {quad }}$.

exista maior diferença entre o teórico e o ótimo em períodos mais altos, conforme figura 42(a), o valor de erro $_{\text {quad }}$ é ligeiramente menor, pois existe uma compensação pontual da diferença no período de pico, sendo muito menor nesta coordenada que no caso comparativo de baixa suavização apresentado na figura $42(\mathrm{~b})$.

Adotando-se o método de cálculo de erro do tipo erro $_{a b s}$ neste caso particular, verifica-se a identificação correta do espectro estimado pois, mesmo sem saber se a estimativa de baixa suavização é ótima ou não, sabe-se que esta é melhor ${ }^{2}$ que a obtida como ótima pela formulação do erro quadrático. Observa-se que neste caso o método erro $_{a b s}$ indica um erro menor associado à estimativa com menos ruído, conforme pode ser verificado na tabela 28.

De fato, o valor ótimo encontrado ao utilizar-se a formulação de erro absoluto fornece o valor erro $_{a b s}=4,4523 \mathrm{com}$ hiperparâmetros $u_{1}=0,00208$ e $u_{2}=0,00564$, sendo o espectro estimado apresentado na figura 43. Em compensação, o método de cálculo de erro quadrático

\footnotetext{
${ }^{2}$ Isto foi percebido durante os testes devido ao conhecimento prévio de estudos anteriores relacionados ao critério ABIC
} 


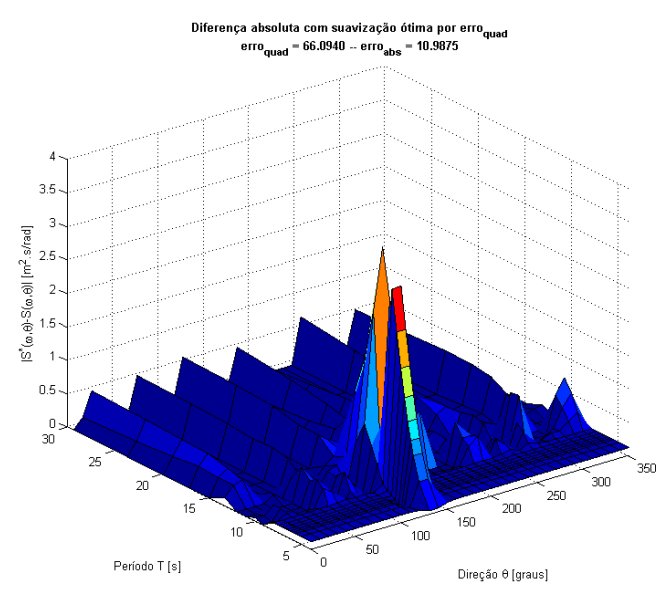

(a) Diferença absoluta caso ótimo.

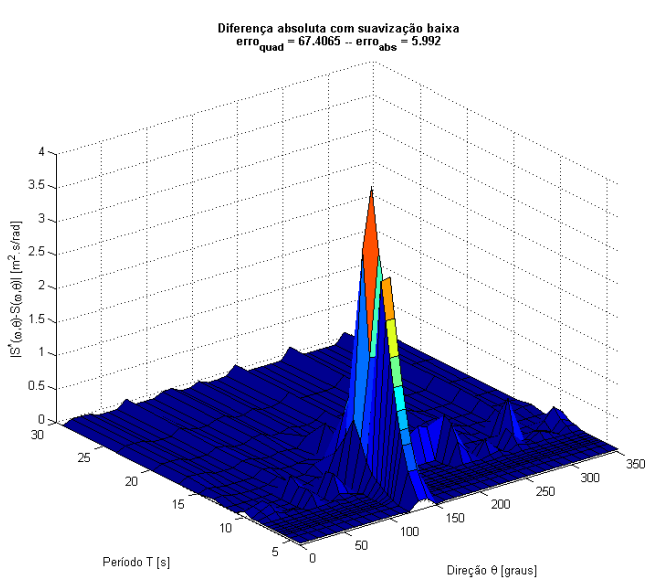

(b) Diferença absoluta caso com baixa suavização.

Figura 42: Diferença absoluta entre espectros teórico e estimados nos casos ótimo e com baixa suavização.

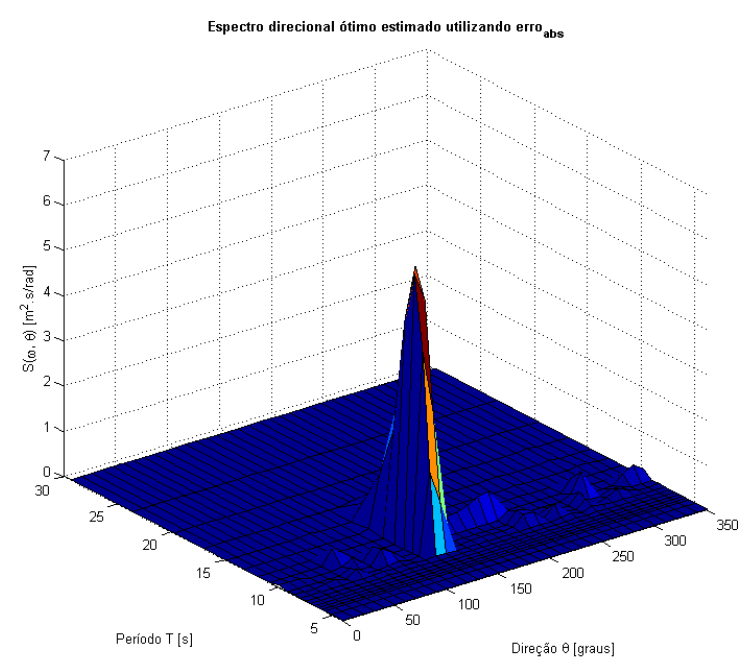

Figura 43: Espectro direcional ótimo estimado utilizando-se a formulação erro $o_{a b s}$.

indica erro quad $=72,3286$ para os mesmos hiperparâmetros, ou seja, não foi capaz de identificar corretamente a melhor estimativa.

\begin{tabular}{|l|c|c|}
\hline Suavização & erro quad & erro \\
\hline Ótima \\
Baixa & 66,0940 & 10,9875 \\
67,4065 & 5,9920 \\
\hline
\end{tabular}

Tabela 28: Formulações de erro e valores obtidos para a comparação das formulações de erro.

Diferenças como as obtidas em períodos altos no caso ótimo do exemplo dado usando a formulação de erro quadrático, terão energia equivalente ao pico do espectro teórico quando vistas pela formulação de erro absoluto, sendo, portanto, contabilizadas com o devido peso, influenciando o valor final de erro da maneira correta, ou seja, neste caso citado é possível identificar estes altos picos de diferenças, o que resulta em um alto valor de erro $_{a b s}$. 
Dados os fatos expostos acima, fica evidente que ao adotar-se o método de cálculo de erro pela expressão (B.3) do erro absoluto, garante-se a estimativa ótima correta. Isto ocorre devido ao fato de que ao se supor que o método Bayesiano não obtém estimativas com perda significativa de energia, basta-se comparar a distribuição desta com o teórico no plano definido pelas frequências e direções, sendo isto atingido pela normalização dos espectros. 
APÊNDICE C - RAOs do FPSO P-50 
RAO - SURGE - P.50 Calado 9m

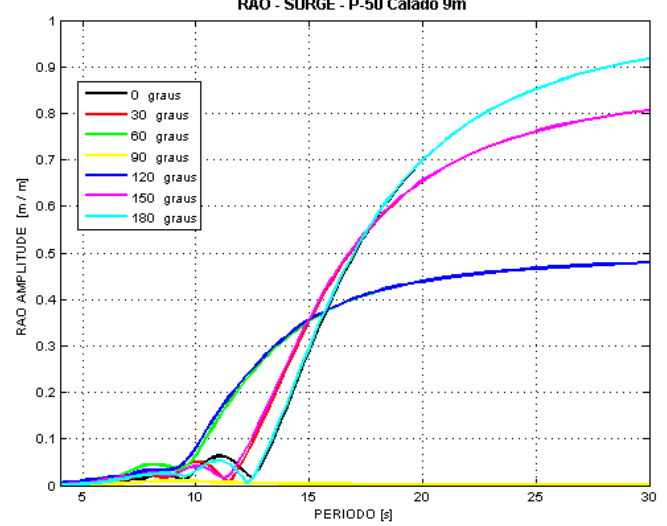

(a) RAO de Surge.

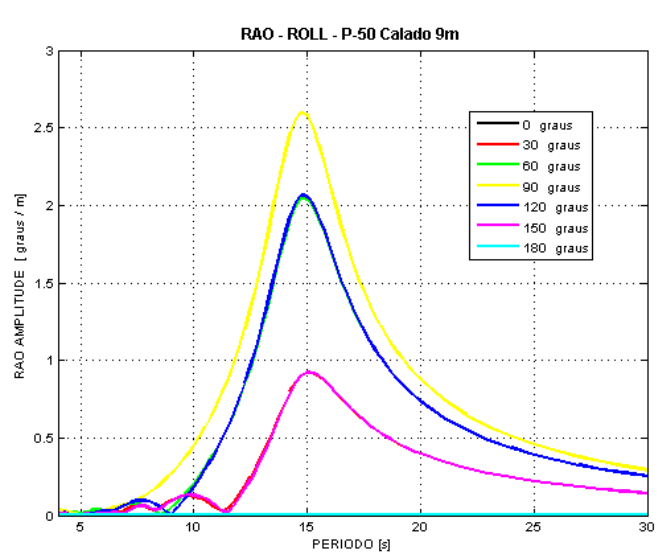

(d) RAO de Roll.

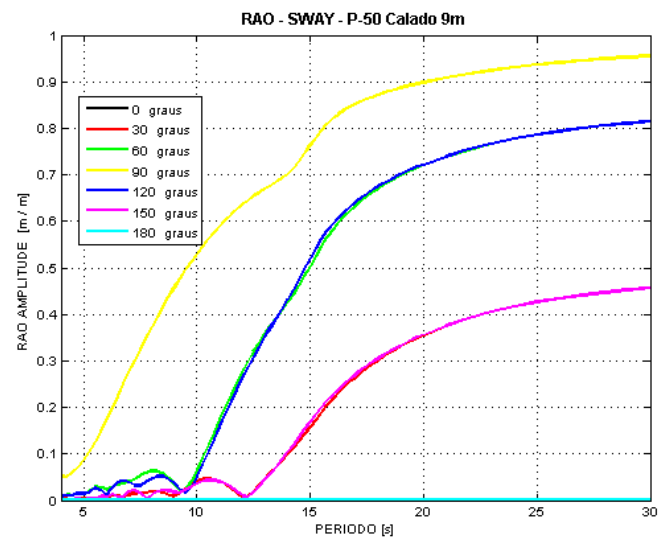

(b) RAO de Sway.

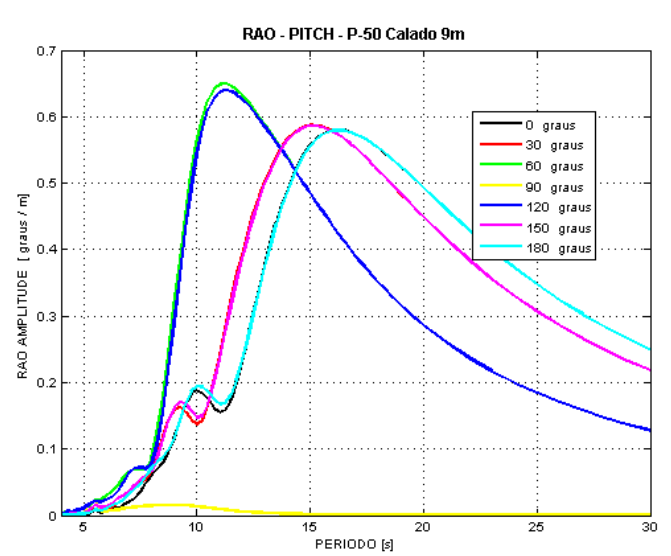

(e) RAO de Pitch.

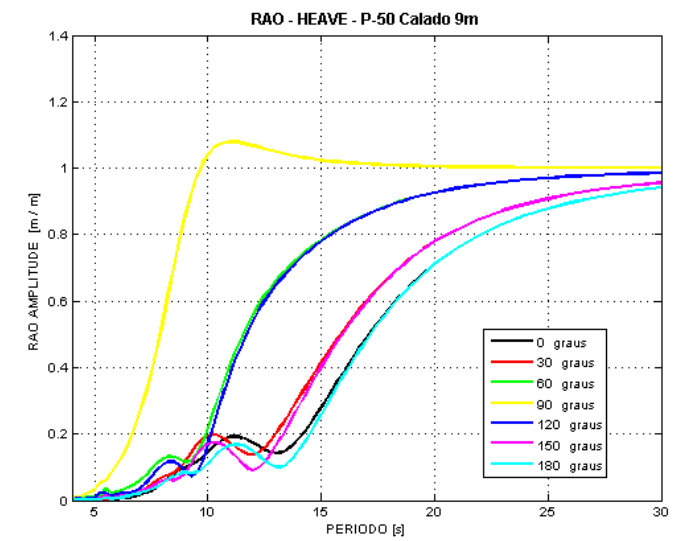

(c) RAO de Heave.

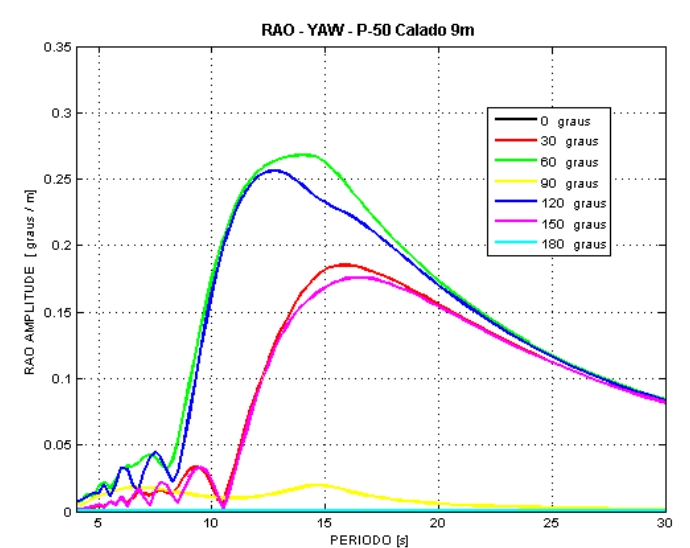

(f) RAO de Yaw.

Figura 44: RAOs de amplitude do FPSO P-50 em calado leve (9m). 
RAO - SURGE - P.50 Calado 14,5m

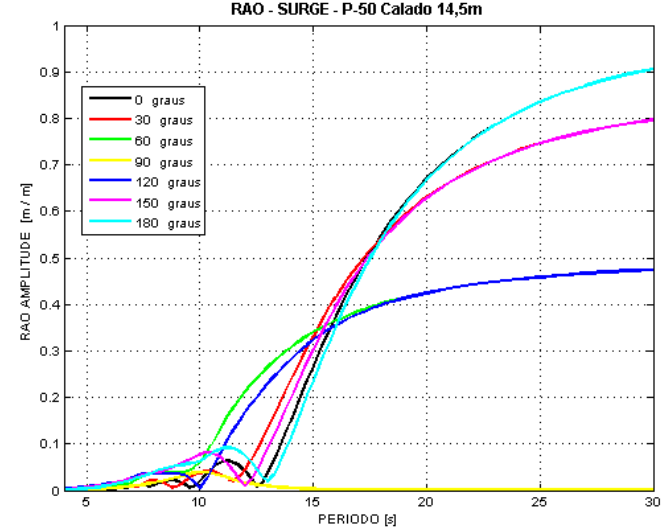

(a) RAO de Surge.

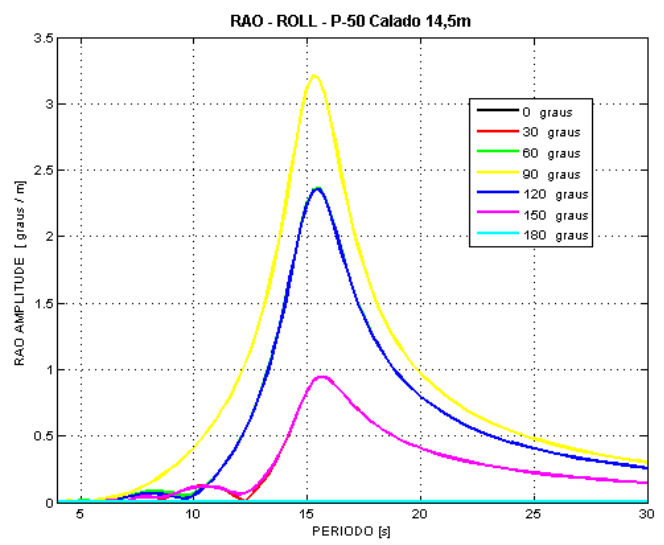

(d) RAO de Roll.

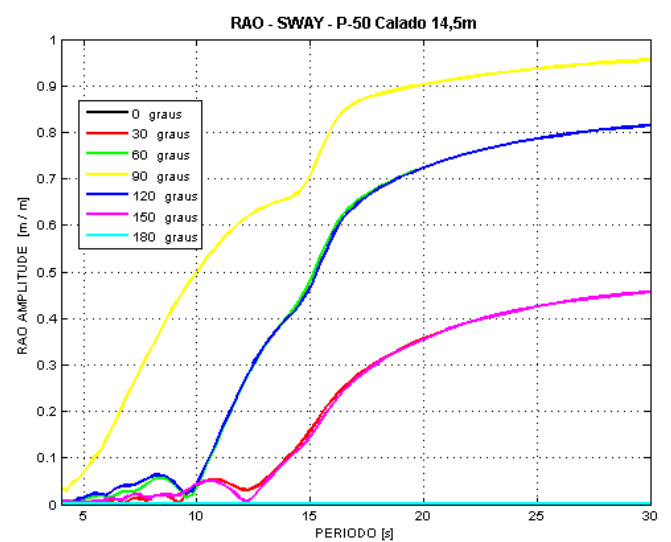

(b) RAO de Sway.

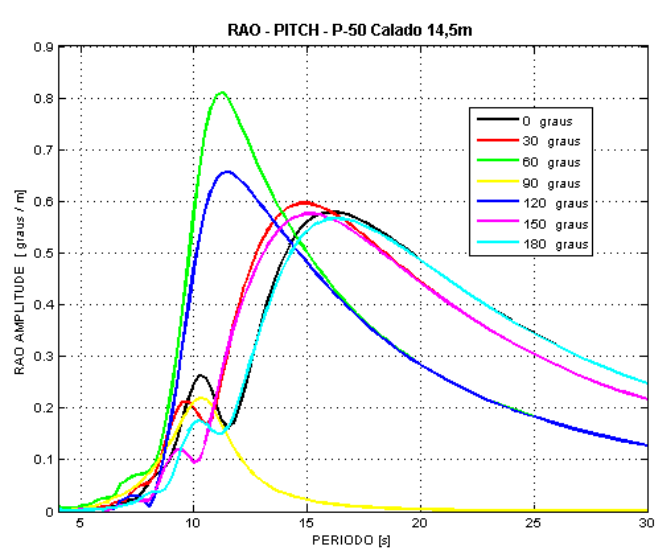

(e) RAO de Pitch.

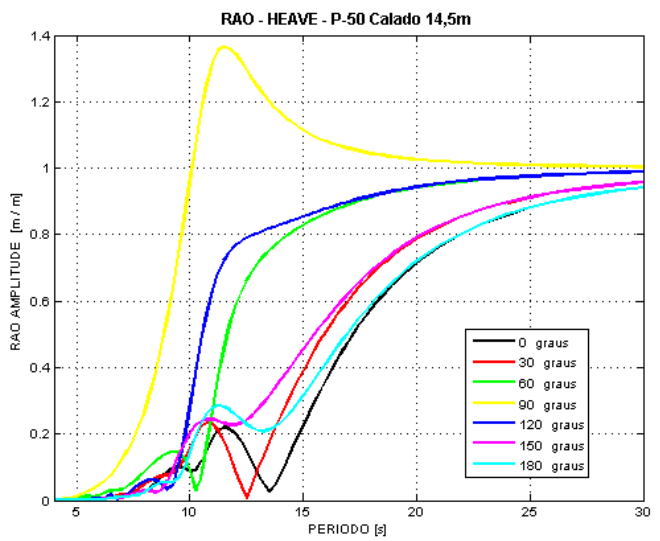

(c) RAO de Heave.

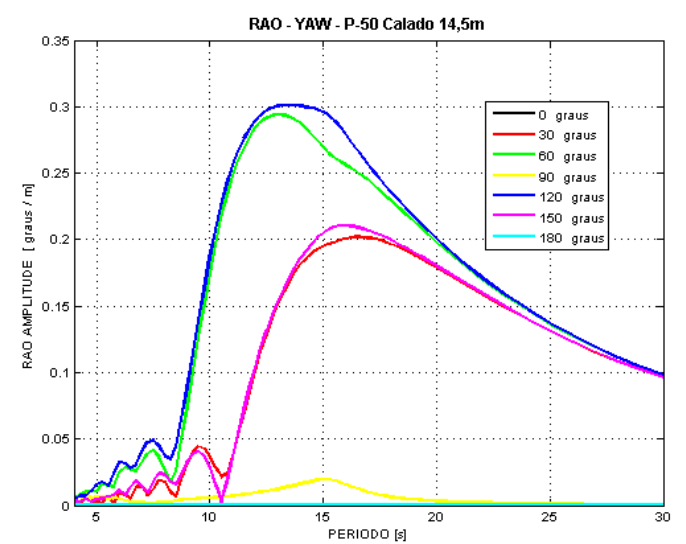

(f) RAO de Yaw.

Figura 45: RAOs de amplitude do FPSO P-50 em calado intermediário (14,5m). 
RAO - SURGE - P.50 Calado 21m

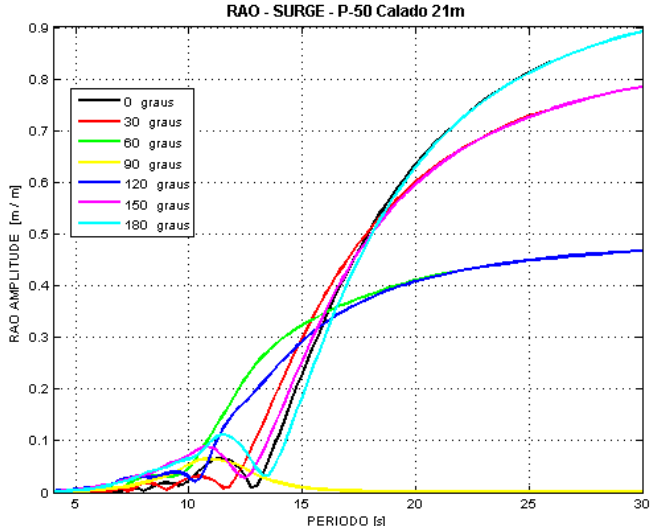

(a) RAO de Surge.

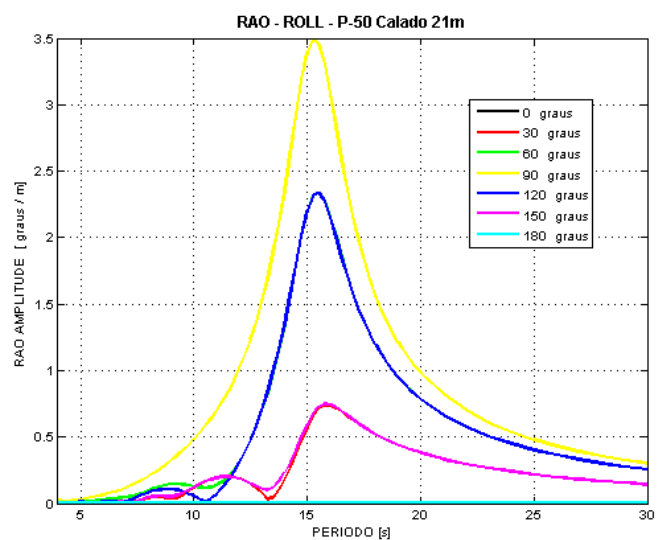

(d) RAO de Roll
RAO - SWAY - P.50 Calado 21m

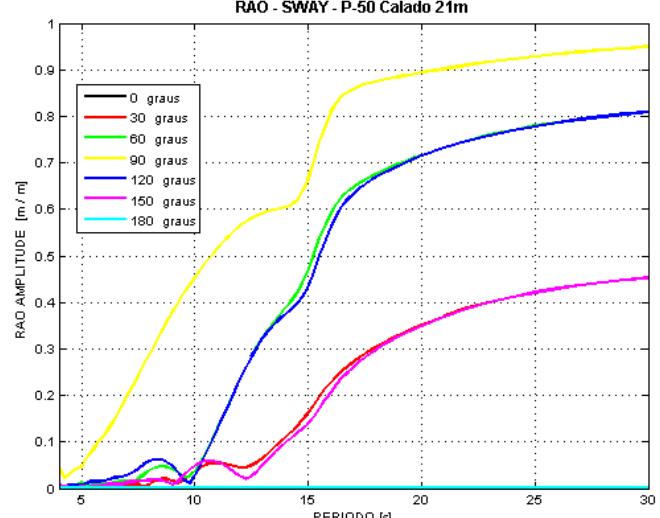

(b) RAO de Sway.

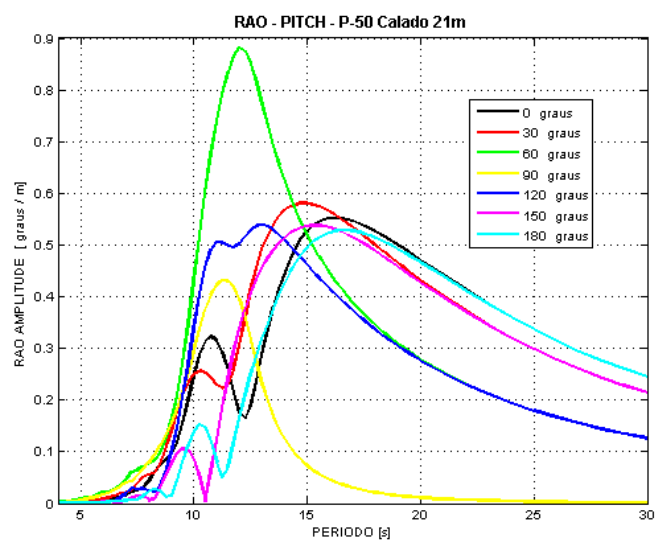

(e) RAO de Pitch.

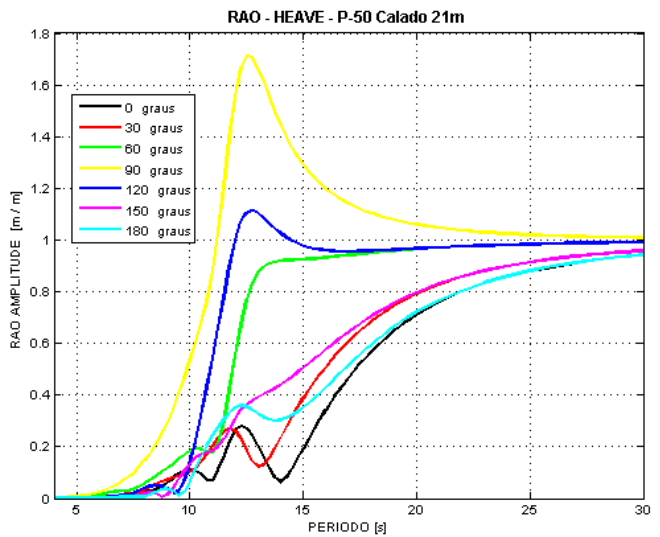

(c) RAO de Heave.

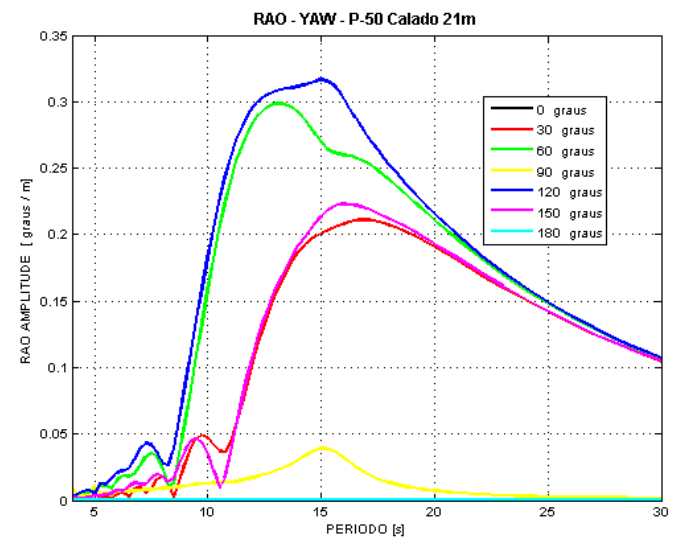

(f) RAO de Yaw.

Figura 46: RAOs de amplitude do FPSO P-50 em calado cheio $(21 \mathrm{~m})$. 


\section{APÊNDICE D - Tabelas de resultados do caso exaustivo}




\begin{tabular}{|c|c|c|c|c|c|c|c|c|c|}
\hline \multicolumn{7}{|c|}{ EXAUSTÃO } & \multicolumn{3}{|c|}{ VARIAÇÃO COM TEÓRICO } \\
\hline \multirow{2}{*}{$\theta_{m}\left[^{\circ}\right]$} & \multicolumn{9}{|c|}{ Calado $9 \mathrm{~m}$} \\
\hline & Mínimo erro $_{a b s}$ & $u_{1}$ & $u_{2}$ & $H_{s}^{\text {est }}[\mathrm{m}]$ & $T_{p}^{e s t}[s]$ & $\theta_{m}^{e s t}\left[{ }^{\circ}\right]$ & $\Delta H_{s}[\%]$ & $\Delta T_{p}[\%]$ & $\Delta \theta_{m}\left[{ }^{\circ}\right]$ \\
\hline 0 & 3,995 & 0,00208 & 0,00010 & 1,712 & 9,95 & 0,036 & -14 & $-0,5$ & 0,036 \\
\hline 30 & 3,164 & 0,00208 & 0,00010 & 1,802 & 9,95 & 29,098 & -10 & $-0,5$ & 0,902 \\
\hline 45 & 4,915 & 0,00406 & 0,00010 & 1,814 & 9,95 & 39,853 & -9 & $-0,5$ & 5,147 \\
\hline 60 & 2,586 & 0,00406 & 0,02228 & 1,983 & 9,95 & 60,551 & -1 & $-0,5$ & 0,551 \\
\hline 90 & 2,773 & 0,00406 & 0,01673 & 1,968 & 9,95 & 89,257 & -2 & $-0,5$ & 0,743 \\
\hline 120 & 2,476 & 0,00406 & 0,02228 & 1,968 & 9,95 & 118,825 & -2 & $-0,5$ & 1,175 \\
\hline 135 & 3,946 & 0,00406 & 0,00564 & 1,843 & 9,95 & 139,331 & -8 & $-0,5$ & 4,331 \\
\hline 150 & 3,541 & 0,00208 & 0,00010 & 1,812 & 9,95 & 151,573 & -9 & $-0,5$ & 1,573 \\
\hline 180 & 5,591 & 0,00208 & 0,00010 & 1,735 & 9,95 & 179,975 & -13 & $-0,5$ & 0,025 \\
\hline \multirow{2}{*}{$\theta_{m}\left[^{\circ}\right]$} & \multicolumn{9}{|c|}{ Calado $14,5 \mathrm{~m}$} \\
\hline & Mínimo erro $_{a b s}$ & $u_{1}$ & $u_{2}$ & $H_{s}^{\text {est }}[\mathrm{m}]$ & $T_{p}^{e s t}[s]$ & $\theta_{m}^{e s t}\left[{ }^{\circ}\right]$ & $\Delta H_{s}[\%]$ & $\Delta T_{p}[\%]$ & $\Delta \theta_{m}\left[{ }^{\circ}\right]$ \\
\hline 0 & 3,841 & 0,00208 & 0,00010 & 1,751 & 9,95 & 0,009 & -12 & $-0,5$ & 0,009 \\
\hline 30 & 3,065 & 0,00208 & 0,00564 & 1,779 & 9,95 & 28,423 & -11 & $-0,5$ & 1,577 \\
\hline 45 & 10,317 & 0,00208 & 0,00010 & 2,068 & 9,95 & 13,715 & 3 & $-0,5$ & 31,285 \\
\hline 60 & 2,873 & 0,00604 & 0,02782 & 2,077 & 9,95 & 60,822 & 4 & $-0,5$ & 0,822 \\
\hline 90 & 2,469 & 0,05000 & 0,12500 & 1,855 & 9,95 & 90,549 & -7 & $-0,5$ & 0,549 \\
\hline 120 & 2,882 & 0,00604 & 0,03337 & 1,991 & 9,95 & 125,838 & 0 & $-0,5$ & 5,838 \\
\hline 135 & 4,083 & 0,00406 & 0,00564 & 1,865 & 9,95 & 145,836 & -7 & $-0,5$ & 10,836 \\
\hline 150 & 3,367 & 0,00208 & 0,00010 & 1,837 & 9,95 & 152,351 & -8 & $-0,5$ & 2,351 \\
\hline 180 & 5,490 & 0,00208 & 0,00010 & 1,790 & 9,95 & 179,985 & -10 & $-0,5$ & 0,015 \\
\hline \multirow{2}{*}{$\theta_{m}\left[^{\circ}\right]$} & \multicolumn{9}{|c|}{ Calado 21m } \\
\hline & Mínimo erro $_{a b s}$ & $u_{1}$ & $u_{2}$ & $H_{s}^{\text {est }}[\mathrm{m}]$ & $T_{p}^{e s t}[s]$ & $\theta_{m}^{\text {est }}\left[{ }^{\circ}\right]$ & $\Delta H_{s}[\%]$ & $\Delta T_{p}[\%]$ & $\Delta \theta_{m}\left[{ }^{\circ}\right]$ \\
\hline 0 & 4,103 & 0,00406 & 0,00010 & 1,758 & 9,95 & $-0,001$ & -12 & $-0,5$ & 0,001 \\
\hline 30 & 3,545 & 0,00208 & 0,00564 & 1,820 & 9,20 & 28,494 & -9 & $-8,0$ & 1,506 \\
\hline 45 & 8,468 & 0,00208 & 0,01119 & 1,861 & 9,95 & 5,934 & -7 & $-0,5$ & 39,066 \\
\hline 60 & 2,908 & 0,00802 & 0,03891 & 2,016 & 9,95 & 60,421 & 1 & $-0,5$ & 0,421 \\
\hline 90 & 2,060 & 0,03500 & 0,09250 & 1,702 & 9,95 & 90,507 & -15 & $-0,5$ & 0,507 \\
\hline 120 & 2,914 & 0,00406 & 0,02782 & 1,918 & 9,95 & 121,785 & -4 & $-0,5$ & 1,785 \\
\hline 135 & 4,434 & 0,00208 & 0,00564 & 1,468 & 10,85 & 141,508 & -27 & 8,5 & 6,508 \\
\hline 150 & 3,573 & 0,00208 & 0,00564 & 1,644 & 9,95 & 152,251 & -18 & $-0,5$ & 2,251 \\
\hline 180 & 5,993 & 0,00208 & 0,00010 & 1,835 & 9,95 & $-179,996$ & -8 & $-0,5$ & 0,004 \\
\hline
\end{tabular}

Tabela 29: Resultados do processo exaustivo para o Mar $1-H_{s}=2 m$ e $T_{p}=10 s$. 


\begin{tabular}{|c|c|c|c|c|c|c|c|c|c|}
\hline \multicolumn{7}{|c|}{ EXAUSTÃO } & \multicolumn{3}{|c|}{ VARIAÇÃO COM TEÓRICO } \\
\hline \multirow{2}{*}{$\theta_{m}\left[^{\circ}\right]$} & \multicolumn{9}{|c|}{ Calado $9 \mathrm{~m}$} \\
\hline & Mínimo erro $a b s$ & $u_{1}$ & $u_{2}$ & $H_{s}^{e s t}[\mathrm{~m}]$ & $T_{p}^{e s t}[s]$ & $\theta_{m}^{e s t}\left[{ }^{\circ}\right]$ & $\Delta H_{s}[\%]$ & $\Delta T_{p}[\%]$ & $\Delta \theta_{m}\left[{ }^{\circ}\right]$ \\
\hline 0 & 4,806 & 0,00010 & 0,00010 & 2,821 & 8,54 & 0,071 & -29 & 0,5 & 0,071 \\
\hline 30 & 4,220 & 0,00010 & 0,00010 & 3,061 & 8,54 & 33,040 & -23 & 0,5 & 3,040 \\
\hline 45 & 9,362 & 0,00208 & 0,00010 & 2,514 & 9,95 & 60,407 & -37 & 17,1 & 15,407 \\
\hline 60 & 4,318 & 0,00208 & 0,00010 & 3,231 & 8,54 & 55,395 & -19 & 0,5 & 4,605 \\
\hline 90 & 3,350 & 0,00406 & 0,03337 & 3,360 & 8,54 & 90,064 & -16 & 0,5 & 0,064 \\
\hline 120 & 4,368 & 0,00208 & 0,00010 & 3,071 & 8,54 & 124,520 & -23 & 0,5 & 4,520 \\
\hline 135 & 7,860 & 0,00208 & 0,00564 & 2,709 & 9,20 & 134,110 & -32 & 8,2 & 0,890 \\
\hline 150 & 4,543 & 0,00010 & 0,00010 & 3,022 & 8,54 & 143,932 & -24 & 0,5 & 6,068 \\
\hline 180 & 6,897 & 0,00010 & 0,00010 & 2,887 & 8,54 & 179,943 & -28 & 0,5 & 0,057 \\
\hline \multirow{2}{*}{$\theta_{m}\left[^{\circ}\right]$} & \multicolumn{9}{|c|}{ Calado $14,5 \mathrm{~m}$} \\
\hline & Mínimo erro $_{a b s}$ & $u_{1}$ & $u_{2}$ & $H_{s}^{e s t}[\mathrm{~m}]$ & $T_{p}^{e s t}[s]$ & $\theta_{m}^{\text {est }}\left[{ }^{\circ}\right]$ & $\Delta H_{s}[\%]$ & $\Delta T_{p}[\%]$ & $\Delta \theta_{m}\left[{ }^{\circ}\right]$ \\
\hline 0 & 6,098 & 0,00208 & 0,00010 & 2,571 & 8,54 & 0,007 & -36 & 0,5 & 0,007 \\
\hline 30 & 4,823 & 0,00010 & 0,00010 & 3,139 & 8,54 & 37,246 & -22 & 0,5 & 7,246 \\
\hline 45 & 10,354 & 0,00010 & 0,00010 & 4,266 & 8,54 & $-148,860$ & 7 & 0,5 & 103,860 \\
\hline 60 & 5,126 & 0,00208 & 0,00010 & 3,253 & 8,54 & 52,673 & -19 & 0,5 & 7,327 \\
\hline 90 & 3,306 & 0,02000 & 0,20000 & 3,038 & 8,54 & 89,077 & -24 & 0,5 & 0,923 \\
\hline 120 & 5,195 & 0,00010 & 0,00010 & 3,950 & 8,54 & 118,207 & -1 & 0,5 & 1,793 \\
\hline 135 & 7,730 & 0,00208 & 0,00010 & 2,836 & 8,54 & 159,687 & -29 & 0,5 & 24,687 \\
\hline 150 & 5,987 & 0,00010 & 0,00010 & 3,218 & 8,54 & 154,498 & -20 & 0,5 & 4,498 \\
\hline 180 & 6,445 & 0,00010 & 0,00010 & 3,016 & 8,54 & 179,904 & -25 & 0,5 & 0,096 \\
\hline \multirow{2}{*}{$\theta_{m}\left[{ }^{\circ}\right]$} & \multicolumn{9}{|c|}{ Calado 21m } \\
\hline & Mínimo erro $_{a b s}$ & $u_{1}$ & $u_{2}$ & $H_{s}^{e s t}[\mathrm{~m}]$ & $T_{p}^{e s t}[s]$ & $\theta_{m}^{\text {est }}\left[{ }^{\circ}\right]$ & $\Delta H_{s}[\%]$ & $\Delta T_{p}[\%]$ & $\Delta \theta_{m}\left[{ }^{\circ}\right]$ \\
\hline 0 & 5,834 & 0,00010 & 0,00010 & 2,933 & 8,54 & $-0,029$ & -27 & 0,5 & 0,029 \\
\hline 30 & 5,493 & 0,00010 & 0,00010 & 3,319 & 8,54 & 37,250 & -17 & 0,5 & 7,250 \\
\hline 45 & 11,276 & 0,00208 & 0,00010 & 3,538 & 9,20 & $-72,224$ & -12 & 8,2 & 27,224 \\
\hline 60 & 5,389 & 0,00208 & 0,00564 & 2,989 & 8,54 & 47,483 & -25 & 0,5 & 12,517 \\
\hline 90 & 3,956 & 0,01500 & 0,15000 & 2,624 & 9,20 & 82,629 & -34 & 8,2 & 7,371 \\
\hline 120 & 4,961 & 0,00208 & 0,00564 & 2,472 & 9,20 & 120,475 & -38 & 8,2 & 0,475 \\
\hline 135 & 9,196 & 0,00208 & 0,01119 & 1,659 & 9,95 & 154,970 & -59 & 17,1 & 19,970 \\
\hline 150 & 5,400 & 0,00010 & 0,00010 & 3,336 & 8,54 & 156,383 & -17 & 0,5 & 6,383 \\
\hline 180 & 6,988 & 0,00208 & 0,00010 & 2,541 & 8,54 & $-179,999$ & -36 & 0,5 & 0,001 \\
\hline
\end{tabular}

Tabela 30: Resultados do processo exaustivo para o Mar $2-H_{s}=4 m$ e $T_{p}=8,5 s$. 


\begin{tabular}{|c|c|c|c|c|c|c|c|c|c|}
\hline \multicolumn{7}{|c|}{ EXAUSTÃO } & \multicolumn{3}{|c|}{ VARIAÇÃO COM TEÓRICO } \\
\hline \multirow{2}{*}{$\theta_{m}\left[^{\circ}\right]$} & \multicolumn{9}{|c|}{ Calado 9m } \\
\hline & Mínimo erro $_{a b s}$ & $u_{1}$ & $u_{2}$ & $H_{s}^{e s t}[\mathrm{~m}]$ & $T_{p}^{e s t}[s]$ & $\theta_{m}^{e s t}\left[{ }^{\circ}\right]$ & $\Delta H_{s}[\%]$ & $\Delta T_{p}[\%]$ & $\Delta \theta_{m}\left[{ }^{\circ}\right]$ \\
\hline 0 & 3,827 & 0,00010 & 0,00010 & 3,848 & 9,95 & 0,947 & -4 & $-0,5$ & 0,947 \\
\hline 30 & 3,150 & 0,00208 & 0,00010 & 3,588 & 9,95 & 28,898 & -10 & $-0,5$ & 1,102 \\
\hline 45 & 4,908 & 0,00406 & 0,00010 & 3,617 & 9,95 & 39,781 & -10 & $-0,5$ & 5,219 \\
\hline 60 & 2,630 & 0,00406 & 0,02228 & 3,978 & 9,95 & 60,049 & -1 & $-0,5$ & 0,049 \\
\hline 90 & 2,774 & 0,00406 & 0,02782 & 3,925 & 9,95 & 89,594 & -2 & $-0,5$ & 0,406 \\
\hline 120 & 2,470 & 0,00406 & 0,02228 & 3,923 & 9,95 & 118,999 & -2 & $-0,5$ & 1,001 \\
\hline 135 & 3,940 & 0,00406 & 0,00564 & 3,674 & 9,95 & 139,276 & -8 & $-0,5$ & 4,276 \\
\hline 150 & 3,150 & 0,00010 & 0,00010 & 4,003 & 9,95 & 141,556 & 0 & $-0,5$ & 8,444 \\
\hline 180 & 5,435 & 0,00208 & 0,00010 & 3,444 & 9,95 & 179,986 & -14 & $-0,5$ & 0,014 \\
\hline \multirow{2}{*}{$\theta_{m}\left[^{\circ}\right]$} & \multicolumn{9}{|c|}{ Calado $14,5 \mathrm{~m}$} \\
\hline & Mínimo erro $_{a b s}$ & $u_{1}$ & $u_{2}$ & $H_{s}^{e s t}[\mathrm{~m}]$ & $T_{p}^{e s t}[s]$ & $\theta_{m}^{e s t}\left[{ }^{\circ}\right]$ & $\Delta H_{s}[\%]$ & $\Delta T_{p}[\%]$ & $\Delta \theta_{m}\left[{ }^{\circ}\right]$ \\
\hline 0 & 3,449 & 0,00208 & 0,00010 & 3,442 & 9,95 & 0,007 & -14 & $-0,5$ & 0,007 \\
\hline 30 & 3,046 & 0,00208 & 0,00564 & 3,539 & 9,95 & 28,327 & -12 & $-0,5$ & 1,673 \\
\hline 45 & 10,211 & 0,00208 & 0,00010 & 4,086 & 9,95 & 17,003 & 2 & $-0,5$ & 27,997 \\
\hline 60 & 2,844 & 0,00604 & 0,03337 & 4,110 & 9,95 & 59,298 & 3 & $-0,5$ & 0,702 \\
\hline 90 & 2,473 & 0,05000 & 0,12500 & 3,685 & 9,95 & 90,537 & -8 & $-0,5$ & 0,537 \\
\hline 120 & 2,886 & 0,00604 & 0,03337 & 3,976 & 9,95 & 125,884 & -1 & $-0,5$ & 5,884 \\
\hline 135 & 4,044 & 0,00406 & 0,00564 & 3,701 & 9,95 & 145,715 & -7 & $-0,5$ & 10,715 \\
\hline 150 & 3,356 & 0,00208 & 0,00010 & 3,663 & 9,95 & 152,177 & -8 & $-0,5$ & 2,177 \\
\hline 180 & 5,213 & 0,00208 & 0,00010 & 3,518 & 9,95 & 179,990 & -12 & $-0,5$ & 0,010 \\
\hline \multirow{2}{*}{$\theta_{m}\left[^{\circ}\right]$} & \multicolumn{9}{|c|}{ Calado 21m } \\
\hline & Mínimo erro $_{a b s}$ & $u_{1}$ & $u_{2}$ & $H_{s}^{e s t}[\mathrm{~m}]$ & $T_{p}^{e s t}[s]$ & $\theta_{m}^{\text {est }}\left[{ }^{\circ}\right]$ & $\Delta H_{s}[\%]$ & $\Delta T_{p}[\%]$ & $\Delta \theta_{m}\left[{ }^{\circ}\right]$ \\
\hline 0 & 3,847 & 0,00406 & 0,00010 & 3,434 & 9,95 & $-0,001$ & -14 & $-0,5$ & 0,001 \\
\hline 30 & 3,442 & 0,00208 & 0,00564 & 3,597 & 9,20 & 26,892 & -10 & $-8,0$ & 3,108 \\
\hline 45 & 8,470 & 0,00406 & 0,01119 & 3,618 & 9,95 & 5,831 & -10 & $-0,5$ & 39,169 \\
\hline 60 & 2,955 & 0,00802 & 0,03891 & 4,024 & 9,95 & 59,406 & 1 & $-0,5$ & 0,594 \\
\hline 90 & 2,078 & 0,03500 & 0,09250 & 3,404 & 9,95 & 90,587 & -15 & $-0,5$ & 0,587 \\
\hline 120 & 2,897 & 0,00406 & 0,02782 & 3,797 & 9,95 & 121,192 & -5 & $-0,5$ & 1,192 \\
\hline 135 & 4,452 & 0,00208 & 0,00564 & 2,923 & 10,85 & 139,854 & -27 & 8,5 & 4,854 \\
\hline 150 & 3,587 & 0,00208 & 0,00010 & 3,685 & 9,20 & 151,899 & -8 & $-8,0$ & 1,899 \\
\hline 180 & 5,417 & 0,00208 & 0,00010 & 3,480 & 9,95 & $-179,998$ & -13 & $-0,5$ & 0,002 \\
\hline
\end{tabular}

Tabela 31: Resultados do processo exaustivo para o Mar $3-H_{s}=4 m$ e $T_{p}=10 \mathrm{~s}$. 


\begin{tabular}{|c|c|c|c|c|c|c|c|c|c|}
\hline \multicolumn{7}{|c|}{ EXAUSTÃO } & \multicolumn{3}{|c|}{ VARIAÇÃO COM TEÓRICO } \\
\hline \multirow{2}{*}{$\theta_{m}\left[^{\circ}\right]$} & \multicolumn{9}{|c|}{ Calado 9m } \\
\hline & Mínimo erro $_{a b s}$ & $u_{1}$ & $u_{2}$ & $H_{s}^{e s t}[\mathrm{~m}]$ & $T_{p}^{e s t}[s]$ & $\theta_{m}^{e s t}\left[{ }^{\circ}\right]$ & $\Delta H_{s}[\%]$ & $\Delta T_{p}[\%]$ & $\Delta \theta_{m}\left[{ }^{\circ}\right]$ \\
\hline 0 & 3,372 & 0,00010 & 0,00564 & 3,933 & 11,92 & 0,056 & -2 & $-0,6$ & 0,056 \\
\hline 30 & 4,414 & 0,00010 & 0,01119 & 4,055 & 11,92 & 28,549 & 1 & $-0,6$ & 1,451 \\
\hline 45 & 5,016 & 0,00604 & 0,04446 & 4,048 & 11,92 & 41,181 & 1 & $-0,6$ & 3,819 \\
\hline 60 & 3,009 & 0,00208 & 0,00564 & 4,340 & 11,92 & 57,228 & 9 & $-0,6$ & 2,772 \\
\hline 90 & 2,853 & 0,00208 & 0,03891 & 4,066 & 11,92 & 90,127 & 2 & $-0,6$ & 0,127 \\
\hline 120 & 2,855 & 0,00010 & 0,05000 & 4,230 & 11,92 & 117,570 & 6 & $-0,6$ & 2,430 \\
\hline 135 & 4,130 & 0,00406 & 0,00564 & 4,032 & 11,92 & 137,643 & 1 & $-0,6$ & 2,643 \\
\hline 150 & 3,635 & 0,00010 & 0,01673 & 3,880 & 11,92 & 152,239 & -3 & $-0,6$ & 2,239 \\
\hline 180 & 3,737 & 0,00010 & 0,00564 & 3,901 & 11,92 & 179,944 & -2 & $-0,6$ & 0,056 \\
\hline \multirow{2}{*}{$\theta_{m}\left[^{\circ}\right]$} & \multicolumn{9}{|c|}{ Calado $14,5 \mathrm{~m}$} \\
\hline & Mínimo $e r O_{a b s}$ & $u_{1}$ & $u_{2}$ & $H_{s}^{e s t}[\mathrm{~m}]$ & $T_{p}^{e s t}[s]$ & $\theta_{m}^{e s t}\left[{ }^{\circ}\right]$ & $\Delta H_{s}[\%]$ & $\Delta T_{p}[\%]$ & $\Delta \theta_{m}\left[{ }^{\circ}\right]$ \\
\hline 0 & 2,871 & 0,00010 & 0,00010 & 4,261 & 11,92 & 0,086 & 7 & $-0,6$ & 0,086 \\
\hline 30 & 3,942 & 0,00208 & 0,00564 & 3,914 & 11,92 & 28,905 & -2 & $-0,6$ & 1,095 \\
\hline 45 & 8,855 & 0,00406 & 0,00564 & 4,007 & 10,85 & 20,229 & 0 & $-9,6$ & 24,771 \\
\hline 60 & 2,893 & 0,00406 & 0,03337 & 4,193 & 11,92 & 60,657 & 5 & $-0,6$ & 0,657 \\
\hline 90 & 2,858 & 0,01000 & 0,03337 & 4,073 & 11,92 & 89,488 & 2 & $-0,6$ & 0,512 \\
\hline 120 & 2,741 & 0,00604 & 0,03337 & 4,072 & 11,92 & 124,145 & 2 & $-0,6$ & 4,145 \\
\hline 135 & 4,624 & 0,00802 & 0,00564 & 4,041 & 11,92 & 145,776 & 1 & $-0,6$ & 10,776 \\
\hline 150 & 3,738 & 0,00010 & 0,01119 & 4,017 & 11,92 & 153,643 & 0 & $-0,6$ & 3,643 \\
\hline 180 & 4,228 & 0,00208 & 0,00010 & 3,728 & 11,92 & 179,991 & -7 & $-0,6$ & 0,009 \\
\hline \multirow{2}{*}{$\theta_{m}\left[^{\circ}\right]$} & \multicolumn{9}{|c|}{ Calado 21m } \\
\hline & Mínimo $e r o_{a b s}$ & $u_{1}$ & $u_{2}$ & $H_{s}^{e s t}[\mathrm{~m}]$ & $T_{p}^{e s t}[s]$ & $\theta_{m}^{\text {est }}\left[{ }^{\circ}\right]$ & $\Delta H_{s}[\%]$ & $\Delta T_{p}[\%]$ & $\Delta \theta_{m}\left[{ }^{\circ}\right]$ \\
\hline 0 & 3,079 & 0,00010 & 0,00010 & 4,287 & 11,92 & $-0,016$ & 7 & $-0,6$ & 0,016 \\
\hline 30 & 3,836 & 0,00208 & 0,01119 & 3,891 & 11,92 & 27,280 & -3 & $-0,6$ & 2,720 \\
\hline 45 & 9,026 & 0,00604 & 0,01119 & 4,093 & 11,92 & 13,738 & 2 & $-0,6$ & 31,262 \\
\hline 60 & 2,731 & 0,00406 & 0,06000 & 4,136 & 11,92 & 60,687 & 3 & $-0,6$ & 0,687 \\
\hline 90 & 2,276 & 0,03500 & 0,05000 & 3,824 & 11,92 & 89,377 & -4 & $-0,6$ & 0,623 \\
\hline 120 & 2,630 & 0,00208 & 0,06000 & 4,109 & 11,92 & 124,166 & 3 & $-0,6$ & 4,166 \\
\hline 135 & 3,812 & 0,00802 & 0,00564 & 3,670 & 10,85 & 143,131 & -8 & $-9,6$ & 8,131 \\
\hline 150 & 3,640 & 0,00208 & 0,00564 & 4,002 & 10,85 & 151,765 & 0 & $-9,6$ & 1,765 \\
\hline 180 & 3,826 & 0,00010 & 0,00010 & 4,510 & 11,92 & $-179,973$ & 13 & $-0,6$ & 0,027 \\
\hline
\end{tabular}

Tabela 32: Resultados do processo exaustivo para o Mar $4-H_{s}=4 m$ e $T_{p}=12 s$. 


\begin{tabular}{|c|c|c|c|c|c|c|c|c|c|}
\hline \multicolumn{7}{|c|}{ EXAUSTÃO } & \multicolumn{3}{|c|}{ VARIAÇÃO COM TEÓRICO } \\
\hline \multirow{2}{*}{$\theta_{m}\left[^{\circ}\right]$} & \multicolumn{9}{|c|}{ Calado 9m } \\
\hline & Mínimo erro $_{a b s}$ & $u_{1}$ & $u_{2}$ & $H_{s}^{e s t}[\mathrm{~m}]$ & $T_{p}^{e s t}[s]$ & $\theta_{m}^{e s t}\left[{ }^{\circ}\right]$ & $\Delta H_{s}[\%]$ & $\Delta T_{p}[\%]$ & $\Delta \theta_{m}\left[{ }^{\circ}\right]$ \\
\hline 0 & 2,148 & 0,00208 & 0,00010 & 3,964 & 13,23 & 0,061 & -1 & $-5,5$ & 0,061 \\
\hline 30 & 2,766 & 0,00208 & 0,00564 & 4,178 & 14,86 & 30,794 & 4 & 6,1 & 0,794 \\
\hline 45 & 3,345 & 0,00406 & 0,01673 & 4,315 & 14,86 & 43,645 & 8 & 6,1 & 1,355 \\
\hline 60 & 2,758 & 0,00406 & 0,02228 & 4,508 & 14,86 & 56,341 & 13 & 6,1 & 3,659 \\
\hline 90 & 2,421 & 0,00406 & 0,01119 & 4,431 & 14,86 & 90,114 & 11 & 6,1 & 0,114 \\
\hline 120 & 2,800 & 0,00406 & 0,03891 & 4,462 & 14,86 & 120,378 & 12 & 6,1 & 0,378 \\
\hline 135 & 3,050 & 0,00406 & 0,02228 & 4,296 & 14,86 & 138,684 & 7 & 6,1 & 3,684 \\
\hline 150 & 2,541 & 0,00010 & 0,01673 & 4,158 & 13,23 & 151,729 & 4 & $-5,5$ & 1,729 \\
\hline 180 & 2,700 & 0,00010 & 0,01673 & 4,190 & 13,23 & 179,998 & 5 & $-5,5$ & 0,002 \\
\hline \multirow{2}{*}{$\theta_{m}\left[^{\circ}\right]$} & \multicolumn{9}{|c|}{ Calado $14,5 \mathrm{~m}$} \\
\hline & Mínimo erro $_{a b s}$ & $u_{1}$ & $u_{2}$ & $H_{s}^{e s t}[\mathrm{~m}]$ & $T_{p}^{e s t}[s]$ & $\theta_{m}^{e s t}\left[{ }^{\circ}\right]$ & $\Delta H_{s}[\%]$ & $\Delta T_{p}[\%]$ & $\Delta \theta_{m}\left[{ }^{\circ}\right]$ \\
\hline 0 & 2,028 & 0,00208 & 0,00010 & 3,976 & 13,23 & 0,039 & -1 & $-5,5$ & 0,039 \\
\hline 30 & 2,574 & 0,00208 & 0,00564 & 4,200 & 14,86 & 28,516 & 5 & 6,1 & 1,484 \\
\hline 45 & 5,054 & 0,01500 & 0,01119 & 4,063 & 14,86 & 26,805 & 2 & 6,1 & 18,195 \\
\hline 60 & 2,538 & 0,00406 & 0,02228 & 4,446 & 14,86 & 59,162 & 11 & 6,1 & 0,838 \\
\hline 90 & 2,384 & 0,00802 & 0,01673 & 4,335 & 14,86 & 90,606 & 8 & 6,1 & 0,606 \\
\hline 120 & 2,356 & 0,00406 & 0,02228 & 4,415 & 14,86 & 125,098 & 10 & 6,1 & 5,098 \\
\hline 135 & 3,324 & 0,00406 & 0,01119 & 4,379 & 14,86 & 139,299 & 9 & 6,1 & 4,299 \\
\hline 150 & 2,773 & 0,00010 & 0,01673 & 4,192 & 13,23 & 150,055 & 5 & $-5,5$ & 0,055 \\
\hline 180 & 2,459 & 0,00208 & 0,00564 & 4,028 & 13,23 & 179,987 & 1 & $-5,5$ & 0,013 \\
\hline \multirow{2}{*}{$\theta_{m}\left[^{\circ}\right]$} & \multicolumn{9}{|c|}{ Calado 21m } \\
\hline & Mínimo erro $_{a b s}$ & $u_{1}$ & $u_{2}$ & $H_{s}^{e s t}[\mathrm{~m}]$ & $T_{p}^{e s t}[s]$ & $\theta_{m}^{\text {est }}\left[{ }^{\circ}\right]$ & $\Delta H_{s}[\%]$ & $\Delta T_{p}[\%]$ & $\Delta \theta_{m}\left[{ }^{\circ}\right]$ \\
\hline 0 & 1,830 & 0,00208 & 0,00010 & 4,026 & 13,23 & $-0,006$ & 1 & $-5,5$ & 0,006 \\
\hline 30 & 2,468 & 0,00208 & 0,01673 & 4,152 & 14,86 & 28,780 & 4 & 6,1 & 1,220 \\
\hline 45 & 5,830 & 0,01500 & 0,01119 & 4,091 & 14,86 & 19,812 & 2 & 6,1 & 25,188 \\
\hline 60 & 2,404 & 0,00604 & 0,04446 & 4,230 & 14,86 & 61,187 & 6 & 6,1 & 1,187 \\
\hline 90 & 2,200 & 0,03500 & 0,05000 & 4,167 & 14,86 & 88,598 & 4 & 6,1 & 1,402 \\
\hline 120 & 2,356 & 0,00406 & 0,05000 & 4,334 & 14,86 & 127,743 & 8 & 6,1 & 7,743 \\
\hline 135 & 3,023 & 0,00604 & 0,02782 & 4,059 & 14,86 & 138,339 & 1 & 6,1 & 3,339 \\
\hline 150 & 2,475 & 0,00208 & 0,00564 & 4,198 & 13,23 & 149,439 & 5 & $-5,5$ & 0,561 \\
\hline 180 & 2,563 & 0,00010 & 0,02228 & 4,096 & 13,23 & $-179,999$ & 2 & $-5,5$ & 0,001 \\
\hline
\end{tabular}

Tabela 33: Resultados do processo exaustivo para o Mar $5-H_{s}=4 m$ e $T_{p}=14 s$. 


\section{APÊNDICE E - Tabelas de resultados das somas dos erros}




\begin{tabular}{|c|c|c|c|c|c|c|c|c|c|}
\hline \multicolumn{7}{|c|}{ SOMA DOS ERROS } & \multicolumn{3}{|c|}{ VARIAÇÃO COM TEÓRICO } \\
\hline \multirow{2}{*}{$\theta_{m}\left[^{\circ}\right]$} & \multicolumn{9}{|c|}{ Calado $9 \mathrm{~m}$} \\
\hline & Mínimo erro $_{a b s}$ & $u_{1}$ & $u_{2}$ & $H_{s}^{e s t}[\mathrm{~m}]$ & $T_{p}^{e s t}[s]$ & $\theta_{m}^{\text {est }}\left[{ }^{\circ}\right]$ & $\Delta H_{s}[\%]$ & $\Delta T_{p}[\%]$ & $\Delta \theta_{m}\left[^{\circ}\right]$ \\
\hline 0 & 3,995 & & & 1,712 & 9,955 & 0,036 & -14 & $-0,5$ & 0,036 \\
\hline 30 & 3,164 & & & 1,802 & 9,955 & 29,098 & -10 & $-0,5$ & 0,902 \\
\hline 45 & 5,185 & & & 1,873 & 9,955 & 40,665 & -6 & $-0,5$ & 4,335 \\
\hline 60 & 3,173 & & & 2,086 & 9,955 & 56,896 & 4 & $-0,5$ & 3,104 \\
\hline 90 & 3,067 & 0,00208 & 0,000100 & 2,106 & 9,955 & 90,871 & 5 & $-0,5$ & 0,871 \\
\hline 120 & 3,379 & & & 2,065 & 9,955 & 119,281 & 3 & $-0,5$ & 0,719 \\
\hline 135 & 4,372 & & & 1,906 & 9,955 & 142,661 & -5 & $-0,5$ & 7,661 \\
\hline 150 & 3,541 & & & 1,812 & 9,955 & 151,573 & -9 & $-0,5$ & 1,573 \\
\hline 180 & 5,591 & & & 1,735 & 9,955 & 179,975 & -13 & $-0,5$ & 0,025 \\
\hline \multirow{2}{*}{$\theta_{m}\left[^{\circ}\right]$} & \multicolumn{9}{|c|}{ Calado $14,5 \mathrm{~m}$} \\
\hline & Mínimo erro $_{a b s}$ & $u_{1}$ & $u_{2}$ & $H_{s}^{e s t}[\mathrm{~m}]$ & $T_{p}^{e s t}[s]$ & $\theta_{m}^{e s t}\left[{ }^{\circ}\right]$ & $\Delta H_{s}[\%]$ & $\Delta T_{p}[\%]$ & $\Delta \theta_{m}\left[^{\circ}\right]$ \\
\hline 0 & 4,579 & \multirow{9}{*}{0,00208} & \multirow{9}{*}{0,005644} & 1,722 & 9,955 & 0,006 & -14 & $-0,5$ & 0,006 \\
\hline 30 & 3,065 & & & 1,779 & 9,955 & 28,423 & -11 & $-0,5$ & 1,577 \\
\hline 45 & 10,379 & & & 1,918 & 9,955 & $-12,536$ & -4 & $-0,5$ & 32,464 \\
\hline 60 & 3,653 & & & 2,123 & 9,955 & 64,512 & 6 & $-0,5$ & 4,512 \\
\hline 90 & 3,566 & & & 2,151 & 9,955 & 92,888 & 8 & $-0,5$ & 2,888 \\
\hline 120 & 3,286 & & & 2,092 & 9,196 & 128,033 & 5 & $-8,0$ & 8,033 \\
\hline 135 & 4,193 & & & 1,959 & 9,955 & 146,000 & -2 & $-0,5$ & 11,000 \\
\hline 150 & 3,391 & & & 1,751 & 9,955 & 153,670 & -12 & $-0,5$ & 3,670 \\
\hline 180 & 5,880 & & & 1,773 & 9,955 & 179,982 & -11 & $-0,5$ & 0,018 \\
\hline \multirow{2}{*}{$\theta_{m}\left[^{\circ}\right]$} & \multicolumn{9}{|c|}{ Calado $21 \mathrm{~m}$} \\
\hline & Mínimo erro $_{a b s}$ & $u_{1}$ & $u_{2}$ & $H_{s}^{e s t}[\mathrm{~m}]$ & $T_{p}^{e s t}[s]$ & $\theta_{m}^{e s t}\left[{ }^{\circ}\right]$ & $\Delta H_{s}[\%]$ & $\Delta T_{p}[\%]$ & $\Delta \theta_{m}\left[^{\circ}\right]$ \\
\hline 0 & 4,664 & & & 1,767 & 9,955 & $-0,002$ & -12 & $-0,5$ & 0,002 \\
\hline 30 & 3,545 & & & 1,820 & 9,196 & 28,494 & -9 & $-8,0$ & 1,506 \\
\hline 45 & 9,636 & & & 1,981 & 9,196 & $-19,917$ & -1 & $-8,0$ & 25,083 \\
\hline 60 & 3,603 & & & 2,124 & 9,196 & 63,247 & 6 & $-8,0$ & 3,247 \\
\hline 90 & 3,318 & 0,00208 & 0,005644 & 1,998 & 9,955 & 86,793 & 0 & $-0,5$ & 3,207 \\
\hline 120 & 3,331 & & & 2,050 & 9,955 & 127,738 & 3 & $-0,5$ & 7,738 \\
\hline 135 & 4,434 & & & 1,468 & 10,850 & 141,508 & -27 & 8,5 & 6,508 \\
\hline 150 & 3,573 & & & 1,644 & 9,955 & 152,251 & -18 & $-0,5$ & 2,251 \\
\hline 180 & 6,247 & & & 1,735 & 9,955 & $-179,998$ & -13 & $-0,5$ & 0,002 \\
\hline
\end{tabular}

Tabela 34: Resultados do mínimo da soma para o Mar $1-H_{s}=2 m$ e $T_{p}=10 s$. 


\begin{tabular}{|c|c|c|c|c|c|c|c|c|c|}
\hline \multicolumn{7}{|c|}{ SOMA DOS ERROS } & \multicolumn{3}{|c|}{ VARIAÇÃO COM TEÓRICO } \\
\hline \multirow{2}{*}{$\theta_{m}\left[^{\circ}\right]$} & \multicolumn{9}{|c|}{ Calado $9 \mathrm{~m}$} \\
\hline & Mínimo erro $o_{a b s}$ & $u_{1}$ & $u_{2}$ & $H_{s}^{e s t}[\mathrm{~m}]$ & $T_{p}^{e s t}[s]$ & $\theta_{m}^{\text {est }}\left[{ }^{\circ}\right]$ & $\Delta H_{s}[\%]$ & $\Delta T_{p}[\%]$ & $\Delta \theta_{m}\left[^{\circ}\right]$ \\
\hline 0 & 5,851 & & & 2,538 & 8,544 & 0,013 & -37 & 0,5 & 0,013 \\
\hline 30 & 5,906 & & & 2,793 & 8,544 & 27,297 & -30 & 0,5 & 2,703 \\
\hline 45 & 9,362 & & & 2,514 & 9,955 & 60,407 & -37 & 17,1 & 15,407 \\
\hline 60 & 4,318 & & & 3,231 & 8,544 & 55,395 & -19 & 0,5 & 4,605 \\
\hline 90 & 3,512 & 0,00208 & 0,000100 & 3,473 & 8,544 & 89,914 & -13 & 0,5 & 0,086 \\
\hline 120 & 4,368 & & & 3,071 & 8,544 & 124,520 & -23 & 0,5 & 4,520 \\
\hline 135 & 8,040 & & & 2,921 & 8,544 & 148,273 & -27 & 0,5 & 13,273 \\
\hline 150 & 6,603 & & & 2,773 & 8,544 & 153,436 & -31 & 0,5 & 3,436 \\
\hline 180 & 7,348 & & & 2,606 & 8,544 & 179,995 & -35 & 0,5 & 0,005 \\
\hline \multirow{2}{*}{$\theta_{m}\left[^{\circ}\right]$} & \multicolumn{9}{|c|}{ Calado $14,5 \mathrm{~m}$} \\
\hline & Mínimo $e r o_{a b s}$ & $u_{1}$ & $u_{2}$ & $H_{s}^{e s t}[\mathrm{~m}]$ & $T_{p}^{e s t}[s]$ & $\theta_{m}^{e s t}\left[{ }^{\circ}\right]$ & $\Delta H_{s}[\%]$ & $\Delta T_{p}[\%]$ & $\Delta \theta_{m}\left[^{\circ}\right]$ \\
\hline 0 & 6,098 & \multirow{9}{*}{0,00208} & \multirow{9}{*}{0,000100} & 2,571 & 8,544 & 0,007 & -36 & 0,5 & 0,007 \\
\hline 30 & 5,992 & & & 2,772 & 8,544 & 26,041 & -31 & 0,5 & 3,959 \\
\hline 45 & 12,532 & & & 3,430 & 8,544 & 179,494 & -14 & 0,5 & 134,494 \\
\hline 60 & 5,126 & & & 3,253 & 8,544 & 52,673 & -19 & 0,5 & 7,327 \\
\hline 90 & 4,020 & & & 3,208 & 8,544 & 89,371 & -20 & 0,5 & 0,629 \\
\hline 120 & 5,697 & & & 3,177 & 8,544 & 130,976 & -21 & 0,5 & 10,976 \\
\hline 135 & 7,730 & & & 2,836 & 8,544 & 159,687 & -29 & 0,5 & 24,687 \\
\hline 150 & 6,353 & & & 2,810 & 8,544 & 153,461 & -30 & 0,5 & 3,461 \\
\hline 180 & 6,886 & & & 2,611 & 8,544 & 179,983 & -35 & 0,5 & 0,017 \\
\hline \multirow{2}{*}{$\theta_{m}\left[{ }^{\circ}\right]$} & \multicolumn{9}{|c|}{ Calado 21m } \\
\hline & Mínimo $e r O_{a b s}$ & $u_{1}$ & $u_{2}$ & $H_{s}^{e s t}[\mathrm{~m}]$ & $T_{p}^{e s t}[s]$ & $\theta_{m}^{e s t}\left[{ }^{\circ}\right]$ & $\Delta H_{s}[\%]$ & $\Delta T_{p}[\%]$ & $\Delta \theta_{m}\left[^{\circ}\right]$ \\
\hline 0 & 6,391 & & & 2,623 & 8,544 & $-0,004$ & -34 & 0,5 & 0,004 \\
\hline 30 & 5,916 & & & 2,789 & 8,544 & 23,486 & -30 & 0,5 & 6,514 \\
\hline 45 & 11,276 & & & 3,538 & 9,196 & $-72,224$ & -12 & 8,2 & 27,224 \\
\hline 60 & 6,227 & & & 3,379 & 8,544 & 61,771 & -16 & 0,5 & 1,771 \\
\hline 90 & 4,164 & 0,00208 & 0,000100 & 3,073 & 8,544 & 87,061 & -23 & 0,5 & 2,939 \\
\hline 120 & 5,543 & & & 2,855 & 9,196 & 128,746 & -29 & 8,2 & 8,746 \\
\hline 135 & 10,110 & & & 2,679 & 8,544 & 179,313 & -33 & 0,5 & 44,313 \\
\hline 150 & 6,314 & & & 2,768 & 8,544 & 153,433 & -31 & 0,5 & 3,433 \\
\hline 180 & 6,988 & & & 2,541 & 8,544 & $-179,999$ & -36 & 0,5 & 0,001 \\
\hline
\end{tabular}

Tabela 35: Resultados do mínimo da soma para o Mar $2-H_{s}=4 m$ e $T_{p}=8,5 s$. 


\begin{tabular}{|c|c|c|c|c|c|c|c|c|c|}
\hline \multicolumn{7}{|c|}{ SOMA DOS ERROS } & \multicolumn{3}{|c|}{ VARIAÇÃO COM TEÓRICO } \\
\hline \multirow{2}{*}{$\theta_{m}\left[^{\circ}\right]$} & \multicolumn{9}{|c|}{ Calado $9 \mathrm{~m}$} \\
\hline & Mínimo erro $o_{a b s}$ & $u_{1}$ & $u_{2}$ & $H_{s}^{e s t}[\mathrm{~m}]$ & $T_{p}^{e s t}[s]$ & $\theta_{m}^{\text {est }}\left[{ }^{\circ}\right]$ & $\Delta H_{s}[\%]$ & $\Delta T_{p}[\%]$ & $\Delta \theta_{m}\left[{ }^{\circ}\right]$ \\
\hline 0 & 3,908 & & & 3,398 & 9,955 & 0,102 & -15 & $-0,5$ & 0,102 \\
\hline 30 & 3,150 & & & 3,588 & 9,955 & 28,898 & -10 & $-0,5$ & 1,102 \\
\hline 45 & 5,152 & & & 3,719 & 9,955 & 40,616 & -7 & $-0,5$ & 4,384 \\
\hline 60 & 3,194 & & & 4,165 & 9,955 & 56,739 & 4 & $-0,5$ & 3,261 \\
\hline 90 & 3,080 & 0,00208 & 0,000100 & 4,176 & 9,955 & 90,986 & 4 & $-0,5$ & 0,986 \\
\hline 120 & 3,437 & & & 4,146 & 9,955 & 119,026 & 4 & $-0,5$ & 0,974 \\
\hline 135 & 4,419 & & & 3,821 & 9,955 & 142,873 & -4 & $-0,5$ & 7,873 \\
\hline 150 & 3,538 & & & 3,611 & 9,955 & 150,442 & -10 & $-0,5$ & 0,442 \\
\hline 180 & 5,435 & & & 3,444 & 9,955 & 179,986 & -14 & $-0,5$ & 0,014 \\
\hline \multirow{2}{*}{$\theta_{m}\left[^{\circ}\right]$} & \multicolumn{9}{|c|}{ Calado $14,5 \mathrm{~m}$} \\
\hline & Mínimo erro $_{a b s}$ & $u_{1}$ & $u_{2}$ & $H_{s}^{e s t}[\mathrm{~m}]$ & $T_{p}^{e s t}[s]$ & $\theta_{m}^{\text {est }}\left[{ }^{\circ}\right]$ & $\Delta H_{s}[\%]$ & $\Delta T_{p}[\%]$ & $\Delta \theta_{m}\left[^{\circ}\right]$ \\
\hline 0 & 3,449 & \multirow{9}{*}{0,00208} & \multirow{9}{*}{0,000100} & 3,442 & 9,955 & 0,007 & -14 & $-0,5$ & 0,007 \\
\hline 30 & 3,060 & & & 3,604 & 9,955 & 28,950 & -10 & $-0,5$ & 1,050 \\
\hline 45 & 10,211 & & & 4,086 & 9,955 & 17,003 & 2 & $-0,5$ & 27,997 \\
\hline 60 & 4,088 & & & 4,419 & 9,955 & 59,384 & 10 & $-0,5$ & 0,616 \\
\hline 90 & 3,770 & & & 4,421 & 9,196 & 93,255 & 11 & $-8,0$ & 3,255 \\
\hline 120 & 3,809 & & & 4,295 & 9,196 & 130,522 & 7 & $-8,0$ & 10,522 \\
\hline 135 & 4,527 & & & 3,902 & 9,955 & 147,793 & -2 & $-0,5$ & 12,793 \\
\hline 150 & 3,356 & & & 3,663 & 9,955 & 152,177 & -8 & $-0,5$ & 2,177 \\
\hline 180 & 5,213 & & & 3,518 & 9,955 & 179,990 & -12 & $-0,5$ & 0,010 \\
\hline \multirow{2}{*}{$\theta_{m}\left[^{\circ}\right]$} & \multicolumn{9}{|c|}{ Calado $21 \mathrm{~m}$} \\
\hline & Mínimo erro $_{a b s}$ & $u_{1}$ & $u_{2}$ & $H_{s}^{e s t}[\mathrm{~m}]$ & $T_{p}^{e s t}[s]$ & $\theta_{m}^{e s t}\left[{ }^{\circ}\right]$ & $\Delta H_{s}[\%]$ & $\Delta T_{p}[\%]$ & $\Delta \theta_{m}\left[{ }^{\circ}\right]$ \\
\hline 0 & 4,720 & & & 3,529 & 9,955 & $-0,003$ & -12 & $-0,5$ & 0,003 \\
\hline 30 & 3,442 & & & 3,597 & 9,196 & 26,892 & -10 & $-8,0$ & 3,108 \\
\hline 45 & 9,553 & & & 3,935 & 9,196 & $-16,987$ & -2 & $-8,0$ & 28,013 \\
\hline 60 & 3,607 & & & 4,202 & 9,196 & 61,737 & 5 & $-8,0$ & 1,737 \\
\hline 90 & 3,374 & 0,00208 & 0,005644 & 4,021 & 9,955 & 86,454 & 1 & $-0,5$ & 3,546 \\
\hline 120 & 3,316 & & & 4,063 & 9,955 & 126,533 & 2 & $-0,5$ & 6,533 \\
\hline 135 & 4,452 & & & 2,923 & 10,850 & 139,854 & -27 & 8,5 & 4,854 \\
\hline 150 & 3,592 & & & 3,271 & 9,955 & 151,733 & -18 & $-0,5$ & 1,733 \\
\hline 180 & 6,022 & & & 3,405 & 9,955 & $-179,999$ & -15 & $-0,5$ & 0,001 \\
\hline
\end{tabular}

Tabela 36: Resultados do mínimo da soma para o Mar $3-H_{s}=4 m$ e $T_{p}=10 s$. 


\begin{tabular}{|c|c|c|c|c|c|c|c|c|c|}
\hline \multicolumn{7}{|c|}{ SOMA DOS ERROS } & \multicolumn{3}{|c|}{ VARIAÇÃO COM TEÓRICO } \\
\hline \multirow{2}{*}{$\theta_{m}\left[^{\circ}\right]$} & \multicolumn{9}{|c|}{ Calado $9 \mathrm{~m}$} \\
\hline & Mínimo $e r o_{a b s}$ & $u_{1}$ & $u_{2}$ & $H_{s}^{e s t}[\mathrm{~m}]$ & $T_{p}^{e s t}[s]$ & $\theta_{m}^{e s t}\left[{ }^{\circ}\right]$ & $\Delta H_{s}[\%]$ & $\Delta T_{p}[\%]$ & $\Delta \theta_{m}\left[^{\circ}\right]$ \\
\hline 0 & 4,539 & & & 3,658 & 11,923 & 0,012 & -9 & $-0,6$ & 0,012 \\
\hline 30 & 4,588 & & & 3,856 & 11,923 & 27,706 & -4 & $-0,6$ & 2,294 \\
\hline 45 & 5,559 & & & 4,239 & 10,850 & 39,683 & 6 & $-9,6$ & 5,317 \\
\hline 60 & 3,265 & & & 4,406 & 11,923 & 56,755 & 10 & $-0,6$ & 3,245 \\
\hline 90 & 2,890 & 0,00208 & 0,011189 & 4,171 & 11,923 & 89,928 & 4 & $-0,6$ & 0,072 \\
\hline 120 & 3,212 & & & 4,327 & 11,923 & 116,912 & 8 & $-0,6$ & 3,088 \\
\hline 135 & 4,666 & & & 4,213 & 11,923 & 138,540 & 5 & $-0,6$ & 3,540 \\
\hline 150 & 4,058 & & & 3,827 & 11,923 & 151,846 & -4 & $-0,6$ & 1,846 \\
\hline 180 & 6,033 & & & 3,695 & 11,923 & 179,995 & -8 & $-0,6$ & 0,005 \\
\hline \multirow{2}{*}{$\theta_{m}\left[^{\circ}\right]$} & \multicolumn{9}{|c|}{ Calado $14,5 \mathrm{~m}$} \\
\hline & Mínimo $e r o_{a b s}$ & $u_{1}$ & $u_{2}$ & $H_{s}^{e s t}[\mathrm{~m}]$ & $T_{p}^{e s t}[s]$ & $\theta_{m}^{e s t}\left[{ }^{\circ}\right]$ & $\Delta H_{s}[\%]$ & $\Delta T_{p}[\%]$ & $\Delta \theta_{m}\left[^{\circ}\right]$ \\
\hline 0 & 3,779 & \multirow{9}{*}{0,00208} & \multirow{9}{*}{0,005644} & 3,652 & 11,923 & 0,014 & -9 & $-0,6$ & 0,014 \\
\hline 30 & 3,942 & & & 3,914 & 11,923 & 28,905 & -2 & $-0,6$ & 1,095 \\
\hline 45 & 9,619 & & & 4,232 & 10,850 & 22,296 & 6 & $-9,6$ & 22,704 \\
\hline 60 & 4,004 & & & 4,565 & 11,923 & 64,465 & 14 & $-0,6$ & 4,465 \\
\hline 90 & 3,553 & & & 4,415 & 9,955 & 96,496 & 10 & $-17,0$ & 6,496 \\
\hline 120 & 3,291 & & & 4,459 & 11,923 & 125,236 & 11 & $-0,6$ & 5,236 \\
\hline 135 & 5,631 & & & 4,462 & 11,923 & 147,829 & 12 & $-0,6$ & 12,829 \\
\hline 150 & 4,103 & & & 3,874 & 11,923 & 153,011 & -3 & $-0,6$ & 3,011 \\
\hline 180 & 5,205 & & & 3,691 & 11,923 & 179,988 & -8 & $-0,6$ & 0,012 \\
\hline \multirow{2}{*}{$\theta_{m}\left[^{\circ}\right]$} & \multicolumn{9}{|c|}{ Calado $21 \mathrm{~m}$} \\
\hline & Mínimo $e r O_{a b s}$ & $u_{1}$ & $u_{2}$ & $H_{s}^{e s t}[\mathrm{~m}]$ & $T_{p}^{e s t}[s]$ & $\theta_{m}^{e s t}\left[{ }^{\circ}\right]$ & $\Delta H_{s}[\%]$ & $\Delta T_{p}[\%]$ & $\Delta \theta_{m}\left[^{\circ}\right]$ \\
\hline 0 & 4,131 & & & 3,606 & 11,923 & $-0,002$ & -10 & $-0,6$ & 0,002 \\
\hline 30 & 4,253 & & & 3,831 & 11,923 & 26,944 & -4 & $-0,6$ & 3,056 \\
\hline 45 & 9,482 & & & 4,267 & 11,923 & 13,946 & 7 & $-0,6$ & 31,054 \\
\hline 60 & 3,834 & & & 4,498 & 11,923 & 68,529 & 12 & $-0,6$ & 8,529 \\
\hline 90 & 3,659 & 0,00406 & 0,011189 & 4,339 & 10,850 & 97,658 & 8 & $-9,6$ & 7,658 \\
\hline 120 & 4,278 & & & 4,644 & 10,850 & 132,570 & 16 & $-9,6$ & 12,570 \\
\hline 135 & 4,519 & & & 4,079 & 10,850 & 143,959 & 2 & $-9,6$ & 8,959 \\
\hline 150 & 4,289 & & & 3,836 & 10,850 & 152,671 & -4 & $-9,6$ & 2,671 \\
\hline 180 & 6,736 & & & 3,657 & 10,850 & $-179,998$ & -9 & $-9,6$ & 0,002 \\
\hline
\end{tabular}

Tabela 37: Resultados do mínimo da soma para o Mar $4-H_{s}=4 m$ e $T_{p}=12 s$. 


\begin{tabular}{|c|c|c|c|c|c|c|c|c|c|}
\hline \multicolumn{7}{|c|}{ SOMA DOS ERROS } & \multicolumn{3}{|c|}{ VARIAÇÃO COM TEÓRICO } \\
\hline \multirow{2}{*}{$\theta_{m}\left[^{\circ}\right]$} & \multicolumn{9}{|c|}{ Calado $9 \mathrm{~m}$} \\
\hline & Mínimo erro $o_{a b s}$ & $u_{1}$ & $u_{2}$ & $H_{s}^{e s t}[\mathrm{~m}]$ & $T_{p}^{e s t}[s]$ & $\theta_{m}^{\text {est }}\left[{ }^{\circ}\right]$ & $\Delta H_{s}[\%]$ & $\Delta T_{p}[\%]$ & $\Delta \theta_{m}\left[{ }^{\circ}\right]$ \\
\hline 0 & 2,441 & & & 4,038 & 13,231 & 0,011 & 1 & $-5,5$ & 0,011 \\
\hline 30 & 3,093 & & & 4,208 & 13,231 & 28,170 & 5 & $-5,5$ & 1,830 \\
\hline 45 & 4,198 & & & 4,611 & 14,861 & 37,987 & 15 & 6,1 & 7,013 \\
\hline 60 & 2,880 & & & 4,671 & 14,861 & 57,766 & 17 & 6,1 & 2,234 \\
\hline 90 & 2,475 & 0,00208 & 0,011189 & 4,421 & 14,861 & 89,963 & 11 & 6,1 & 0,037 \\
\hline 120 & 3,467 & & & 4,856 & 14,861 & 116,112 & 21 & 6,1 & 3,888 \\
\hline 135 & 3,405 & & & 4,500 & 14,861 & 138,757 & 13 & 6,1 & 3,757 \\
\hline 150 & 2,855 & & & 4,137 & 13,231 & 151,058 & 3 & $-5,5$ & 1,058 \\
\hline 180 & 2,967 & & & 4,015 & 13,231 & 179,993 & 0 & $-5,5$ & 0,007 \\
\hline \multirow{2}{*}{$\theta_{m}\left[^{\circ}\right]$} & \multicolumn{9}{|c|}{ Calado $14,5 \mathrm{~m}$} \\
\hline & Mínimo erro $_{a b s}$ & $u_{1}$ & $u_{2}$ & $H_{s}^{e s t}[\mathrm{~m}]$ & $T_{p}^{e s t}[s]$ & $\theta_{m}^{\text {est }}\left[{ }^{\circ}\right]$ & $\Delta H_{s}[\%]$ & $\Delta T_{p}[\%]$ & $\Delta \theta_{m}\left[^{\circ}\right]$ \\
\hline 0 & 2,511 & \multirow{9}{*}{0,00406} & \multirow{9}{*}{0,011189} & 3,933 & 13,231 & 0,010 & -2 & $-5,5$ & 0,010 \\
\hline 30 & 3,163 & & & 4,131 & 14,861 & 27,397 & 3 & 6,1 & 2,603 \\
\hline 45 & 5,260 & & & 4,292 & 14,861 & 23,029 & 7 & 6,1 & 21,971 \\
\hline 60 & 2,832 & & & 4,612 & 14,861 & 62,308 & 15 & 6,1 & 2,308 \\
\hline 90 & 2,651 & & & 4,414 & 14,861 & 93,772 & 10 & 6,1 & 3,772 \\
\hline 120 & 2,820 & & & 4,613 & 14,861 & 121,987 & 15 & 6,1 & 1,987 \\
\hline 135 & 3,324 & & & 4,379 & 14,861 & 139,299 & 9 & 6,1 & 4,299 \\
\hline 150 & 3,388 & & & 4,095 & 13,231 & 153,102 & 2 & $-5,5$ & 3,102 \\
\hline 180 & 3,234 & & & 3,977 & 13,231 & 179,990 & -1 & $-5,5$ & 0,010 \\
\hline \multirow{2}{*}{$\theta_{m}\left[^{\circ}\right]$} & \multicolumn{9}{|c|}{ Calado $21 \mathrm{~m}$} \\
\hline & Mínimo erro $_{a b s}$ & $u_{1}$ & $u_{2}$ & $H_{s}^{e s t}[\mathrm{~m}]$ & $T_{p}^{e s t}[s]$ & $\theta_{m}^{e s t}\left[{ }^{\circ}\right]$ & $\Delta H_{s}[\%]$ & $\Delta T_{p}[\%]$ & $\Delta \theta_{m}\left[{ }^{\circ}\right]$ \\
\hline 0 & 2,189 & & & 3,914 & 13,231 & $-0,004$ & -2 & $-5,5$ & 0,004 \\
\hline 30 & 2,860 & & & 4,200 & 14,861 & 28,875 & 5 & 6,1 & 1,125 \\
\hline 45 & 6,503 & & & 4,594 & 14,861 & 14,534 & 15 & 6,1 & 30,466 \\
\hline 60 & 3,663 & & & 4,904 & 14,861 & 66,697 & 23 & 6,1 & 6,697 \\
\hline 90 & 3,118 & 0,00406 & 0,005644 & 4,679 & 14,861 & 97,844 & 17 & 6,1 & 7,844 \\
\hline 120 & 3,543 & & & 4,928 & 14,861 & 127,099 & 23 & 6,1 & 7,099 \\
\hline 135 & 3,564 & & & 4,239 & 14,861 & 138,919 & 6 & 6,1 & 3,919 \\
\hline 150 & 2,986 & & & 4,149 & 13,231 & 150,476 & 4 & $-5,5$ & 0,476 \\
\hline 180 & 3,147 & & & 3,978 & 13,231 & $-179,995$ & -1 & $-5,5$ & 0,005 \\
\hline
\end{tabular}

Tabela 38: Resultados do mínimo da soma para o Mar $5-H_{s}=4 m$ e $T_{p}=14 s$. 
APÊNDICE F - Mapas dos espectros estimados com hiperparâmetros definidos pela metodologia de calibração. 


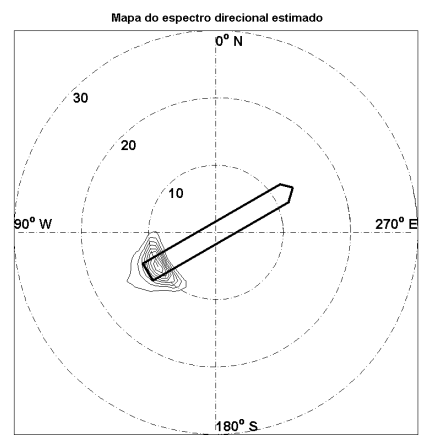

(a) Mar $1, \theta_{m}=0^{\circ}$ e calado $9 \mathrm{~m}$

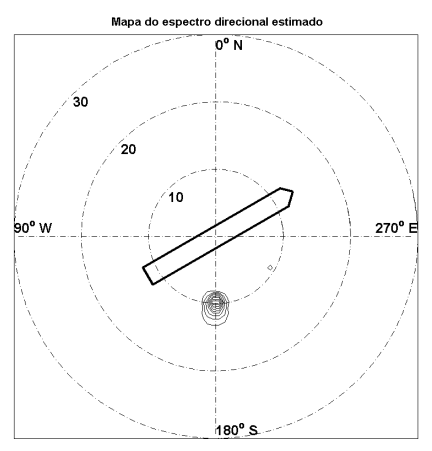

(d) Mar $1, \theta_{m}=60^{\circ}$ e calado $9 \mathrm{~m}$

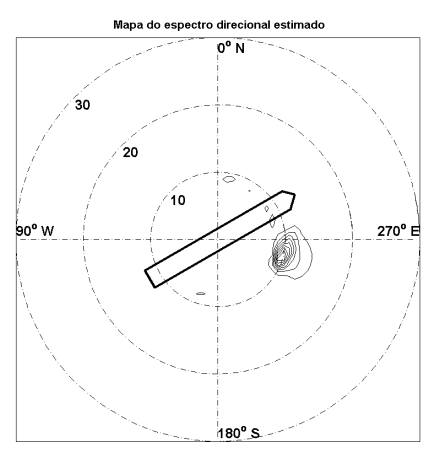

(g) Mar $1, \theta_{m}=135^{\circ}$ e calado $9 \mathrm{~m}$

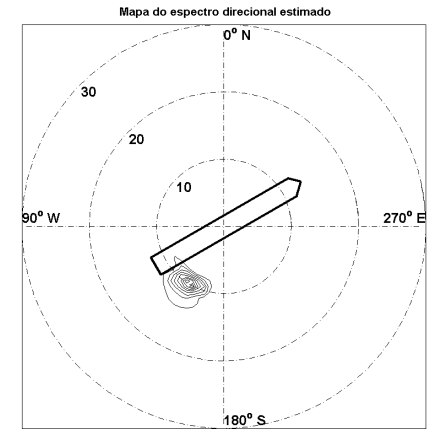

(b) Mar $1, \theta_{m}=30^{\circ}$ e calado $9 \mathrm{~m}$

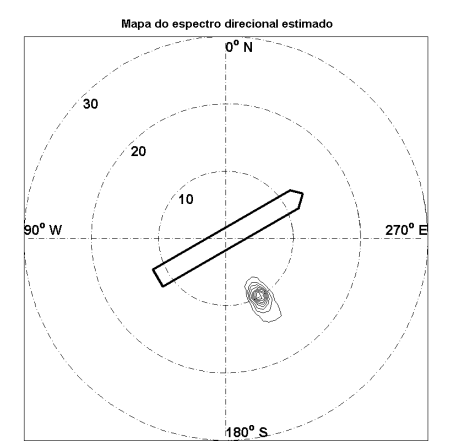

(e) Mar $1, \theta_{m}=90^{\circ}$ e calado $9 \mathrm{~m}$

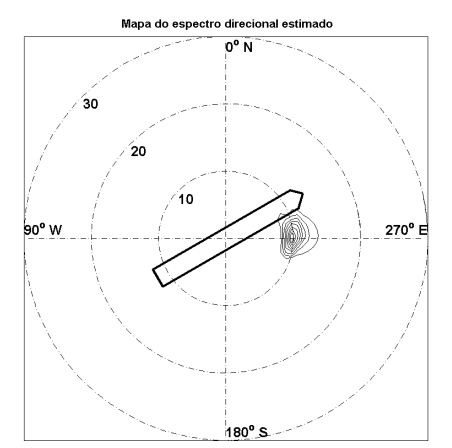

(h) Mar $1, \theta_{m}=150^{\circ}$ e calado $9 \mathrm{~m}$

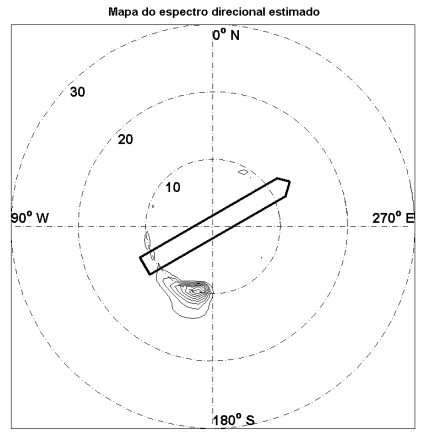

(c) Mar $1, \theta_{m}=45^{\circ}$ e calado $9 \mathrm{~m}$

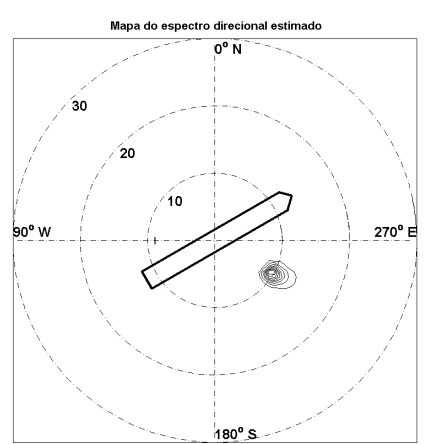

(f) $\operatorname{Mar} 1, \theta_{m}=120^{\circ}$ e calado $9 \mathrm{~m}$

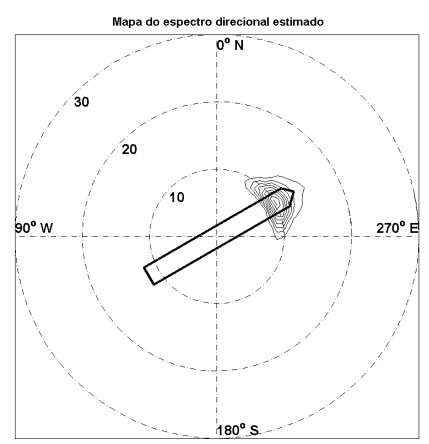

Figura 47: Mapas dos espectros direcionais estimados para o mar 1, com $H_{s}=2 m, T_{p}=10 \mathrm{~s}$ e $s=150$, FPSO P-50 em calado leve. 


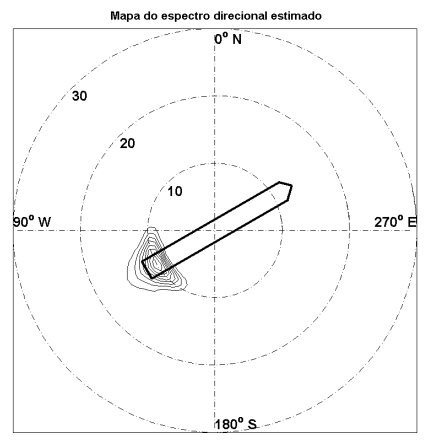

(a) Mar $1, \theta_{m}=0^{\circ}$ e calado $14,5 \mathrm{~m}$

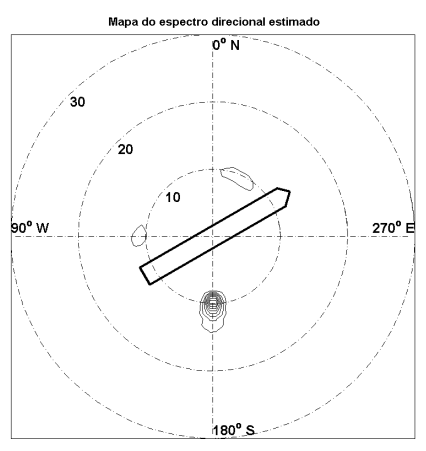

(d) Mar $1, \theta_{m}=60^{\circ}$ e calado $14,5 \mathrm{~m}$

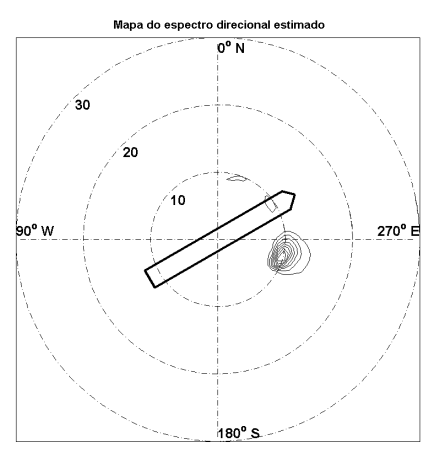

(g) Mar $1, \theta_{m}=135^{\circ}$ e calado $14,5 \mathrm{~m}$

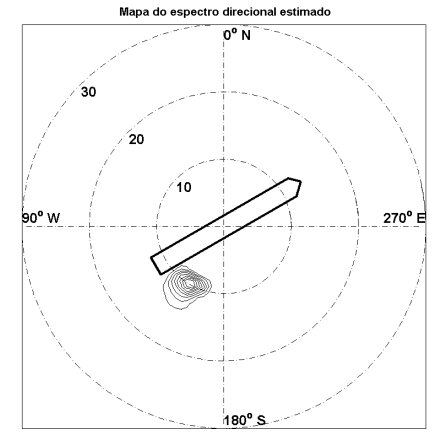

(b) $\operatorname{Mar} 1, \theta_{m}=30^{\circ}$ e calado $14,5 \mathrm{~m}$

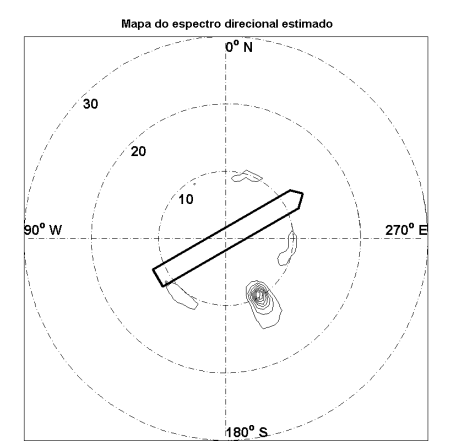

(e) $\operatorname{Mar} 1, \theta_{m}=90^{\circ}$ e calado $14,5 \mathrm{~m}$

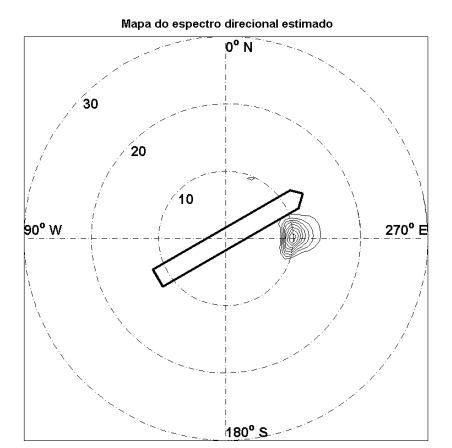

(h) $\operatorname{Mar} 1, \theta_{m}=150^{\circ}$ e calado $14,5 \mathrm{~m}$

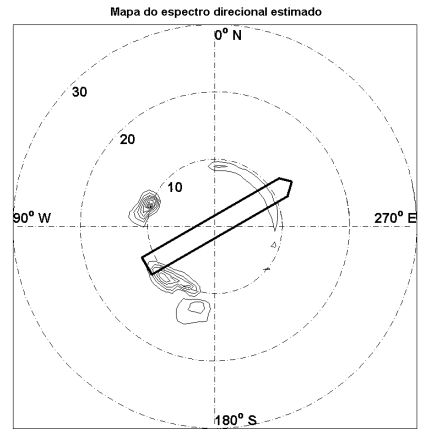

(c) $\operatorname{Mar} 1, \theta_{m}=45^{\circ}$ e calado $14,5 \mathrm{~m}$

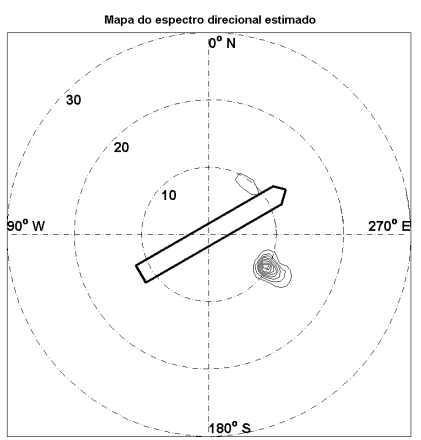

(f) $\operatorname{Mar} 1, \theta_{m}=120^{\circ}$ e calado $14,5 \mathrm{~m}$

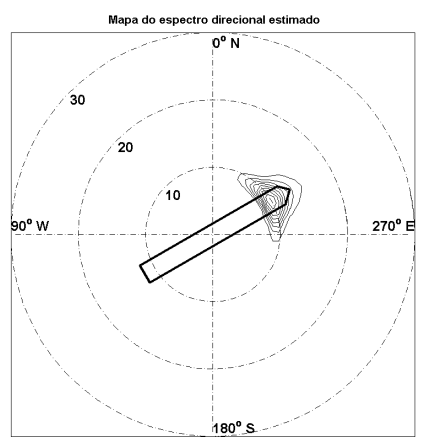

(i) Mar $1, \theta_{m}=180^{\circ}$ e calado $14,5 \mathrm{~m}$

Figura 48: Mapas dos espectros direcionais estimados para o mar 1 , com $H_{s}=2 m, T_{p}=10 \mathrm{~s}$ e $s=150$, FPSO P-50 em calado intermediário. 


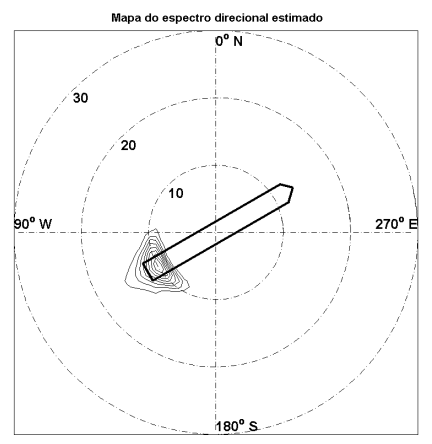

(a) Mar $1, \theta_{m}=0^{\circ}$ e calado $21 \mathrm{~m}$

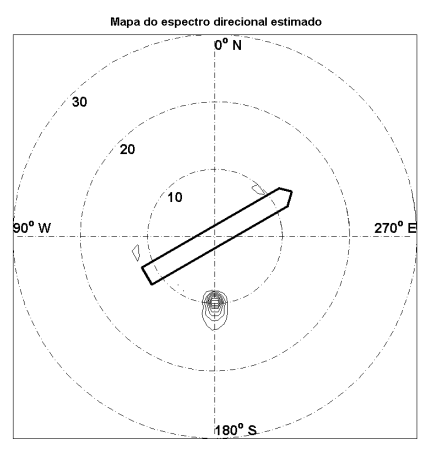

(d) Mar $1, \theta_{m}=60^{\circ}$ e calado $21 \mathrm{~m}$

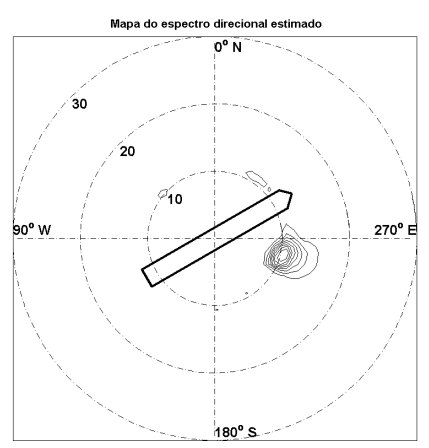

(g) Mar $1, \theta_{m}=135^{\circ}$ e calado $21 \mathrm{~m}$

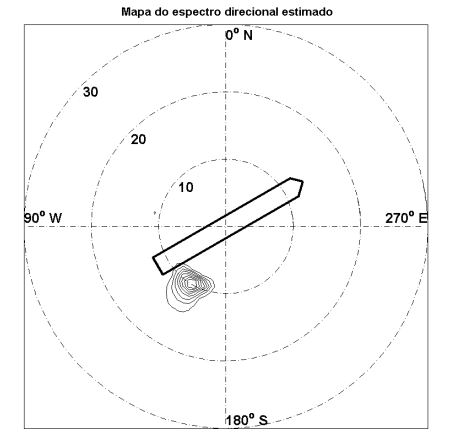

(b) Mar $1, \theta_{m}=30^{\circ}$ e calado $21 \mathrm{~m}$

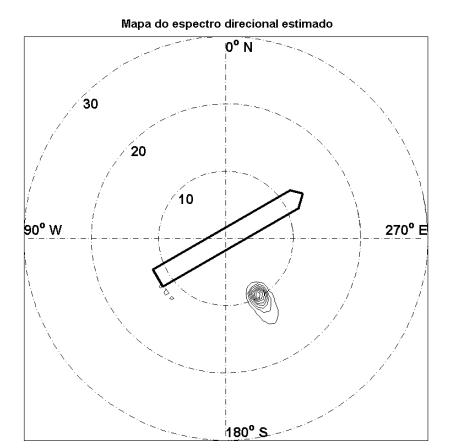

(e) $\operatorname{Mar} 1, \theta_{m}=90^{\circ}$ e calado $21 \mathrm{~m}$

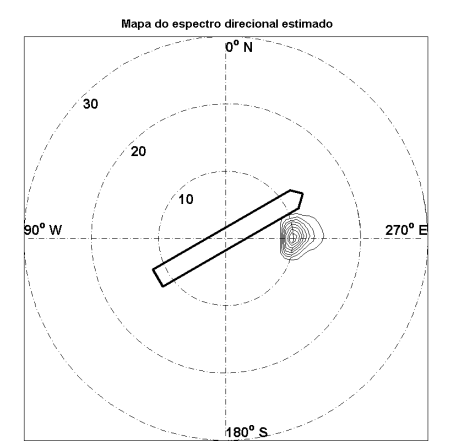

(h) $\operatorname{Mar} 1, \theta_{m}=150^{\circ}$ e calado $21 \mathrm{~m}$

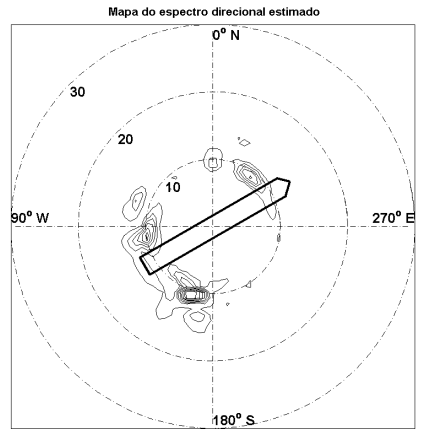

(c) Mar $1, \theta_{m}=45^{\circ}$ e calado $21 \mathrm{~m}$

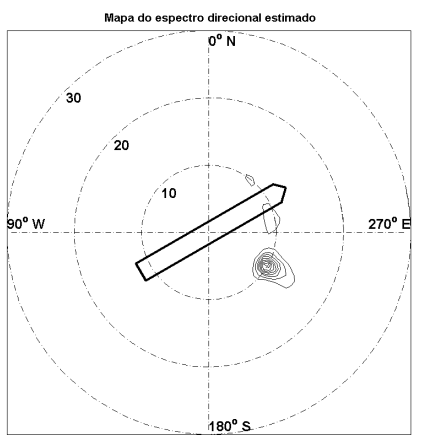

(f) $\operatorname{Mar} 1, \theta_{m}=120^{\circ}$ e calado $21 \mathrm{~m}$

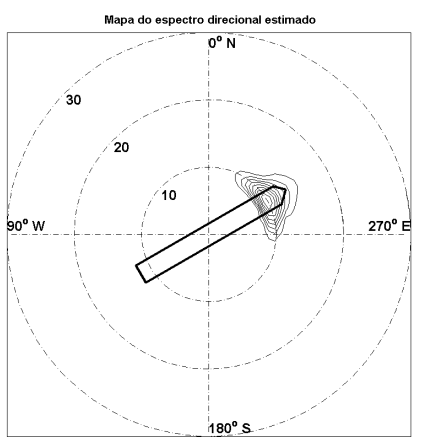

(i) $\operatorname{Mar} 1, \theta_{m}=180^{\circ}$ e calado $21 \mathrm{~m}$

Figura 49: Mapas dos espectros direcionais estimados para o mar 1 , com $H_{s}=2 m, T_{p}=10 s$ e $s=150$, FPSO P-50 em calado cheio. 


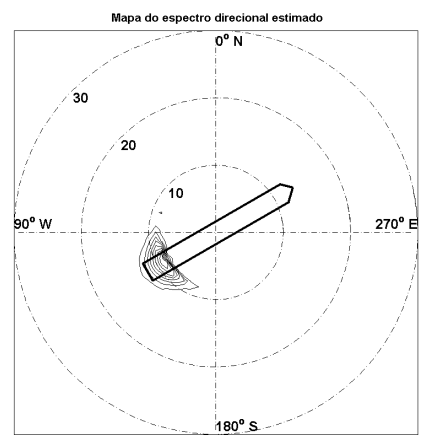

(a) Mar 2, $\theta_{m}=0^{\circ}$ e calado $9 \mathrm{~m}$

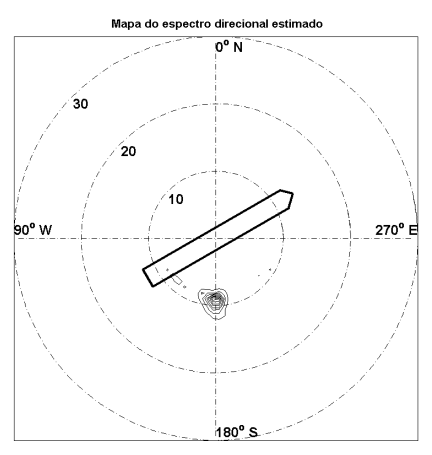

(d) Mar 2, $\theta_{m}=60^{\circ}$ e calado $9 \mathrm{~m}$

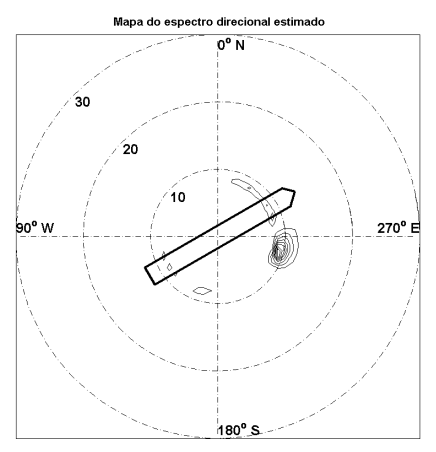

(g) $\operatorname{Mar} 2, \theta_{m}=135^{\circ}$ e calado $9 \mathrm{~m}$

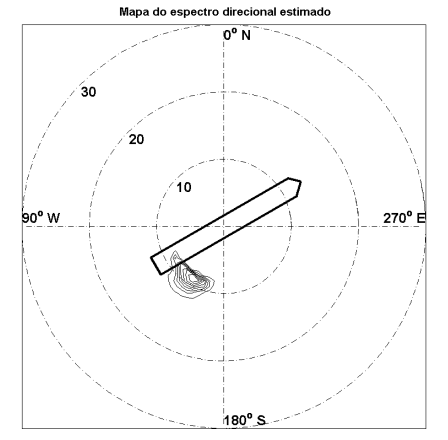

(b) Mar 2, $\theta_{m}=30^{\circ}$ e calado $9 \mathrm{~m}$

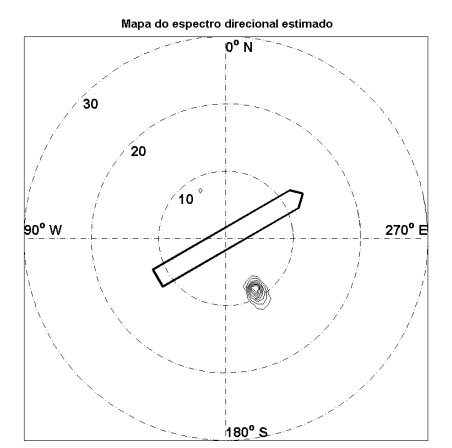

(e) Mar 2, $\theta_{m}=90^{\circ}$ e calado $9 \mathrm{~m}$

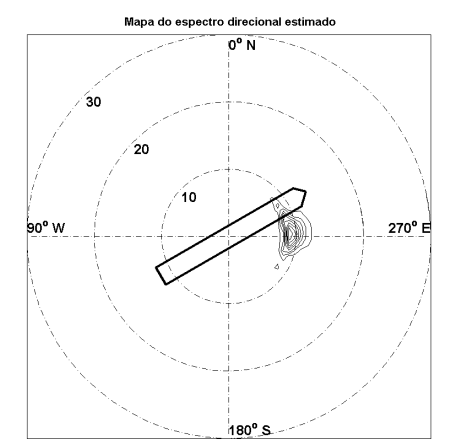

(h) Mar 2, $\theta_{m}=150^{\circ}$ e calado $9 \mathrm{~m}$

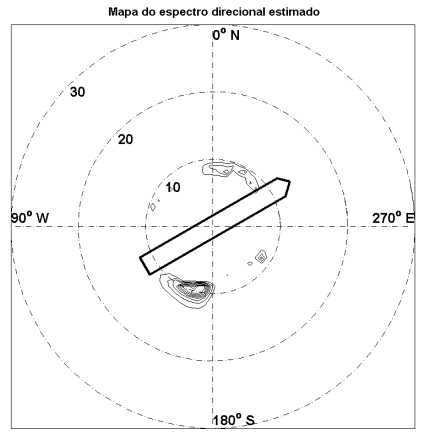

(c) Mar 2, $\theta_{m}=45^{\circ}$ e calado $9 \mathrm{~m}$

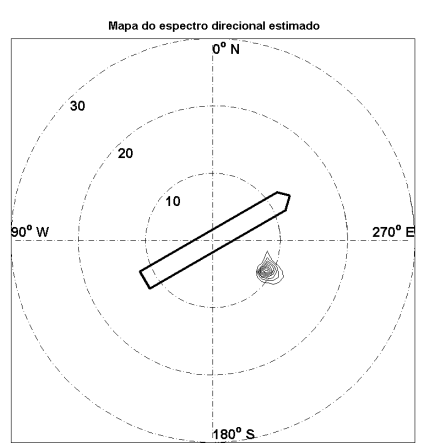

(f) Mar 2, $\theta_{m}=120^{\circ}$ e calado $9 \mathrm{~m}$

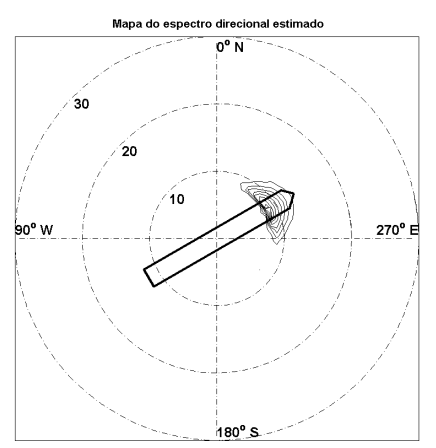

(i) Mar 2, $\theta_{m}=180^{\circ}$ e calado $9 \mathrm{~m}$

Figura 50: Mapas dos espectros direcionais estimados para o mar 2, com $H_{s}=4 m, T_{p}=8,5 s$ e $s=150$, FPSO P-50 em calado leve. 


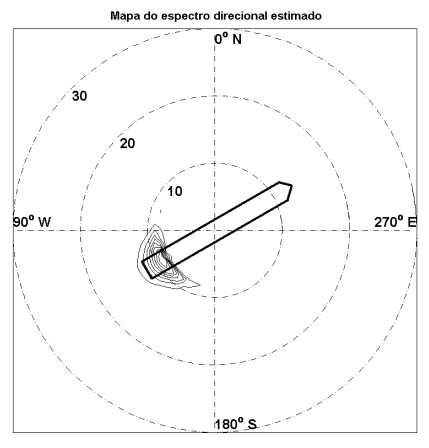

(a) Mar 2, $\theta_{m}=0^{\circ}$ e calado $14,5 \mathrm{~m}$

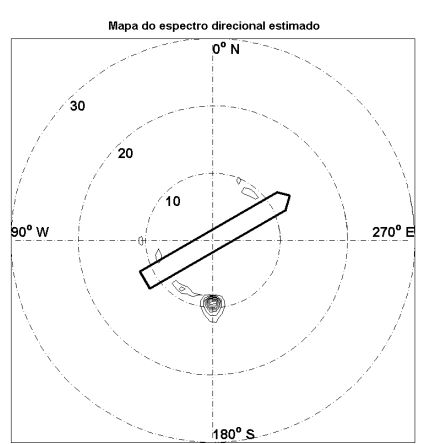

(d) $\operatorname{Mar} 2, \theta_{m}=60^{\circ}$ e calado $14,5 \mathrm{~m}$

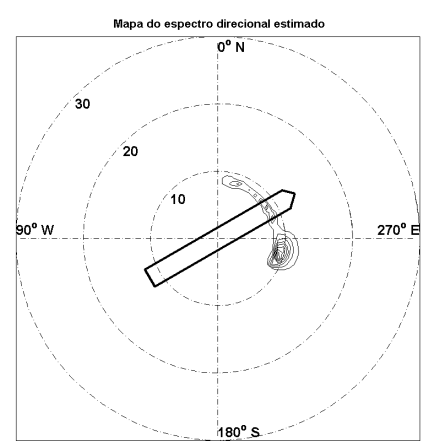

(g) Mar 2, $\theta_{m}=135^{\circ}$ e calado $14,5 \mathrm{~m}$

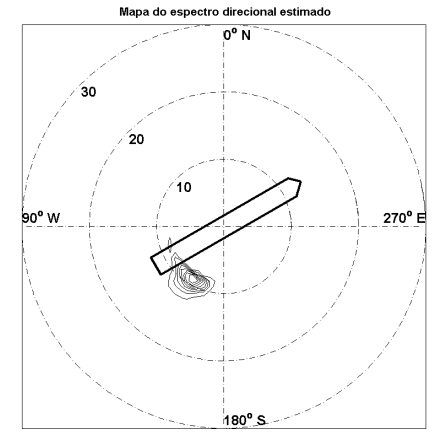

(b) Mar 2, $\theta_{m}=30^{\circ}$ e calado $14,5 \mathrm{~m}$

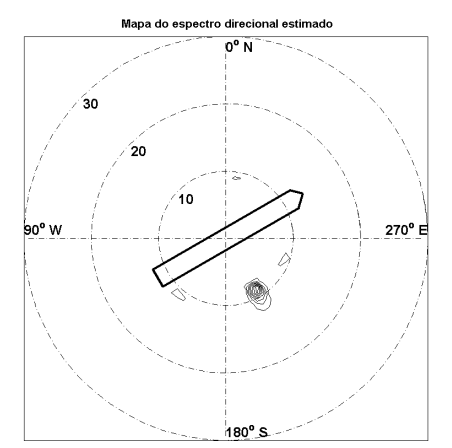

(e) $\operatorname{Mar} 2, \theta_{m}=90^{\circ}$ e calado $14,5 \mathrm{~m}$

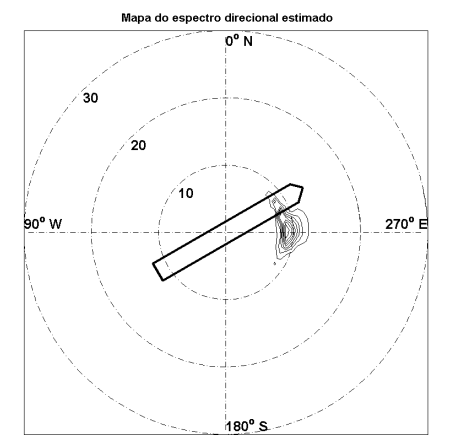

(h) Mar 2, $\theta_{m}=150^{\circ}$ e calado $14,5 \mathrm{~m}$

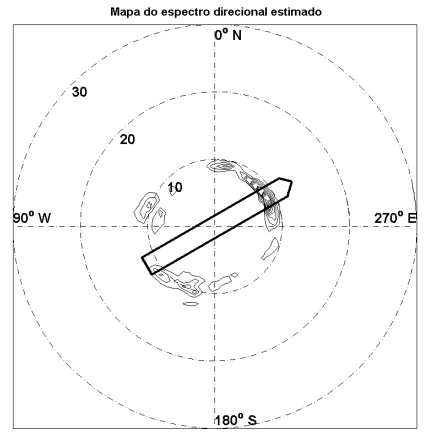

(c) Mar 2, $\theta_{m}=45^{\circ}$ e calado $14,5 \mathrm{~m}$

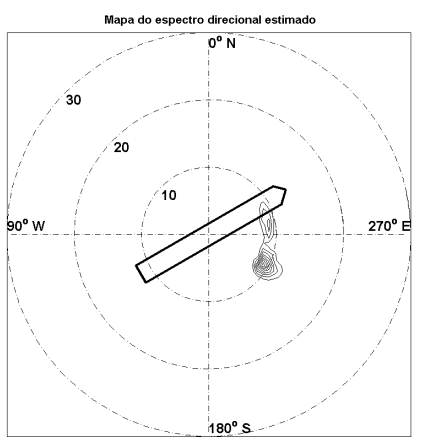

(f) $\operatorname{Mar} 2, \theta_{m}=120^{\circ}$ e calado $14,5 \mathrm{~m}$

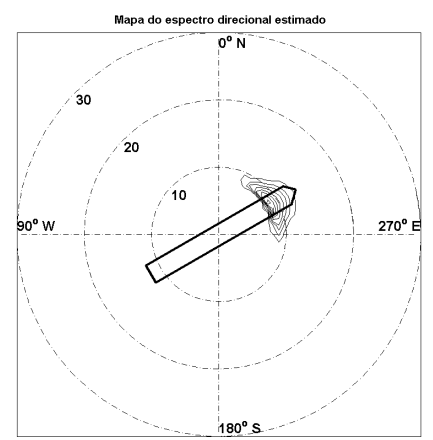

(i) $\operatorname{Mar} 2, \theta_{m}=180^{\circ}$ e calado $14,5 \mathrm{~m}$

Figura 51: Mapas dos espectros direcionais estimados para o mar 2, com $H_{s}=4 m, T_{p}=8,5 s$ e $s=150$, FPSO P-50 em calado intermediário. 


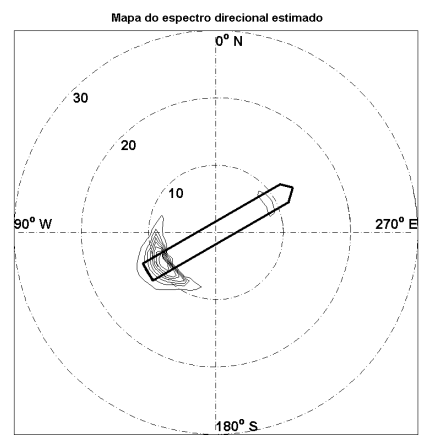

(a) Mar 2, $\theta_{m}=0^{\circ}$ e calado $21 \mathrm{~m}$

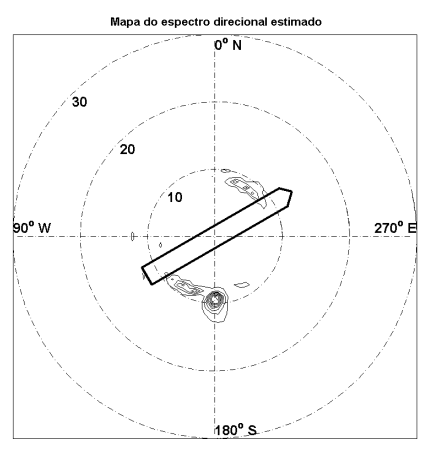

(d) Mar 2, $\theta_{m}=60^{\circ}$ e calado $21 \mathrm{~m}$

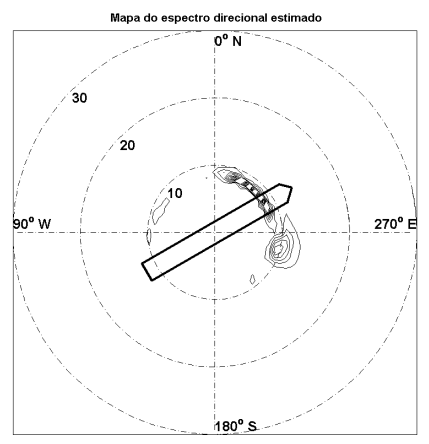

(g) Mar 2, $\theta_{m}=135^{\circ}$ e calado $21 \mathrm{~m}$

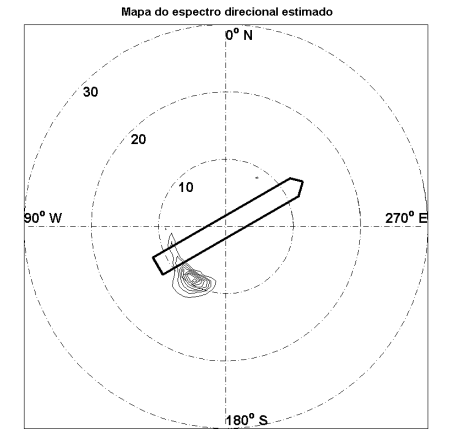

(b) Mar 2, $\theta_{m}=30^{\circ}$ e calado $21 \mathrm{~m}$

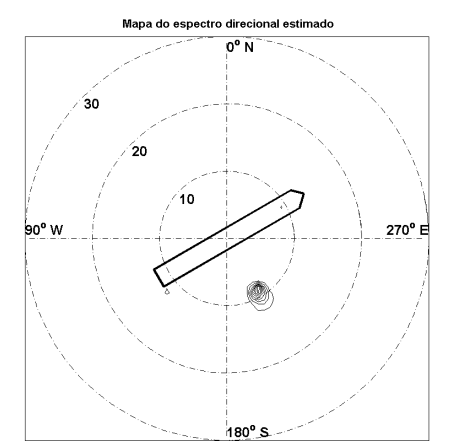

(e) Mar 2, $\theta_{m}=90^{\circ}$ e calado $21 \mathrm{~m}$

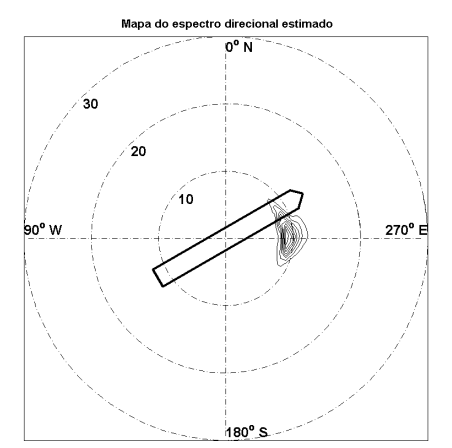

(h) Mar 2, $\theta_{m}=150^{\circ}$ e calado $21 \mathrm{~m}$

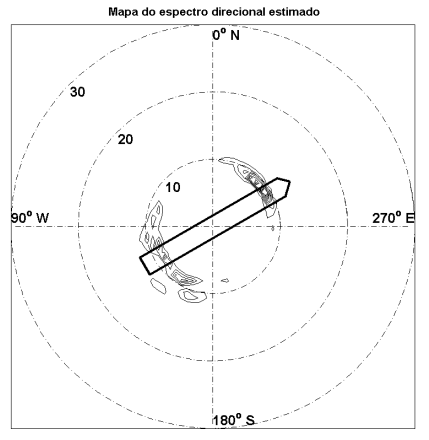

(c) Mar 2, $\theta_{m}=45^{\circ}$ e calado $21 \mathrm{~m}$

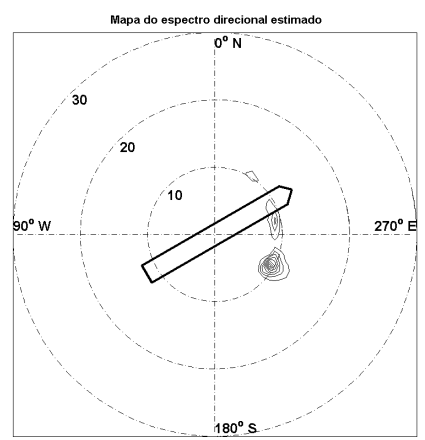

(f) Mar 2, $\theta_{m}=120^{\circ}$ e calado $21 \mathrm{~m}$

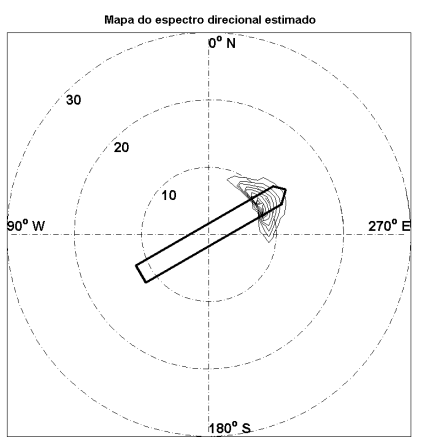

(i) Mar 2, $\theta_{m}=180^{\circ}$ e calado $21 \mathrm{~m}$

Figura 52: Mapas dos espectros direcionais estimados para o mar 2, com $H_{s}=4 m, T_{p}=8,5 s$ e $s=150$, FPSO P-50 em calado cheio. 


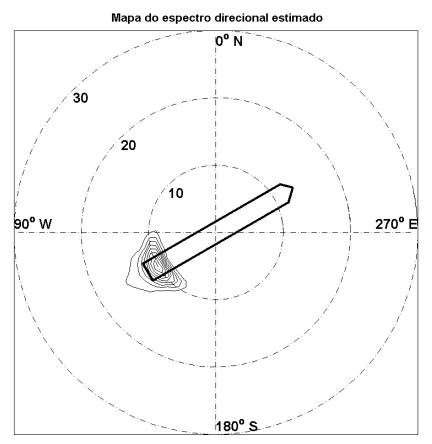

(a) Mar 3, $\theta_{m}=0^{\circ}$ e calado $9 \mathrm{~m}$

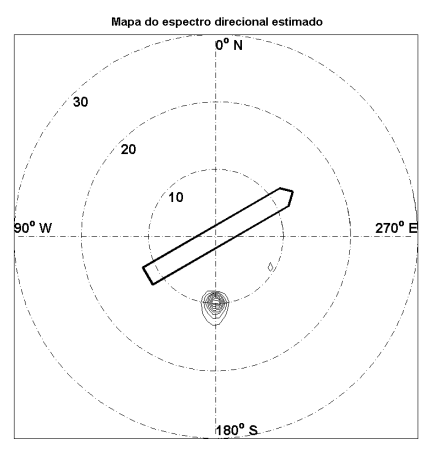

(d) Mar $3, \theta_{m}=60^{\circ}$ e calado $9 \mathrm{~m}$

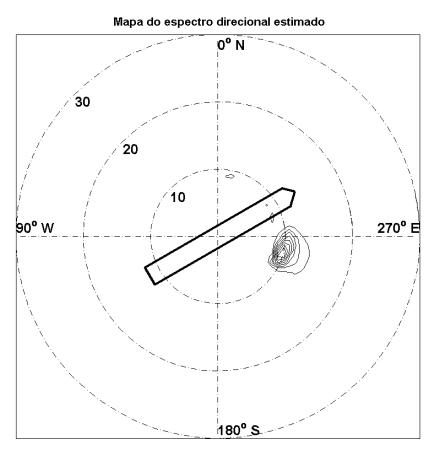

(g) $\operatorname{Mar} 3, \theta_{m}=135^{\circ}$ e calado $9 \mathrm{~m}$

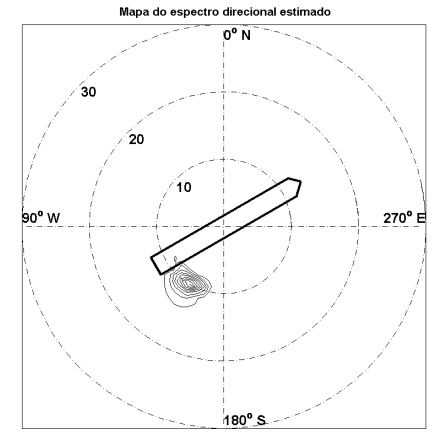

(b) Mar 3, $\theta_{m}=30^{\circ}$ e calado $9 \mathrm{~m}$

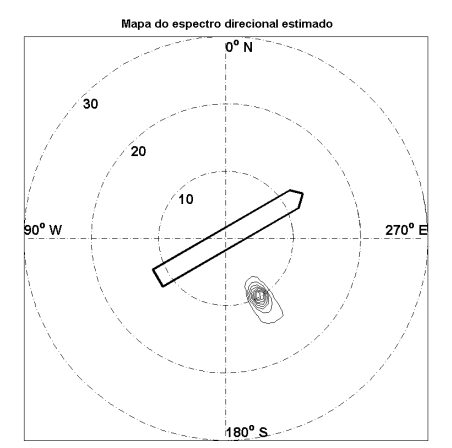

(e) Mar 3, $\theta_{m}=90^{\circ}$ e calado $9 \mathrm{~m}$

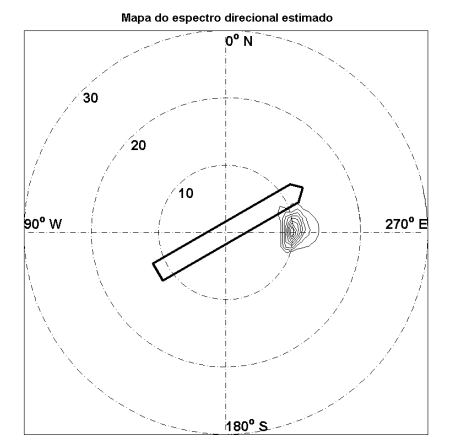

(h) Mar 3, $\theta_{m}=150^{\circ}$ e calado $9 \mathrm{~m}$

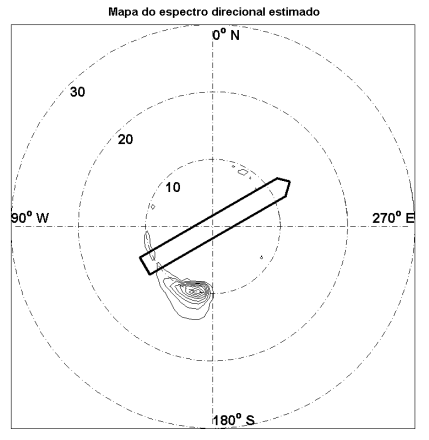

(c) Mar 3, $\theta_{m}=45^{\circ}$ e calado $9 \mathrm{~m}$

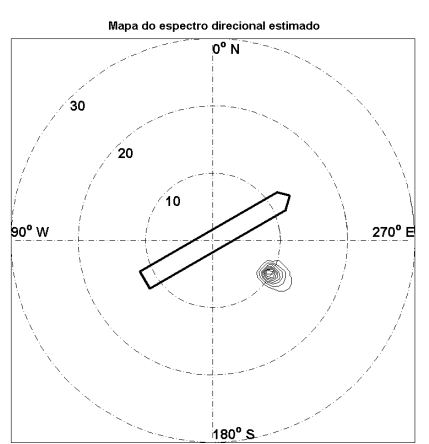

(f) Mar 3, $\theta_{m}=120^{\circ}$ e calado $9 \mathrm{~m}$

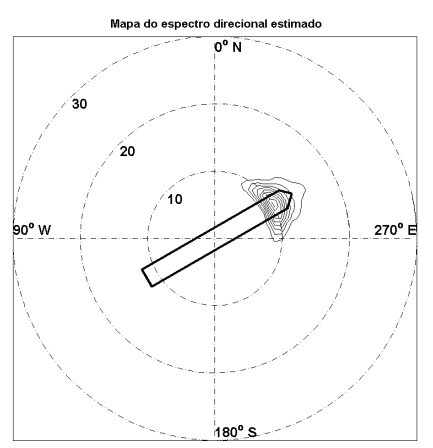

(i) Mar 3, $\theta_{m}=180^{\circ}$ e calado $9 \mathrm{~m}$

Figura 53: Mapas dos espectros direcionais estimados para o mar 3, com $H_{s}=4 m, T_{p}=10 \mathrm{~s}$ e $s=150$, FPSO P-50 em calado leve. 


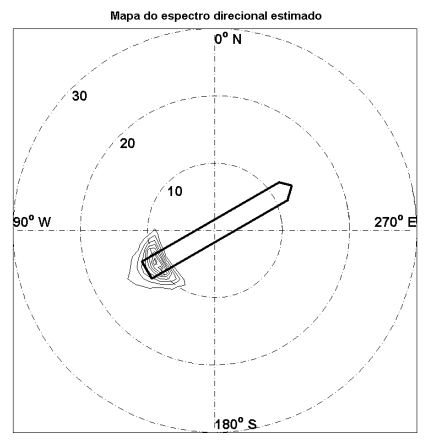

(a) Mar $3, \theta_{m}=0^{\circ}$ e calado $14,5 \mathrm{~m}$

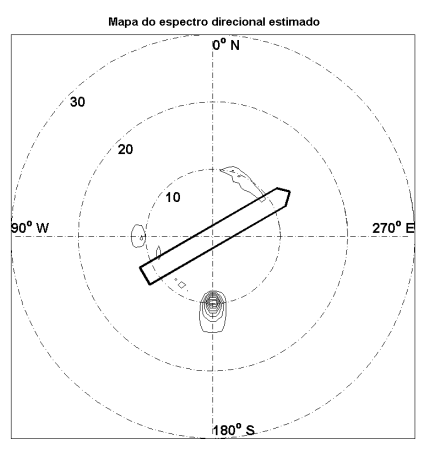

(d) $\operatorname{Mar} 3, \theta_{m}=60^{\circ}$ e calado $14,5 \mathrm{~m}$

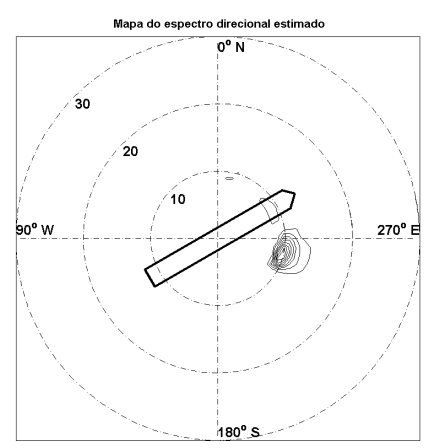

(g) Mar $3, \theta_{m}=135^{\circ}$ e calado $14,5 \mathrm{~m}$

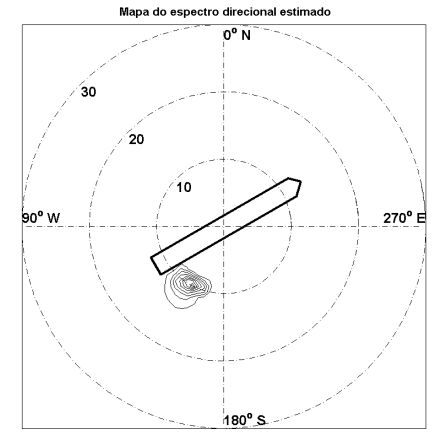

(b) $\operatorname{Mar} 3, \theta_{m}=30^{\circ}$ e calado $14,5 \mathrm{~m}$

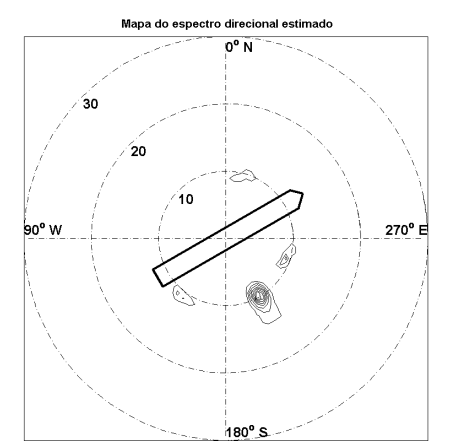

(e) $\operatorname{Mar} 3, \theta_{m}=90^{\circ}$ e calado $14,5 \mathrm{~m}$

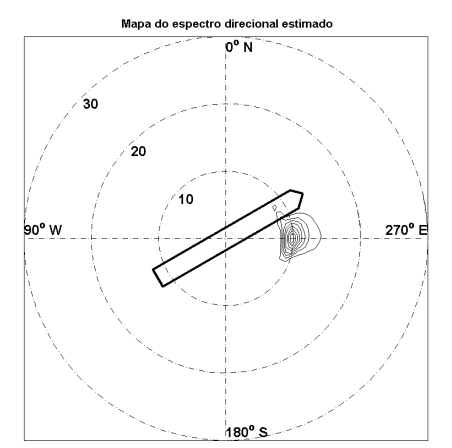

(h) $\operatorname{Mar} 3, \theta_{m}=150^{\circ}$ e calado $14,5 \mathrm{~m}$

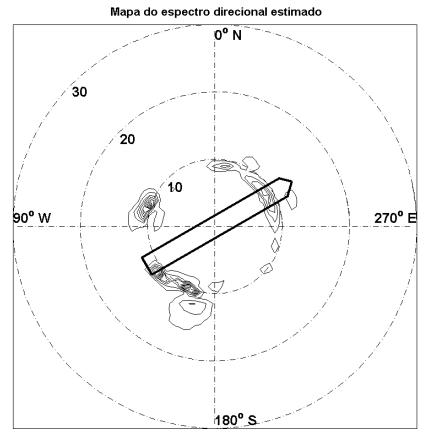

(c) $\operatorname{Mar} 3, \theta_{m}=45^{\circ}$ e calado $14,5 \mathrm{~m}$

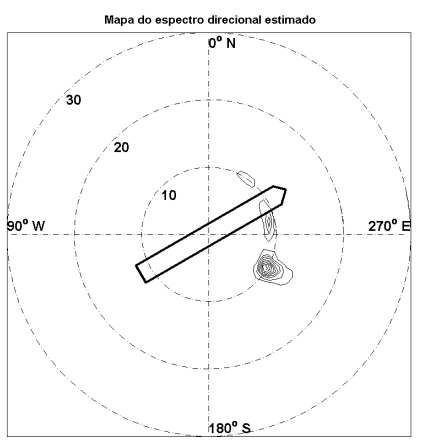

(f) $\operatorname{Mar} 3, \theta_{m}=120^{\circ}$ e calado $14,5 \mathrm{~m}$

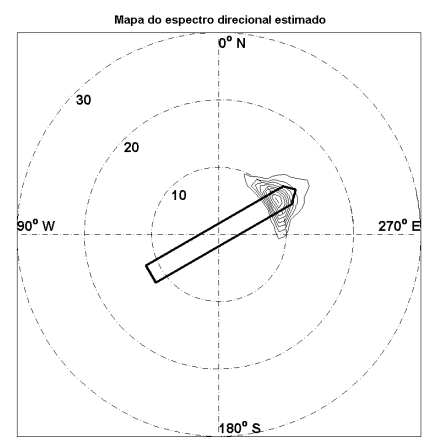

(i) $\operatorname{Mar} 3, \theta_{m}=180^{\circ}$ e calado $14,5 \mathrm{~m}$

Figura 54: Mapas dos espectros direcionais estimados para o mar 3, com $H_{s}=4 m, T_{p}=10 \mathrm{~s}$ e $s=150$, FPSO P-50 em calado intermediário. 


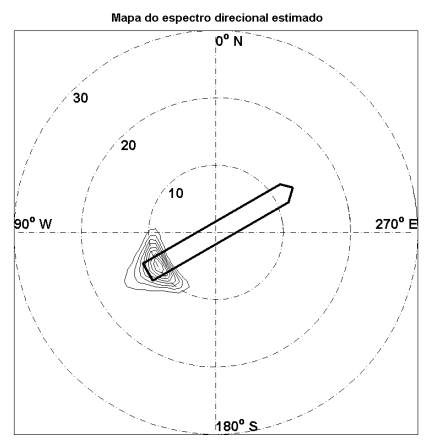

(a) Mar 3, $\theta_{m}=0^{\circ}$ e calado $21 \mathrm{~m}$

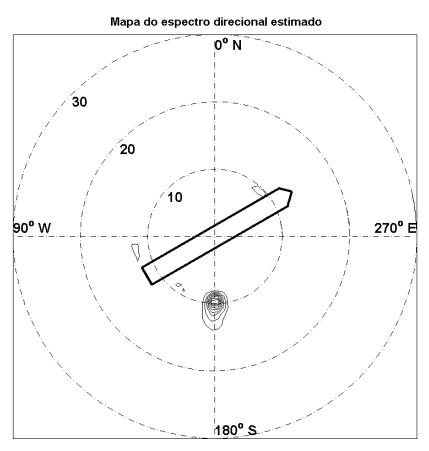

(d) Mar 3, $\theta_{m}=60^{\circ}$ e calado $21 \mathrm{~m}$

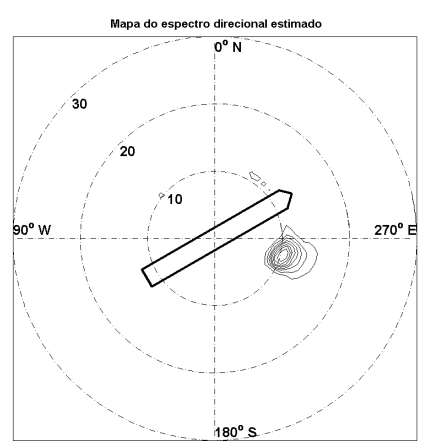

(g) Mar 3, $\theta_{m}=135^{\circ}$ e calado $21 \mathrm{~m}$

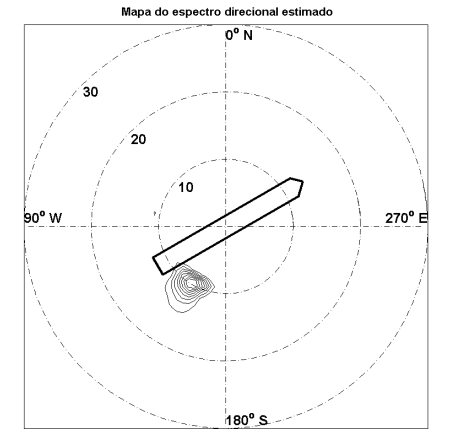

(b) $\operatorname{Mar} 3, \theta_{m}=30^{\circ}$ e calado $21 \mathrm{~m}$

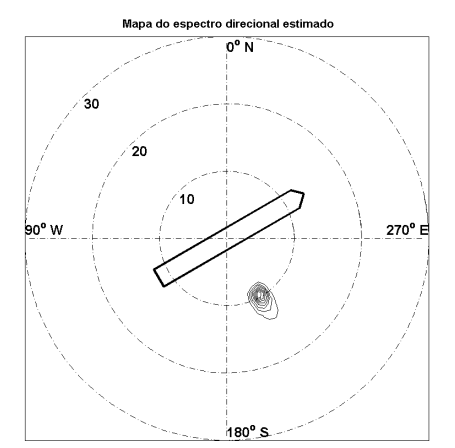

(e) $\operatorname{Mar} 3, \theta_{m}=90^{\circ}$ e calado $21 \mathrm{~m}$

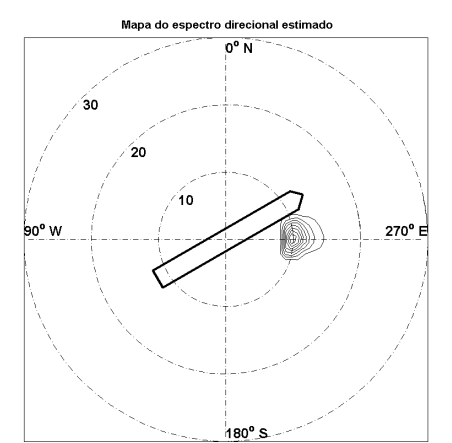

(h) $\operatorname{Mar} 3, \theta_{m}=150^{\circ}$ e calado $21 \mathrm{~m}$

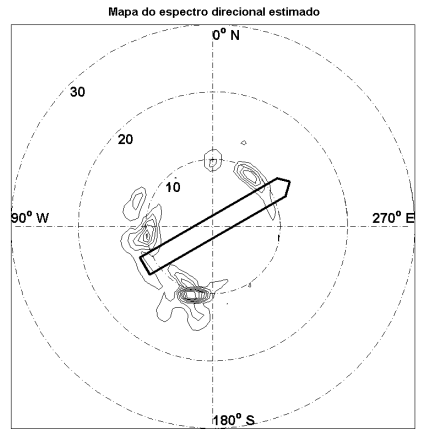

(c) $\operatorname{Mar} 3, \theta_{m}=45^{\circ}$ e calado $21 \mathrm{~m}$

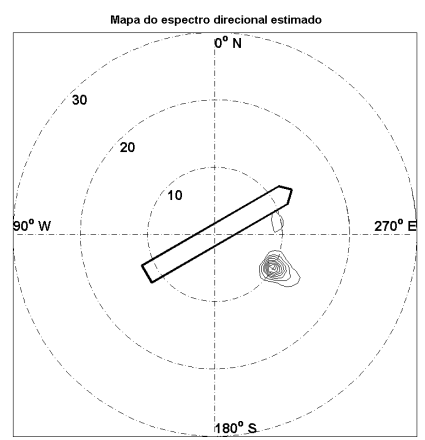

(f) Mar 3, $\theta_{m}=120^{\circ}$ e calado $21 \mathrm{~m}$

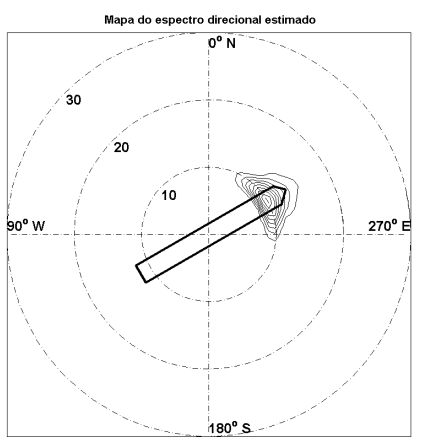

(i) $\operatorname{Mar} 3, \theta_{m}=180^{\circ}$ e calado $21 \mathrm{~m}$

Figura 55: Mapas dos espectros direcionais estimados para o mar 3, com $H_{s}=4 m, T_{p}=10 \mathrm{~s}$ e $s=150$, FPSO P-50 em calado cheio. 


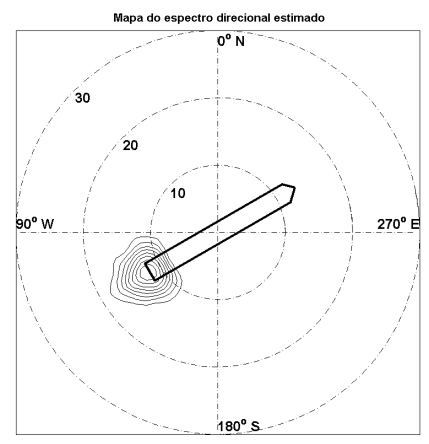

(a) Mar $4, \theta_{m}=0^{\circ}$ e calado $9 \mathrm{~m}$

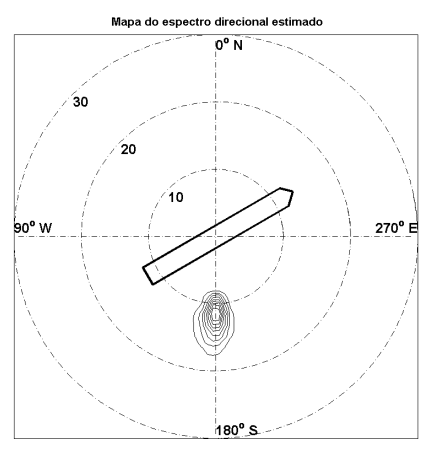

(d) Mar 4, $\theta_{m}=60^{\circ}$ e calado $9 \mathrm{~m}$

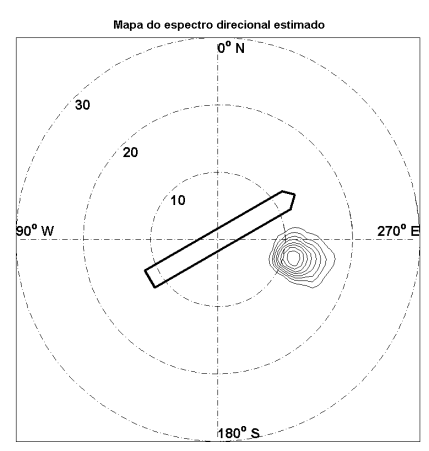

(g) Mar 4, $\theta_{m}=135^{\circ}$ e calado $9 \mathrm{~m}$

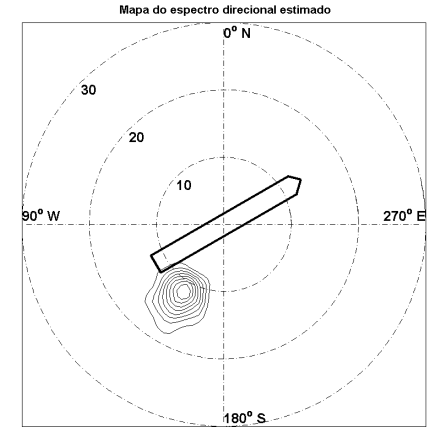

(b) Mar $4, \theta_{m}=30^{\circ}$ e calado $9 \mathrm{~m}$

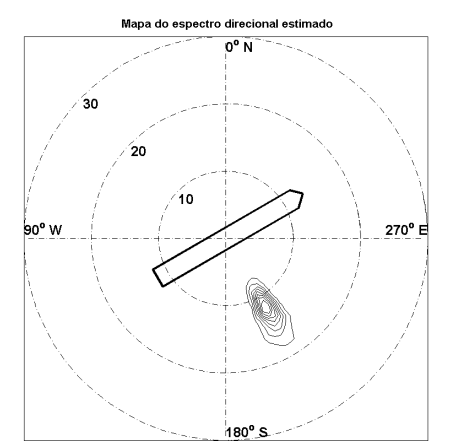

(e) Mar $4, \theta_{m}=90^{\circ}$ e calado $9 \mathrm{~m}$

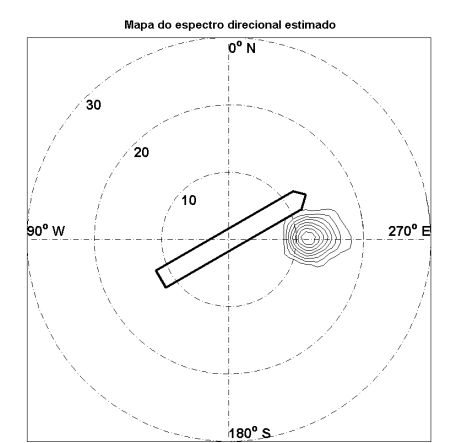

(h) Mar $4, \theta_{m}=150^{\circ}$ e calado $9 \mathrm{~m}$

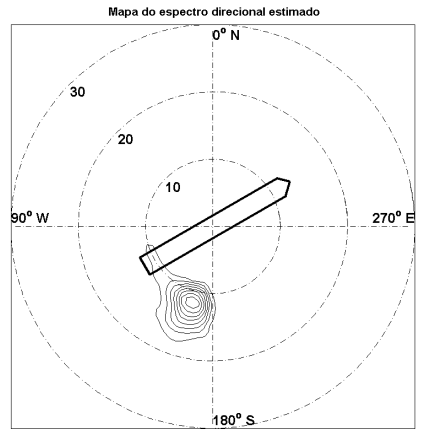

(c) Mar 4, $\theta_{m}=45^{\circ}$ e calado $9 \mathrm{~m}$

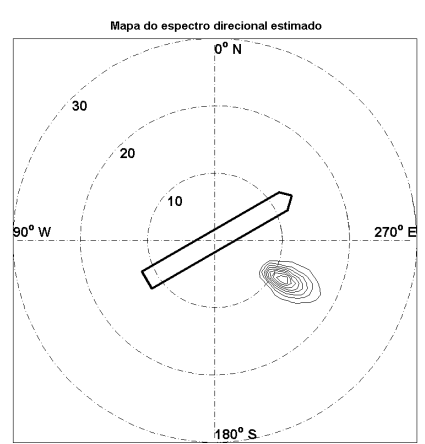

(f) Mar $4, \theta_{m}=120^{\circ}$ e calado $9 \mathrm{~m}$

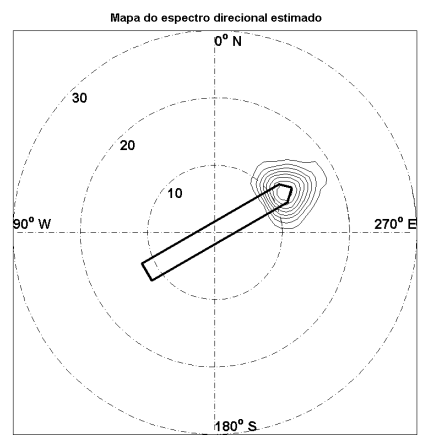

(i) $\operatorname{Mar} 4, \theta_{m}=180^{\circ}$ e calado $9 \mathrm{~m}$

Figura 56: Mapas dos espectros direcionais estimados para o mar 4, com $H_{s}=4 m, T_{p}=12 s$ e $s=150$, FPSO P-50 em calado leve. 


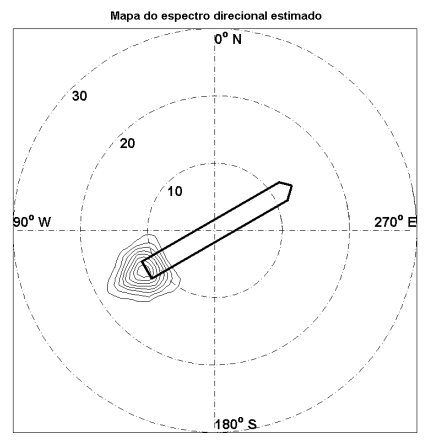

(a) Mar $4, \theta_{m}=0^{\circ}$ e calado $14,5 \mathrm{~m}$

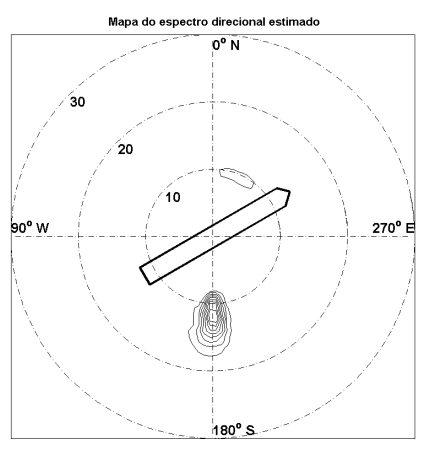

(d) Mar $4, \theta_{m}=60^{\circ}$ e calado $14,5 \mathrm{~m}$

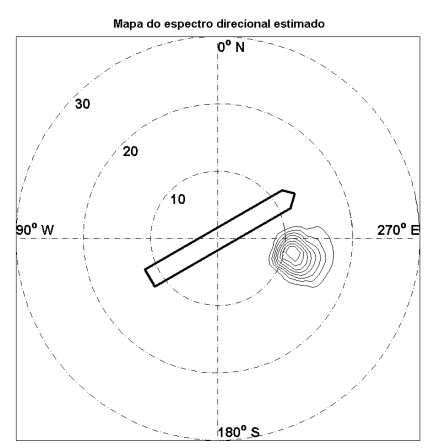

(g) Mar $4, \theta_{m}=135^{\circ}$ e calado $14,5 \mathrm{~m}$

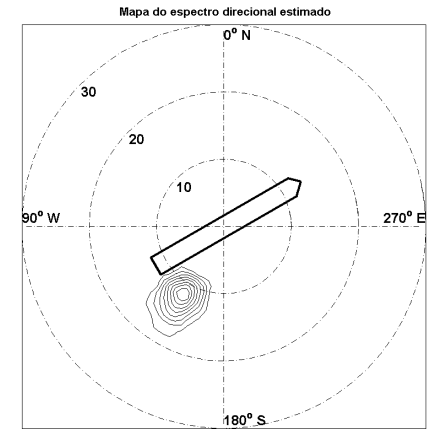

(b) $\operatorname{Mar} 4, \theta_{m}=30^{\circ}$ e calado $14,5 \mathrm{~m}$

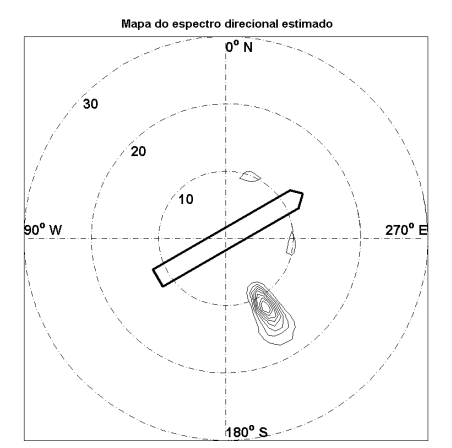

(e) $\operatorname{Mar} 4, \theta_{m}=90^{\circ}$ e calado $14,5 \mathrm{~m}$

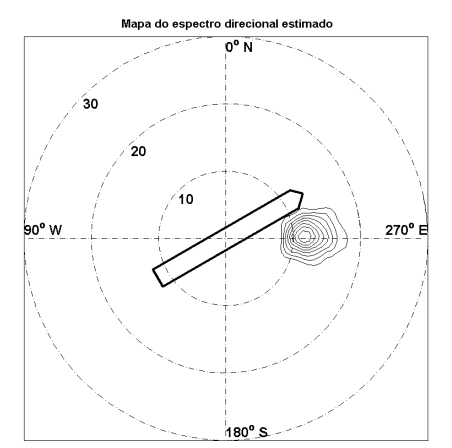

(h) $\operatorname{Mar} 4, \theta_{m}=150^{\circ}$ e calado $14,5 \mathrm{~m}$

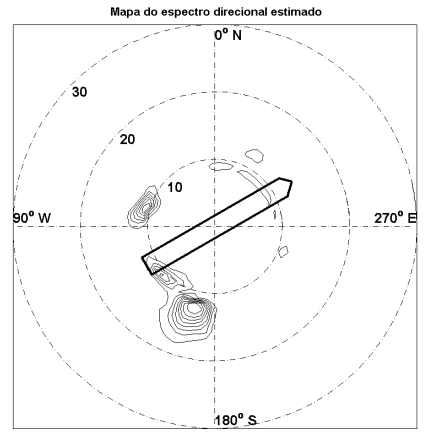

(c) Mar $4, \theta_{m}=45^{\circ}$ e calado $14,5 \mathrm{~m}$

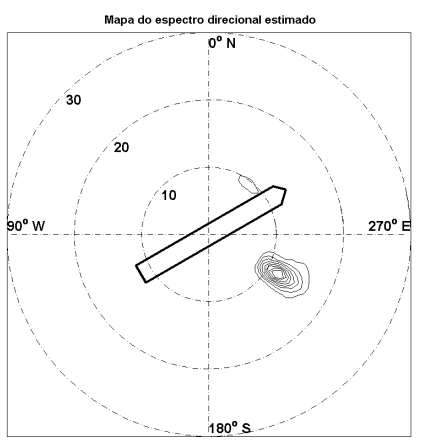

(f) $\operatorname{Mar} 4, \theta_{m}=120^{\circ}$ e calado $14,5 \mathrm{~m}$

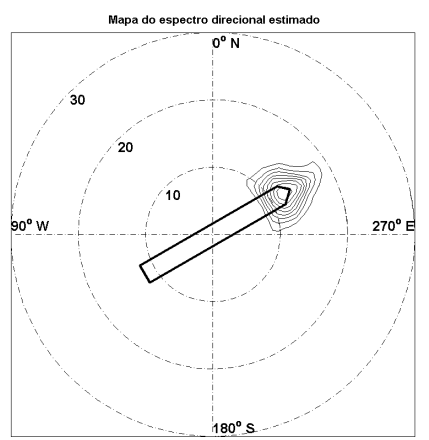

(i) Mar $4, \theta_{m}=180^{\circ}$ e calado $14,5 \mathrm{~m}$

Figura 57: Mapas dos espectros direcionais estimados para o mar 4, com $H_{s}=4 m, T_{p}=12 s$ e $s=150$, FPSO P-50 em calado intermediário. 


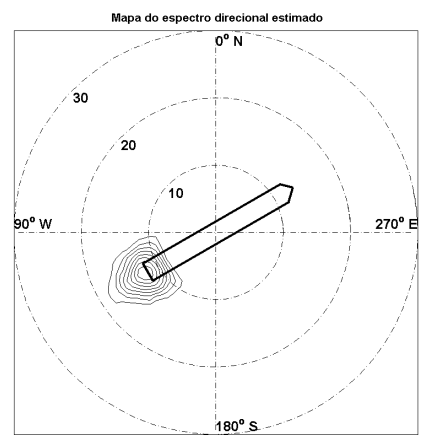

(a) Mar $4, \theta_{m}=0^{\circ}$ e calado $21 \mathrm{~m}$

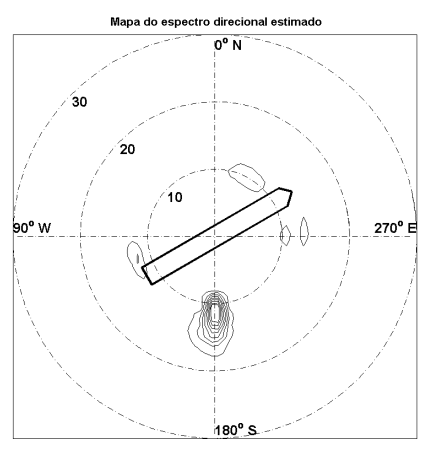

(d) Mar 4, $\theta_{m}=60^{\circ}$ e calado $21 \mathrm{~m}$

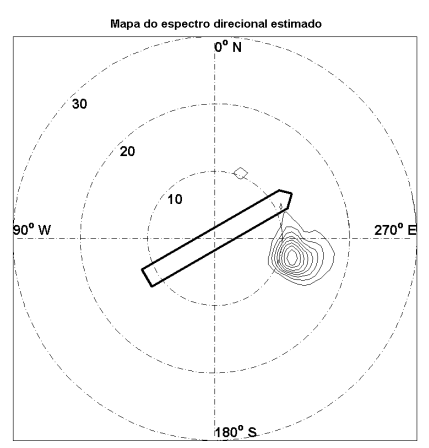

(g) Mar 4, $\theta_{m}=135^{\circ}$ e calado $21 \mathrm{~m}$

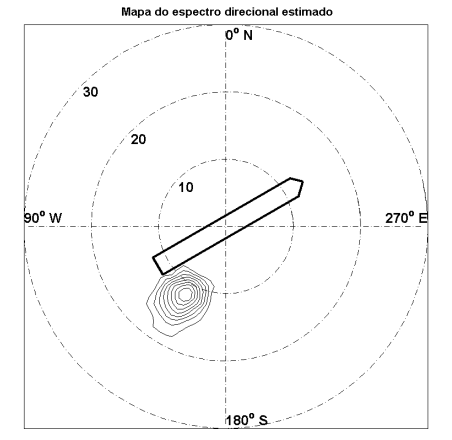

(b) Mar $4, \theta_{m}=30^{\circ}$ e calado $21 \mathrm{~m}$

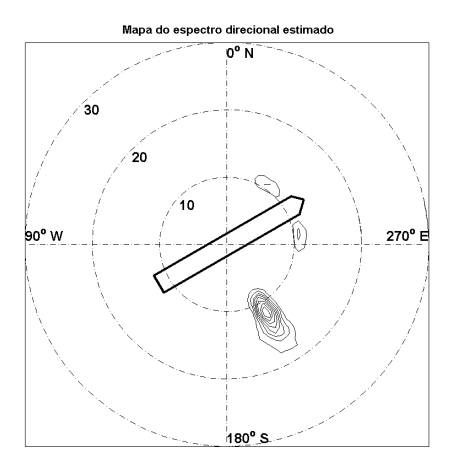

(e) $\operatorname{Mar} 4, \theta_{m}=90^{\circ}$ e calado $21 \mathrm{~m}$

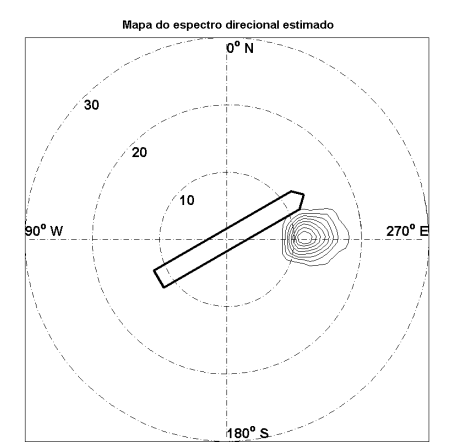

(h) Mar $4, \theta_{m}=150^{\circ}$ e calado $21 \mathrm{~m}$

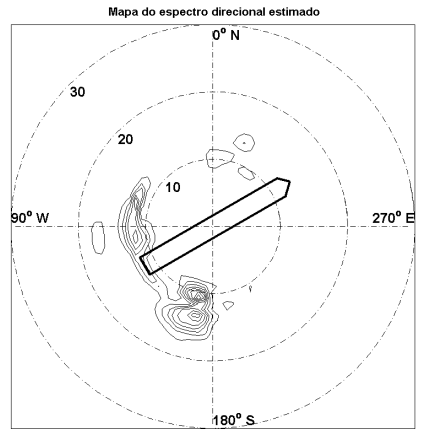

(c) Mar $4, \theta_{m}=45^{\circ}$ e calado $21 \mathrm{~m}$

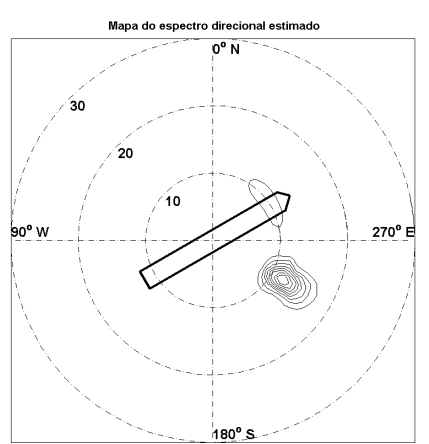

(f) $\operatorname{Mar} 4, \theta_{m}=120^{\circ}$ e calado $21 \mathrm{~m}$

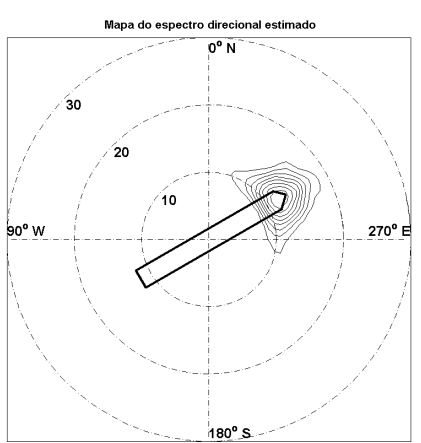

(i) Mar $4, \theta_{m}=180^{\circ}$ e calado $21 \mathrm{~m}$

Figura 58: Mapas dos espectros direcionais estimados para o mar 4, com $H_{s}=4 m, T_{p}=12 s$ e $s=150$, FPSO P-50 em calado cheio. 


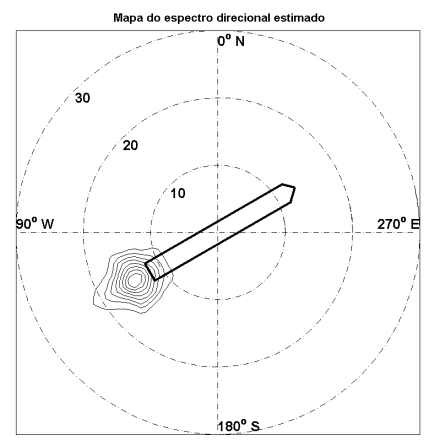

(a) $\operatorname{Mar} 5, \theta_{m}=0^{\circ}$ e calado $9 \mathrm{~m}$

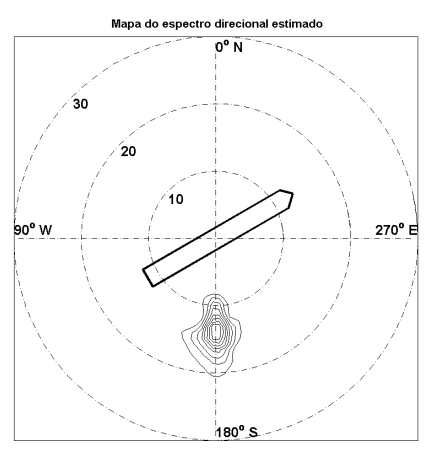

(d) Mar 5, $\theta_{m}=60^{\circ}$ e calado $9 \mathrm{~m}$

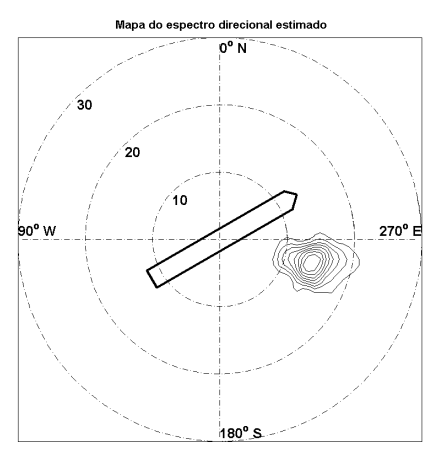

(g) Mar 5, $\theta_{m}=135^{\circ}$ e calado $9 \mathrm{~m}$

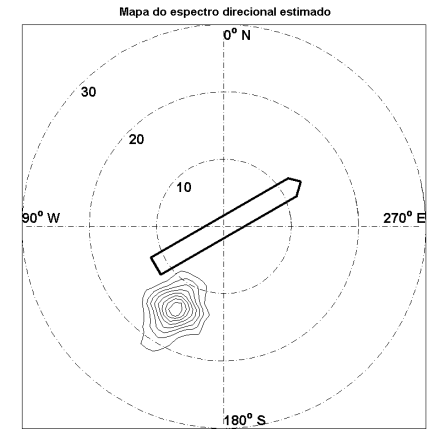

(b) Mar 5, $\theta_{m}=30^{\circ}$ e calado $9 \mathrm{~m}$

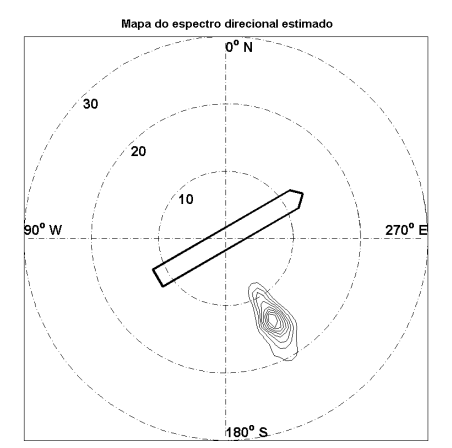

(e) Mar $5, \theta_{m}=90^{\circ}$ e calado $9 \mathrm{~m}$

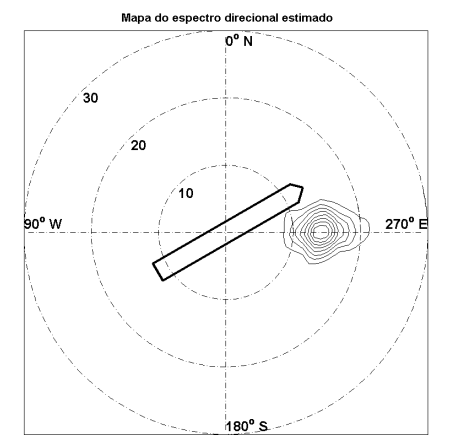

(h) Mar $5, \theta_{m}=150^{\circ}$ e calado $9 \mathrm{~m}$

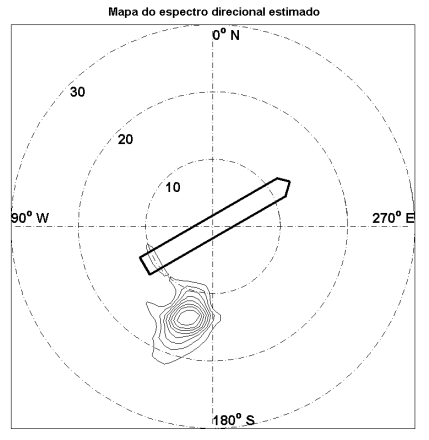

(c) Mar $5, \theta_{m}=45^{\circ}$ e calado $9 \mathrm{~m}$

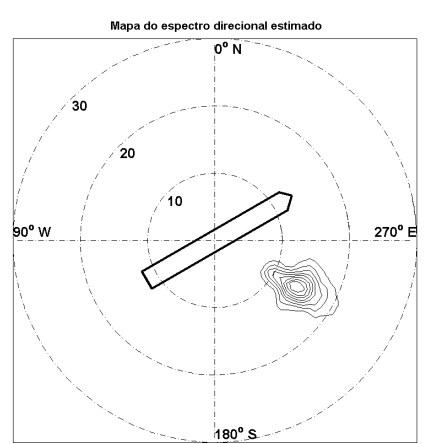

(f) $\operatorname{Mar} 5, \theta_{m}=120^{\circ}$ e calado $9 \mathrm{~m}$

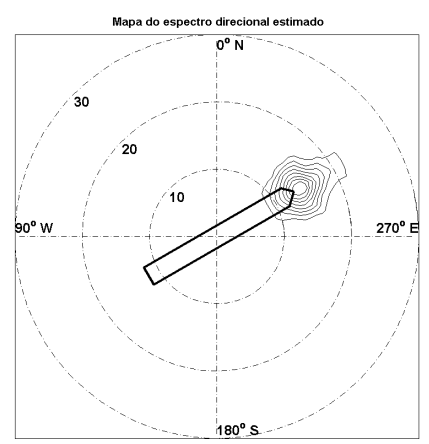

(i) Mar 5, $\theta_{m}=180^{\circ}$ e calado $9 \mathrm{~m}$

Figura 59: Mapas dos espectros direcionais estimados para o mar 5, com $H_{s}=4 m, T_{p}=14 s$ e $s=150$, FPSO P-50 em calado leve. 


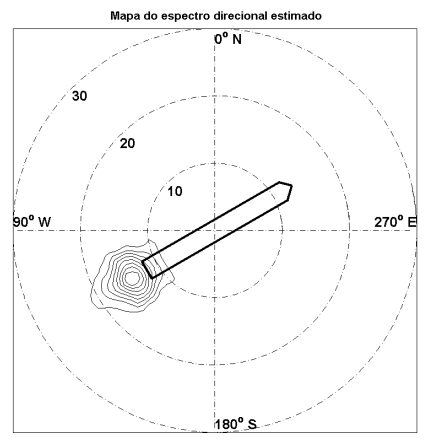

(a) $\operatorname{Mar} 5, \theta_{m}=0^{\circ}$ e calado $14,5 \mathrm{~m}$

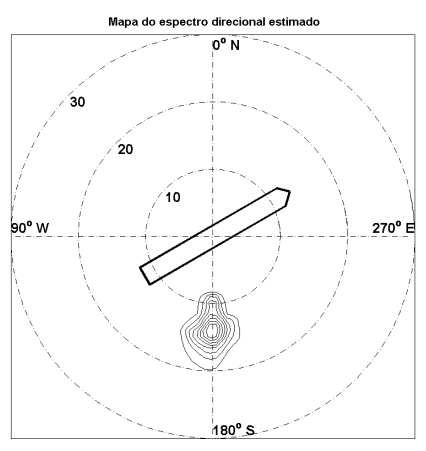

(d) $\operatorname{Mar} 5, \theta_{m}=60^{\circ}$ e calado $14,5 \mathrm{~m}$

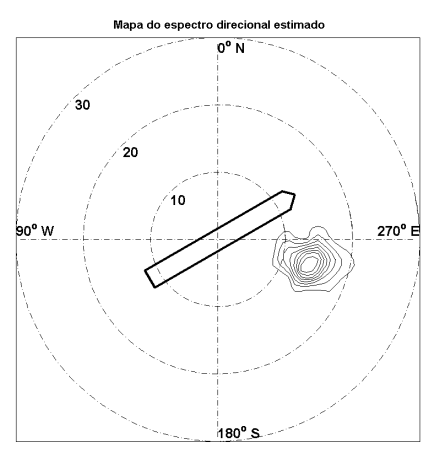

(g) Mar 5, $\theta_{m}=135^{\circ}$ e calado $14,5 \mathrm{~m}$

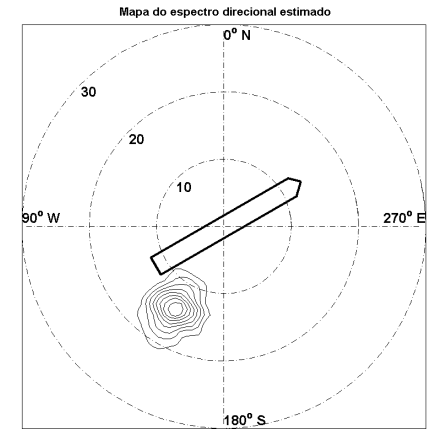

(b) $\operatorname{Mar} 5, \theta_{m}=30^{\circ}$ e calado $14,5 \mathrm{~m}$

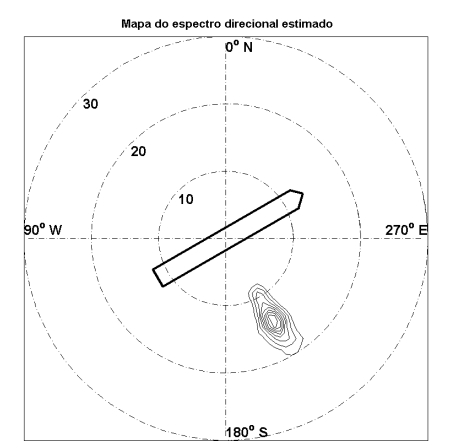

(e) $\operatorname{Mar} 5, \theta_{m}=90^{\circ}$ e calado $14,5 \mathrm{~m}$

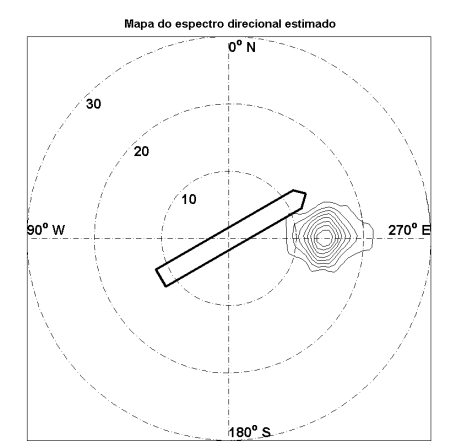

(h) $\operatorname{Mar} 5, \theta_{m}=150^{\circ}$ e calado $14,5 \mathrm{~m}$

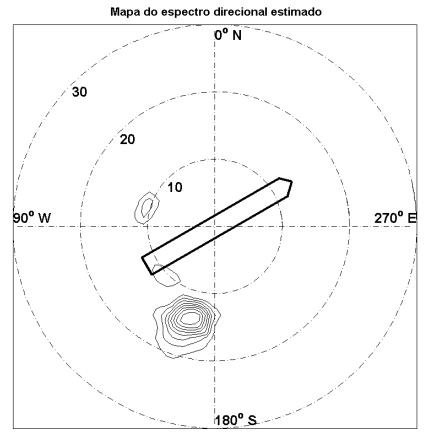

(c) $\operatorname{Mar} 5, \theta_{m}=45^{\circ}$ e calado $14,5 \mathrm{~m}$

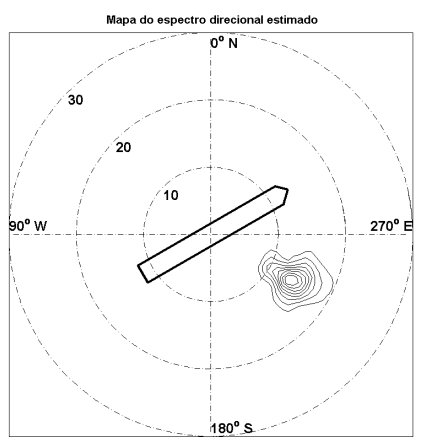

(f) $\operatorname{Mar} 5, \theta_{m}=120^{\circ}$ e calado $14,5 \mathrm{~m}$

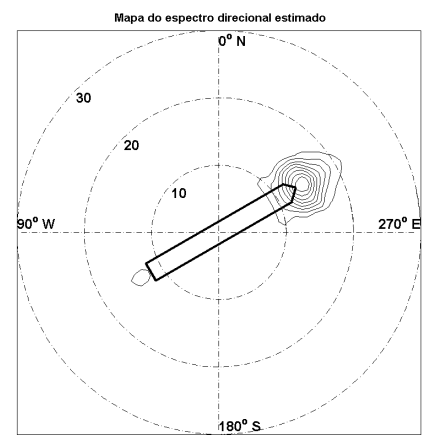

(i) $\operatorname{Mar} 5, \theta_{m}=180^{\circ}$ e calado $14,5 \mathrm{~m}$

Figura 60: Mapas dos espectros direcionais estimados para o mar 5, com $H_{s}=4 m, T_{p}=14 s$ e $s=150$, FPSO P-50 em calado intermediário. 


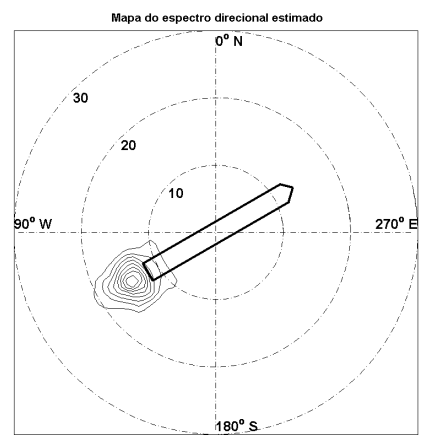

(a) Mar $5, \theta_{m}=0^{\circ}$ e calado $21 \mathrm{~m}$

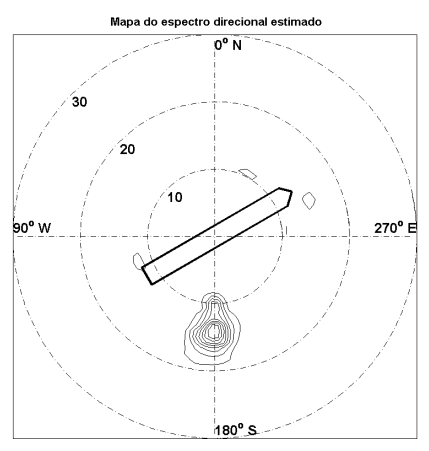

(d) Mar 5, $\theta_{m}=60^{\circ}$ e calado $21 \mathrm{~m}$

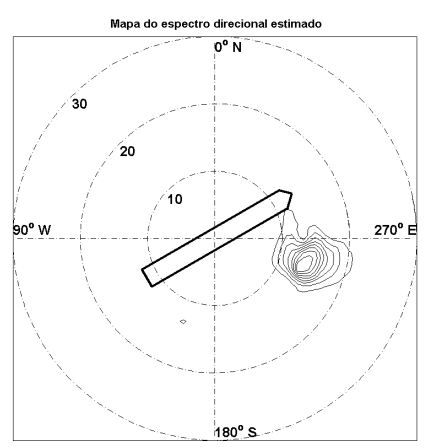

(g) Mar 5, $\theta_{m}=135^{\circ}$ e calado $21 \mathrm{~m}$

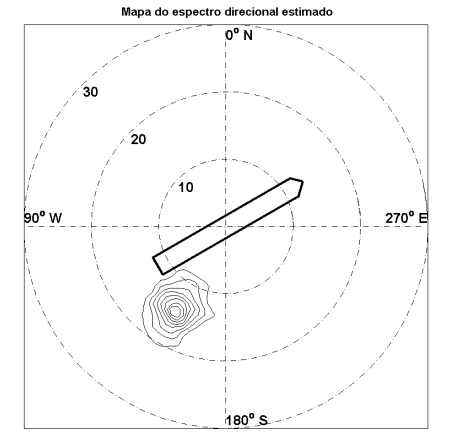

(b) Mar 5, $\theta_{m}=30^{\circ}$ e calado $21 \mathrm{~m}$

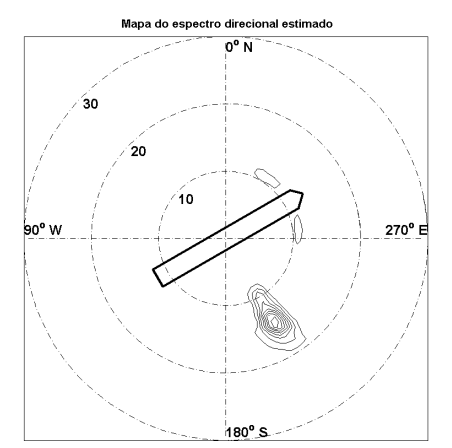

(e) $\operatorname{Mar} 5, \theta_{m}=90^{\circ}$ e calado $21 \mathrm{~m}$

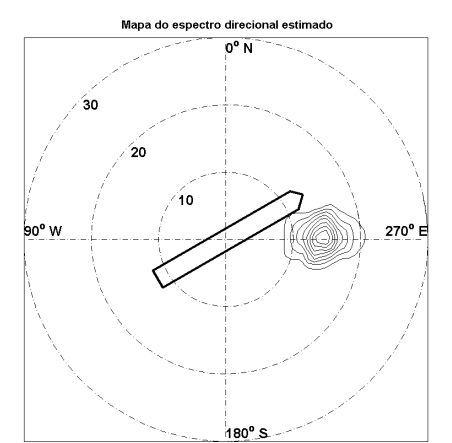

(h) $\operatorname{Mar} 5, \theta_{m}=150^{\circ}$ e calado $21 \mathrm{~m}$

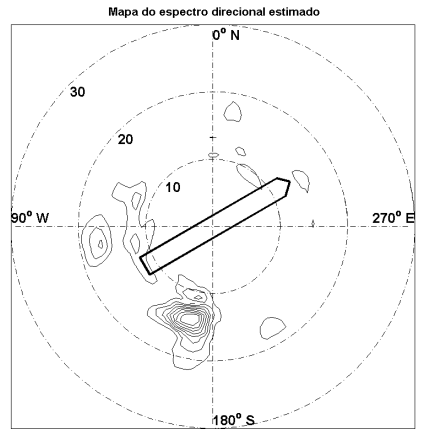

(c) Mar $5, \theta_{m}=45^{\circ}$ e calado $21 \mathrm{~m}$

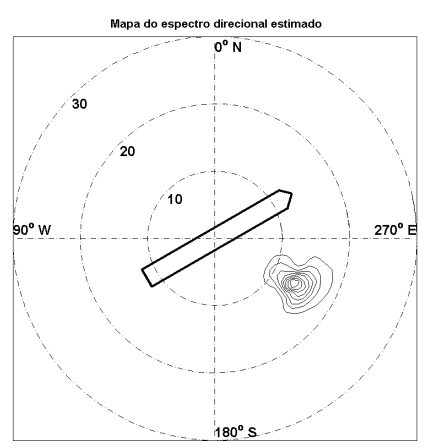

(f) Mar $5, \theta_{m}=120^{\circ}$ e calado $21 \mathrm{~m}$

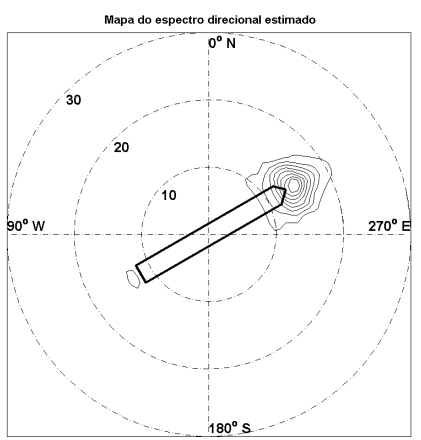

(i) $\operatorname{Mar} 5, \theta_{m}=180^{\circ}$ e calado $21 \mathrm{~m}$

Figura 61: Mapas dos espectros direcionais estimados para o mar 5, com $H_{s}=4 m, T_{p}=14 s$ e $s=150$, FPSO P-50 em calado cheio. 


\section{APÊNDICE G - Resultados da estimação paramétrica}




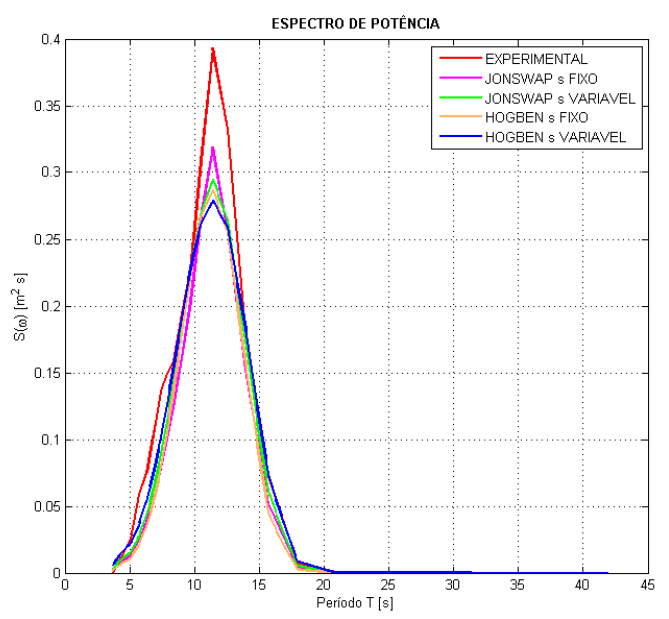

(a) Espectros de Potência - Medido e Estimados.

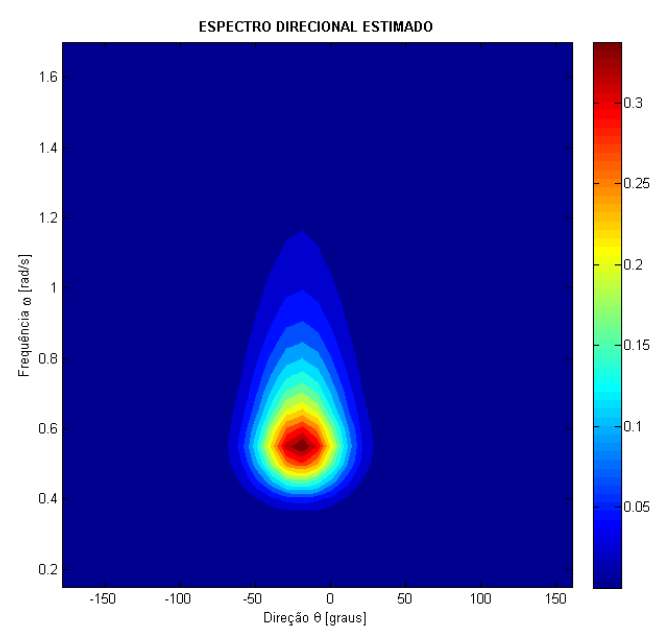

(c) JONSWAP com $s$ fixo.

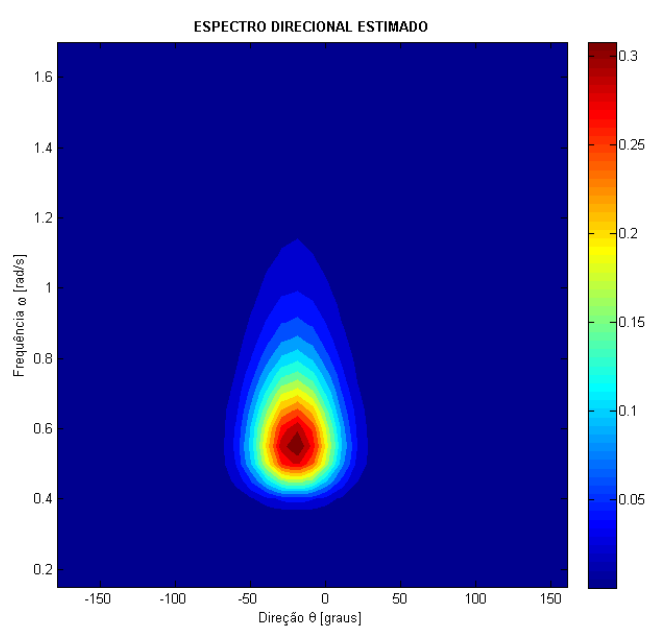

(e) Hogben \& Cobb com $s$ fixo.

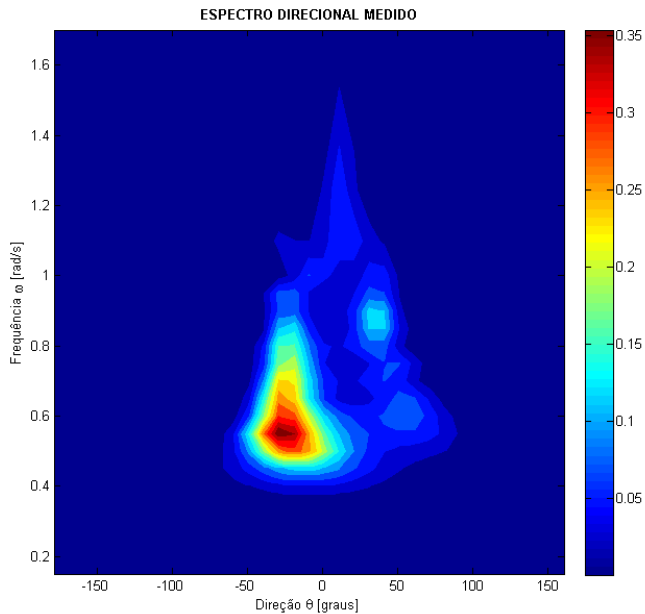

(b) Espectro direcional do ensaio.

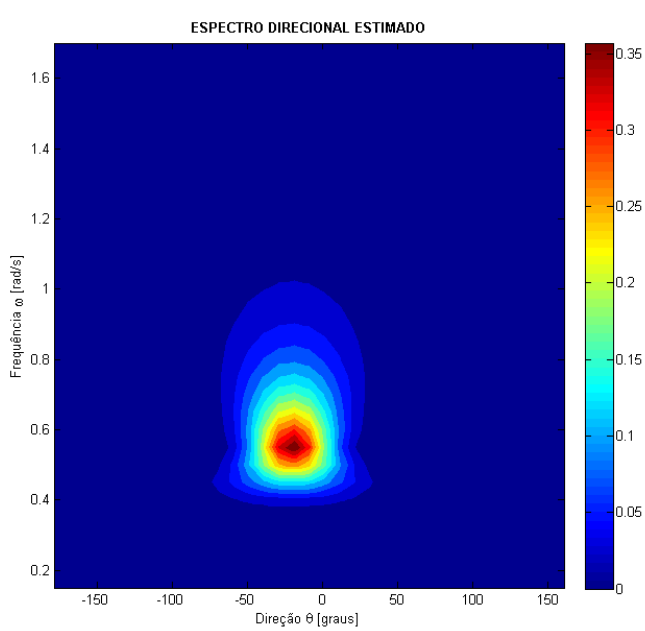

(d) JONSWAP com $s$ variável.

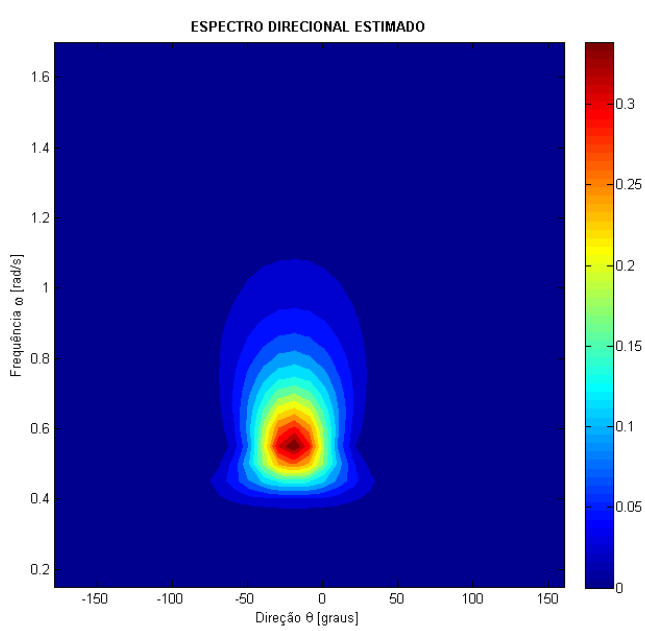

(f) Hogben \& Cobb com s variável.

Figura 62: Espectros resultantes das estimações para o ensaio W06-10109. 


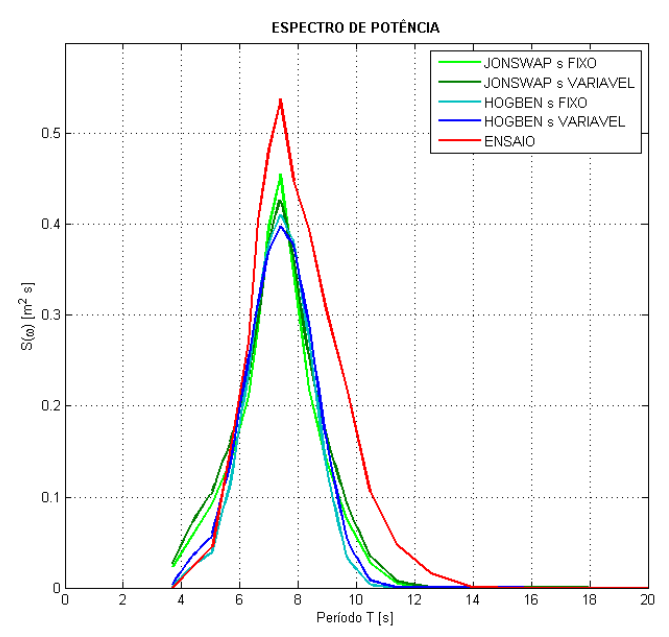

(a) Espectros de Potência - Medido e Estimados.

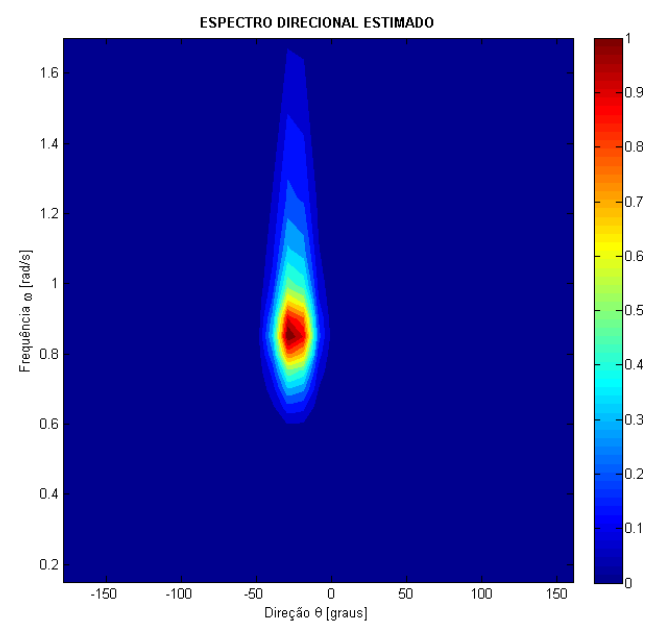

(c) JONSWAP com $s$ fixo.

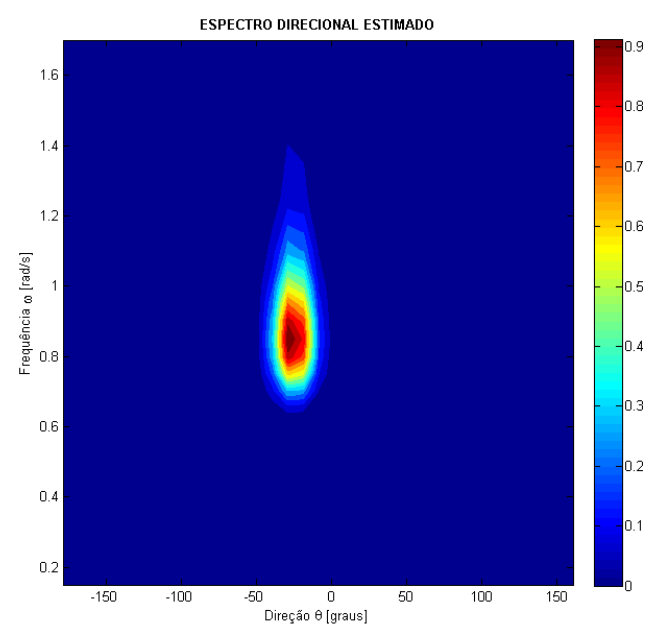

(e) Hogben \& Cobb com s fixo.

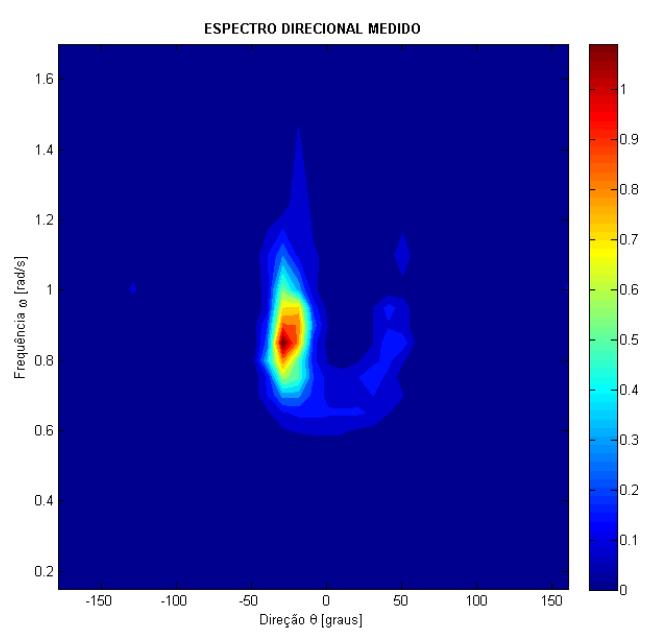

(b) Espectro direcional do ensaio.

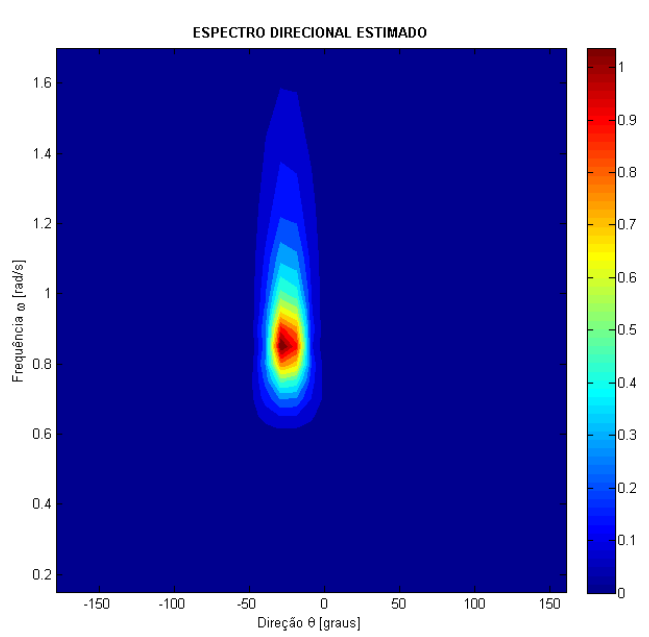

(d) JONSWAP com s variável.

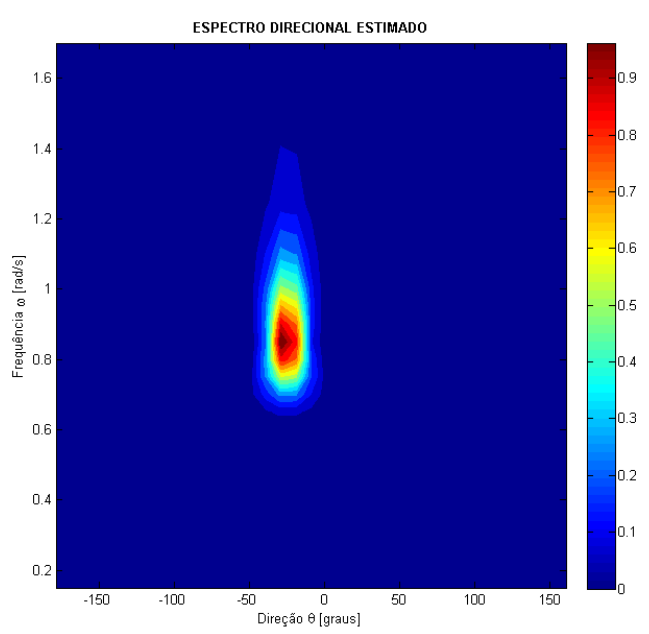

(f) Hogben \& Cobb com s variável.

Figura 63: Espectros resultantes das estimações para o ensaio W06-10200. 


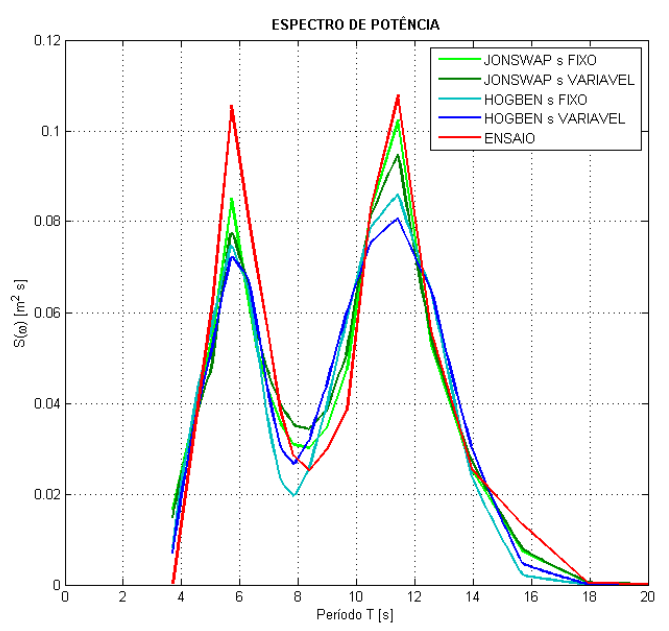

(a) Espectros de Potência - Medido e Estimados.

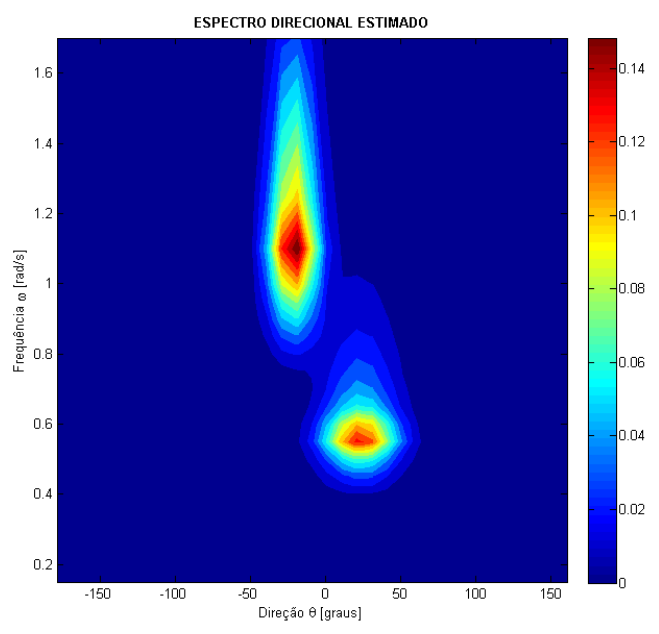

(c) JONSWAP com $s$ fixo.

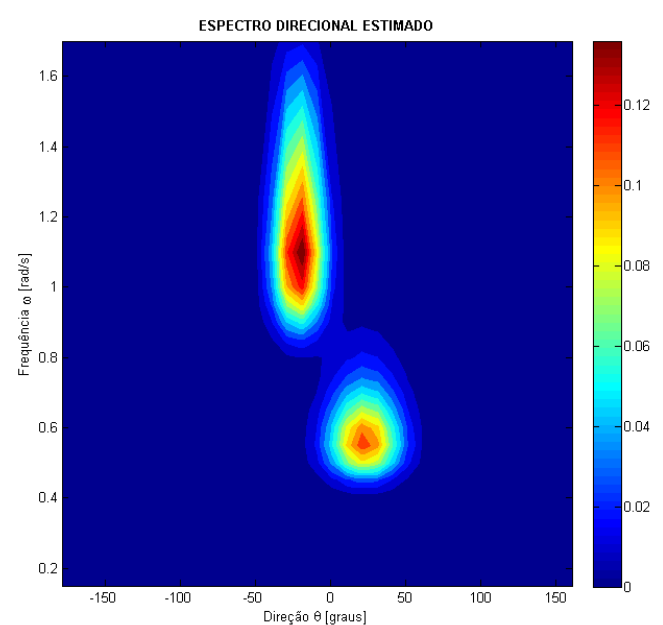

(e) Hogben \& Cobb com $s$ fixo.

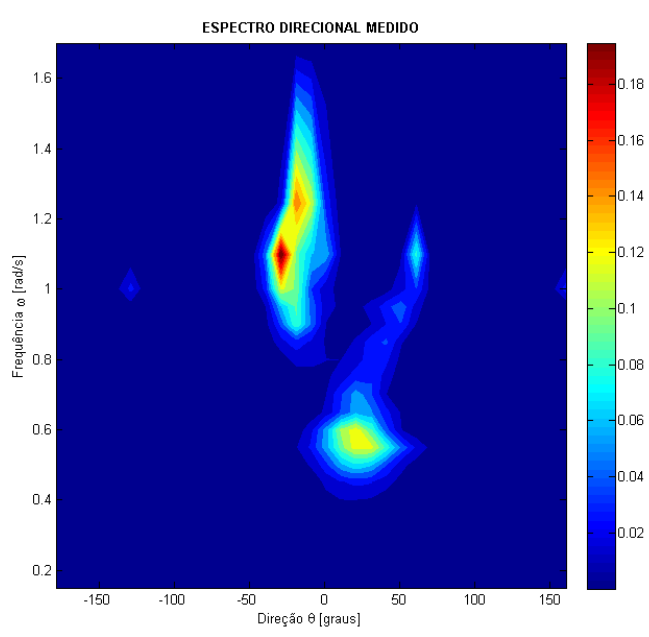

(b) Espectro direcional do ensaio.

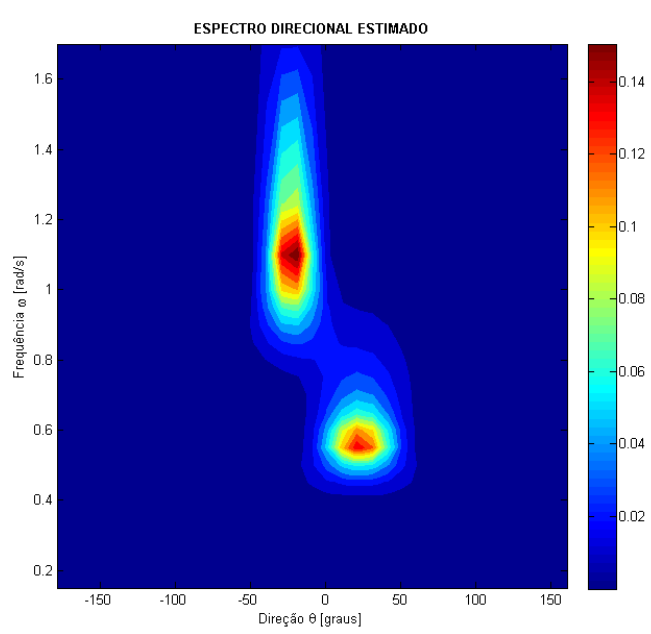

(d) JONSWAP com s variável.

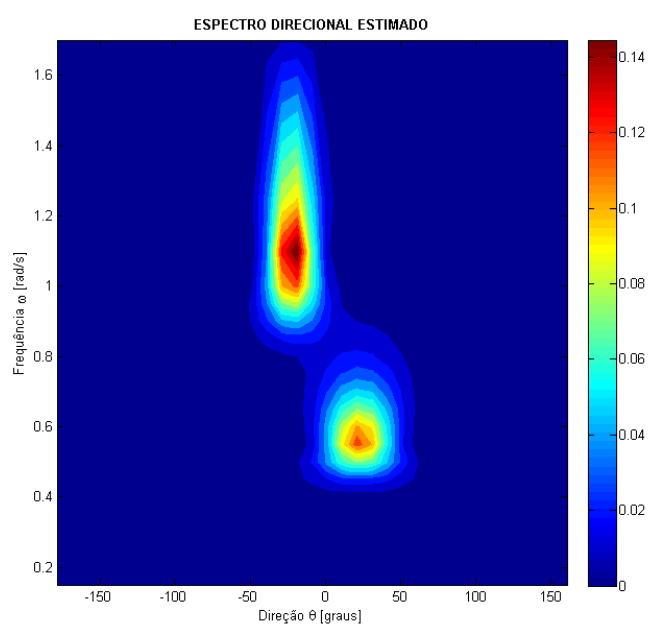

(f) Hogben \& Cobb com s variável.

Figura 64: Espectros resultantes das estimações para o ensaio W06-10300. 


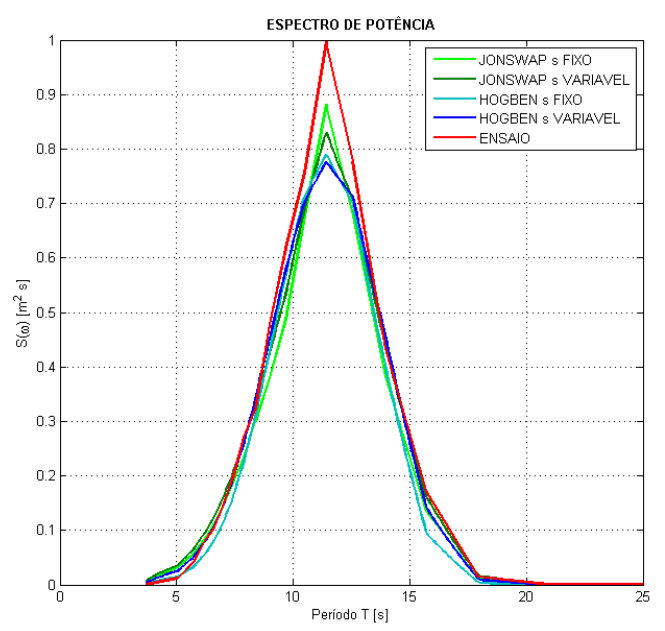

(a) Espectros de Potência - Medido e Estimados.

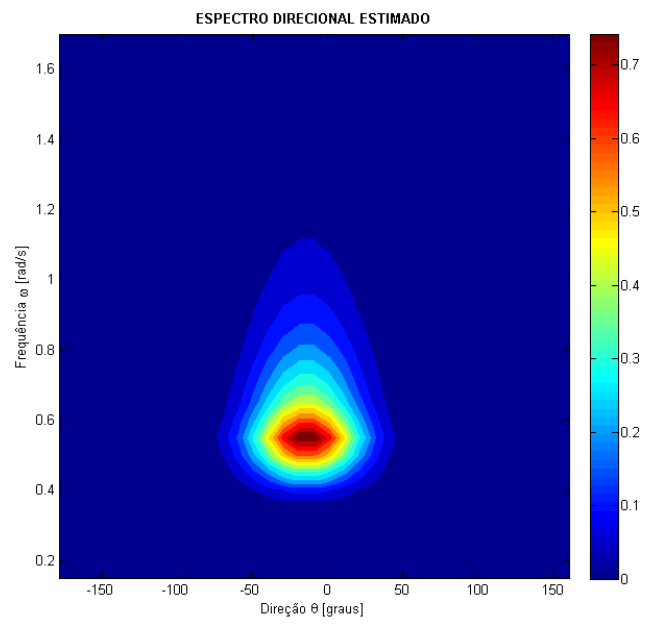

(c) JONSWAP com $s$ fixo.

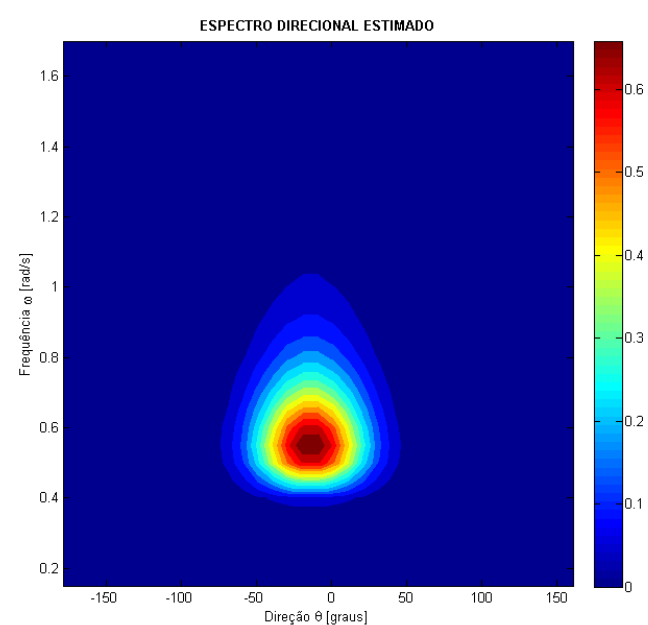

(e) Hogben \& Cobb com $s$ fixo.

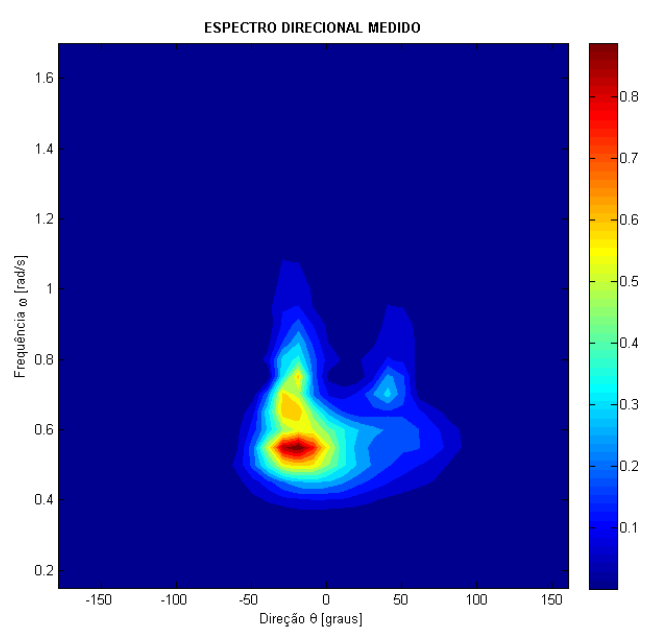

(b) Espectro direcional do ensaio.

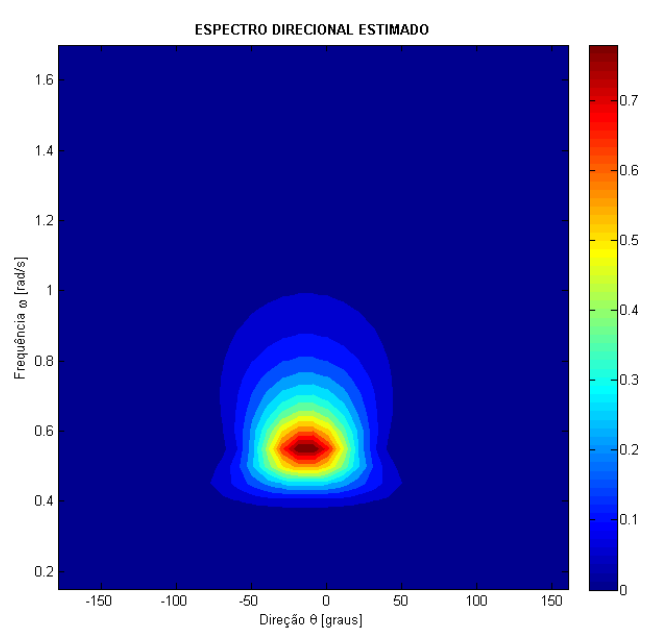

(d) JONSWAP com s variável.

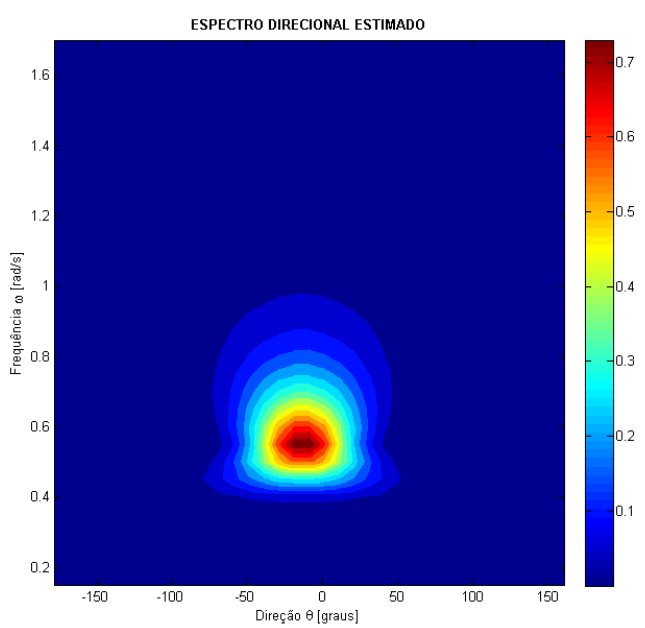

(f) Hogben \& Cobb com s variável.

Figura 65: Espectros resultantes das estimações para o ensaio W06-10400. 


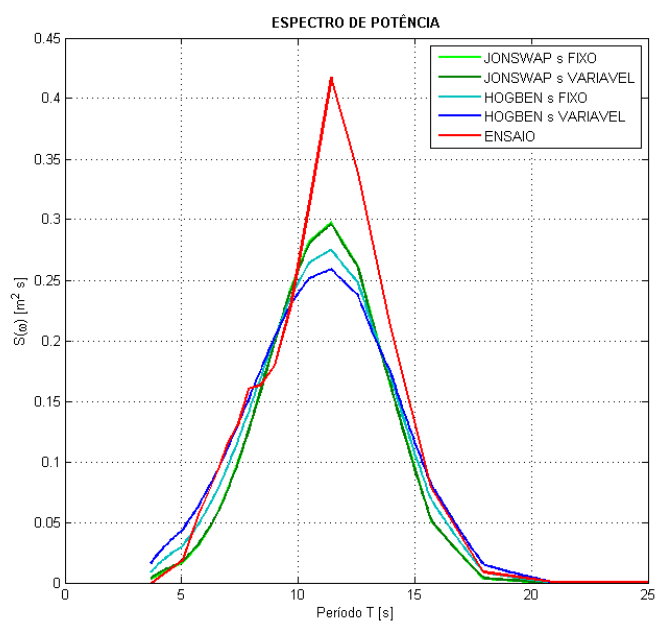

(a) Espectros de Potência - Medido e Estimados.

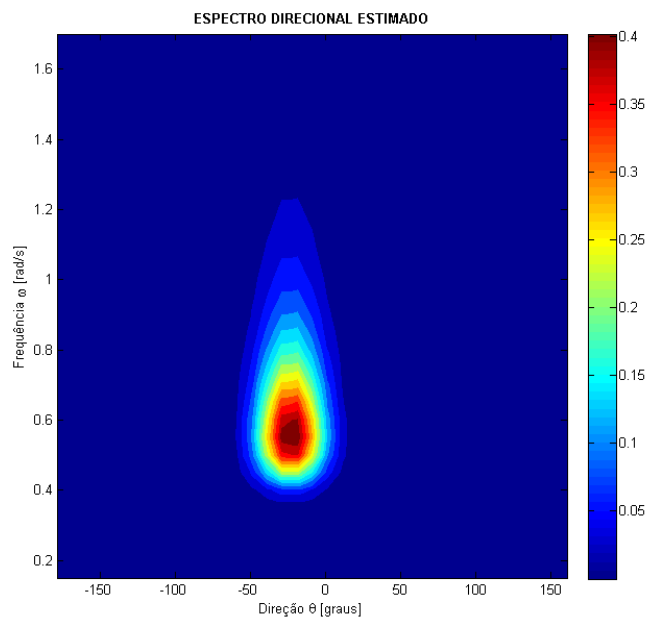

(c) JONSWAP com $s$ fixo.

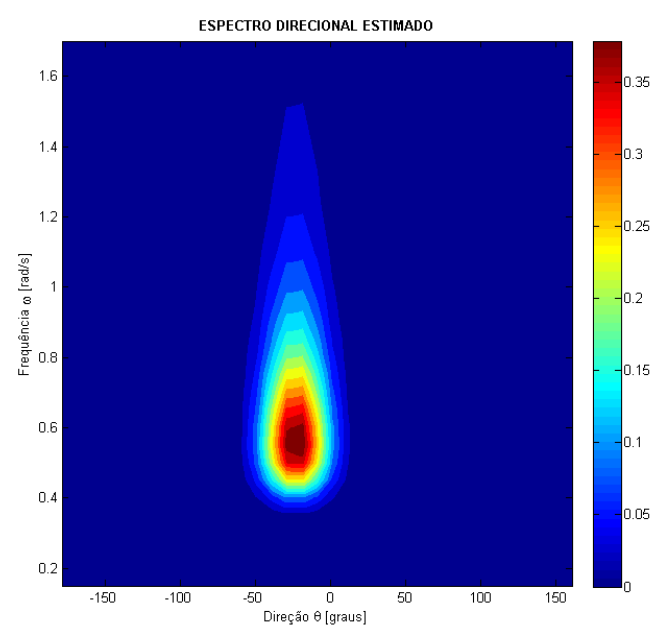

(e) Hogben \& Cobb com $s$ fixo.

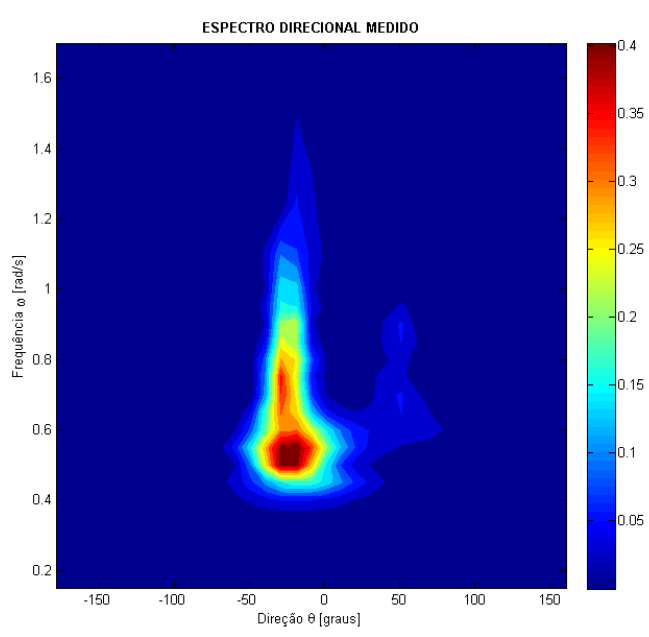

(b) Espectro direcional do ensaio.

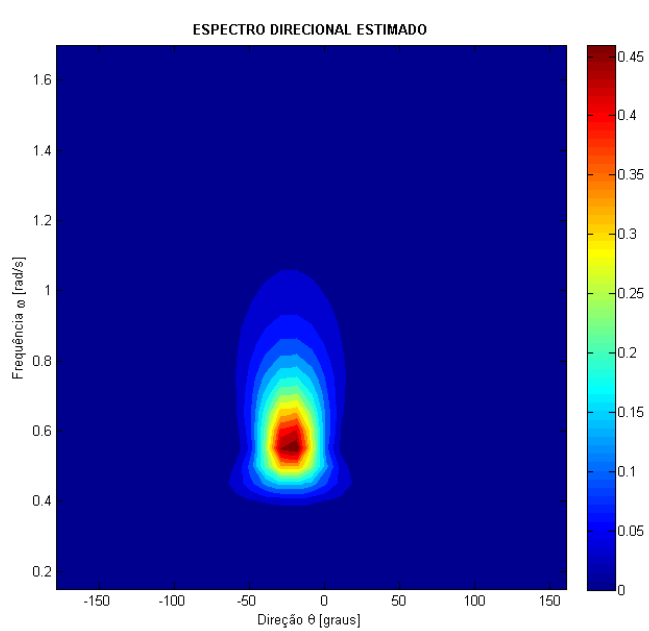

(d) JONSWAP com s variável.

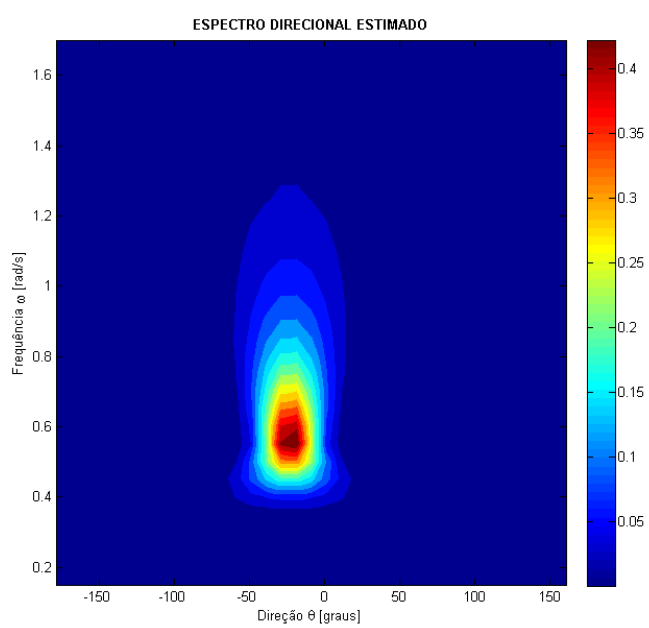

(f) Hogben \& Cobb com s variável.

Figura 66: Espectros resultantes das estimações para o ensaio W06-10500. 


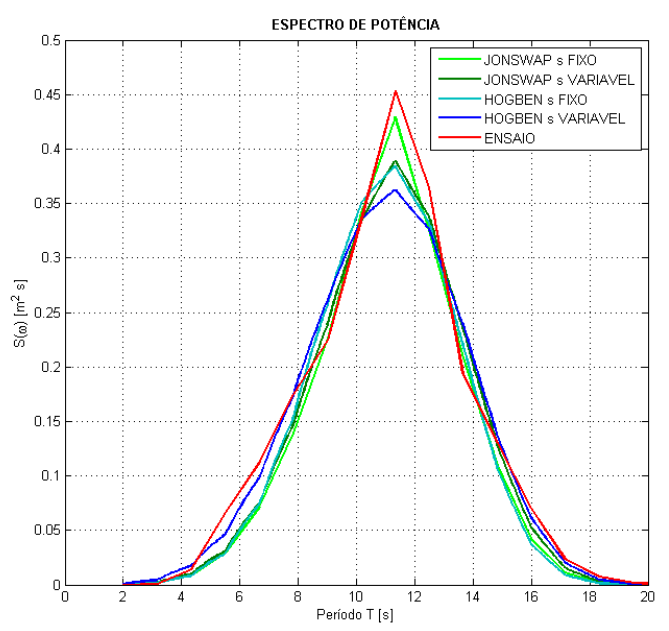

(a) Espectros de Potência - Medido e Estimados.

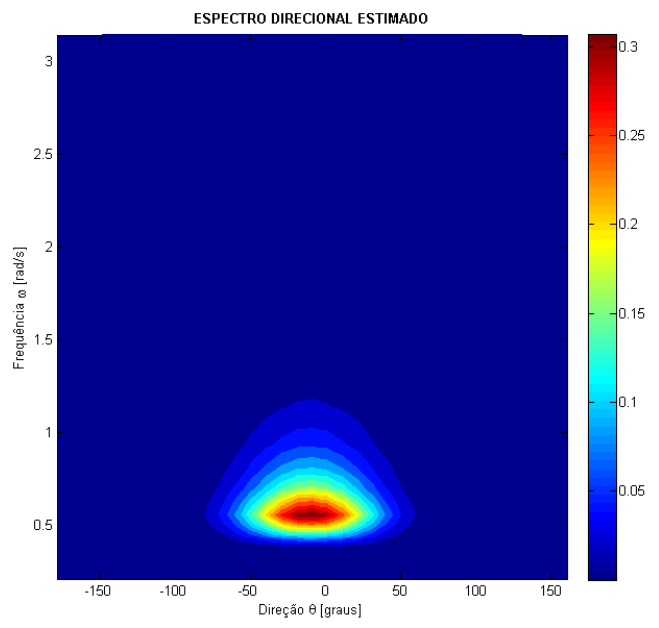

(c) JONSWAP com $s$ fixo.

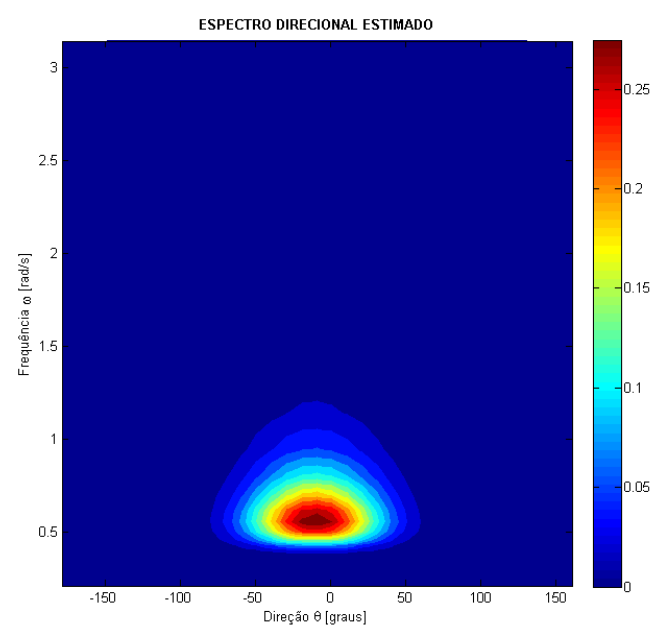

(e) Hogben \& Cobb com $s$ fixo.

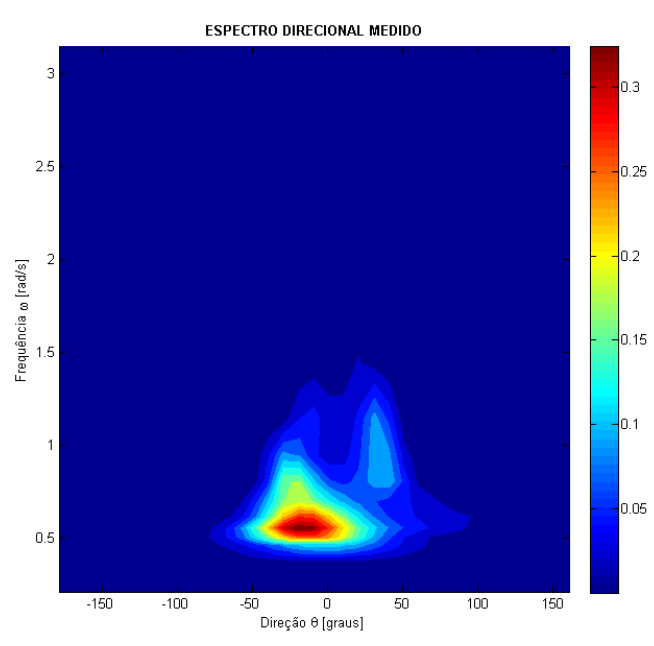

(b) Espectro direcional do ensaio.

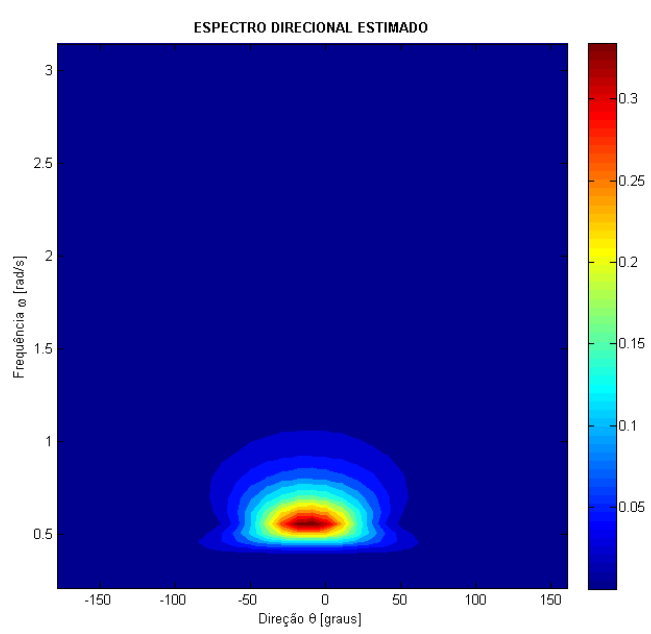

(d) JONSWAP com $s$ variável.

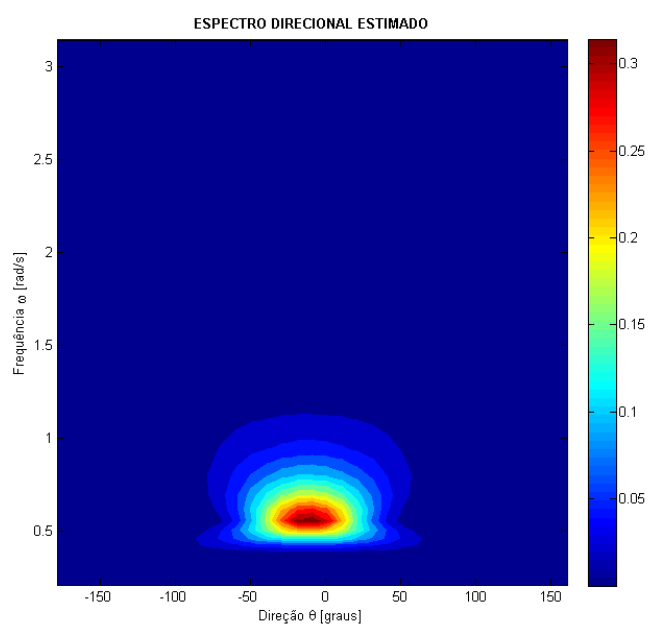

(f) Hogben \& Cobb com s variável.

Figura 67: Espectros resultantes das estimações para o ensaio W06-20100. 


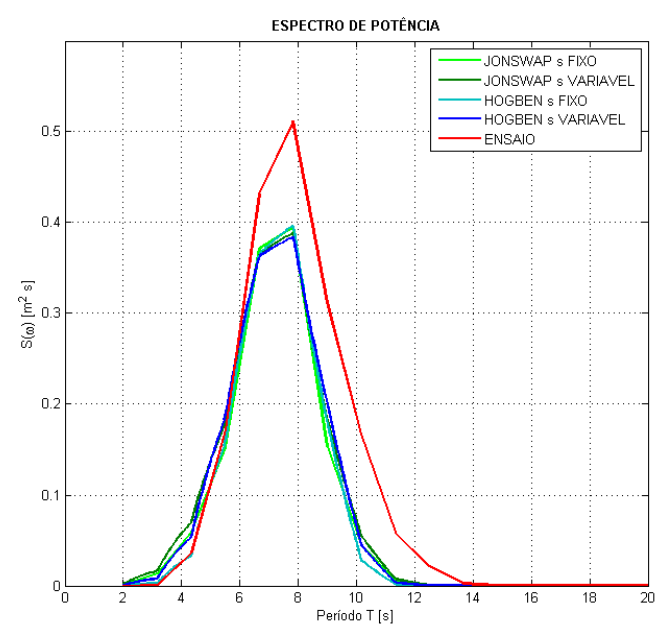

(a) Espectros de Potência - Medido e Estimados.

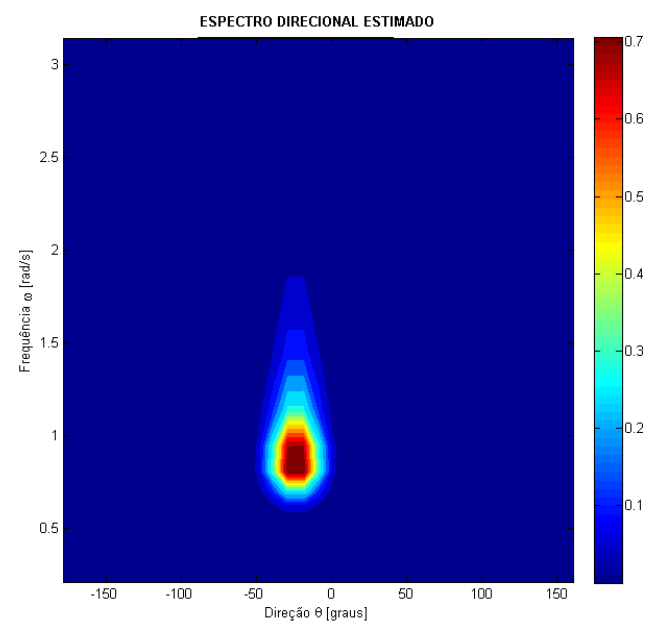

(c) JONSWAP com $s$ fixo.

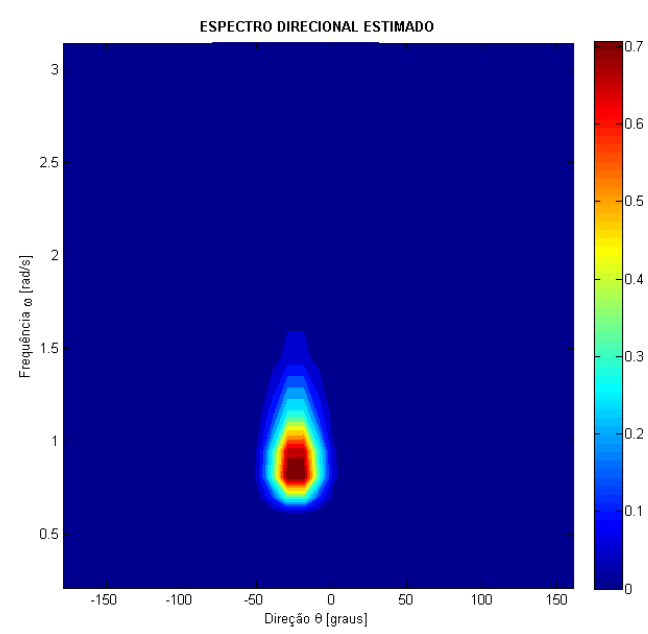

(e) Hogben \& Cobb com $s$ fixo.

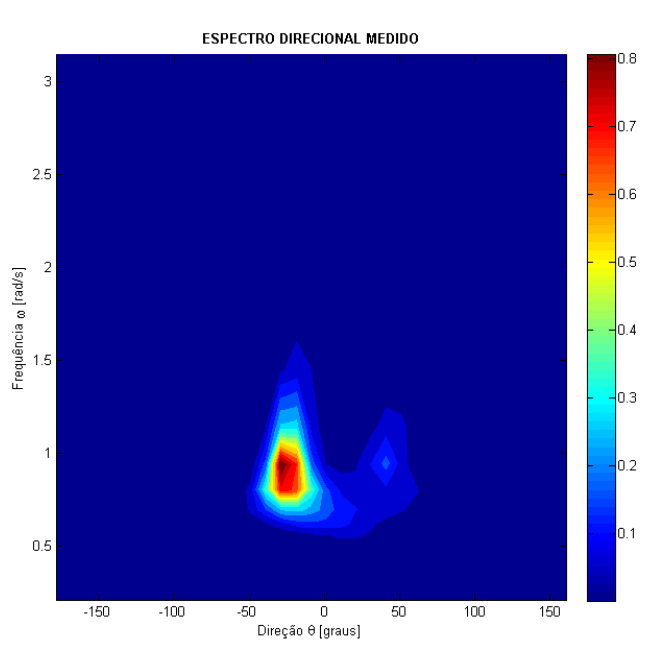

(b) Espectro direcional do ensaio.

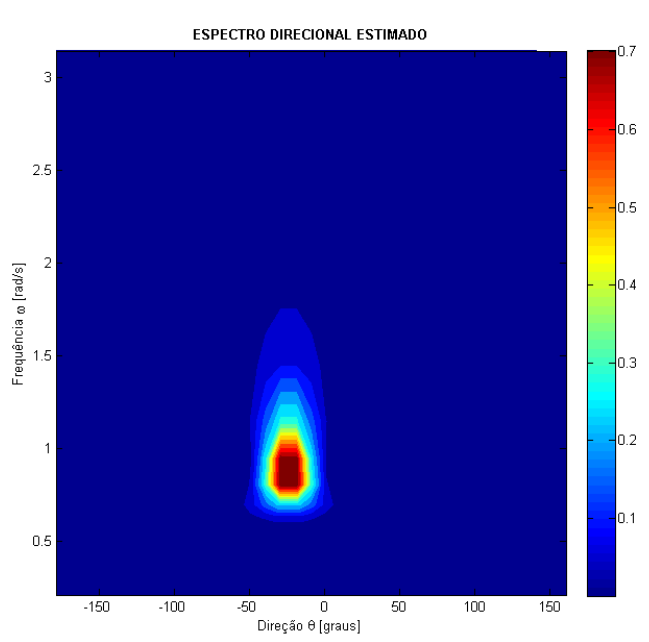

(d) JONSWAP com s variável.

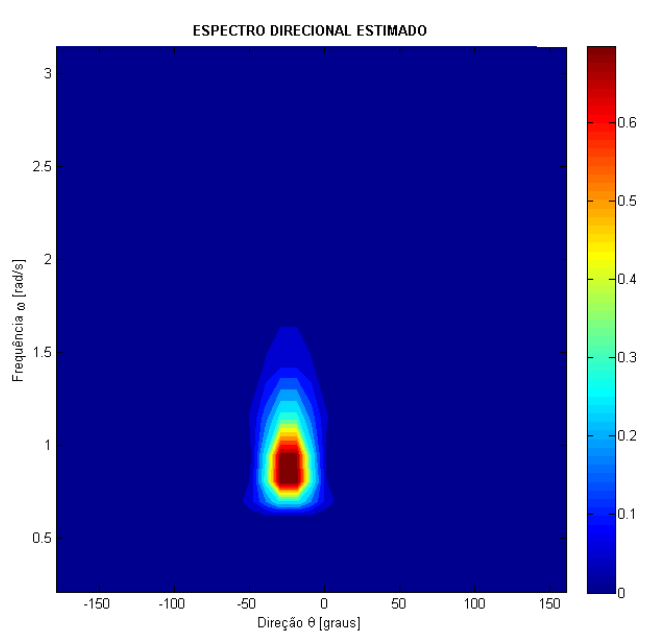

(f) Hogben \& Cobb com s variável.

Figura 68: Espectros resultantes das estimações para o ensaio W06-20200. 


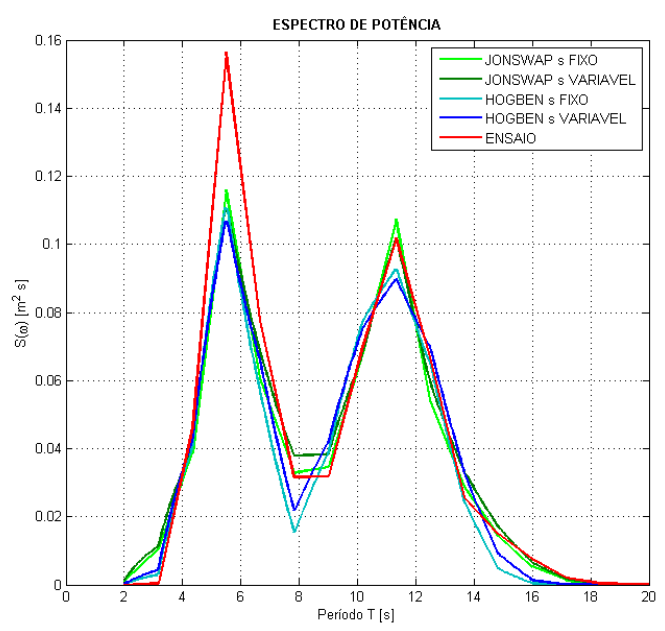

(a) Espectros de Potência - Medido e Estimados.

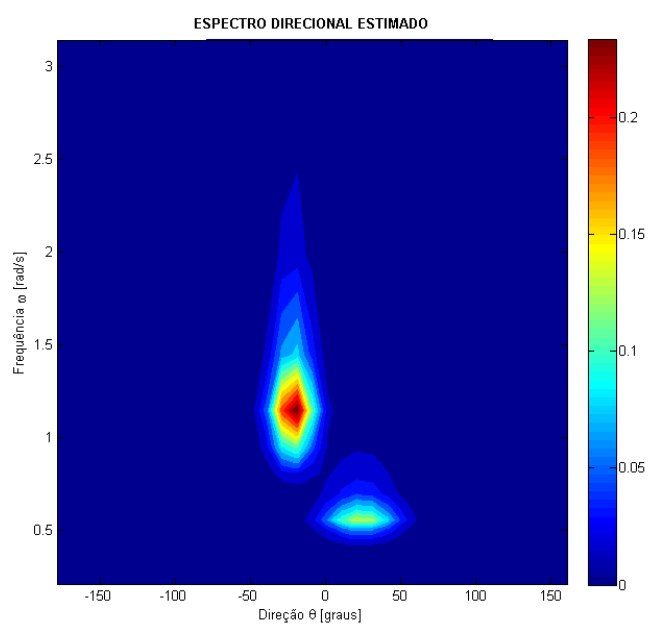

(c) JONSWAP com $s$ fixo.

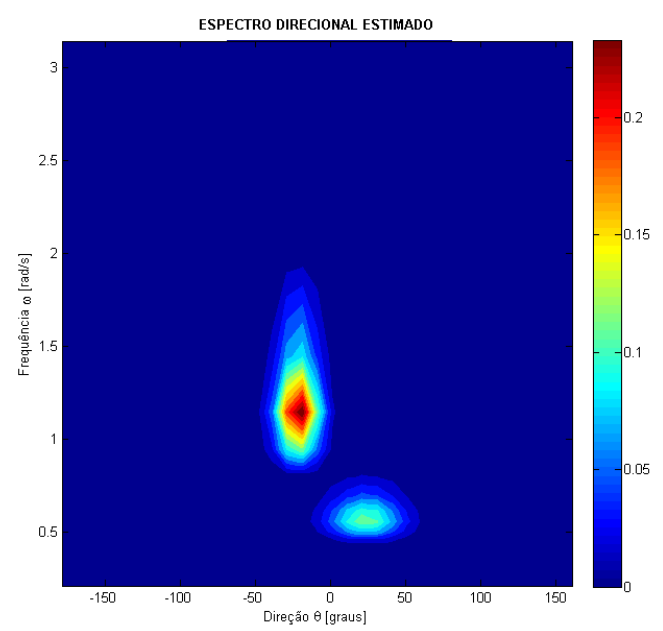

(e) Hogben \& Cobb com $s$ fixo.

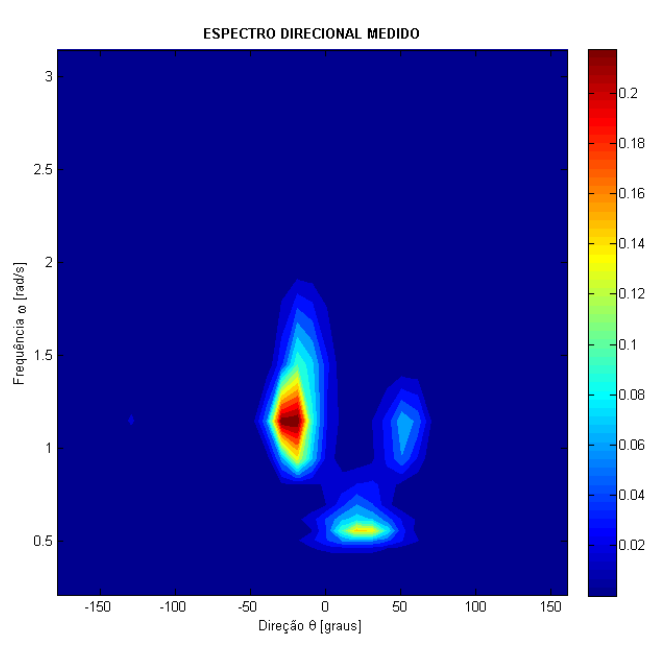

(b) Espectro direcional do ensaio.

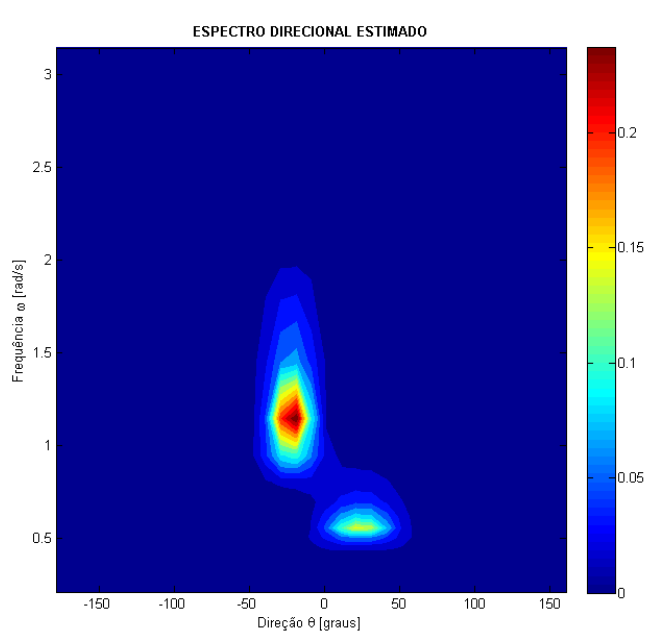

(d) JONSWAP com s variável.

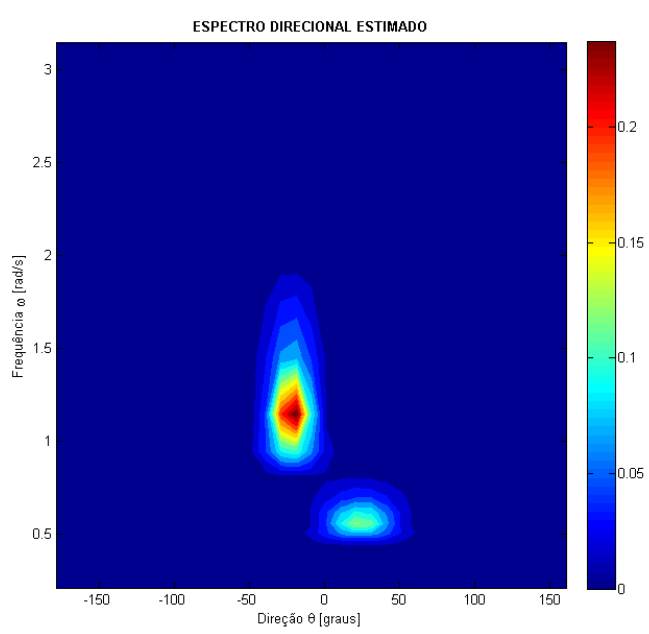

(f) Hogben \& Cobb com s variável.

Figura 69: Espectros resultantes das estimações para o ensaio W06-20300. 


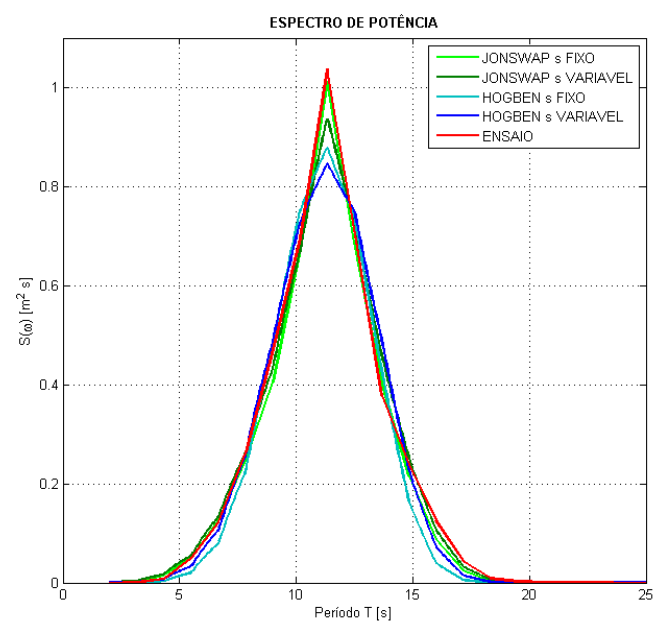

(a) Espectros de Potência - Medido e Estimados.

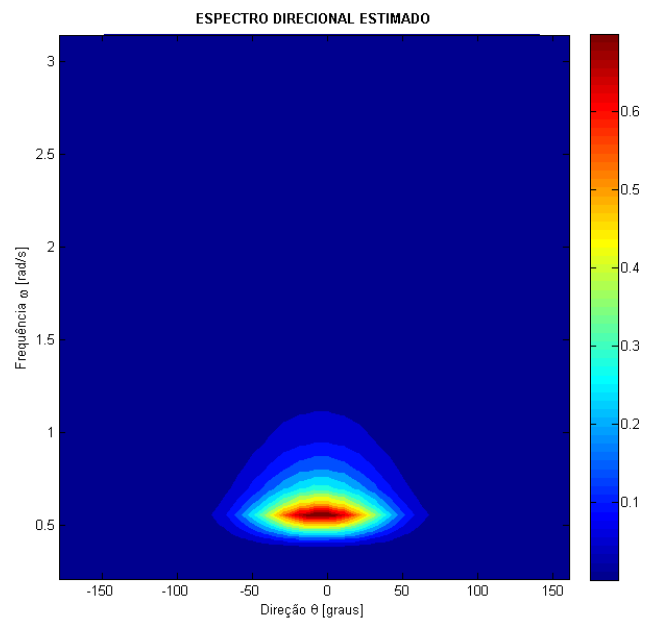

(c) JONSWAP com $s$ fixo.

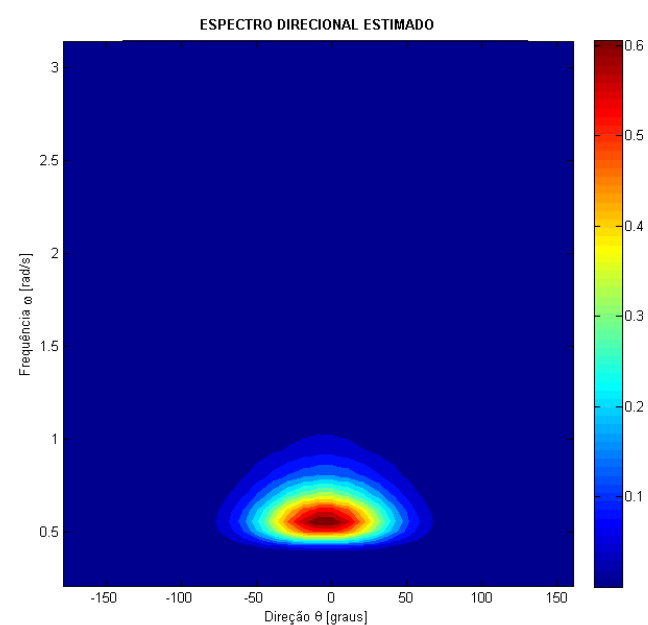

(e) Hogben \& Cobb com $s$ fixo.

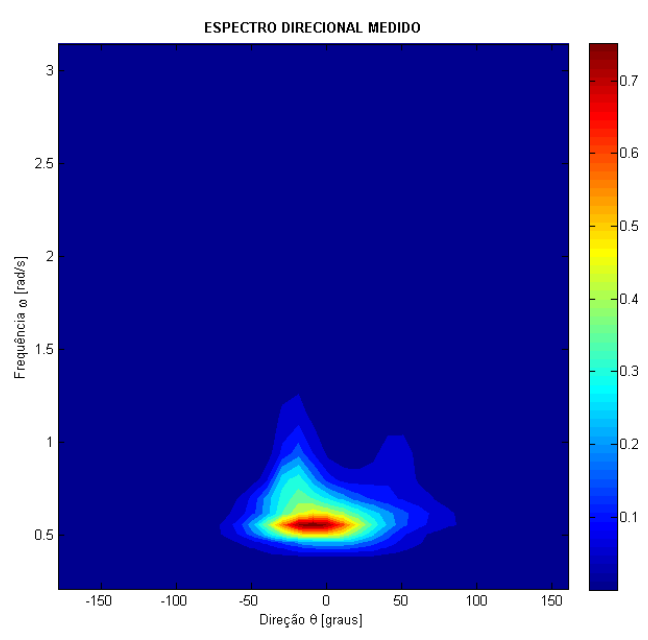

(b) Espectro direcional do ensaio.

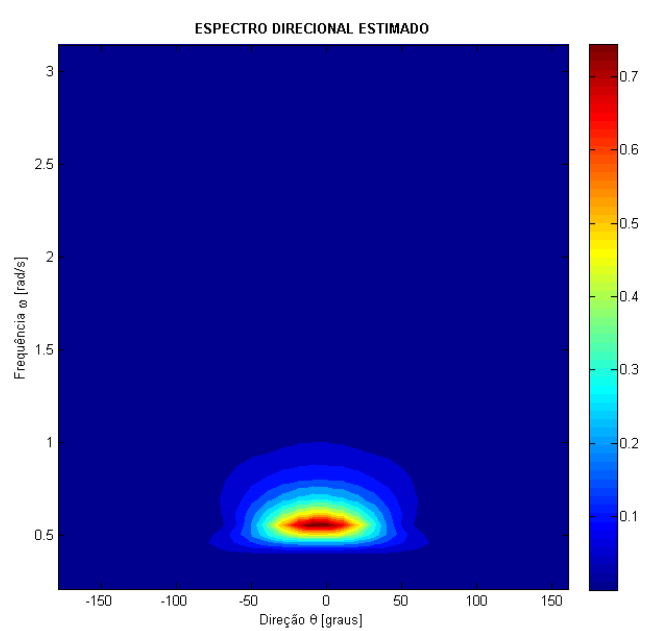

(d) JONSWAP com s variável.

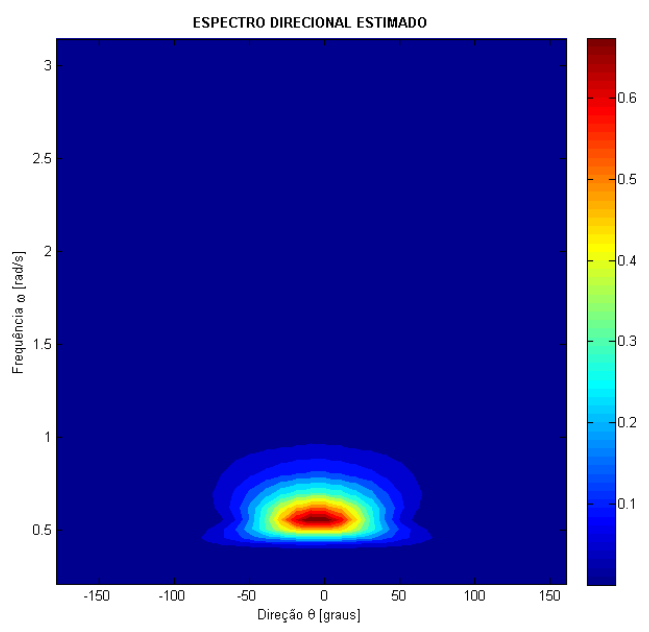

(f) Hogben \& Cobb com $s$ variável.

Figura 70: Espectros resultantes das estimações para o ensaio W06-20400. 


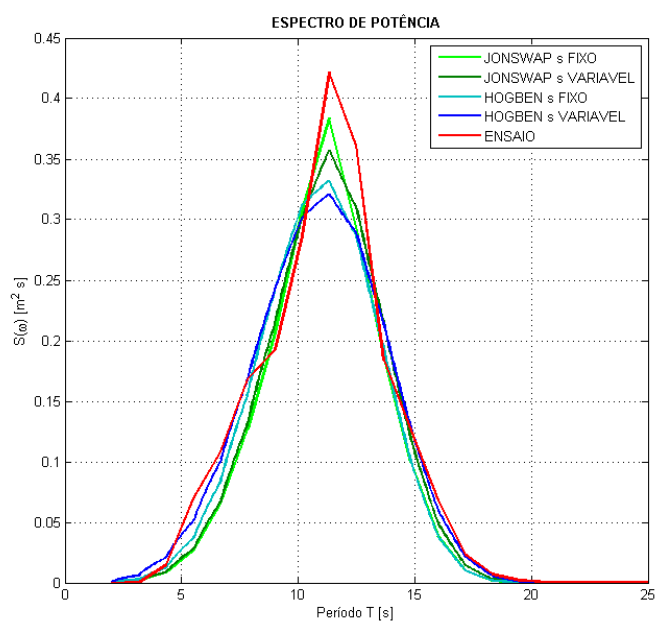

(a) Espectros de Potência - Medido e Estimados.

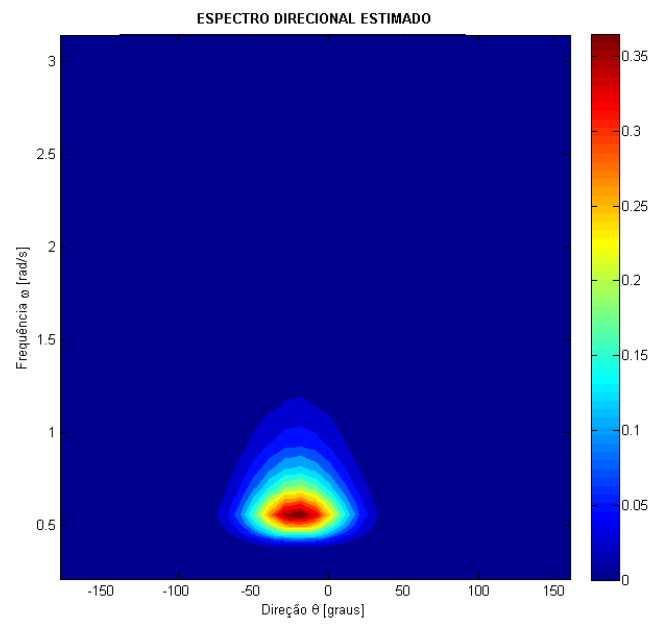

(c) JONSWAP com $s$ fixo.

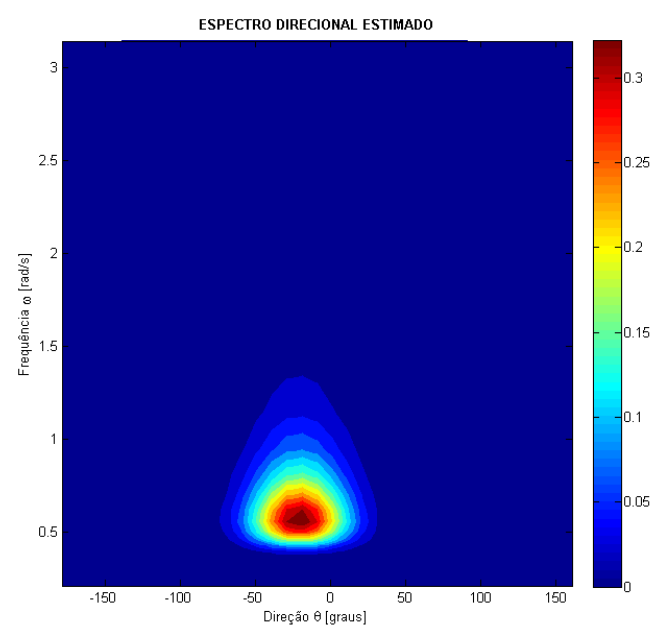

(e) Hogben \& Cobb com s fixo.

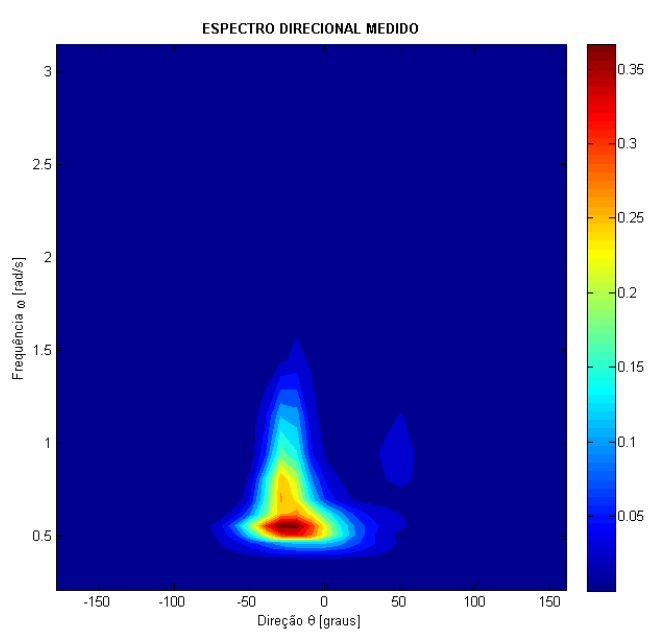

(b) Espectro direcional do ensaio.

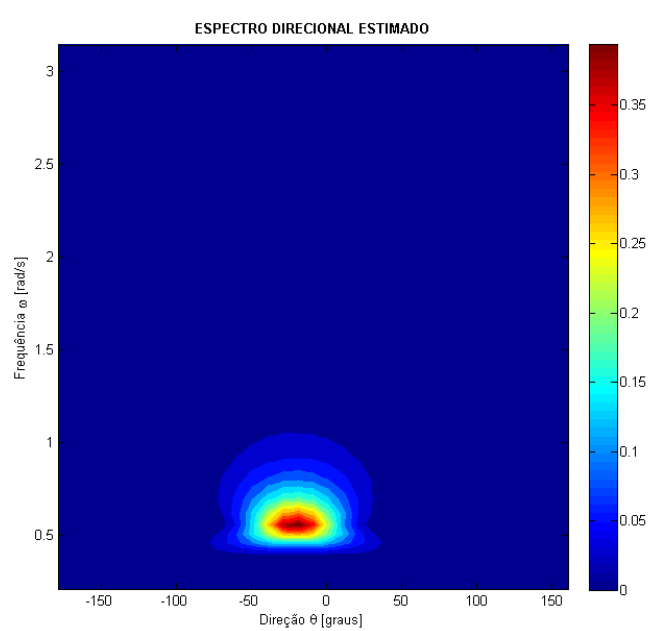

(d) JONSWAP com s variável.

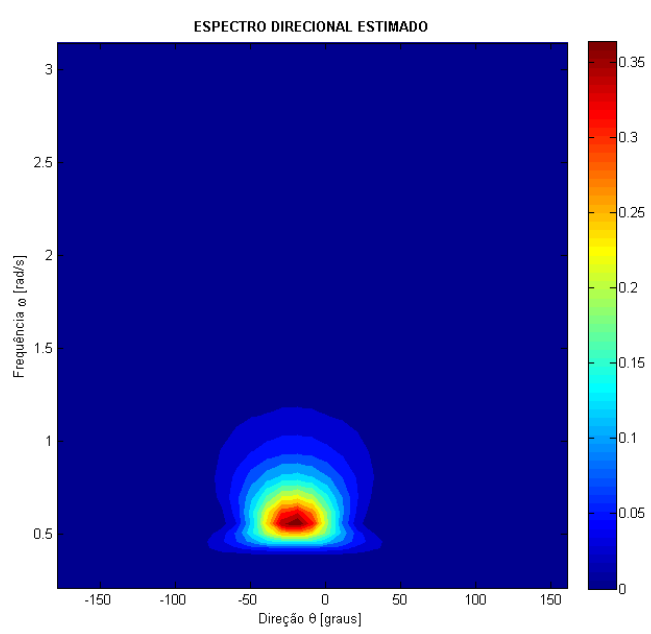

(f) Hogben \& Cobb com s variável.

Figura 71: Espectros resultantes das estimações para o ensaio W06-20500. 


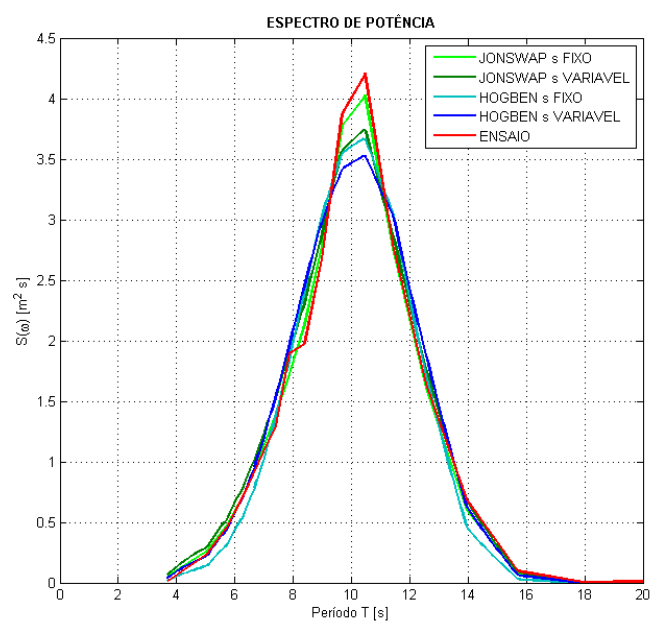

(a) Espectros de Potência - Medido e Estimados.

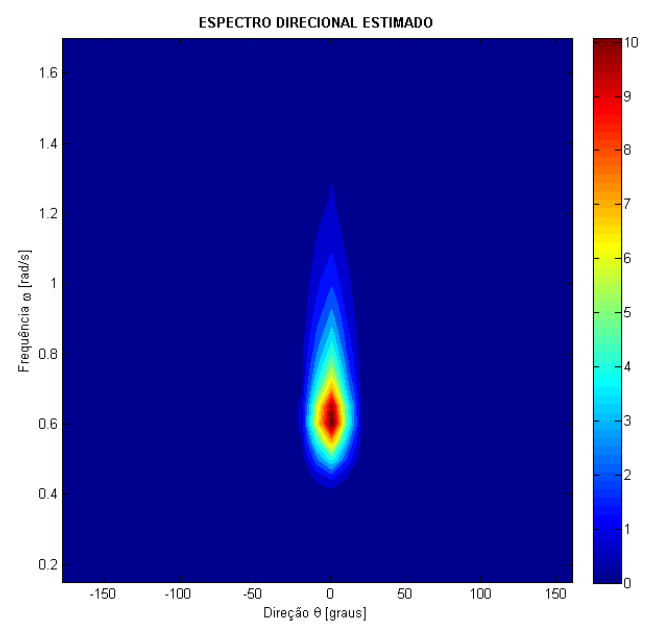

(c) JONSWAP com $s$ fixo.

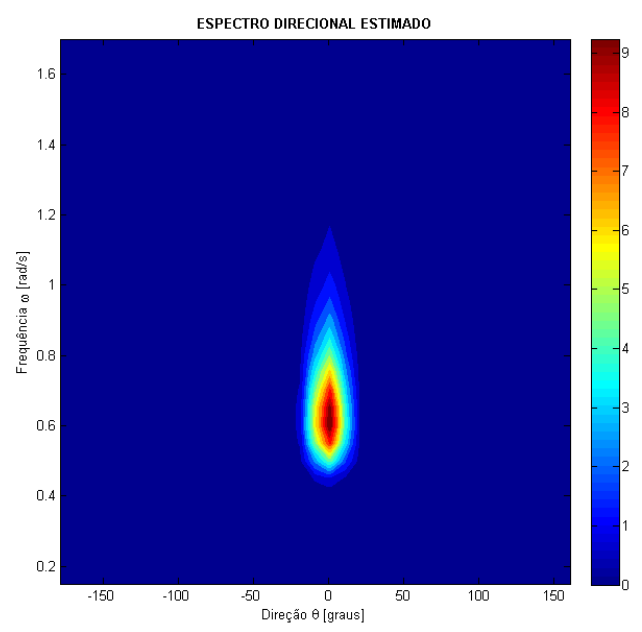

(e) Hogben \& Cobb com s fixo.

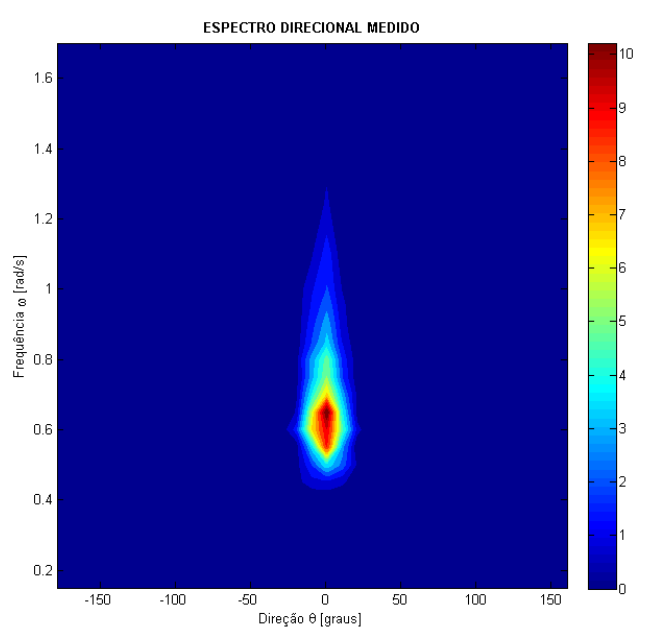

(b) Espectro direcional do ensaio.

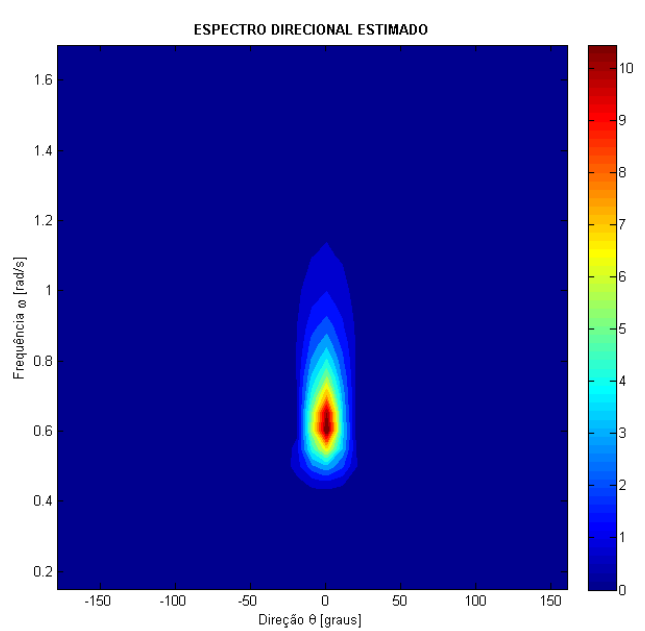

(d) JONSWAP com s variável.

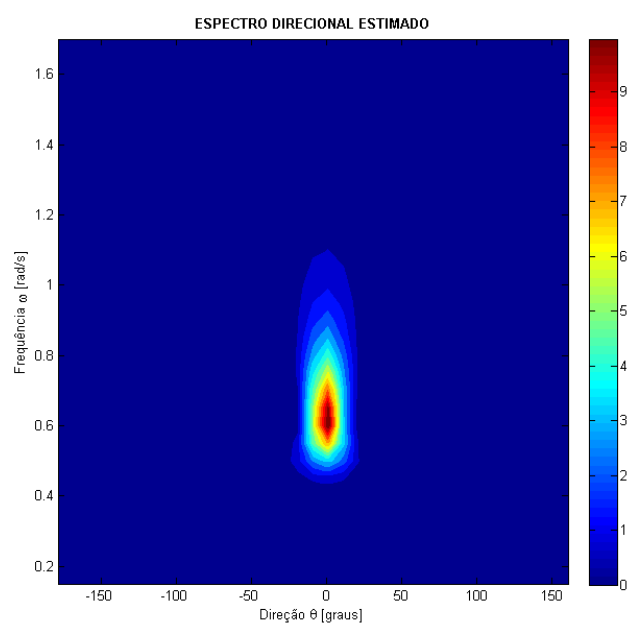

(f) Hogben \& Cobb com s variável.

Figura 72: Espectros resultantes das estimações para o ensaio W07-10102. 


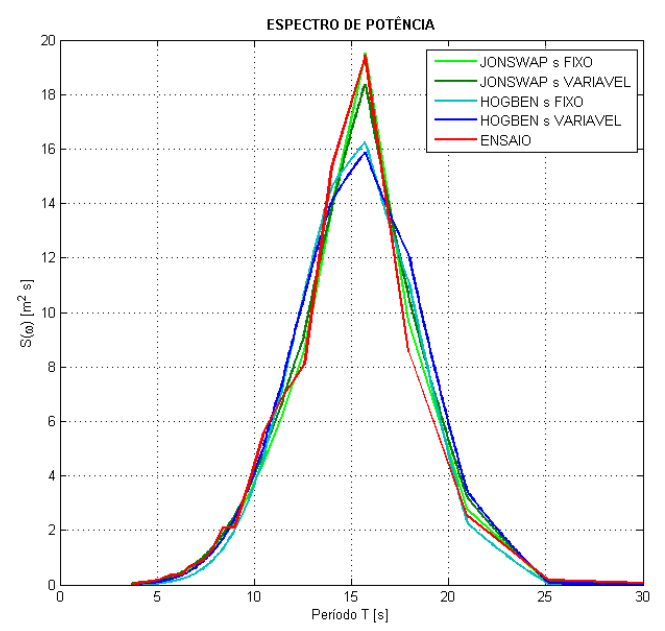

(a) Espectros de Potência - Medido e Estimados.

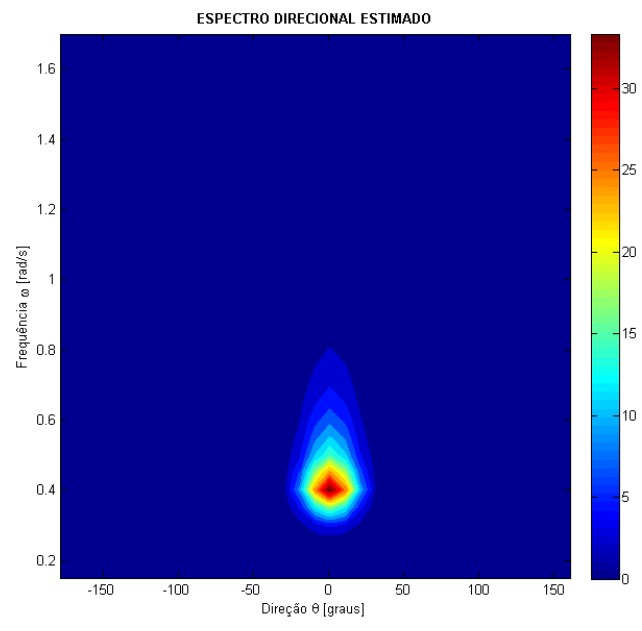

(c) JONSWAP com $s$ fixo.

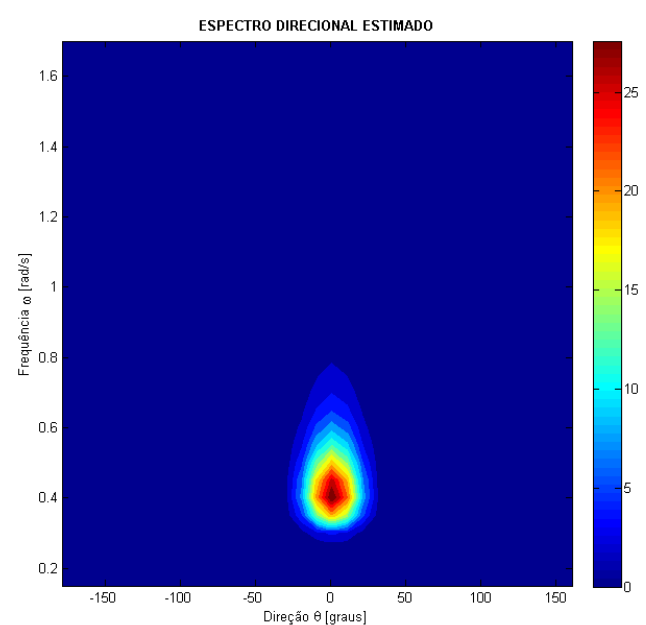

(e) Hogben \& Cobb com s fixo.

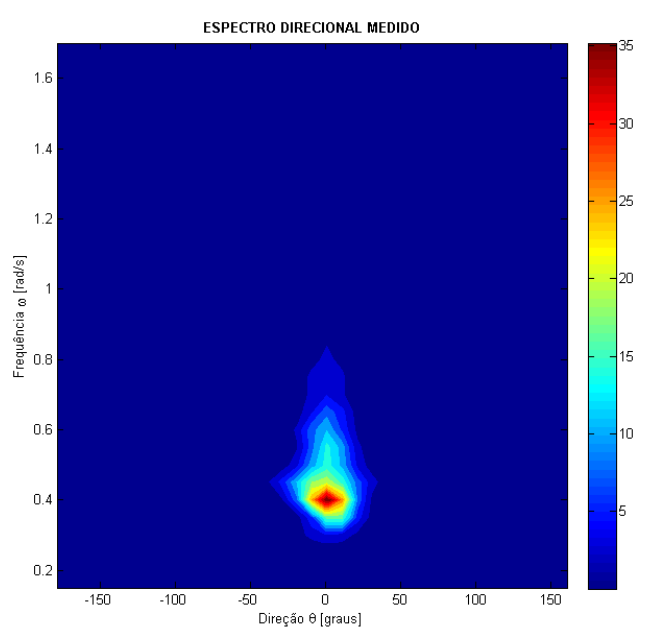

(b) Espectro direcional do ensaio.

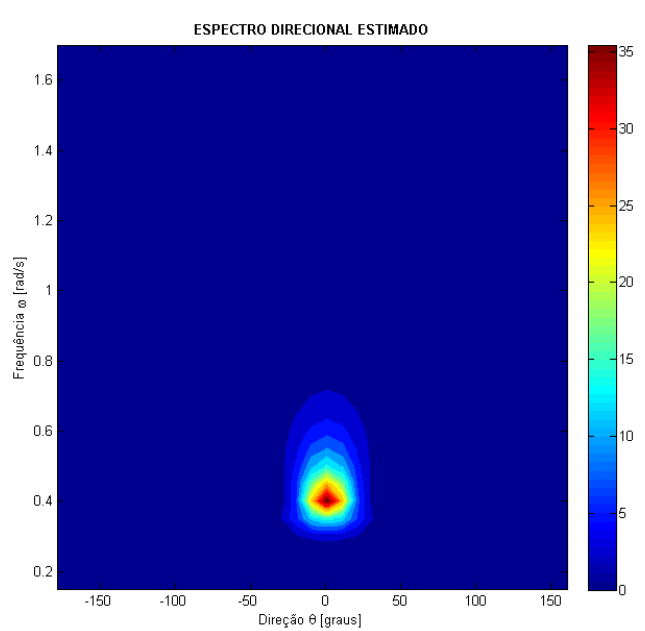

(d) JONSWAP com s variável.

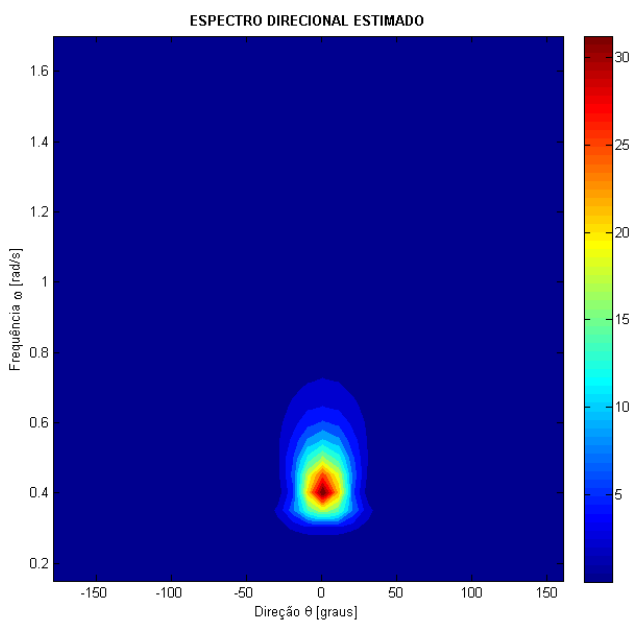

(f) Hogben \& Cobb com s variável.

Figura 73: Espectros resultantes das estimações para o ensaio W07-10202. 


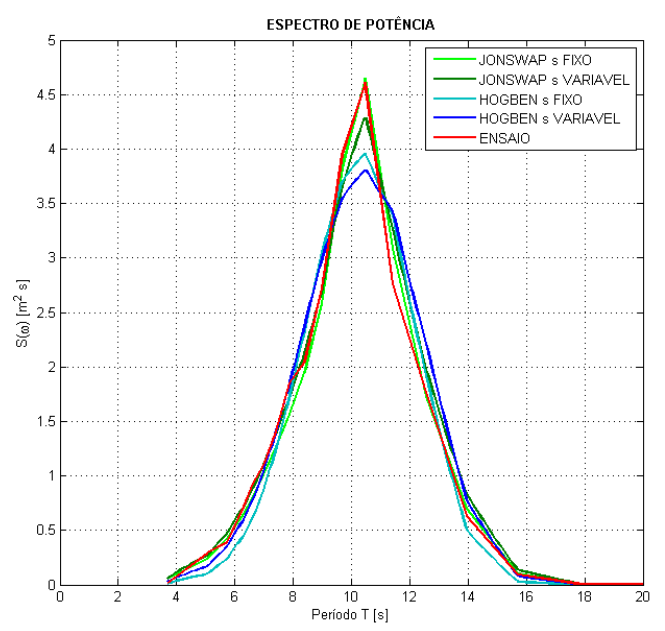

(a) Espectros de Potência - Medido e Estimados.

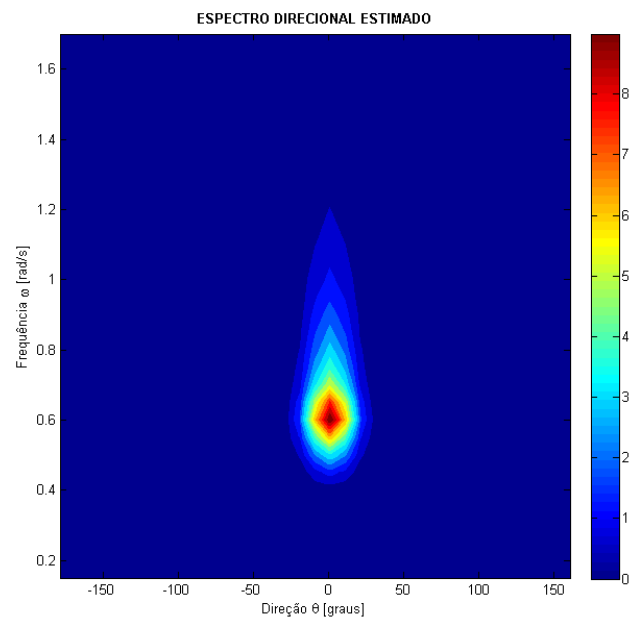

(c) JONSWAP com $s$ fixo.

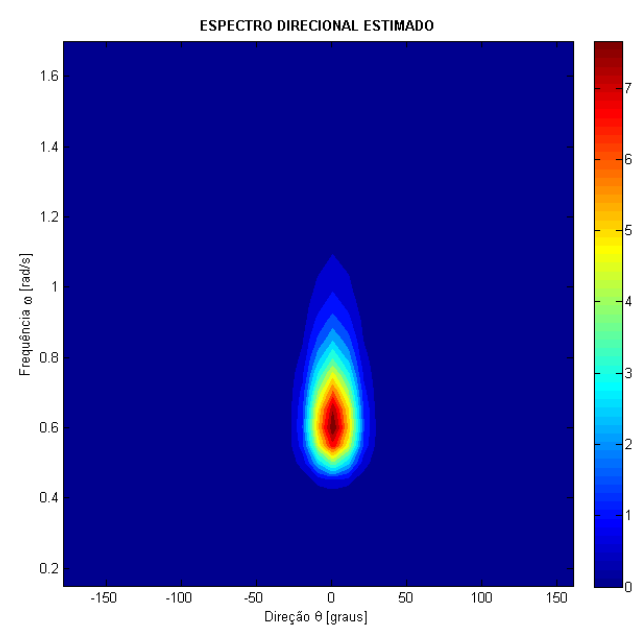

(e) Hogben \& Cobb com s fixo.

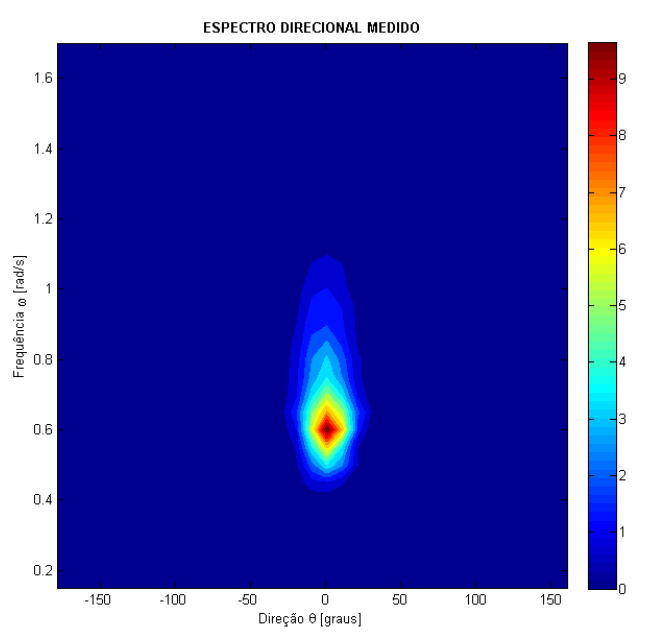

(b) Espectro direcional do ensaio.

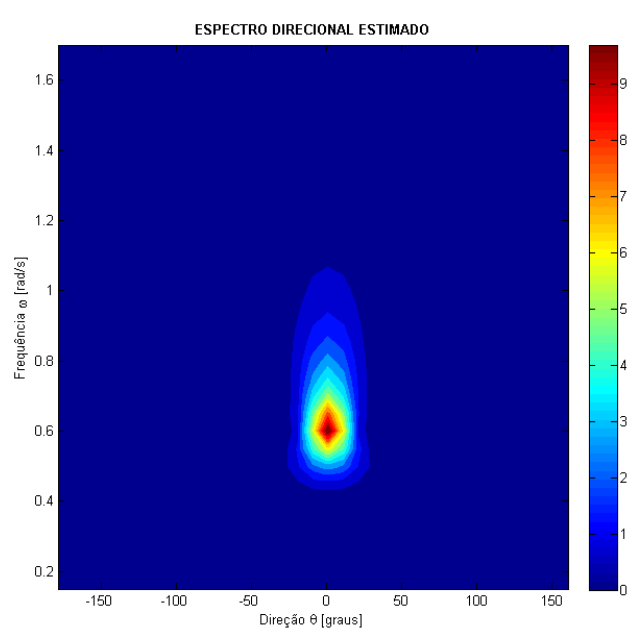

(d) JONSWAP com s variável.

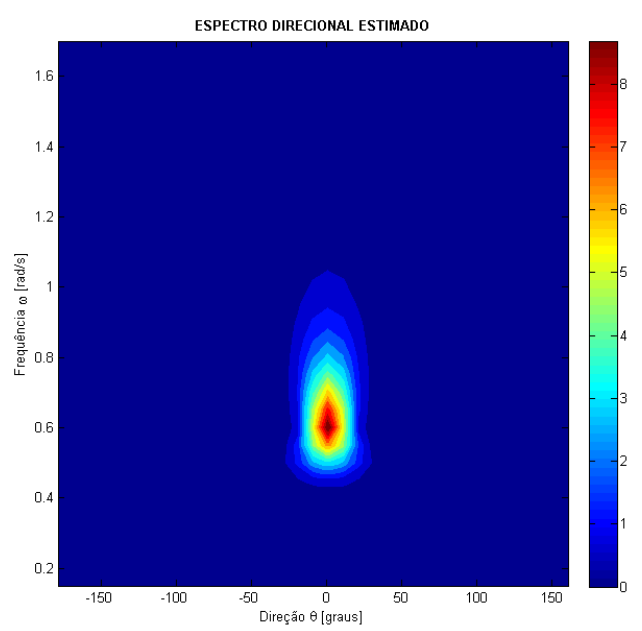

(f) Hogben \& Cobb com s variável.

Figura 74: Espectros resultantes das estimações para o ensaio W07-10301. 


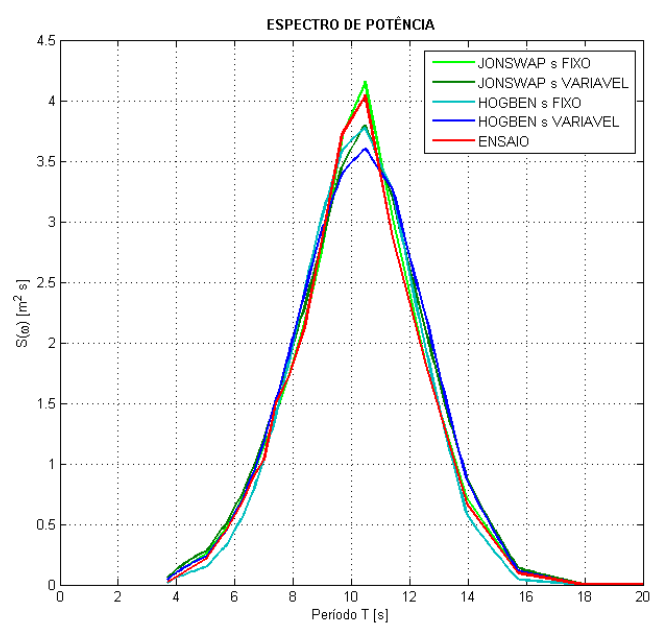

(a) Espectros de Potência - Medido e Estimados.

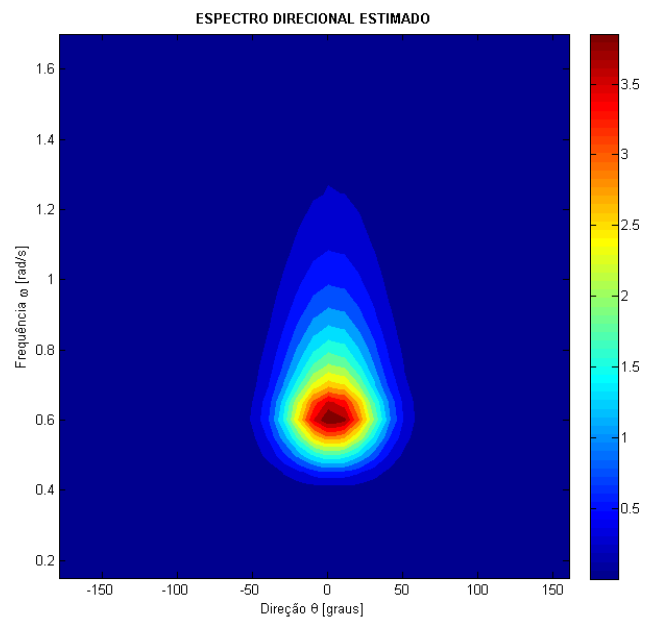

(c) JONSWAP com $s$ fixo.

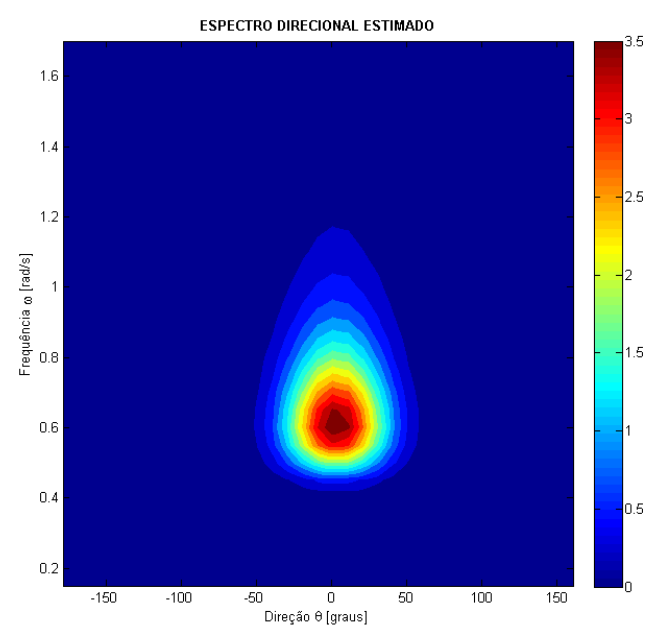

(e) Hogben \& Cobb com $s$ fixo.

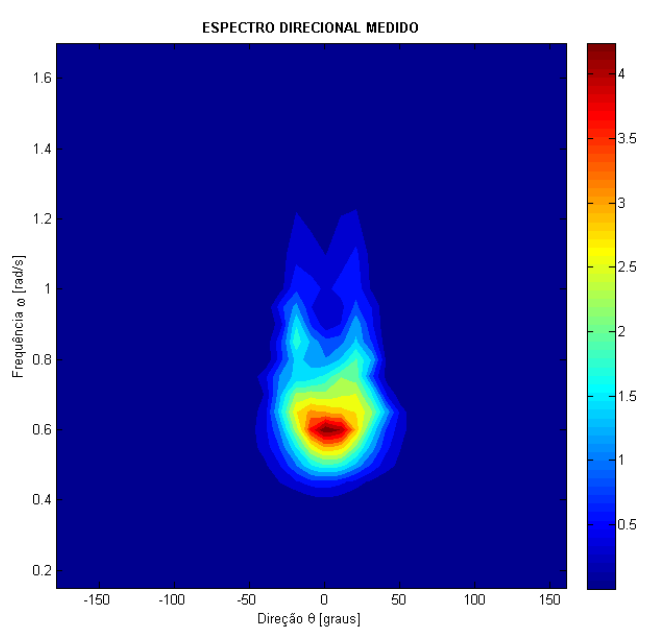

(b) Espectro direcional do ensaio.

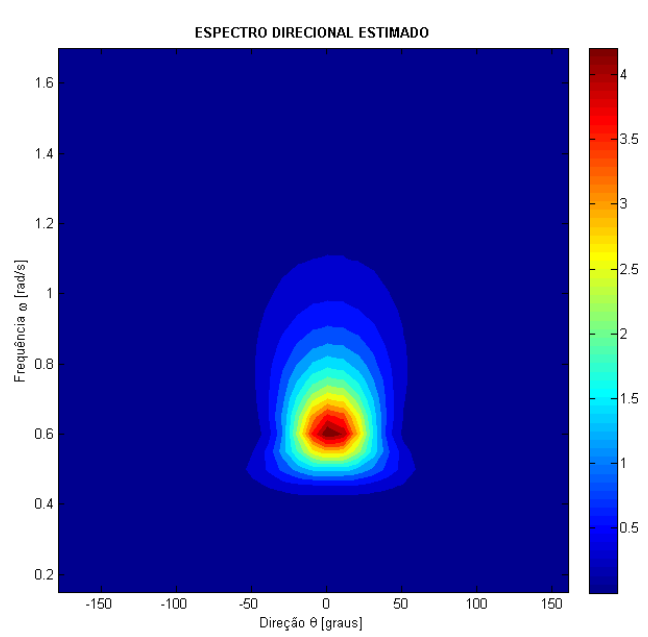

(d) JONSWAP com s variável.

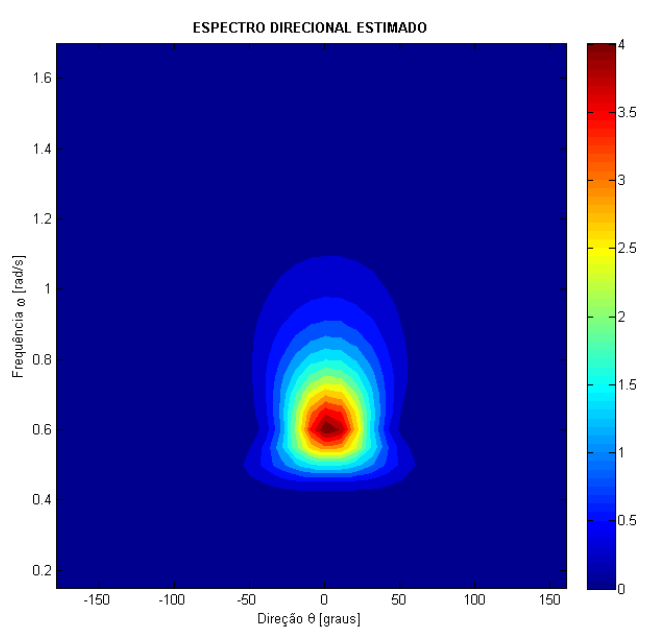

(f) Hogben \& Cobb com s variável.

Figura 75: Espectros resultantes das estimações para o ensaio W07-10401. 


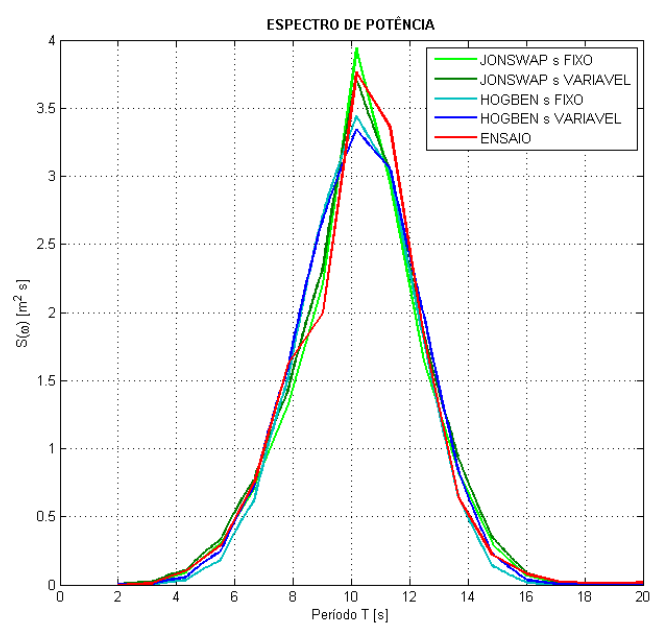

(a) Espectros de Potência - Medido e Estimados.

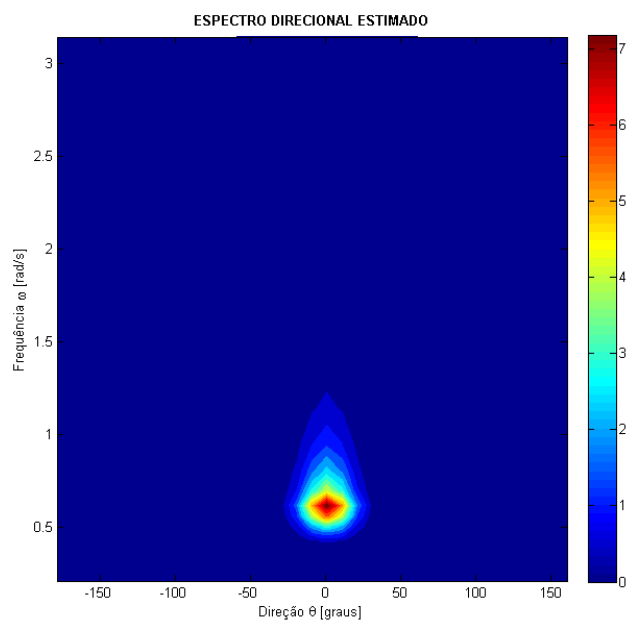

(c) JONSWAP com $s$ fixo.

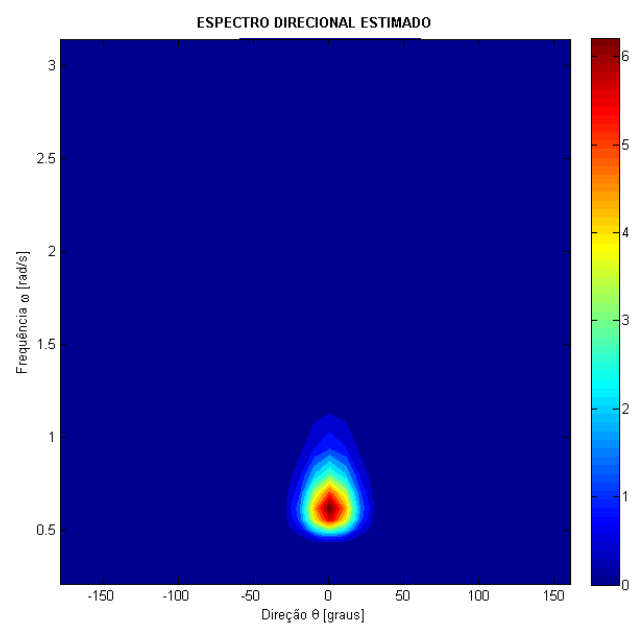

(e) Hogben \& Cobb com $s$ fixo.

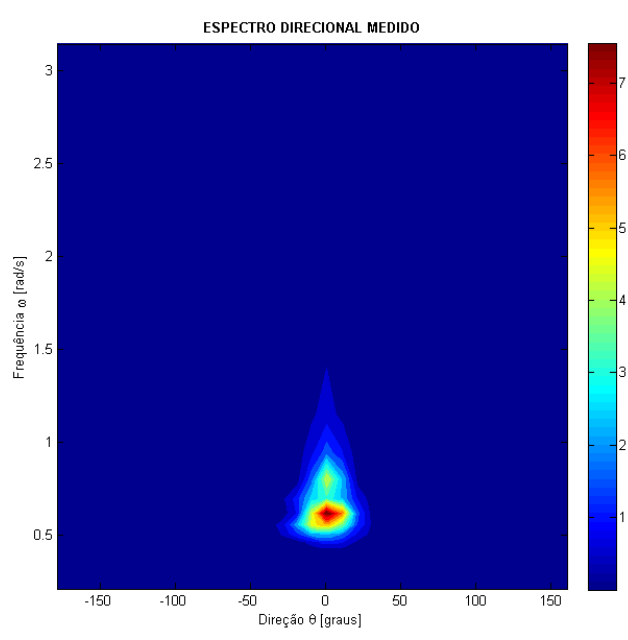

(b) Espectro direcional do ensaio.

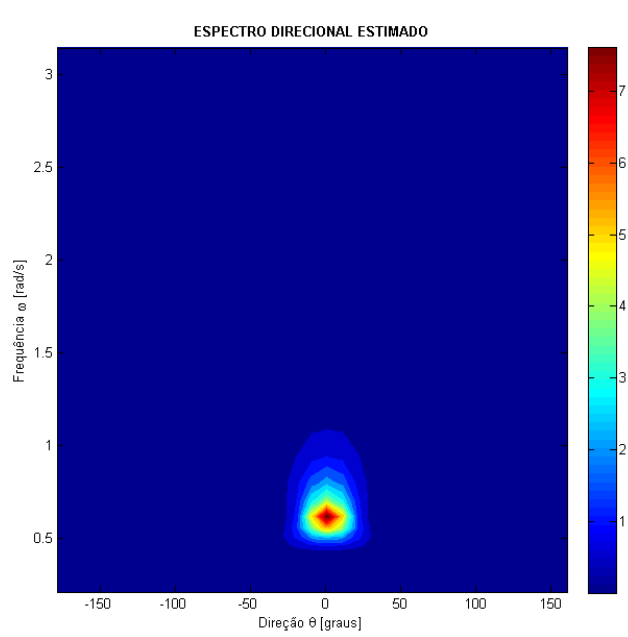

(d) JONSWAP com s variável.

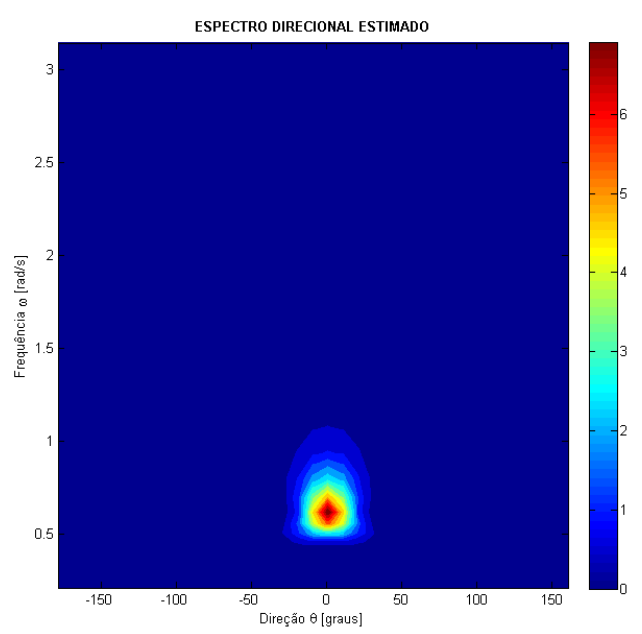

(f) Hogben \& Cobb com s variável.

Figura 76: Espectros resultantes das estimações para o ensaio W07-20104. 


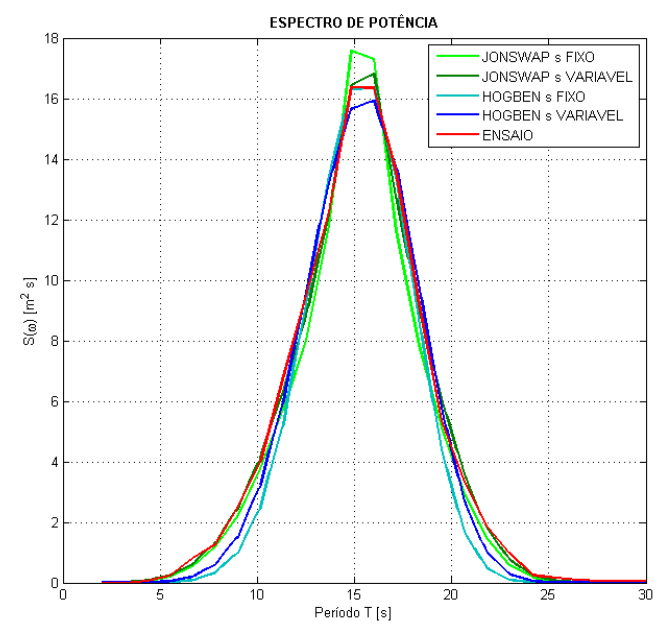

(a) Espectros de Potência - Medido e Estimados.

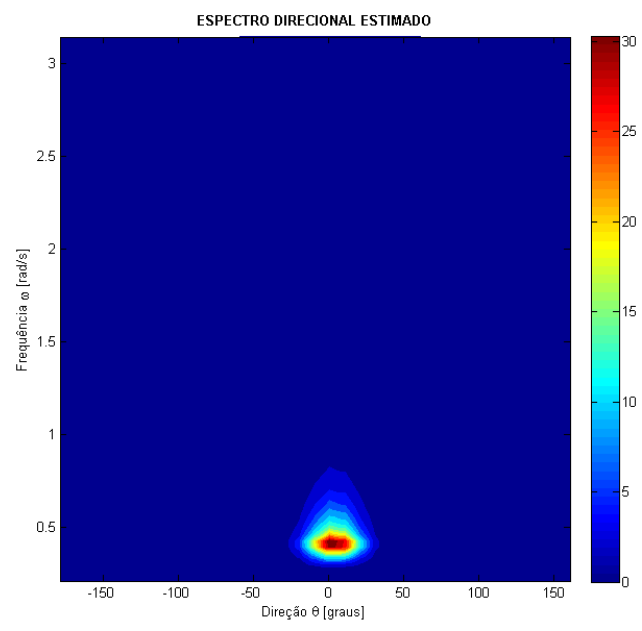

(c) JONSWAP com $s$ fixo.

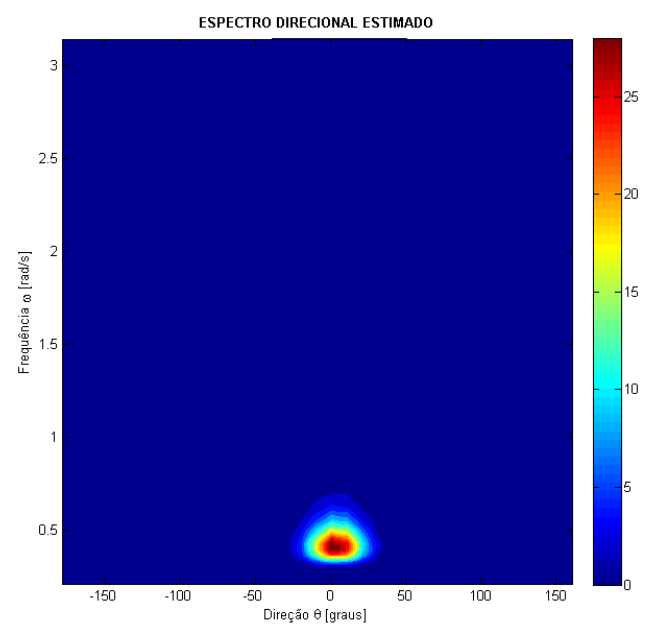

(e) Hogben \& Cobb com $s$ fixo.

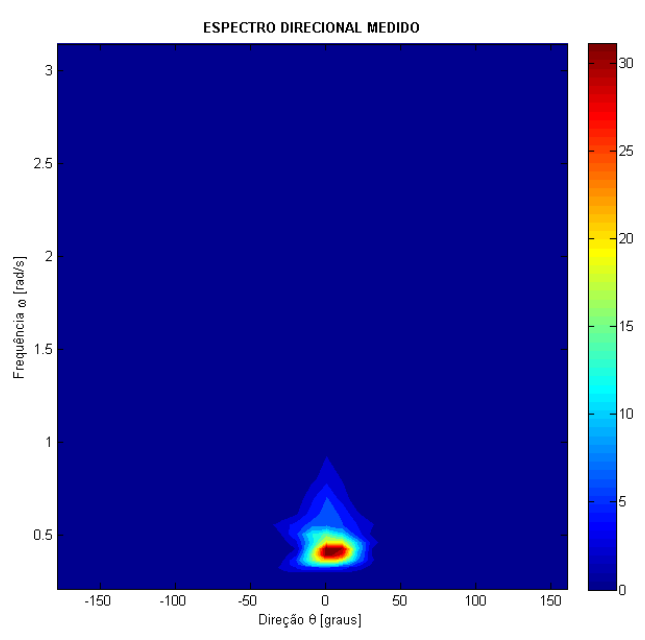

(b) Espectro direcional do ensaio.

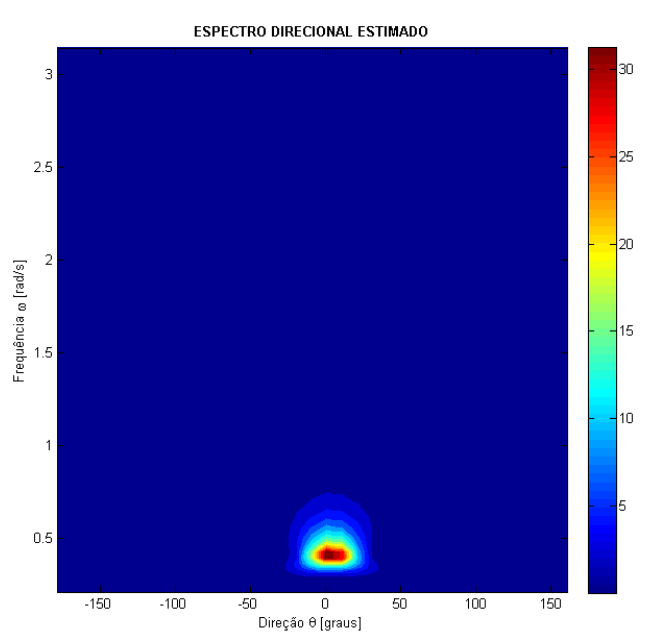

(d) JONSWAP com s variável.

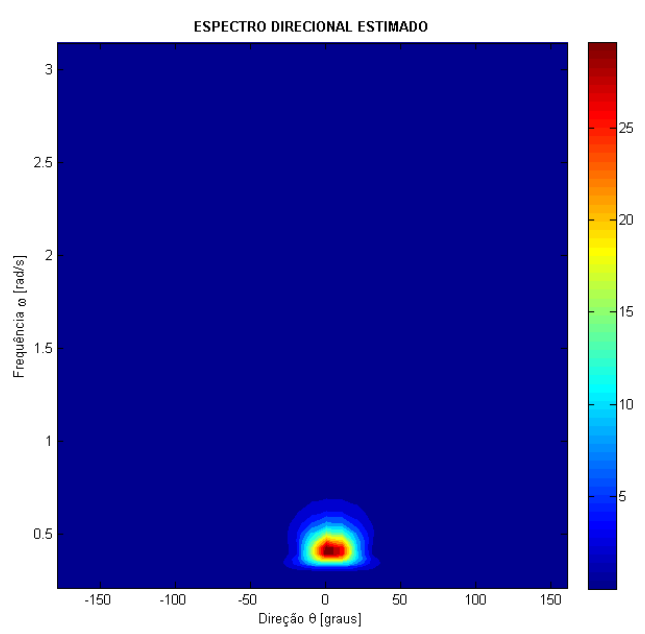

(f) Hogben \& Cobb com s variável.

Figura 77: Espectros resultantes das estimações para o ensaio W07-20203. 


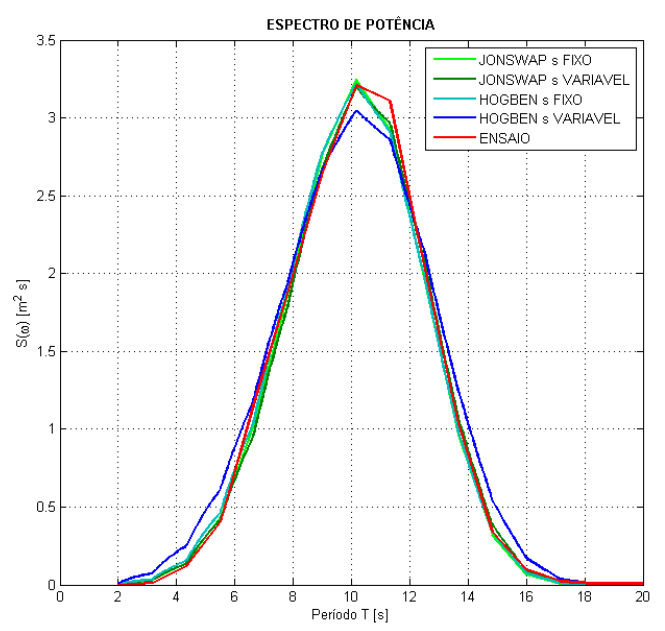

(a) Espectros de Potência - Medido e Estimados.

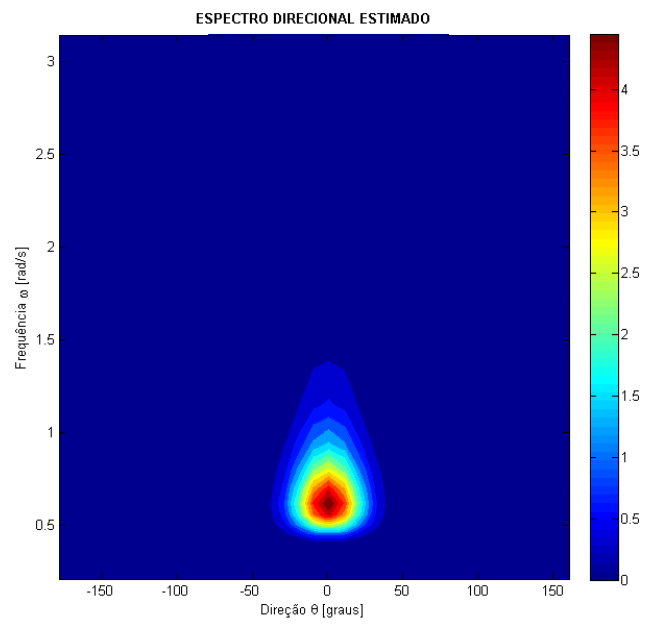

(c) JONSWAP com $s$ fixo.

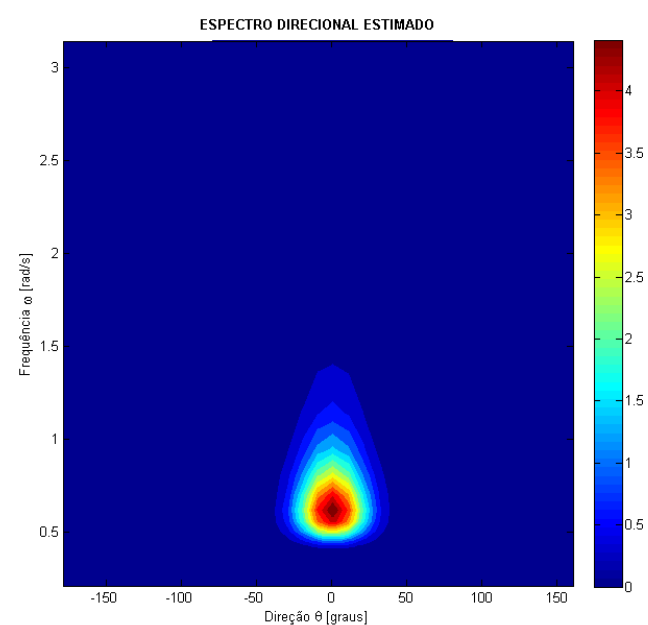

(e) Hogben \& Cobb com $s$ fixo.

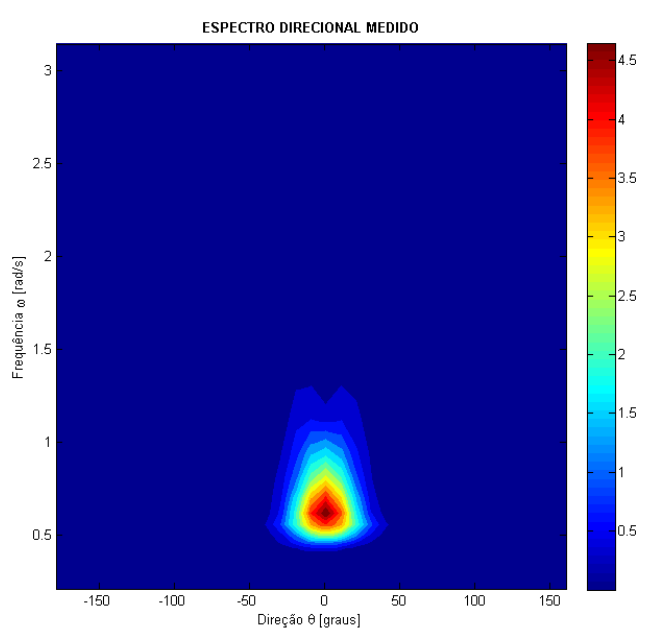

(b) Espectro direcional do ensaio.

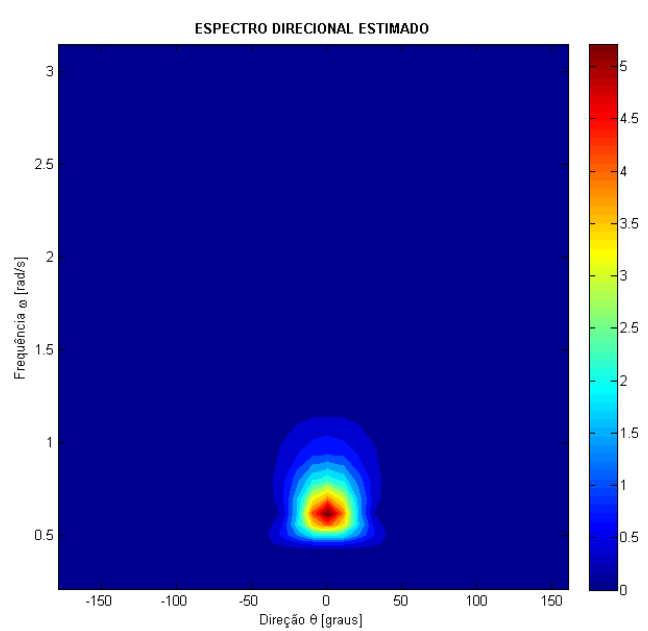

(d) JONSWAP com s variável.

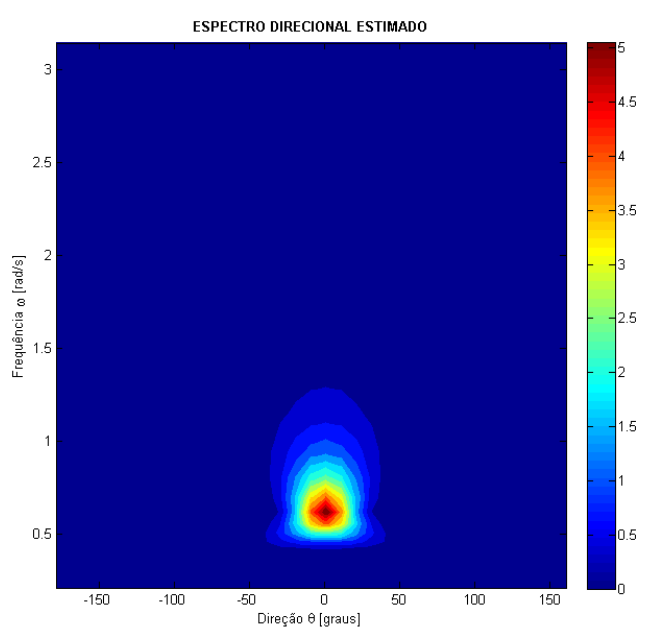

(f) Hogben \& Cobb com s variável.

Figura 78: Espectros resultantes das estimações para o ensaio W07-20301. 


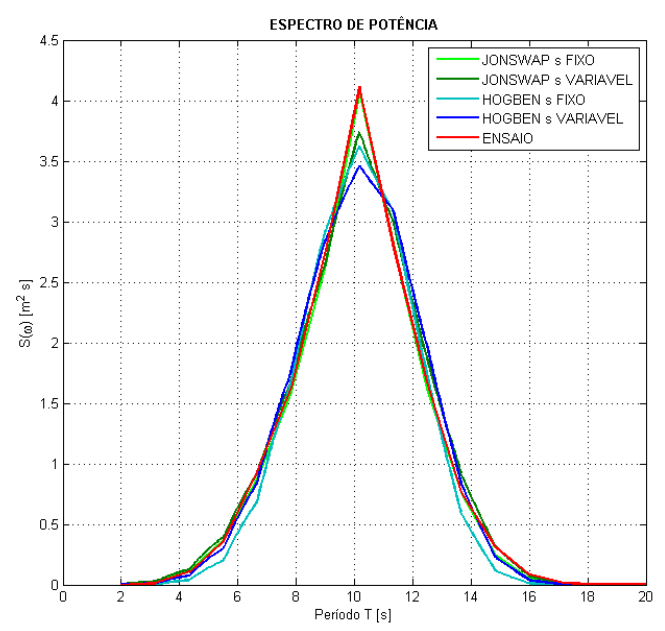

(a) Espectros de Potência - Medido e Estimados.

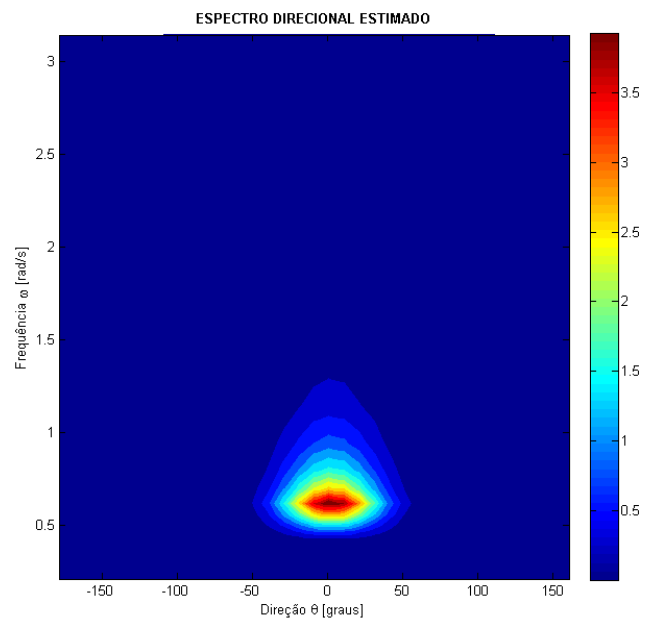

(c) JONSWAP com $s$ fixo.

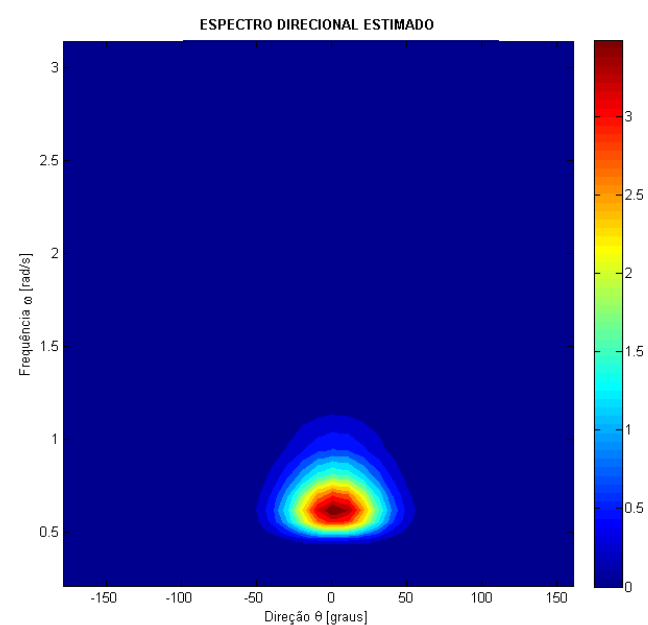

(e) Hogben \& Cobb com $s$ fixo.

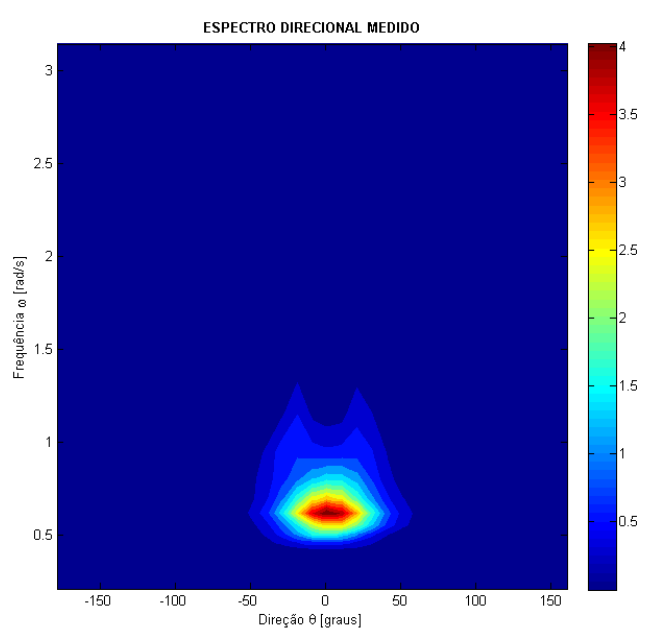

(b) Espectro direcional do ensaio.

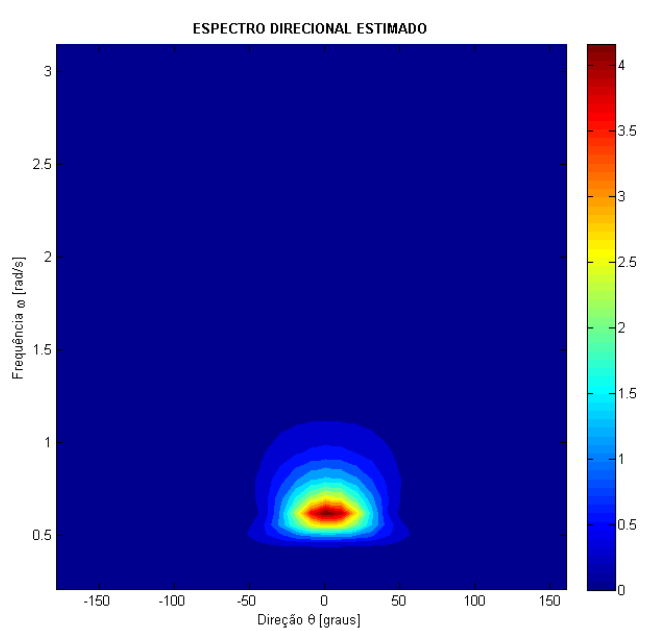

(d) JONSWAP com s variável.

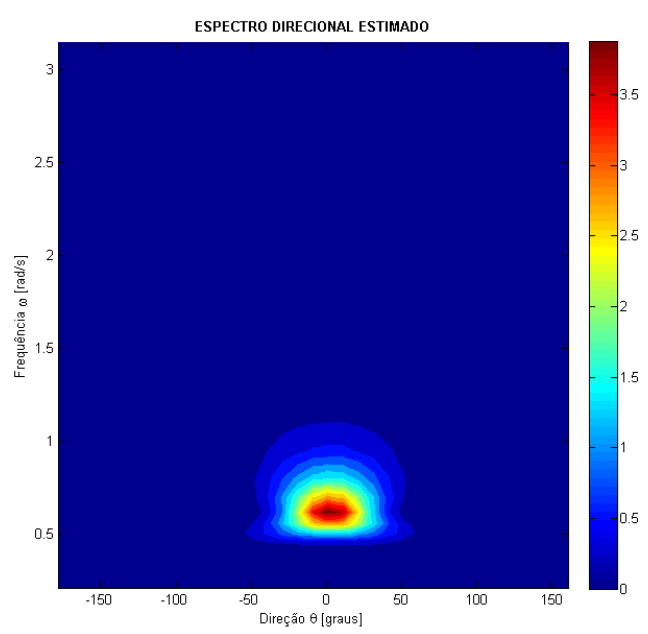

(f) Hogben \& Cobb com s variável.

Figura 79: Espectros resultantes das estimações para o ensaio W07-20401. 


\section{Referências}

AKAIKE, H. Likelihood and the Bayes procedure. In: J.M. Bernardo, M.H. De Groot, D.U. Lindley \& A.F.M. Smith, Bayesian Statistics. [S.I.]: University Press, 1980. p. 143-166.

BENASSAI, G.; PORTA, S. D. Bimodal analysis of the directional wave spectra of some sea storms recorded offshore the Italian coasts. 2000.

BESNARD, J.; BENOIT, M. Representative directional wave parameters - Review and comparison on numerical simulations. International Symposium: Waves - Physical and numerical modelling., p. 901-909, 1994.

BOLSTAD, W. Introduction to Bayesian Statistics. [S.I.]: Wiley, 2007.

EHLERS, R. Introdução à inferência bayesiana. 2003.

GIROLAMO, P. D. Computation of sea-wave direction of propagation of random waves. J. Wat., Port, Coas., Ocean Eng., v. 121, p. 203-208, 2004.

GODA, Y. Random Seas and Design of Maritime Structures. London: World Scientific, 2000.

GRAHAM, R.; JUSZKO, B.-A. Parametrization of directional spectra and its influence on ship motion prediction. Journal of Ship Research, v. 37, p. 138-147, 1993.

HASHIMOTO, N.; KOBUNE, K.; KAMEYAMA, Y. Estimation of directional spectrum using the Bayesian approach, and its application to field data analysis. Control Engineering Practice, 2000.

HOGBEN, N.; COBB, F. Parametric modelling of directional wave spectra. Proceedings of 18th Offshore Technology Conference, 1986.

ISEKI, T. Real-time estimation of directional wave spectra using non-stationary ship motion data. In: International Conference on Offshore Mechanics and Arctic Engineering. [S.I.: s.n.], 2009. p. $1-6$.

ISEKI, T. A study on akaike's bayesian information criterion in wave estimation. In: International Conference on Offshore Mechanics and Arctic Engineering. [S.I.: s.n.], 2011.

ISEKI, T.; NIELSEN, U. Estimation of sea state parameters from measured ship responses the bayesian approach with fixed hyperparameters. In: International Conference on Offshore Mechanics and Arctic Engineering. [S.I.: s.n.], 2010.

ISEKI, T.; NIELSEN, U. The wave buoy analogy - analysis of synthetic data by bayesian modelling. In: International Conference on Offshore Mechanics and Arctic Engineering. [S.I.: s.n.], 2010.

ISEKI, T.; OHTSU, K. Bayesian estimation of directional wave spectra based on ship motions. Control Engineering Practice, 2000. 
KOBUNE, K.; SASAKI, H.; HASHIMOTO, N. Characteristics of ocean waves of Cape Nojimanin the Northwestern Pacific, measured with a discus buoy. 1985.

KUIK, A.; VLEDDER, G. V.; HOLTHUUSEN, L. A Method for the Routine Analysis of Pitch-and-Roll Buoy Wave Data. Journal of Physical Oceanography, v. 18, p. 1020-1034, 1988.

LEE, P. Bayesian Statistics: An Introduction. [S.I.]: Hodder Arnold, 1997.

LONGUET-HIGGINS, M. The Statistical Analysis of a Random, Moving Surface. Royal Society, v. 249, n. 966, p. 321-387, 1957.

LONGUET-HIGGINS, M.; CARTWRIGHT, D.; SMITH, N. Observations of the directional spectrum of sea waves using the motion of a floating buoy. Proc. Conf. Ocean wave spectra, p. 111-132, 1961.

MITSUYASU, $\mathrm{H}$. et al. Observations of the directional spectrum of ocean waves using a cloverleaf buoy. Journal of Physical Oceanography, v. 5, p. 750-760, 1975.

NIELSEN, U. Introducing Two Hyperparameters in Bayesian Estimation of Wave Spectra. p. 1-20, 2008.

OCHI, M.; HUBBLE, E. Six parameter wave spectra. Proceedings of the 15th Coastal Engineering Conference Honolulu, 1976.

PISCOPIA, R.; PANIZZO, A.; GIROLAMO, P. D. An efficient method to identify cross-sea states from wave measurements. Coastal Engineering, v. 51, n. 10, p. 941-965, nov. 2004.

SHILLER, R. A distributed lag estimator derived from smoothness priors. Econometrica, v. 41, p. $775-778,1973$.

SIMOS, A. et al. Estimating wave spectra from the motions of moored vessels: Experimental validation. Applied Ocean Research, v. 32, p. 191-208, 2009.

SPARANO, J. Método de Estimação de Espectro Direcional de Ondas Baseado em Movimentos de Primeira Ordem de Sistemas Oceânicos: Validação em Escala Reduzida e Verificação em Escala Real. Tese (Doutorado) — EPUSP, 2008.

TANNURI, E. et al. Estimation of directional wave spectrum using a wave-probe array. In: $3^{\text {rd }}$ International Workshop on Applied Offshore Hydrodynamics. [S.I.: s.n.], 2007.

TANNURI, E. et al. Directional Wave Spectrum Estimation Based on Moored FPSO Motions. International Conference on Offshore Mechanics and Arctic Engineering, 2001.

TANNURI, E. et al. Estimating Directional Wave Spectrum Based on Stationary Ship Motion Measurements. Applied Ocean Research, v. 25, n. 5, p. 243-261, out. 2004. 